
- Uapetur Menstrapo Marysears 



\title{
BEITRÄGE ZUR NATURGESCHICHTE
}

DER

\section{HYIROMEDUSEN.}

\author{
ION
}

DR. ERNST HAECKEL.

\author{
ERSTES HEFI': \\ DIE FAMILIE DER RÜSSELQUALLEN \\ ( GERYONIDA ).
}

MIT \& KUPFERTAFEIN

UND IN DEN TEXT GEDRUCKTEN HOLZSCHNITTEN.

\section{LEIPZIG,}

VERLAG VON WILHELM FNGELMANN.

1865. 


\title{
DIE
}

\section{FAVIILIE DER RÜSSELQUALLEN} (GERY0NIDA).

\section{EINE MONOGRAPHIE}

\author{
VON
}

\section{1). ERNST HAECKEL,}

UND IN DEN TEXT GEDRUCKTEN HOLZSCHNITTEN.

\section{LEIPZIG,}

VERLAG VON WILHELM ENGELMANN. 
Abdruck aus der Jenaischen Zeitschrift für Medicin und Naturwissenschaft I. und II. Bd. 


\section{0 r w 0 r t.}

Seit längerer Zeit mit Untersuchungen uber Hỵdromedusen beschäftigt, beabsichtige ich eine Reihe von Beitrïgen zur Naturgeschichte dieser Thiere in einzelnen Heften herauszugeben, von denen das vorliegende hiermit als das erste erscheint.

Die allgemeinere Theilnahme und das erhöhte Interesse, welehes in den tetzten Decennien den niederen Thieren zugewendet worden ist, hat vielleicht auf keinem Gebiete eine solche Fülle von complicirten und unerwarteten Verhïltnissen im Bau und den Lehenserscheinungen aufgedeckt, als in den Kreise der Coelenteraten und namentlich in der Glasse der Ilydromedusen. Die Masse des hier noch verborgen liegenden Materials ist so gross, dass wir wohl noch lange mit Ausgraben und Herbeischaflen der einzelnen Bausteine uns werden begnügen müssen, ehe es uns möglich sein wird, aus diesen das Gebände einer allgemeinen Naturgeschichte dieser wunderbaren Thiergruppe aufzurichten und den gesetzlichen Zusammenhang in der Fïlle der einzelnen Erscheinungen aufzufinden.

Einen einzelnen solchen Baustein soll die vorliegende Monographie der Rüsselquallen oder Geryoniden licfern, einer Medusenfamilie, welche bisher unvollstiandiger, als die meisten anderen bekannt war, obwohl sie in mehr als einer Beziehung zu ciner genauen Untersuchung besonders aufforderte. Dass die darauf verwendete Sorgfalt dureh manches unerwartete Resultat, zum Theil auch von allgemeinerer Bedeutung, belohnt wurde, wird vielleicht aus der in Folgenden gegebenen Darstellung des feineren Baues und der Entwickelung der Geryoniden hervorgehen.

Ueber die eigenthümliche und neue Form des Generationswechsels, welche die Geryoniden mit den Aeginiden auf das Innigste verbindet, 
und welcho im VHI. und X. Abschnitt als Mlloeogresis beschrichen und erliutert ist ${ }^{1}$ ), habe ich zu Anlang dieses Jahres eine kurze vorlintige Mittheilung in den Monatsheriehten der Berliner Akademie (p. s::; Sitzung vom 2. Felmuar 186:3) veröffentlicht. Jiese Mithcilung finde ich in der Juni-Nummer der "Annals and Magazine of natural histor! " (1860̈, p. 137) ron IV. S. Daxus in das Englische iibersetz1, und zugleich kritisch erliutert von Professor Alzyax (ibid. p. i68-izi), dem wir schon so manche werthvolle Beitrige zur Naturgeschichte der IIydromedusen rerdanhen. Insbesondere hat derselbe dort die allọcmeine Bedeutung, welche die Alloeogenesis für die Theorie des Grnerationswechsels iberhaupt lat, einer eingedenden Betrachtung unterzogen.

Leh selbst hatle von ciner solchen allgemeinen Erörterung dieser w underbaren Erscheinung vorliufig algesehen, weil ich diesellse $z u$ einer solchen noch nicht reif genug, und noch zu unvollstindigy bekannt erachtete. Der Kern meiner Beolachtungen beschüinkt sich darant, dass die sechszihlige Geryonia (Curmarma) hastola, und zwar Jeide Geschlechter derselben, zu derselben Zeit, zu welcher sie reife Zoosjermien und Eier in ihren Genitalblittem entwickelt, auf der Oberfliehe ilser Zunge, innerhalh der Magenhohle, Knospen treibt, welche sicl zu der achtstrahligen Cumina rhodoductylu entwickeln, einer Aeginide, welche selbst wieder reife Geschlechtsproducte in ihren Genitalblittern erzengt. In wolehem weiteren genealogischen Zusammenhange diese beiden, anscheinend so sehr vorschiedenen Medusenformen stehen, und wie etwa die Aeginiden-Generation (Cunina) wieder in die GeryonidenGeneration (Commarina) zuruchschliggt, habe ich leider noch nicht zu elunitteln vernochl.

Aturax erörtert mun die verschiodenen Mögr lichkeiten, welche hier denkbar sind, in selı klarer und äbersichtlicher form, stellt dieselhen mit anderen eigenthiimlichen Modificationen des Generationswechsels, die sich bei anderen Medusen linden, zusammen, und kommt schliess-

1) Diese Alloeogenesis war mil moch nicht bekamt, als ter zweite . Mbshnitt der vorliggenden Lntersuchungen bereits gedruckt wurde. Ich litte denhalb die irrive Angabe, welehe sich dort S. 18 iber den Generationswerhsel und inber die ungeschlerhtliche Fortphanzung der Gergoniden fiblet, zu entschuldisen und 7.4 streichen. 
lich zu dem Resultate, dass die Alloeogenesis der Geryoniden sich nicht in dem Grade, wie ich es behaupte, von den ubrigen, bereits bekannten complicirteren Formen des Generationswechsels unterscheide.

Die Ilauptschwierigkeit in dem ron mir beobachteten Vorgange, durch welche derselbe sich meines Erachtens von allen ihnlichen bekannten Erscheinungen unterscheidet, liegt nach meiner Ansicht darin, dass nicht, wie-sonst immer, cine geschlechtliche und einc forler mehrere ungeschlechtliche Generation mit einander abwechsehn, sondern dass die sechszählige Geryonide, welche auf ungeschlechthichem Wege die gesehlechtsreif werdende Aeginide erzeugt, gleichzeitig selbst gesehleehtsreil ist, und sowohl Eicr als Zoospermien aus dem subumbralen Epithel ihrer taschenförmig erweiterten Radialeanile entwicket. Nithin sind beide, so sehr verschiedene Medusen-Generationen, die dem Formenhreis einer einzigen "Species« ang̣ehören, sexual, und es kann nicht die knospentreibende Geryonide als ungeschlechtliche Generation angِeschen werden. Diese Hauptschwieriğkeit sucht nun Atzuax dadurch zu heben, dass er die Geryonide selbst für eine ungeschlechtliché Generation, und ilure Geschlechtsorgane (die blatförmigen Erweiterungen der Radialcaniile) für selbststindige rudimentäre Individuen (Zooiden) ciner geschlechtlichen Generation häh; die letztere soll von der ersteren auf ungesehtechtlichem Wege (durch Knospung im Gastrovascularsystem) erzeugt werden und unabhingig von derselben Geschlechtsproducte entwickeln. Die Carmarina hastata ist also nach Ablman nicht eine sexuate Meduse, oder ein "Gonocheme«, wie Oceania, Bongaimvillia etc., sondern eine escxuale Meduse oder ein "Gonoblastocheme«, wihrend die Genitalblitter derselben eine selbststindige sexuale Generation darstellen.

So schr ich den Scharfsinn von Prof. Alzuar und die Vorzüge dieser Auffassung anerkenne, und so sehr ich selbst bemüht gewesen bin, durch eine :ihnliche Deutung eine Verbindung zwischen deut von mir beobachteten Vorgange und den niichstihnlichen Erscheinungen des Generationswechsels bei anderen Hydromedusen herzustellen, so kann ich mich dennoch so wenig von Alcmav's Deutung, als von meinen eigenen Erkliirungsversuchen befriedigt fühlen. Aus Grïnden, welche ich an einem anderen Orte ausführlicher erliutern werde, vermag ich 
nicht die Genitalb]itter der Gery oniden, welche nichts anderes, als ganz cinfache seitliche Erweiterungen der Radialeanäle sind, in denen sich das Epithel stellenweis (und zwar nur auf der subumbralen Seite) zu Fiern oder zu Zoospermien differenzirt, als selbststindige individuelle Bildungen (Zooiden) anzuerkennen. Der Bau und die Entwickelung dieser flachen seitlichen Ausstülpungen der Radialcanile scheinen mir lieser Auffassung ebenso zu widersprechen, wie die Homologie derselben mit anderen Bildungen, welche Albuar selbst unzweifelhaft für Theile oder Organe des Medusenkörpers, und nicht für eine selbststïndige Generation hilt. Ich muss daher, bis weitere Beobachtungen diesen wunderbaren Vorgang nach allen Seiten hin aufgeklart haben werten, an meiner Auffassung festhalten.

Die anatomischen und histologisehen Theile der vorliegenden $\mathbf{Y}_{0-}$. nographic waren bereits in vorigen Jahre vollendet, und nur die Untersuchungen iiber die Entwickelungsverhältnisse der Cumina verzögerten den Abschluss der ganzen Arbeit noch bis Ende Januar, wo das Manuscript zum Druck alggeliefert wurde. Ich bemerke dies mit Rücksicht auf den histologisehen Theil der Untersuchungen, da inzwischen »vergleichend-anatomisehe Untersuchungen “ von Prof. A. Kö́lı́ker ") erschienen sind, welche im Herbst 1864 an der Westküste von Schottland angestellt wurden und sich "wesentlich auf die Histologic der Hydrozoen, Ctenophoren und Anneliden beziehen«. Unsere, ganz unabhingig von einander ausgefuhrten Untersuchungen haben da, wo sie denselben Gegenstand, nämlich die von Köцlıkr hier allein berücksichtigten Bindesubstanzen betrafen, ein fast iibereinstimmendes Resultat gehabt. Dies gilt namentlich von dem Bau der Gallertscheibe und der soliden Tentakehn der niederen Melusen. Das Gewebe, welches KöLlı́r als zzellige einfache Bindesubstanz der niederen Medusen (Hydroiden) beschreiht, seheint mir ganz oder doch grossentheils mit dem von mir als „Knorpel“ gedeuteten Gewebe zusammenzufallen.

1) Wurzburger naturwissenschaftliche Zeitschrift. Bd. V.

Jena, am I i. Juli 1865 . 


\section{I n h a l t.}

Vorwort. . . . . . . . . . V

Einleitung . . . . . . . . . 1

Literatur der Geryoniden • . . . . 2

1. Geschichte der Geryoniden . . . . . . 3

II. Organisation der Geryoniden . . . . . . 8

111. System der Geryoniden . . . . . . . 21

I. Liriopida. . . . . . . . 29

1. Liriope. . . . . . . 22

2. Glossocodon . . . . . . . 26

II. Carmarinida . . . . . . . . . $\quad$. 28

3. Leuckartia . . . . . . . 28

6. Geryonia . . . . . . . . 30

5. Carmarina . . . . . . 32

IV. Anatomie von Glossocodon eurybia (Liriope eurybia) • 33

1. körperform . . . . . . . 33

2. Gastrovascularsystem . . . . . . $\quad 36$

3. Skelet . . . . . . . . 43

4. Nuskelsystem . . . . . . . . . 44

5. Nervensystem . . . . . . . 47

6. Sinnesbläschen . . . . . . . 52

V. Metamorphose von Glossocodon eurybia (Liriope eurybia) . 60

VI. Anatomie von Carmarina hastata (Geryonia hastata) . . 74

1. körperform . . . . . . . 74

2. Gastrovascularsystem . . . . . . 77

3. Skelet . . . . . . . . $\quad 82$

4. Muskelsystem . . . . . . . 87

5. Nervensystem . . . . . . . $\quad$. 99

6. Sinnesbläschen . . . . . . . . . 101

VII. Metamorphose von Carmarina hastata (Geryonia hastata) . 105

VIII. Knospenbildung in der Magenhöhle (an der Zunge) von Carmarina hastata . . . . . 115 
IX. Anatomie von Cunina rhododactyla . . . . . 125

1. Körperform . . . . . . . 125

2. Gastrovascularsystem . . . . 128

3. Skelet . . . . . 132

4. Muskelsystem . . . . , . 135

5. Nervensystem . . . . . . 136

6. Sinnesbläschen . . . . . . 138

X. Verwandtschaft und Generationswechsel zwischen den Geryoniden und Aeginiden . . . . 139

XI. Gewebe der Geryoniden . . . . . . 160

1. Epithelialgewebe . . . . . . . 162

2. Mantelgewebe . . . . : . 165

3. Knorpelgewebe . $\quad . \quad$. $\quad$. $\quad$. 169

4. Muskelgewehe . . . . . . 178

3. Nervengewebe . . . . . 180

Erklärung der Abbildungen . . . . . . 183 
Die Familie der Rüsselquallen oder Geryoniden umfasst Thiere, welche durch eigenthümliche Verlialtnisse des Baues und der Entwickelung sich vor den iibrigen eraspedoten oder eryptocarpen Mecinsen mehrfach auszeichnen und in mehr als einer Beziehung̣ ein besonderes Interesse zu erregen gecignet sind. Schon die sehr charakieristische P'ilzoder Sehirmform ilres langgestietten Glockenkörpers, sowie die sehr bedeutende Grösse einiger Arten zeiclmet sie so aus, dass sie bereits vor langer Zeil die besondere Aufmerhsamkeit der mit dem Studium der Seethiere beschiaftigten Naturforseher auf sich zogen. Allein obwohl schon im vorigen Jahıhundert (17ï) eine verhältnissmässig genaue Beschreilsung und Abbildung einer grösseren Geryonide veröffentlicht wurde, und obwohl die Zahl der beobachteten Arten bald sehr vermehrt wurde, so blieben doch die Organisationsverhthitnisse und die Entwickelungsgeschichte der Riisselquallen unvollstindiger bekinnt, als diejenigen vieler anderer niederer Meetusen, die weniger Eigenthümlictıkeiten darbieten. Die : ilteren Autoren warfen die eigentlichen Geryoniden mit anderen Craspedoten zusammen, denen sic zwar : iusserlich iihnlich sind, von denen sie sich aher durch ihre innere Organisation wesentlich unterseheiden. Leber die letztere findet man noch bei den neuern Autoren die auffallendsten Widersprüche und namentlich haben die verschie-

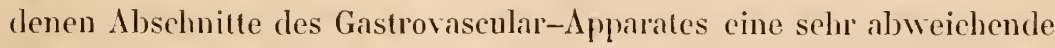
und vielfach irrige Deutung erfahren. Selbst in dem trefllichen "Versuch eines Systemes der. Medusen " von Gegexbacr (1 8.56) ist der eigentliche Bau der letzteren nicht erkannt, und die Charakteristik der Gerı̣oniden-Familie daher weniger zutreflend, als die der ubrigen Craspedoten-Fanilien. In der neusten grösseren Naturgeschichte der Medusen, 
von Agssstz, isı die Fanilie der Rüsselquallen sogar, auf Grund älterer widersprechender $A$ gaben, in zwei, anscheinend wesentlich verschiedene Fanilien, die Leuchartiden und die eigentlichen Geryoniden, gespalten werden.

Inter diesen Umsländen war es mir sehr erwünscht, dass ein siebenwöchentlicher $\Lambda$ ufenthalt an Meerbusen von Nizza im Mirrz und April dieses Jahres mir Gelegenheit gab, zwei Arten dieser Familie, welche dort in Menge vorkommen, und zwar zwei typische kepräsentanten ibrer beiden Unterfamilien, andauernd in lebendem Zustande zu beobachten. Durch meine Lntersuchungen über den feineren Bau und dic Entwichelung derselben glaube ich in den Stand gesetzt zu sein, die Grundzüge der Organisation dieser merkwürdigen Quallen definitiv feststellen und die differenten Angaben der verseliedenen Autoren über dieselben erhliren zu können. Zugleich gab nir eine Verglcichung der Literatur mit meinen eigenen Forsebungen Gelegenheit, die Systematik der ganzen Familie zu verbessern und sowohl den Charakter der einzelnen Gattungen und Arten, als auch der ganzen Familie schärfer, als es bisher möglich war, zu umschreiben. Die einzelnen Abschnitte der so zu Stande gekommenen monographischen Skizze sind so vertheilt, dass auf eine historische Uebersicht der bisherigen Beobachtungen über Geryoniden zunächst eine iibersichtliche und kritische allgemeine Darstellung der Organisation der Familie folgt, darauf der Versuch eines Systemes der Geryoniden, mil kurzer Charahteristik aller Gattungen und Arten, und endlich als жweiter Ilauptabschnill die genaue Darstellung der gesanmten Organisation und der Entwickelung und Metanorphose der beiden von mir beobachteten typischen Species.

\section{Literatur uer Geryoniden.}

1. Forski̊L, Descriptiones animalium, ynac in itinere orientali collegil. 1775. p. $10 \mathrm{~S}$. (Besebreibung der Medusa proboscitalis).

2. Forsk ̊̊, lcones rerum naturalimm, quas in itinere orientali depingi curavit. 1776. Taf. XXXV1, Fig. J (Abbildung der Medusa proboscidalis).

3. Ṕ́ron et Lesuevil, Tableau des caractères genćriques et speciliques de toutes les espèces de Méduses eonnues jus(ju'i ce jour. Annales du iluscium d'histoire nalurelle. Tom. XlV. 1509. 1). 329 (Beschreihung del Geryomia hexaphylla).

4. P'́ron et Lesuetr, Abbildung der Geryonia hexaphylla in : Cuvien, le règne animal, cdition illustrée, 1849 . Les Zoophy tes, par HiLxe-EDWAnds etc., Pl. 52 , Fig. 3.

5. Chantso et Ersenuand, De animalibus quilusdam e classe vermitu Linnaeana. Nova acta phys. med. Tom. X, 4. 1820. p. 357; Tal. X.XVII, Fig. 2. A. B. C. (Geryonia tetraphyilu).

6. Qyor et Gamano, Momoire sur la famille des Diphides; Mnual. des se. nat. Tou. X, 1827. Pl. V1, lig. 5-8. (Deutsch in Ores's lsis. Wol. XX1, 1828. p. 342. Tal. V. Fig. 5-8). (Dianuea exigua). 
7. Eschscholtz, System der Acalephen. 1\$29, p. 86-91, Taf. XI, Fig. 1, 2. (Familie der Geryoniden. Genus Geryonia mit 6 Species).

8. Buand, Ausführliche Beschreihung der von C. H. Nertess auf seiner Weltumsegelung beohachteten Schipmquallen. Mémoires de l'Académie impériale des sciences de S. Petershourg. VI. Série. Tom. II. 1838. p. 389; Taf. XVIII, Fig. 1, 2. (Geryonia hexaphylla).

9. Lesson, Htistoire naturelle der Zoophytes. Acalèphes. 1843. p. 329-333; PI. VI, Fig. 3. (Geryonia mit 4, Liriope mit 2, Tanthea mit 1 Species).

10. Forbes, A Monograph of the British naked-eyed Medusae 1848. p. 36. PI. V, Fig. 2. (Geryonia appendiculata).

11. Gegexnaur, Versuch eines Systemes der Medusen. Zeitselur. für wiss. Zoologie Bd. VIII. 1856. p. 252-258. Taf. VIII, Fig. 16, 17. (Familie der Geryoniden. Geryonia proboscidalis. Liriope mucronala).

12. Leuckart, Beiträge zur Kenntniss der Medusenfauna von Nizza. Archiv für Naturgesch. XXII. Jahrg. 1. Bd. 1856, p. 3-9. Taf. I, Fig. 1-4. (Geryonia exigua. G. proboseidalis).

13. Fritz Müller, Polypen und Quallen vou S. Catharina. Arehiv für Naturgeseh. XXV. Jahrg. 1. Bd, 1859. p. 310-321. Taf. XI, Fig. 1-25. (Die Formwandlungen der Liriope catharinensis).

14. Mc. Crady, Gymnophthalmata of Charleston Harbor. Proceedings of the Elliott Society of natural history. Vol. I. 1859. p. 207-208. (Liriope scutigera).

15. Agassiz, Contrihutions to the natural history of the United States of America. Second Jonograph. Part. IV. Hydloidac. 1862. P. 364-365. [Familien der Geryoniden (Geryonia mit 2 Species) mnd der Leuchartiden (Leuckarlia mit 1, Liriope mit 6, Tanthea mit 2 Species). Liriope tenuirostris?.

16. HAECKEL, Beschreibung neuer craspedoter Medusen aus dem Golfe von Nizz: Vergl. Jenaische Zeitschr. f. Med. u. Naturw. 1. Bd. p. 327-330. (Geryonia hastata und Liriope eurybia).

\section{Geschichte der Geryoniden.}

Die älteste Beschreibung uud Abbildung einer zur Familie der Geryoniden gehörigen Meduse findet sich in der 1775 ersehienenen Darstellung der von Fonskil auf seiner orientalischen Reise beobachteten Thiere. Die betreffende grosse Rüsselqualle wurde von ihm im Mittelmeer beobachtet und Medusa proboscidalis benannt. Auf eine dieser nahe stehende, ebenfalls im Mittelmecr gefundene Art grundeten 1809 Pénox und Lesceur ihre neue Gattung Geryomia, welche sie mit folgenden Worten charakterisirten: „Point de bras; des filets ou des lames an pourtour de l'ombrelle; une trompe inféricure et centrale «. Ausser jener grossen, der Medusa proboscilalis verwandten $\Lambda \mathrm{rt}$, welche diese Forscher Geryonia hexaphylla nannten, zogen sie dazu noch eine zweite, sehr verschiedene Meduse, G. dinema, welche Escuscmontrz später $S a-$ phenia dinema taufte, und welehe jetzt unter diesem Namen zur Familie der Geryonopsiden gerechnet wird. Dagegen wurde bald ein anderes, wirklich zur Familie der Geryoniden gehöriges Thier, welehes die ailteste beobachtete Art der Galtung Liriope ist, von Gнимsso im indischen Ocean entdeckt und 1820 als Geryonia tetroplylla beschrieben und alsgehildet. Endlich wurde eine dritte, ebenfalls zur Gattung Liriope ge- 
hörige Art 182i von Qcox und Gamand unter dem Namen Dianaea exigna bekannt gemacht.

In der ersten Naturgeschichte der "medusenartigen Strahtthiere ", dem 1829 erschienenen trefflichen "System der Acalephen « von Escuscnot.tz, finden wir die Gattung Geryonia zum 'T!pus einer eigenen Familie, der Geryoniden, erhoben, in welchem ausserdem noch 6 Gattungen zusammengestellt werden (Dianaea, Limuche, Saphenia, Eirene, Limnorea, Favonia). Mit Ausnahme der ersten Galtung , die bei Escnscnoltz nur eine Varietiit von Dianaea (Liriope) exigna enthialt, gehören diese Genera zu ganz verschiednen Familien. Das Auszeichnende seiner neuen Familie der Geryoniden fundet Escuscnot.tz „ in einem langen Fortsatze, welcher aus der Mitte der untern Fliiche der Scheibe entspringt, aus derselben gallertigen Masse gebildet ist, wie die Scheibe selbst, und nicht zur Aufnahme von groben Nahrungsstoflen dient, sondern nur ihre Siffte einzicht. Denn dieser Stiel ist ganz so beschaffen wie die Arme und der Stiel bei den Rhizostomiden: an seiner Spitze befinden sich Saugöffnungen, die in feine den Sticl durchlaufende Canïle übergehen, und so den Nahrungssaft den Verdaumugshöhlen zufiihren."

Von dem Genus Geryonic sagt Escuscuoltz (l. c. p. 86). "Ventriculi plures cordati in cirenitu disci. Cirrhi marginales totidem majores. Pedunculus ante appendicem plicatam constrictus «. »Die durchsichtige Scheibe aller bekannten Arten dieser merkwürdigen Gattung liasst an ihrem Unfang mehrere (4, 6 oder 8) herzförmige, flache, gefirbte Theile leicht erkennen, welche als einzelne getrennte Magenhöhlen anzusehen sind. Ihre Spitze ist dem Rande zugewandt und steht cinem Fangfaden schr nahe, welcher denn auch seinen Ursprung von hier nimmt. Der Stiel hat kurz vor seinem Ende eine Einselniurung, worauf ein gefalteter Anhang folgt, dessen Falten sich nach der Zahı der Magenhöhlen zu richten scheinen. Yon dem Anhange entspringen ebenso viele kleine Canikie, als Magenhöhlen vorhanden sind, die in der Masse des Stiels an den Seiten desselben hinaufsteigen und sich zur Nitte des inneren landes der herzörmigen Anbinge begeben, wo sie grleichsan den Stiel des her\%förmigen Blattes ausmachen. Als liortsetzung der Caniile bemerkt man noch einen dunklern Streifen durch die Mitte des Blatts verlaufen, wo die Magenhöhle wahrscheinlich noch eine Palte hat «. Wic aus dieser treflichen Beschreibung hervorgeht, halte EscmscmotT\% die anatomischen Eigenthimlichkeiten von Geryonia vollkommen richtig aufgefasst, abyesehn von dem einzigen Irrthum, dass er in dem ngefalteten Anhange a des Scheibensticles den Magen nicht crkannte und vielmehr die flachen herzförmiggen Blitter, welche die Genitalien darstellen, für 
einzelne getrennte Magenhöhlen hielt. Von den 6 Species, welche Escnscmoltz unter dem Genus Geryonia aufführt, kann nur eine einzige, G. proboscidalis, mter demsellsen stehen bleiben. Eine zweite, nicht hinreichend bekannte Art, G. mimima (dic Mednsa mimima von Baster, Orylhia mimima von Pérox und Lesueur) gehört einer andern Familie. an. Die 4 übrigen Arten (3. G. tetraphylla, 4. G. bicolor, 5. G. rosacea, 6. G. exigua) sind zu Liviope zu ziehen.

Eine neue grosse, von Mertaxs im stillen Ocean aufgefundene Geryoniden-Art wurde 1838 von Braxnt als Geryonia hexaphylla heschrieben, obwohl sie oflenbar von der mit dem gleiehen Namen von Péron mud Lesquér bezeichneten Art sehr verschieden ist. Durch die in der Abbildung von Braxnt sehr deutlich dargestellten centripetalen Radialeanaile stimmt diese Form ïherein mit der von Gegexraur bei Messina beobachteten Art, mit welcher zusammen sie in der Gattung Geryonia stehen bleiben kann.

In der 1843 erschienenen nIIstoire naturelle des Zoophyles Acalèphes « von Lessor werden die bis dahin hekannten, zur Familie der Geryoniden gehörigen Medusen eingereiht in seine sTroisième Groupe: Les Meduses agaricines ou Meduses proboseidées: $\Lambda$ disque domnant attache en dessous et au milieu à un stipe plus ou moins long et épais, entier, à peine divisé au sommet, ou parfois garni de fibrilles terminales ou latérales«. Die Geryoniden vertheilt Lessor auf 3 Gattungen, welche er durch folgende Diagnosen mnterseheidet: "1. Geryonia: Ombrelle hémisphérique, ayant \& cirles marginaux, \& appendices foliiformes à l'estomac, pédoncule assez long, ç̣lindrique, ayant 4 ouvertures au sommet ou une ouverture entourée de petites folioles. 2. Liriope: Ombrelle hémisphérique, exeavé en dessous, ayant 4 ou 6 tentacules marginaux, 4 ou 6 lohes stomacaux cordiformes; 1 m pédoncule central, gros, dilaté au sommet en cupule, à six lobes et perforé au milien. 3. Xanthea: Ombrelle hémisphérique, sans lobes de l'estomac foliolaires, à pourtour évasé, garni de 8 tentacules très courts. Face inlérieure du disque exeavée à prolongement probosciforme lonğ, eylindrique, terminé à son sommet par une ouverture simple. Diese Diagnosen sind, wie man sieht, in jeder Beziehung ganz ungenïgend und mologisch. Geryonin und Liviope unterseheiden sich hiernach lediglich dadureh, dass bei der ersteren der Mund ron 4, bei der letzleren von 6 Mundlappen umgeben ist, wähend die andern Theile bei beiden in Vierzahl vorkommen können. Zu Liriope stellt L.sssox ausser Geryonia proboscidalis eine individnelle Varietiil oder Monstrositiit ron G. exigua, welche er Liviope cerasiformis nenut, und welche auch Escuscuoutz als Dianaea exigua von ersterer getrennt hatu. Bei Geryonia lisst Lessox 
1. Arten stehen (1. G. teleriphylla, 2. G. bicolor, 3. G. rosacea, 1. G. exigua). Von seinem Genus . Yanthea fuhrt er nur eine Art auf, $X$ ayaricina: „Onbrelle hỵalin, à huit courts tentacules. P'édoneule allongé, çlindrique, perfore. « Das ist offenbar nur eine tiviope mit noch nicht entwickelten Genitalien.

Von den beiden neuen Arten Geryonia, welche Wir. 18\% in seinen 》Horae tergestinae a aufführte, gehört die eine, G. planata, zur Familie der Eucopiden, die andere, G. pelhucida, zur Familie der Geryonopsiden und zwar zur Gattung Timu. Dagegen beschreibt Forbes 18.8 unter seinen "British nacked-eyed Medusae " eine neue Geryonia "ppendiculala, welche zur Gattung Liriope im Sinne der neueren Autoren gehört.

Eine bestimmte Begrenzung erhielten die beiden Gattungen Geryouia und Liriope erst 1836 durch Gegexbatr, welcher in scinem trefflichen »Versuch eines Systemes der Medusen " zugleich die Familie der Geryoniden schärfer zu umschreiben und die sehr verschiedenartigen, bisher damit gemengten Bestandtheile anderer Familien auszuscheiden suchte. Zu diesen letztern gehören namentlich mehrere jetzt zur Familie der Geryonopsiden gestellte Gattungen. Den Charakter der eigentlichen Geryoniden findet Gegenbatr einerseits in der eigenthumlichen, an die Aeginiden erinnernden und von allen andern Craspedoten abweichenden Bildung der Geschlechtsorgane, welehe als ganz flache blattförmige Ausbuchtungen der Radialeanäle sich nicht uber die Fläche cler Subunbrella erheben, andererseits in der eigenthümlichen Bildung des Schirmstieles, von dem er irrthumlich annimmt, dass er win seinem Innern nur einen grossen Behailter für den mit Seewasser gemischten Chymus vorstellea. - „Vom Magengrunde erstreckt sich cin Canal unter allmihlicher, dem Umfang des Stiels entsprechenden Zunahme seines Lumens bis in den Schirm, wo er sich in eine geräumige, im Unfange die Radiärcanäle abgebende Iöhlung erweiter"«. Die beiden Gencra der Geryonidenfamilie, Geryouia und Liriope, unterscheidet Gegexmaur dadurch, dass bei ersterer blind geendigte centripetale Fortsaitze zwischen den Radialcanälen vom Ringeanale ausgehen, wiihrend diese bei letzterer fehlen. Von beiden Gattungen beobachtete er in Ilessina einen Repräsentanten. Seine Geryouia proboscidalis ist von der gleichnamigen Form der friiheren Autoren sicher versehieden. Seine neue Liriope mucronata zciehnet sich durch einen, ebenfalls irrthünlich für hohl gehaltenen, kegelförmigen Fortsatz des untern Endes vom [Schirmstiele aus, der die Magenhöhle frei durchsetzt und oft weit aus dem Munde hervorragt. Wir werden dieses eigenthumliche Gebilde fortan als »Zungenkegel « bezeichnen. 
Fast gleichzeitig mit Gegenratr und unabhiingig von diesem beschrieb 1856 Leuckart 2 ebenfalls mediterrane, von ibmı hei Nizza bcobachtete Vertreter der beiden genannten Gattungen, von denen er den einen mit Geryonia proboscidalis von Escuscuoltz, den andern mil G. exigua von Lessox (Diunaea e. Liriope e.) für identisch hielt. Indess wcicht deren Beschreibung und Abbildung so sebr von derjenigen der genannten und auch aller andern Geryoniden ab, dass, falls sie naturgetreu ist, beide unzweifelhaft als eigene Arten abzusondern sind. Von sciner G. exigna, die wir unten als Liviope lignrina aufführen werden, beobachtete LecckarT auch zahlreiche jugendliche Fornen, die in vielen Beziehungen so schr von den erwachsenen abweichen, dass man ohne Kenntniss der vermittelnden Zwischenstufen beide als Angehörige ganz verschiedener Medusenfamilien betrachten würde.

Eine noch vollständigere Entwickelungsgeschichte lieferte $18: 59$ Fratz MüLlen von ciner neuen liriope, die er nach ihrem brasilischen Fundorte L. catharimensis nanntc. Es schliesst sich diese Art am nächsten an $L$. mucronata an, und namentlich verlangert sich auch hier der Schirmstiel unten in den Magen hinein in Form eines langen soliden „Zungenkegels «. Die jugendliche Laryenform dieser Art steht den von Leuckart beschriebenen Larven der $G$. exigna sehr nahe, und MüLlen weist von beiden nach, dass sie nicht wesentlich von den noch nicht geschlechtsreifen Medusenformen versehieden sind, welche Escuscuoutz als Eurybia und Gegexbacn als En'ybiopsis beschrieben haben.

In der 4839 erschienenen Arbeit von Mc Cranr über die nGymophthalmata of Charleston Iarbor findet sich die Beschreibung einer neuen Liriope, welche derselbe wegen ihrer sehr grossen kreisrunden schildförmigen Genitalblätter $L$. scutigera nennt.

Eine andere nordamerikanische Art von Liriope wurde von Agsssız bei Key West (Florida) gefunden. Sie zeichnet sich durch enorm langen Magenstiel aus, der $\$$ mul so lang als der Schirmdurchmesser ist. Diese Art wird von Agassiz 1862 in seinem grossen Acalephen-Werke (IV. Band der Contributions ete.) als $L$. temmirostris aufgefülurt. In der "Tabular view of the whole order of Hydroidace, Welche Agassiz in diesem Werke gicbt, finden wir dic systematische Gruppirmng der Geryoniden in einer ganz neuen Form. Zunächst scheidet Agassiz mit Recht, wie schon GEgExbsun gethan hatte, aus dieser Familie diejenigen craspedoten Medusen als Geryonopsiden aus, welche mit den Geryoniden zwar den riisselihnlichen langen Magenstiel theilen, aber durch die Bildung der Genitalien ganz von diesen abweichen und sich vielmehr den Eucopiden anschliessen. Ausserchem spaltet er aber, auf die irrige Angabe Gegenbatu's von dem Bau der Geryonia gestuit»t, die 
Familie der Geryoniden in 2 Familien, von denen diejenige der eigentlichen Geryoniden bloss durch Geryonia (G. proboscidalis, Gegexbacr und (r. hexaphylla, Busnt) gebildel wird (mit angeblich einfach hohlem Magenstiel), wïhrend die andere der Leuckartiden (mit getrennten Caniilen des solidten Magenstiels) alle andern Gattungen umfasst (Liriope, Ianthea und Lenchartia [Geryonia proboscidalis, Lztck.11т]). Dass diese spaltung auf irrthïmlichen Voraussetzungen beruht, wird sogleich näher bewiesen werden.

Meine eigenen Anschaumgen über den Bau und die Entwickelung der Geryoniden grüulen sich auf die eingehende Untersuchung von 2 Species, welche ich in grosser Anzahl im Frihjahr 186 ' im Golfe von Nizza zu beobachten Gelegenheit hatte, und welche hereits auf p. 397 der Jenaischen Zeitsehr. f. Med. u. Naturw. (1. Bd.) als Cieryonia hustatu und Liriope eurybia beschrieben worden sind. Ehe ich auf die speciellere Darstellung derselben eingehe, werde ich cinen allgemeinen Ueberblick ïber die Organisation der Familie geben, und den Versuch machen, die aufgeführten in der Systematik der Geryoniden entstandenen Differenzen zu lösen und durch brauchbare Charaktere die verschiedenen hierher gehörigen Gattungen und Arten zu scheiden, wolsei ich meine oben erwaihnte Nittheilung (p. 327) als bekannt voraussetze.

\section{Organisation der Geryoniden.}

„Die Fanilie der Russselquallen ist wohl die bezugglich ihres Baues am wenigsten aufgeklirte, und bis in die neneste Zeit ziehen sich widersprechende Angaben über die Structurverhältnisse dieser Wesen in den einzelnen Lehrbiichern fort «. Dass dieser Satz, mit dem Gegexbaur 18:36 die Besprechung der Geryoniden beginnt, auch hentzutage noch vollkommen gültig ist, wird jeder zugeben, der die im Vorhergehenden citirten sehr versehiedenen Angaben der zalılreichen Beobachter näher geprift und in Einklang zu bringen versucht hat. Als der auffalligste aussere Charakter der Geryoniden sprinğt zmäachst unmittelbar jedem Beobachter der »Rüssel « in die Augen, d. h. der lange, bewegliche, cylindrische oder ronische Magensticl, weleher an seinem unteren Ende den verhailtnissmässig sehr hleinen Magen triggt, wïhrend das obere Ende allmählich conisch verdickt in die untere Fläche des Gallertschirms ibergeht und diesen ebenso trigt, wie der Stiel eines Ifutpilzes seinen Hut.

Allein so auffallend anch dieser lange Schirmstiel ist, so reicht er Joch nicht ans, die Familie der echten Geryoniden allein zu charakterisiren, denn ein gleicher Stiel kommt anch bei vielen andern Craspe- 
doten, obschon nicht in so hohem Grade entwickelt, vor, erstens bei der von Agissız als Geryonopsiden getrennten Familie, und dann auch bei zahlreichen Medusen aus Gegexaur's Abtheilnng der Oceaniden und Thaumantiaden. Die letzleren sind jedoch, abgesehen von der ganz verschiedenen Bildung der Genitalien, sofort an den Pigmentflecken (Ocelli) des Schirmmandes zu mnterscheiden, während die Geryoniden, ebenso wie die Geryonopsiden, stets nur Randblikschen (mit Otolithen), niemals Ocelli tragen. Was nun die Trennung der eigentlichen Goryoniden von den Geryonopsiden betrifft, so sei hier von vornherein hervolgehoben, dass dieselbe sehr leicht nach der ganz verschiedenen Bildung der Genitalien zu bewerkstelligen ist. Die Familie der Geryonopsiden von Agassaz umfasst die Gattungen: Geryonopsis, Ërrene, Tima, Eutima, Orythia und Saphenic (Forres), welche nach Gegenbaur's System in dessen Familie der Eucopiden gehören wïrden, sich aber von den echten Eucopiden (mit sitzendem Magen) durch den Magensticl unterscheiden. Bei allen diesen Geryonopsiden verlaufen die Genitalien als meistens cylindrische Wülste, Falten oder Rippen längs der Radialcanäle und springen stets mehr oder weniger von der Subumbrella in die Schirmhöhle vor, oder hïngen auch wohl, wie bei den cchten Eucopiden, als bläschen- oder sackförmige Ausstülpungen der Radialcaniile in letzlere hinein. Dagegen hei allen Geryoniden breiten sich die Genitalien als ganz diinne llache Blaitter in der Suloumbrella aus, ohne in die Schirmhöhle irgend vorzuspringen. Es sind diese sehr verschieden gestalteten "Genitalblitter" nichts Anderes, als ganz flache taschenförmige seitliche Ausstiblpungen der hadialcanile, welche letzteren selbst wie eine Blattrippe mitten durch jedes Genitalblatt hindurchlaufen. So erscheinen hier die Ernährungs- und Fortpflanzungsorgane noch inniger verbunden, als bej allen andern Medusen, nur die Aeginiden ausgenommen. Dies hat schon Gegexbaur mit Recht hervorgehoben, indem er (1. c. p. 263) bemerkt: "In der Bildung dieser Organe, oder vielmehr, da hier keine so scharfe Differenzirung der keimbereitenden Stitte von dem Gastrovascularsysteme stattindet, in der Bildung der Geschlechtsproducte, nïhern sich die Rüsselquallen auffallend genug den Aeginiden «.

Wahrend so die charakteristische Genitalbildung der Geryoniden von Gegexbark vollkommen richtiğ erkannt und gew ürdigt wurde, so irrte er dagegen in einer andern Bezichung, indem er bei den echten Rüsselquallen (Geryonia und Liriope) auch eine eigenthümliche Construction des Magenstiels zu erkennen glaubte, und eine Bildung des Gastrovascularsystems, welche wesentlich von derjenigen der Geryonopsiden verschieden sei. Diese irrige Angabe erfordert namentlich 
deshalb eine besondere Widerlegung, weil Asissız, lediglich dureh sie bewogen, die Gruppe der Rüsselquallen in seine 2 Familien der eigentlichen Geryoniden (Geryonia proboscidulis, Gegexsarr und fr. hexaphylla Braxwт) und der Leuckartiden (die übrigen Geryoniden) spaltete. "Der Sticl der Geryoniden ", sagt Gegexbaur, meharakterisirt sich vorzigglich durch den Mangel von gesonderten Canälen; er stellt in seinem Innern nur einen grossen Bchätter für den mit Seewasser gemischten Chỵmus vor, und unterseheidet sieh somit wesentlich von ahnlichen stielartigen Verlängerungen «. Bei Geryonia (proboscidalis) entspringt von der concaven Unterfliche des Schirms munter almïhlicher Verjungung der etwa 21/2" lange Stiel, an dessen Ende der meist gefaltete Magen sitzt. Vom Magengrunde erstreckt sich ein Canal unter allmählicher dem Lmfange des Stiels entsprechenden Zunahme seines Lumens bis in den Sehirm, wo er sich in eine geriumige, im Unfange die Radiärcanaile ahgebende Höhlung erweitert. Solcher Canile sind 6 vorhanden. Sic sind die Fortsetzungen von eloen so vielen weisslichen Streifen, welche vom Magen an längs des Stielcinals verlaufen, ohme dass sie jedoch auf dieser Strecko irgend etwas mit einer Canalbildung zu schaffen hatten, und werden einfach durch einen besondern Epitheliiberzug, dessen Zellen durch ihren feinhörnigen Inhalt weisslich erscheinen, dargestellt. Erst da, wo diese weisslichen Streifen im Schirme gegen den Rand hin gerichtet nach abwirts liegen, beginnen die wirklichen Canaile, in deren Auskleidung dic Zellen der Streifen sich fortsetzen. Bis dahin erstreckt sich auch die trichterförmige llöhle als Fortsetzung des Stielcanals und wird in ihrem Lumen dureh eine von der Gallertsubstanz des Sehirms gebildete Vorragung etwas verengert ". Wenn diese Darstellung richtig wäre, so würde sie $\Lambda$ gassiz. in der That zur Aufstellung einer besonderen Familic berechtigen. Allein die sorgfiltige anatomische und mikroskopische Untersuchung eines vollkommen wohl erhaltenen, von Gegenaaur selbst aus Messina mitgebrachten Originalexemplares sciner Geryonic proboscidalis erlaubte mir das Irrthimliche jener Darstellung nachzuweisen und mich zu überzeugen, dass hier ebenso wie hoi den ibbrigen Geryoniden und wie bei allen Geryonopsiden, die Stielcanible bereits getrennt aus dem Magengrunde entspringen, isolirt in der Aussenfläche des soliden Magensticls zur Unterlliche des Schirms verlaufen und hier ummittelbar in die Radialeanale sich fortsetzen, welehe die Genitalblätter durehlaufen und in den Ringeanal münden. Querschnitte durch den Magenstiel in allen versehiedenen Höhen vom Magen bis zum Schirm zeigten das Verhailtniss sehr klar und gaben dasselbe Bild, welches ich Taf. XI. Fig. 4. 8. von Geryonia haslate dargestellt habe. Die relativ miichtige Gallertmasse des soliden Magen- 
sticls ist übrigeus so vollkommen farblos, wasserhell, durchsichtig, homogen und structurios, und leistet dem Eindringen eines spitzen Instrumentes, mit dem man die scheinbare Stielhöhle untersuchen will, so wenig Widerstand, dass man selır leicht zur Annahme der letzteren verieitel werden kamn. Der lirthum von Gegenbaur war aber um so leichter möglich, als derselbe, wie ich aus mündlicher Mittheilung weiss, nur wenige und dabei grossentheils verstummelte Exemplare in Messina zu untersuchen Gelegenheit hatte.

Dasselbe Organisationsverhailtniss des Stiels wie bei Geryonia findet sich auch bei Liriope. Der Magenstiel ist auch hier ein solider Zapfen, an dessen Oberfläche die Radialcanale vom Magengrund zur Subumbrella enporsteigen und ebenso ist anch die merkwürdige Fortsetzung des Magenstiels solid, welche als "Zungenkegel " in die Magenböhle hinein und oft auch aus der Mundöffnung herausragt. Für Liriope catharinensis hat dies bereits Fritz MüLLer 1859 nachgewiesen. Ich habe nich bei L. eurybia ebenfalls auf das Sicherste davon iblorzeugt. Damit fallen auch die Schwierigkeiten hinweg, welche Gegexbatr, verleitet durch die Annahme einer blind geschlossnen, "seinen aussern Contouren conformen Ilöhle « des Zungenkegels, bezüglich der scheinbar so abweichenden Bildung des Gastrovaseularapparates von Liriope findet und iber welche er sich (1. c. p. 258) ausfuhrlich ausspricht.

Es ist mithin nun festgestellt, dass das Gastrovascularsystem und namentlich der im Magenstiel liegende Theil desselben bei Geryonia sich nicht anders, als bei den ithrigen Geryoniden verhailt, dass vielmehr alle diese Medusen hicrin vollkommen unter einauder und auch mit den Geryonopsiden übereinstimmen. Die von Agıssız aufgestelle Familie der Leuckartiden muss deshalb wieder eingezogen werden und die darunter zusammengefassten Gattungen Leuclartia, Liviope, Sunthea muissen mit Geryonia in der alten Familie der Geryoniden vereinigt bleiben. Diese erscheint dann als eine interessante Mittelgruppe zwischen den beiden Familien der Geryonopsiden und der Aeginiden, indem sie mit jener die Structur des Gastrovascularapparates, und namentlich des Magenstiels theilt, dieser dagegen dureh die eigenthiumliche Bildung der Genitalien sich nihert.

Nachdem so die Grenzen der Familie der Rüsselquallen festgestellt sind, erscheint es lohnend, auch auf die ibrigen Organisationsverhailtnisse der Geryoniden im Allgemeinen einen Blick zu werfen. Obschon das vorliegende Material ïber diese merkwürdigen Thiere in Ganzen noch sehr dürtig und unvollkommen ist, und erst schr wenige Arten genauer untersucht sind, so weichen doch schon diese unvollkommenen 
Erfahrungen lin, ein besonderes Interesse fur diese mehrfach ausgezeichnete Quallenfanilie zu erregen.

Die iussere Körperform der Geryoniden zeigt im Ganzen einen sehr iihereinstimmenden Irabitus. Der Schirm ist meistens mehr orler weniger halbkugelig, l,isweilen fast kugelig gewölbt, seltener flacher, scheibenförmig, uhrglasförmigg oder kegelförmig. Dagegen bietet die Zusammensetzung des Körpers aus mehreren gleichen (homotypischen) radialen Ausschnitten oder Kugelsegmenten dadurch ein besonderes Interesse, dass bei einem Theile der Geryoniclen die Zahl dieser homotypischen Körperabschnitte regelmaissig Sechs ist, während bei dem andern Theile diese Zahl, wie bei allen übrigen Medusen stets nur Vier beträgt. Alle Geryoniden mit sechszihligem Typus zeichnen sich durch sehr bedeutende Grösse und Körpermasse nicht allein vor den übrigen Thieren dieser Familie, sondern auch vor fast allen craspedoten Medusen aus, so dass sie wohl als die absolut umfangreichsten Thiere dieser ganzen Gruppe (der Hydroiden) zu betrachten sind. Dasselbe gilt dann auch von der Entwicklung aller einzelnen Theile, die sich deshalb zu einer eingehenden Untersuchung besonders eignen. Ich spalte auf Grund dieses sehr merkwïrdigen Verhältnisses dic Familie der Geryoniden in 2 verschicdene Unterfamilien: die Liriopiden mit vierzähligem und die Garmariniden mit sechszahligem Typus, zumal auch andere feinere Unterschiede diese beiden Gruppen ticfer tremnen. Die homotypische Grundzahl gilt in diesen beiden Subfamilien ganz durchgreifend für alle cinzelnen Körpertheile und Organe, so dass also nicht nur die Radialcanäle und die Genitalblätter, sondeın auch die Magenfalten, die Mundlappen, die Randbliischen und die Tentakeln bei den Liriopiden constant zu 4. oder $x \times$ ', bei den Calmariniden zu 6 oder $x \times 6$ vorhanden sind. Es hätte dieses wichtige Verhüitniss gewiss schon früher in der Systematik der Geryoniden die verdiente Berucksichtigung gefunden, wenn nicht eine vereinzelte Angabe über eine scheinbare Ausnahme die friheren Autoren irre geleitet hialte. Qror und Ganmand nimlich bildeten neben ihrer Dianaen (Liriope) exigua "un autre individu (derselben $\Lambda \mathrm{r}^{\prime} \mathrm{ab}$, das sich nur durch den Mangel der Genitalbläter und dureh einen sechslappigen Mund von der gewöhnlichen Form unterschied, während die andern Theile, wie gewöhnlich in Vierzahl vorhanden waren. Diese Form wurde num später als eine sehr auffallende Combination des vier- und sechszihligen Typus besonders hervorgehoben und nicht bloss specifisch, sondern sogar generisch von Geryonia exigna getrennt. Lesson führt sie als Liriope ceresiformis neben Liriope (Geryonia) mroboscidalis aul und Escuscunot t. grindet sogar auf sie allein scine Gatlung Dicunca: "Cirrhi marginales 
quatuor. Pedunculus apice labio sexies lobato (1. c. p. 90). Indessen hahen wir es hier, wie ich unten zeigen werde, zweifelsohne nur mit einem Individuum der Liriope exigua zu thun, bei dem die Genitalien gerade nicht entwickelt und der vierlappige Mund zufälig in 6 Falten gelegt war, wie schon Forbes bei seiner Geryonia appendiculata öfter beobachtet hatte, und ich nachher bei Glossocodon eurybia oft gesehen liabe.

Die Form des Mundes kann iberhaupt nicht, wie es öfter versucht worden ist, zur Charakteristik ler verschiedenen Arten, oder gar Gattungen der Geryoniden mit Vortheil verwendet werden. Dieser Theil ist nämlich :iusserst contractil und beweglich und weclıselt seine Form fast bestindig, oft in iiberraschendem Grade. Während ich bei Glossocodun eurybia den Saum des geöflneten Mundes incist unregelmässig viereckig, oft aber auch ganz regelniissig quadratisch fand, sah ich ihn zu andern Zeiten scheinbar in 4 grosse Lappen tief gespalten. Diese Lappen ergaben sich aber bald nur als voribbergehende Falten des Mundsaumes, entstanden dureh tiefes Einziehen der Mitte jeder Quadratseite und Zusammenlegen der beiden den Quadratwinkel einschliessenden Schenkel. Nicht selten bildete sich dann noch an 2 gegenüber liegenden Stellen zwischen je z Falten eine fünfte und sechste, und ofters endlich zwischen diesen noch eine siebente und achte Falte. Dagegen scheint die AnzahI der Nesselwarzen, welehe den Mundsaum zieren, hei verschiedenen $\Lambda$ rten constant verschieden zu sein.

Ein löchst merkwürdiges Organ, das in keiner anderen Medusengruppe bisher aufgefunden worden ist, besitzen einige, vielleicht viele Geryoniden in dem mehrfach erwilınten seltsamen "Zungenkeg̨el ", einer gleichmässig conisch zugespitzion soliden Verlängerung des Magenstiels in die Magenhöhle hinein, in welcher dieser stiletförmige Kegel theils ganz zurückgezogen liegt, theils aus der Mundöffnung weit hervorgestreckt werden kann. Es wurde dieses Organ zuerst von GegexBavr bei seiner Liriope mucronala, später von Fritz Mǘlen bei $L$. catharinensis und külzlich von mir bei $L$. eurybia bcobachtet. Sein Vorkonmen beschränkt sich aber nicht auf die vierzähligen Liriopiden, sondern erstreckt sich auch auf die sechszähligen Carmariniden, wo ich es bei Geryonia hastata nachgewiesen habe. Da der Zungènkegel, namentlich bei der letzteren, eine beträchtliche Grösse besitzt und oft weit aus dem Magen hervorragt, so kann ich haum glauben, dass die früheren Beobachter bei den andern Arten denselben übersehen haben sollten. Namentlich ist nicht anzunehmen, dass Gegexbaur, der bei Liriope mucronatu den Zungenkegel zuerst entdeckte, denselben bei seiner viel grösseren Geryonia proboscidalis, wenn er hier vorhanden 
wäre, nicht bemerkt haben sollte. Ich halte daher dieses auffallende Organ für einen wesentlichen generischen Charakter der betreffenden Arten und schlage vor, die vicrähligen Liriopiden mit Zungenkegel in der neuen Gattung Glossocodon, die sechszïlligen Geryoniden mit Zungenkegel in der neuen Gattung Carmarina zu vereinigen und von den zungenlosen Geryoniden abzutrennen. Leber die Function dieses sstiletförmigen Organs « hat sich Futrz Mü̈.ler nicht ausgesprochen. Gegens.u'R vermuthet, "dass es in engerer Bezieliung zur Aufnahme oder zur Veranderung der Nahrung stehe «. Ich glaube darin vorzugsweise ein feines Tastorgan und nebenbei vielleicht zugleich ein Geschmacksorgan, eine wirkliche Zunge, zu erkennen, worüber das Nihere unten in der speciellen Beschreibung von Glossocodon eurybia zu vergleichen ist.

Der Magensack ist bei allen Geryoniclen, namentlich aber bei den vierzahligen, von verhältnissmässig sehr geringer Grösse, so dass die früheren Autoren darin nur die Mundhöhle erblickten, und die eigentlich verdauenden Mageneavitäten in den Genitablättern suchten. Die Verdauungskraft desselben ist nichtsdestoweniger ausserordentlich gross, so dass nicht allein die weicheren wasserreichen pelagischen Organismen, sondern auch hartschalige Crustaceen, Mollusken und selbst kleine Fische in sehr kurzer Zeit mehr oder weniger vollstindig verdaut, theils in einen unförmlichen Klumpen verwandelt, theils als Brei von feinen Körnchen mit dem aufgenommenen Seewasser in die Radialcanäle übergeführt werden. Dies entspricht ganz dem ausnehmend rïulverisehen und wilden Charahter dieser behenden, gefrassigen und kühnen Raubthiere. Mc Grady sah eine Liriope scutigera einen Fisch, der 3 mal so gross als sie selbst war, mit den langen Tentakeln und dem offenen Magenschlauche, der saugende Bewegungen ausführte, umschlingen und in kurzer Zeit tödten. Ich fand bisweilen den Magen von Glossocodon eurybia durch Aufnahme grosser Nahrungsmengen bis um das Zehnfache seines ursprünglichen Volums ausgedehnt. Im ruhigen Zustande hïngt der Magen meist in Falten geschlagen als dünner Gylinder oder Kegel von dem Magenstiel herab; bei geöffneten Munde und rerstrichenen Falten erscheint er meist glockenförmig.

Der durchsichtige solide Magenstiel ist meist scharf von dem undurchsichtigen Magen alygesetzt, cylindrisch oder, besonders nach oben, kegelförmig verdickt, nach unten verdunnt und geht oben ganz allmählich in die Gallertmasse des Schirmes über. Wie diese, besteht er lediglich aus wasserklarer, hyaliner, rollkommen homogener Gallerte, in wolcher keine anderen Formelemente, als zahlreiche zerstreute, selı lange und feine, spitzwinklig verzweigte Fasem zu erkennen sind, die die ganze Dicke des Gallertmantels durehsetzen. Als matt weiss- 
liche, seltener röthlich oder grünlich gefärbte Streifen (bisweilen aber auch ganz farblos und dann of selwwer zu erkennen) steigen an der Oberfläche des Magenstiels die 4 oder $\&$ Radialcanäle empor, welche getrennt mit alsschliessharen Oeffnungen aus dem Magengrunde entspringen. Die Breite dieser Canäle ist sehr verschieden und seheint, wie überhaupt der Durchmesser ihres Lumens, nach dem verschiedenen Füllungszustande selı' zu weehseln. Meist sind die Stielcanäle schmäler, als ihre $Z w$ ischenräume, die von sehr entwickelten Lingsmuskelbändern eingenommen werden.

Die 4 oder 6 Genitalblitter sind, wie schon mehrfach erwihnt wurde, nichts Anderes, als ganz flache, taschenartige Ausstülpungen der Radialcanäle. Letztere gehen, während sie an der Subumbrella herablaufen, mit offenem Lumen mitten durch die mit Geschlechtsprodueten erfüllten loreiten Tasehen hindureh, wie Blattrippen durch das Blatt. Die Genitalproducte entwickeln sich lediglich in den Winden dieser flachen Taschen aus deren Epithel, während das Epithel des mitten dureh das Blatt hindurehtretenden Canals unver:indert bleibt. Eigentlich befindet sich also jederseits jedes Canals ein Genitalblatt als seitliche Ausstülpung desselben und genau genommen sind mithin 8 oder 12 Genitaltaschen vorhanden. Die Genitalproducte können sowohl in das Lumen des Canals, das mit der Tasche beiderseits in Communieation bleibt; als auch unmittelbar nach aussen gelangen, indem sie die dunne Subumbrella durchbrechen. Das letztere habe ich bei Carmarina lastalu beobachtet. Die Farbe der Genitall)latter ist meist mattweisslich, bisweilen röthlich odler hellgrüı. Ihre Gestalt ist meist mehr oder weniger dreieckig oder' herzförmig, seltener elliptiseh, lanzett-oder spiessförmig, sehr selten hreisrund. Die oft tief eingeschnittene Basis des Herzens ist meistens den Grunde des Magenstiels, die Spitze desselben dem Ringeanal zugekehrt, den sie oft erreicht. Nur bei den beiden von Levckart in Nizza beobachteten Geryoniden ist ungekehrt die Ilerzbasis dem Schirmrande zugekehrt. Bisweilen nehmen die Genitalblatter fast die ganze Unterfliche des Schirms (Subumbrella) ein, z. B. bei Liviope sculigera; gewöhnlich aber bleiben zwischen ihnen grosse Interstitien oder sie berühren sich bloss mit ihren Basen.

Als eine sehr auffallende Formbeugung des Gastrovascularsystems, die bei keiner anderen Familie der eraspedoten Medusen sich wiederfindet, sind die Gentripetaleanäle zu erwilinen, welche lediglich bei einem Theile der sechszähligen Carmariniden vorkommen. Es sind dies breite eylindrische oder bandförmige Ausstülpungen des Ringcanales, welche von diesem zwischen den Genitalblättern ausgehen und sieh in radialer Richtung verschieden weit gegen die Basis des Magen- 
stiels hin erstrecken, wo sie blind enden, olne letzteren zu erreichen. Die Zahl derselben ist verschicelen, stets unpaar, und nimmt mit dem Alter der Thiere zu, so dass bei den jugendlichen Larven zuerst in der Mitte zwischen je 2 Radialeanälen 1 Centripelalcanal auftritt, dann 2 seilliche zwischen diesem und jenen, und so fort. Bei Geryonia hastata finden sich dann zuletzt 7, bei G. conica sogar 9 z ischen je 2 Radialcanälen. Zuerst wurden diese Centripetaleanäle von Pénox und Lesceen bei ihrer G. hexaphylla gesehen, wie zwar nieht aus ihrer Beschreibung, wohl aber aus der von MiLxe-Enwards veröffentlichten $\Lambda$ bbildung derselben hervorgeht. Ebenso wurden sie von Bвaxt) bei G. conica abgebildet. Ihre eigentliche Natur wurde aber erst von Gegexnatn bei G. messanensis erkannt, der dieselben zugleich als generisehen Charakter der Gattung Geryonia hervorhob. Ich lasse dieses Genus in dem so von GegExbuck enger unschriebenen Umfange bestehen, wonach es also die 3 zuletzt erwihmten Arten umfasst. Dagegen scheide ich als Carmarina die von nir beobachtete G. hastata aus, welche zwar mit jenen 3 Arten dureh den Besitz der Centripetaleanäle iilsereinstimmt, sich aber durch den Besitz des Zungenkegels von ihnen unterscheidet. Als eine dritte Gattung in der Tribus der Carmariniden würden endlich diejenigen Gergonien zu bezcichnen sein, welche sowohl des Zungenkegels als der Gentripetalcaniile enthehren. Für diese hann der Gattungsuame Leucliartia, den Agsssız bereits einer ihrel Arten verliehen hat, passend beibehalten werden. Ls gehören hierher die beiden von Fonskit und von Lveckant beobachteten Geryonien, welehe zwar auch beide als Geryonic proboscidalis bezcichnet sind, indessen den Abbildungen nach zu urtheilen (selbst wenn diese nur anniher'nd genau sind) sowohl unter sich, als von den ersterwähnten Arten verschieden sein inüssen. Dass die Centripetaleanïle so scharfsichtigen Forsehern, wie Fonskil und Leuckart, entgangen sein sollten, ist nicht zu erwarten.

Zwischen dem Ringcanale und cinem darunter gelegenen breiten, aus Nesselzellen gebildeten Ringe, der als dicher kreisrunder Wulst den Schirmrand vom Velum trennt, liegt bei den Geryoniden ein selir schmaler blasser Ring, der wohl als Nervenring $\underset{q}{q} z u$ deuten ist, zumal er unmittelbar unter jedem Randblischen zu einen zelligen Knoten (Ganglion?) anschwillt und an jede Tentahelbasis einen faserigen (?) Strang sendet. Ueber die näheren Verhailtnisse ist unten die Anatomic von Glossocodon eurybia zu vergleichen.

Randbliischen seheinen sich bei allen Geryoniden doppelt so viel als Radialeanäle zu finden, also 8 bei den Liriopiden, 12 bei den Carmariniden. Ueber den feineren Bau derselhen rergl. unten die 
Anatomie von Carmarina hastata. Die Hiilfte derselben sitzt an der Basis der Radialtentakeh, oder viclmehr constant unmittelbar neben derselben, am Ringcanal. Die andere Iälfte sitzt in der Mitte zwischen jenen, unter der Basis der Interradialtentakeln, wo solche noch beim Erwachsenen vorhanden sind. Sehr eigenthümlich ist es, dass sich zuerst die interradialen und erst viel spitter die radialen Randblischen entwickeln.

Tentakeln sind bei den erwachsenen Geryoniden mindestens ebenso viele als Radialcaniile vorhanden, und am Ende derselben angebracht, bei den Liriopiden 4, bei den Carmariniden 6. Ausserdem haben aber viele Arten noch eben so viele interradiale Tentakeln, welche in der Mitte zwischen jenen aussen über dem Schirmrande angeheftet sind, und in der Jugend scheinen diese niemals zu fehlen. Ja in einer gewissen Jugendperiode scheint bei allen Geryoniden noch ein dritter Kreis von Tentakeln vorhanden zu sein, welche oberhalb der radialen (in denselben Meridianebenen) angebracht sind, so dašs die Liriopiden dann 12, die Carmariniden 18 Tentakeln gleichzeitig besitzen (vergl. die Bemerkungen über Entwicklung). Die radialen Tentakeln aller erwachsenen Geryoniden sitzen am Schirmrande schräg gegenüber der Einmündung der Radialcanäle in den Cirkelcanal. Ein Fortsatz des letzteren durchliuft sie bis zum blinden Encle. Sie sind meistentheils lang, im ausgestreckten Zustande mehrmals länger als der Magenstiel, können sich aber sehr rasch und sehr bedeutend verkürzen. Meist sincl sie cylindrisch, gleichmissig fadenförmig dünn rom Anfang bis zum Ende, häufig röthlich gefärbt. Thre starke Wandung enthält entwickelte Längsmuskelzüge. In ganz regelmässigen Abstinden sind sie von sehr zahlreichen ringförmigen Wü̈sten ungeben, die dicht mit Nesselzellen gespickt sind. lhre Bewegungen nach allen Richtungen hin sind ausserst ausgiebig und lebhaft. Ganz verschieden davon sind die interradialen Tentakeln, welche etwas oberhalb des Ringcanales von der Aussenfliiche des Schirmes entspringen. Sie sind sehr viel kürzer, meist kürzer als der Schirmradius, und auffallend starr, so dass ihre Bewegungen nur sehr langsam pendelartig sind, ganz wic bei den Tentakeln der Trachynemiden. Meist sind sie zierlich nach aussen und aufwïts gebogen, und hornförmig gekrümmt, so dass cine Reihe von mehreren auf ihrer inneren (unteren) Seite angebrachten Nesselwarzen dann nach aussen sicht. Verkürzen können sie sich gar nicht oder nur sehr wenig. Auch sind sie nicht von einem Canal durchzogen, sondern ganz solid, starr, aus einer Reihe grosser heller Zellen zusammengesetzt, ilher welche ein sehr diinner Muskelschlauch weggeht.

Das Velum der Geryoniden ist gewöhnlich strafl horizontal aus- 
gespannt, ron mittlerer Breite, derb und mit schr entwickelten radialen und circularen Mushelziigen versehen. Dagrgen sind clie Muskelfasern viel schwiicher an der Unterfliche des Schirms (Subumbrella) entwichelt. Bei Glossocodon eurybia und hei Carmarina hastatu fand ich die Muskeln, sowohl an Velum und der Subumbrelli, als an den Tentakeln und dem Magenstiele, sehr deutlich quergestreift, und zwar selion an lebenden Thiere. So scharf als bei Wirbelthieren tritt die Querstreifung an den in Weingeist und Salzlösung auflewahrten Thieren hervor. (Ëine vereinzelte $\Lambda$ ngabe von Rcoolpu Wagxer ausgenommen, der allein vor langer Zeit bei Oceania [Thaumanlias] cruciala quergestreifte Muskeln heobachtete, galten die Muskeln der craspedoten Medusen für glatt). Die quergestreiften Muskelelemente konnte ich als selır dünne spindelförmige Fasern von sehr versehiedener, zum Theil von betrichtlicher Länge isoliren, die meist viele, seltener nur einen Kern zeigten, und der Linge nach neben und hinter einander gereiht waren. Das Epithel der Subumbrella und des Velum fand ich aus grossen polygonalen Zellen mit feinkörnigem Inlualt und grossem Kern zusammengesetzt, wogegen das Epithel der Unbrella, der Aussenfliche des Schirms aus ganz hellen, oft schwer unterseheidbaren Zellen bestand.

Die Entwickelung der Geryoniden scheint stets ohne Generationswechsel und olme ungeschlechtliche Fortpflanzung, auf dem einfachen Wege der geschleehtlichen Zeugung zu erfolgen. Knospenbildung, Sprossung, Theilung sind noch niemals beobachtet worden. Die Männchen, welche ich viel seltener als die Weibehen fand, sind oft schon äusserlich an der trüberen, opaken Färbung und ğösseren Undurehsichtigkeit der Genitall,bitter zu erkennen, während diese beim Weibchen heller und transparenter sind. Dic Entwicklung aller Geryoniden scheint aber durch eine sehr interessante Meta morph os e ausgezeichnet zu sein, indem das aus dem Ei hervorkommende Junge ganz von dem Erwachsenen versehieden ist und die liorm des letzteren erst annimmt, nachdem es rerschiedene, sehr abweichende Larvenformen durchlaufen hat. Diese Laryen sind von einzelnen vier\%ihligen Liriopiden schon frilier beobachtet, aber als selbststindige Medusengattungen beschrieben worden. Eine solche Liriopidenlarve ist die Eurybia exiguu von Escuscnoltz, die Eurybiopsis anisostyla von Gegrmmn. Die vollstindige Verwandlung der Larve ist bisher nur von Fntтz Mǘlen bei seiner Liriope catharinensis verfolgt worten. In ganz iilnlicher Weise habe ich dieselbe kürzlich in Nizza bei $L$. em'ybia verfolgt mol mich dort auch an den Larven von Carmarina hastata iiber\%eugh, dass die sechsziihligen Ciarmariniden ganz dieselbe Metamorphose durchmachen, 
wie die vierzahligen Liriopiden. Die jüngsten beobachteten Larven sind kugelig, an einer Stelle des Umfangs mil einer flachen kleinen, nach aussen offenen Höhle versehen, an deren Mündungsrand dann \& (resp. 6) sehr kleine Tentakel hervorsprossen, aus einem dicken kurzen Faden bestehend, der am Ende einen einfachen Nesselknopf mit einem geisselförmigen Anhang trägt. In der Mitte zwischen diesen erseheinen später 4 (resp. 6) längere Tentakeln, an deren Unterseite eine Reihe Nesselwarzen sich entwickelt. Das sind die starren interradialen Tentakeln, welche bei vielen Arten zeitlebens, wenn auch nur verkümmert, erhalten bleiben, und als kleine hornförmig gebogene Fäden nach aussen und oben gerichtet werden. Erst nach diesen tritt die Anlage des Gastrovascularsystems auf, ein Stern von \& (resp. 6) sehr breiten Strahlen, welche sich in der Mitte der kleinen Schirmhöhlenwölbung durch einen einfachen, von einem wulstigen Rand umgebenen Mund offnen, wiihrend sie nach aussen als Radialeanïle auf die zuerst entwickelten Tentakelrudimente zuwachsen und sich durch einen Ringeanal rerbinden. Später erseheinen die 4 oder 6 interradialen Randbläschen und noch späiter die 4 oder 6 bleibenden radialen Tentakeln, welche sich am Sehirmrande sehräg unterhalb der primären Tentakelrudimente entwickeln. Dic letzteren sehwinden späterhin in allen Faillen. Zuletzt treten die radialen Randbläschen auf und nun beginnt auch der Gallertsehirm sich mehr abzuflachen und in der Mitte der Schirmhöhlenwölbung in einen Magenstiel auszuwaehșen, dessen Ende den stärker sich erhebenden und zum Magensehlauch ausziehenden Mundwulst trägt.

Die Zahl der Tentakeln scheint demnach bei allen Geryoniden, mag die homotypisehe Grundzahl f oder 6 sein, zuerst bloss das Einfache, dann das Doppelte, später das Ireifache der Grundzahl zu betragen, dann aber im weiteren Verlaufe der Verwandlung wieder auf das Doppelte und endlich zuletzt bei vielen Arten auf das Einfache der Grundzahl zurückzusinken. Die primären rudimentären Radialtentakeln verschwinden wohl stets; sobald die secundären bleibenden eine gewisse Grösse erreicht haben. Dagegen die starren soliden Interradialtentakeln verschwinden bei vielen Arten erst kurz vor oder selbst nach Eintritt der Geschlechtsreife, wihrend sie bei anderen, sonst sehr nahe stehenden Arten das ganze Leben hindureh, wenn auch nur als sehr reducirte Rudimente bestehen bleiben. Es seheint mir noch zweifelhaft, ob man diese geringe Differenz mit Vortheil zur Aufstellung besonderer Gattungen wird benutzen können. AGassız trennt allerdings generisch die mit bloss 4 (radialen) Tentakeln rersehenen Arten von Liriope ab von denjenigen, welche ausserdem noch die 4 interradialen Larvententakel beibehalten und übertriggt auf letztere den von Lessov in an- 
derem Sinne aufgestellten Namen Xanthea ("are eight-tentaculated Liriope ", AGassız). Da ich aber diesen Lnterschied nicht fül sehr wesentlich halte und bei geschlechtsreifen Individuen von Liriope emrybia, die gewöhmlich keine Spur mehr von den ínterradialen Larvententakehn zeigen, dieselben doch bisweilen noch als kumo Rudimente vorgefunden labe, so kann ich jenen heiden Gruppen bloss den Werth von Untergattungen lassen. Ich bezeichne demgemäss von den zungenlosen Liriopiden die mit \& Tentakeln versehenen als Liriope (im engeren Sinne), die mit 8 Tentakeln versehenen als Xanthea; und entsprechend nenne ieh von den mit Zungenkegel versehenen Liriopiden die ersteren Glossocodon (im engeren Sinne), die letzteren Glossocomus. Bei den sechszihligen Carmariniden seheint die generische Trennung der mit 6 und der mit 12 Tentakeln versehenen Arten noch misslicher zu sein, da hier die starren Interradialtentakehn nur selten und als ganz unbedeutende Rudimente persistiren, vielleicht sogar constant beim geschlechtsreifen Thiere spaiter verschwinden.

Die F i r bung der Geryoniden ist, wo sie vorkommt, sehr zart. Viele Arten sind vollkommen farblos und glashell. Bei den andern, die durch sehr reine und helle Farbentöne ausgezeichnet sind, finden sich dieselben fast nur in den Wandungen des Gastrovascularapparates entwickelt. Es sind also der Mund (namentlich der Mundsaum), der Magen, die Radialcanäle in ihrem ganzen Vertaufe, die Genitalblïtter, der Ringeanal, die holılen Radialtentakeln, in deren Wand das Pigment entwickelt ist. Dasselbe tritt bei den sechsziiluligen Carmariniden bisweilen als Milehweiss, sonst stets nur als ein zartes, meist helles Rosa anf, das bald mehr in Violett, bald meln in Fleisehroth hinüber spielt. Bej den vierzähligen Liriopiden tritt bald ebenfalls Rosa, bald Weiss, hald ein helles gelbliches Grün auf, bisweilen auch Grün und Rosa combinirt (Liriope bicolor).

Die geographische Verbreitumg der Geryoniden scheint sich über alle grossen Meere der Erde zu erstrecken; in den wïrmeren Meeren scheinen sie häufiger zu sein. Yon den 18 im Folgenden besehriebenen Arten ist der Fundort einer $\Lambda \mathrm{rt}$ (Lessov's Xanthea agaricina) unbekannt. Von ten 17 übrigen Species sind 4 süullich, 13 nördlich vom Aequator beobachtet worden. 10 Arten wurden an den europ:iisehen Küsten gefunden, 3) im Bereich der asiatisehen Kïste, 4 an der amerikanischen (Ost-) Küste (davon 2 in Nordamerika, 2 in Sudamerika). Von den 10 europäischen Speeies kommen 9 auf das Nittelmeer, 1 auf den englisch-französischen Canal. Die (i bisher beobachteten Arten aus der Unterfamilie der Carmariniden gehören siimmulich der nördlichen Erdhälfte und zwar ä dem Hittelmeere, 1 dem grossen 
Ocean an; letztere ist die von Mertess zwischen Japan und der BoninsInseln beobachtele Geryonia conica. An den afrihanischen und australischen Küsten sind bisher noch keine Rüsselquallen beobachtet worden. Was die 9 mediterranen Arten betrifft, so halte ich es nicht für unwahrscheinlich, dass deren Zahl, wenn eine Vergleichung der von den rerschiedenen Autoren beobachteten Originalexemplare möglich wäre, sehr reducirt werden würde. Namentlich gilt dies von den 5 Garmariniden des Mittelmecres. Indess weichen die von den verschiedenen Beobachtern gegebenen Beschreibungen und Abbildungen so vielfach und in so rvesentlichen Sticken von einander ah, dass, wenn dieselben auch nur einigermaassen naturgetreu sind, sic nothwendig als verschiedene Arten und zum Theil sogar Gatiungen unterschieden werden müssen. Dies gilt besonders von jenen fünf, ganz verschieden dargestellten, Species, fiir welche bisher die beiden Namen Geryonia proboscidalis und $G$. hexaphylla in so wechselnder und willkürlicher Weise von den verschiedenen Autoren gebraucht worden sind, dass es, um die Verwirrung nicht noch zu steigern, nöthig erschien, diese beiden Speciesbezcichnungen ginzlich zu eliminiren und durch neue neutrale zu ersetzen. Grosse Vorsicht ist aber, wenn man die von verschiedenen Forschern gegebenen Darstellungen auf ein und dieselbe zu Grunde liegende $\operatorname{Art}$ (z. B. Geryonia proboscidalis) zu reduciren versucht, gerade hier um so melır nöthig, als das periodische Erscheinen und Verschwinden grosser Schwirme, das viele Geryoniden mit anderen Medusen theilen, den verschicdenen Forschern, welche zu verschiedenen Zeiten einen und denselben Küstenpunct besuchen, nahe verwandte und doch gut unterschiedene Arten in die Iände führen kann.

\section{System der Geryonilen.}

Familie der Geryoniden von Gegenbaur ( $\mathrm{nicht}$ von Eschschoutz und nicht von Afassiz).

Gharakter der Familie: Schirm in der Mitte der Unterfläche in einen cylindrischen oder conischen soliden Magenstiel ausgezogen, dessen unteres Ende den Magen trägt, und in dessen Oberfläche 1 oder 6 getrennte Canile, vom Magengrunde ausgehend, emporsteigen, um oben am Schirm in die Radialcanïle umzubiegen. Genitalien 4 oder 6 breite und flache, blattörmige Erweiterungen der Radialcanäle, welche in der Fliche der Subumbrella liegen und nicht in die Schirmhöhle als Wiilste oder Falten rorspringen. Randblischen \& oder I 2. Tentakeln: 4 oder 6 radiale an Ende der Radialcanile, hohl, sehr beweglich; ausserdem oft noch 4 oder 6 interradiale, in der Mitte dazwi- 
schen, solid, starr. Bei der Larve (oft) noch eine dritte Zone von $i$ oder 6 später abfallenden primären Radialtentakehn.

Uebersicht der Gattungen in der Familie der Geryoniden.

1. Radialcanäle Kein Zungenkegel/s Tentakeln . . 1. Xauthea. (Keine Centripetal- (Liriope) 14 Tentakeln . . 2. Liriope. canäle)

Liriopida.

II. 6 Radialeanäle Jkein Zungenkegel Keine Centripetalcanäle 5. Leuckartla.

Carmarinida. $\left\{\begin{array}{l}\text { Ein Zungenkegel Viele Centripetalcanäle 6. Geryouia. } \\ \text { 7. Carmarina. }\end{array}\right.$

\section{Unterfamilie: Liriopida, Haeckel.}

Körper aus vier homotypischen Theilen zusammengesetzl.

1. Genus: Liriope, Lesson (sensu mutato).

Gattungscharakter: Körper aus vier homotypischen Abschnitten zusammengesetzt. 4 Radialcanale. Keine blinden Centripetalcanäle am Ringcanal. 8 Randblischen. 4. oder 8 Tentakeln. Magenstiel nicht in die Magenhöhle in Form eines Zungenkegels verlaingert.

I. Subgenus: Xanthea, Lessox (1. c. p. 333) (sensu mutato).

8 Tentakeln am Schirmrande des erwachsenen Thieres; 4 radiale, lang, sehr beweglich, hohl, am Ende der Radialeanäle; in der Mitte dazwischen \& interradiale, kurz, starr, solid.

1. Liriope tetraphylla, Gegenaur (1. c. p. 25i).

Geryonia tetraphylla, Cuamsso (1. c. p. 357).

Canthea letraphylla, Agsssiz (1. c. p. 36̈̈).

Schirm halbkugelig, ungefilhr $3 / 4-1$ Zoll Durchmesser. Magenstiel cylindrisch, sehr dünn und beweglich, 2 Zoll lang, unten scharf abgesetzt von dem kegelförmigen Magen, der unten mit 's grünen Flecken bezeichnet ist und dessen Mundöffnung von \& kurzen Mundlappen umgeben ist ("ore quadrivalvato "; nach Eschscuoutz »kann er seinen unteren mit \& grünen Flecken versehenen Rand in 'f Falten legen (). Zwischen den 'i. grünen Hagenflecken entspringen die fir ziemlich breiten weisslichen Radialeanäle, welche am Magenstiel getrennt heraufsteigen. Die 4. Genitalblätter ("Mägen () sind nach EscuscuoLtz »breit, herzförmig, an dem breiten inneren Rande fast gerade abgeschnitten, der Quere nach fein weisslich gestreift, die breite Mittelrippe grasgrün. "In der Mitte der Scheibe ist ein weisslicher, vierlappiger lileck zu bemerken«. Die i Radialtentakeln sind nach der Abbildung noch nicht 
halb so lang als der Magenstiel, jedoch viel lïger, als die ganz hurzen interradialen Tentakeln.

Fundort: In der Sundastrasse beim Eintritt in den indischen Oecan. Cunmsso.

2. Liriope appendiculata, Gegenuaur (1. c. p. 2:3i).

Geryonia appendiculata, Fonвes (1. c. p. 36 ; Taf. V, Fig. 2).

Tanthea appendiculata (vergl. oben 1). 22).

Schirm halbkugelig, von $1-1 \frac{1}{2}$ Zoll Durchmesser. Ebenso lang ist der kegelförmige, sehr bewegliche, beträchtlich diche Magenstiel, dessen Ende scharf abgesetzt ist von dem kleinen, flach glockenlörmigen Magen. Dic weite Mundöffnung des letzteren ist von 4 kurzen, ihre Form sehr wechselnden Mundlappen umgeben. Die \& Radialgefässe, welche am Magenstiel emporsteigen, sind schmal, farblos. Die 4. Genitalblatter sind herzförmigg, etwas länger als breit, hellgrün gefirbt, und mit der Basis nach imnen, nit der Spitze nach aussen gegen den Schirmrand gerichtet, von dem sie jedoch weit abstehen. Die 4 sehr contractilen Radialtentakeln sind röthlich gefärbt und in ausgedehntem Zustand viel lïnger als der Magenstiel. Die \& starren Interradialtentaheln sind kaum so lang als die Genitalblatter, farblos, und an der Unterseite mit ungefär 8 Nesselwarzen besetzt.

Fundort: An den englischen Küsten de la Manche. Forbes.

\section{Liriope ligurina, HaEckel.}

Geryonia exigua, Leucks t. (1. p. 3, Taf. I, Fig. 1, 2, 4).

Xanthea ligurina (vergl. oben p. 22).

Schirm halbkugelig, von 1/2 Zoll Durchmesser. Etwa ebenso lang ist der eylindrische, oben eonisch verdickte Magenstiel, der den kleinen, von 4 Mundzipfeln umgebenen, glockenförmigen Magen trägt. Die sehr schmalen Radialgefïsse, welche am Magenstiel emporsteigen, sind farblos, wie das ganze Thier. Dic \& Genitalblätler sind zwar auch bei dieser Art herzförmig, wie bei vielen anderen Geryoniden; allein die Spitze des Herzens ist hier (unigekehrt wie bei den anderen) nach innen gegen den Magenstiel gerichtet, während das mabgestumpfte äussere Ende dem Mantelrande bis auf geringe Entfernung angenähert ist«. Die 4 sehr langen und contractilen Radialtentakeln sind in ausgedehntem Zustande mehrmals länger, als der Magensticl. Die 4 starren Interradialtentakeln sind sehr viel kürzer, kaum mehr als I"' lang, und »hornförmig nach der Kuppel der Mantelglocke zu emporgekriimmt«. Ueber die von Levckart beobachtete Larvenform dieser Art vergl. unten die Entwickelungsgeschichte ron Glossocodon enrybia.

Fund or t: Im Mittelmeer bei Nizza. Lecckart. 
4. Liriope seutigera, Mc Crady (1. c. p. 208).

Lanthea scutigera (vergl. oben p. 22).

Schirm fast kugelig. Der lange conische Magenstiel tright am unteren sehr verdünnten Ende den kleinen kelchförmigen Magen, der von \& kurzen Mundlippen ungeben ist. Die \& schmalen Radialcanäle, welche am Magenstiel emporsteigen, sind farblos, wie das ganze Thier. Die \& Genitalbliitter sind durch Form und Grösse sehr ausgezeichnet. Sie sind kreisrund und so ausgedehnt, dass sie sich fast mit den Scitenwänden berihren und fast die ganze Unterfliche des Schirms einnehmen. Die 4 langen, sehr contractilen Radialtentakeln sind 2-3 mal so lang als der Magenstiel. Die 4 staren Interradialtentakeln sind sehr viel kürzer und an der Unterseite mit einer Reihe Nesselwarzen besetzt.

Fundort: Charleston Harbor (Süd-Carolina), zeitweise in sehr grossen und zahlreichen Schwämen. Mc Cradr.

5. Liriope agaricina (?) Gegenbatr (1. c. p. 254).

Xanthea agaricina, Lessor (1. c. p. 333, Pl. VI, Fig. 3).

Alles, was Lrssor von dieser Medusenart sagt, ist Folgendes: „Ombrelle hyalin, à huit courts tentacules. Pédoncule allongé, cylindrique, perforéঞ. Da die von Lesson gegebene Abbildung ebenso oberllächlich und unvollstiandig, als diese Beschreibung ist, und da auch nicht einmal der Fundort dieser Meduse angegeben ist, so liisst sich ilıre Stellung im Systeme nicht nïher ermitteln. Es kömnte eben so gut eine Geryonopside als eine Geryonide scin. Wenn Letzteres der Fall ist, so würde sie wahrscheinlich der Gattung Xanthea in dem eben angegebenen Sinne (nicht nach Lsessox's ursprünglicher Definition) angehören.

\section{Subgenus: Liriope, Lesson (1. c. p. 331) (sensu strictiori).}

4. radiale Tentakeln am Schirmrande des erwachsenen Thieres, am Ende der Radialcanäle. Die interradialen Tentakeln, in der Mitte dazwischen, sind nur in der Jugend (im Larvenzustande) vorhanden, und fallen meist vor der Geschlechtsreife ab.

6. Liriope exigua, Gegenbaur (1. c. p. 2̈̈7).

Dianaea exigna, Qcor et Gamand (l. c. PI. VI, Fig. "̈-8).

Geryonia exigue, Escischoltz (1. c. p. 89).

Dianaea exigua, Eschscholtz (1. c. p. 91).

Liriope cerasiformis, Lasson (1. c. p. 332).

Schirm fast kugelig, von der Grösse einer starken Kirsche, vollkonmen larblos und durchsichtig, mit sehr dickem Gallertmantel, so 
dass die äussere Fläche des Schirms viel stärker, als die innere gewölbt ist. Der Magenstiel cylindrisch, ungefiahr ebenso lang, als der Schirmdurchmesser (etwa $9^{\prime \prime \prime}$ ). Das untere etwas kolbig verdickte Ende ist scharf abgesetzt von dem sehr kleinen, flach glockenförmigen Magen, dessen Mundöffnung von 4 sehr kleinen Lappen oder Falten ungeben ist. Die 4 Radialcanile schmal. Die \& Genitalhlitter sehr klein, breit herzförnig, eben so breit als lang, um ilıre eigene Länge vom Schirnırande entfernt, die scharfe Spitze des Ilerzens nach dem Sehirmrand gekehrt. Die i Radialtentakehn sehr kurz, kürzer als der Magenstiel.

Wïhrend die gewöhnliche Form dieser Art, welche die Entdecher Quoy und Gamaro in Oken's Isis 1828 auf Taf. V, Fig. 5, 6 als Dimaea exiguu abgebildet haben, von EscnscnoLtz und später von Lessov als Geryonia exigna aufgeführt wird, haben die beiden letztgenannten Autoren nicht nur specifisch, sondern sogar generisch eine Form von derselben abgetrennt, welche von Quor und Gamarn nur als ein etwas abweichendes Individum (ibid. Fig. $\tau$, 8) neben der gewöhnlichen Form abgebildet wird. Es unterscheidet sich ron letzterer lediglich dureh etwas dickeren Magensticl, rosettenartig in 6 Falten gelegten Mund und den Mangel der i herzförmigen Genitalblätter. Nach meiner Ueberzeugung haben wir es hier nur mit einem unreifen Individuum zu thum, bei dem die Genitalblitter noch nicht entwickelt (octer vielleicht auch schon rückgebildet) sind. Die 6 (statt der gewölnnlichen 4) Mundfalten sind bei der wechselnden Form der Mundöffnung ohne alle Bedeutung. Schon Fonses hat bei seiner Geryonia appendiculata gezeigt, dass die gewöhnlich vierlappige Mundöflinung (1. c. Fig. 2 c, 2h) gelegentlich auch sechslappig erscheint (1. c. Fig. 2a). Dasselbe habe ich wiederholt bei Glossocodon eurybia, sogar bei einem und demselben Indivirluum zu verschiedenen Zeiten, beobachtet. Es ist mithin der Name Dianaea exigua, den Escuscurotz, und der Name Liriope cerasiformis, den Lessor diesem Individuum von Geryonia exigna beigelegt haben, einzuziehen.

Fundort: Mecrenge von Gibraltar. Qroy und Gamsnio.

7. Liriope bicolor, Gegexbaur (1. c. p. 257).

Geryonia bicolor, Eschscholtz (l. c. p. 89; Taf. 11, Fig. I).

Schirm halbkugelig, ungefähr von $1 / 2-3 / 4$ Zoll Durchmesser. Mitgensticl cylindrisch, etwas länger als der Schirmdurchmesser, sowohl oben als unten kegelförmig verdickt und unten in den conischen Magen übergehend, dessen Mundöffinung kurz vierlappig, am Rande mhellgriun, öfters mit Rosenroth eingefasst ist«. Auch der untere Theil des Stiels ist öfters rosenroth gefärbt. Die f im Magensticl aufsteigenden Radial- 
canäle sind farblos. Die \& Genitalblatter sind breit eiförmigg, oder fast herzförmig, mit der Spitze gegen den Schirmrand gerichtet mmit feinen weissen Puncten bezeichnet", und mit einer breiten griunen Mittelrippe versehen, wie bei der sehr ähnlichen L. tetraphylla. Die \& Radialtentakeln sind etwa so lang als der Magenstiel und mit "weissen Querstreifen (Nesselringen?) versehen.

Fundort: Atlantisches Meer an der brasilischen Küste, an Gap Frio (unweit Rio de Janeiro). Eschscholtz.

8. Liriope rosacea, Gegenmaur (I. c. p. 2:57).

Geryonia rosacea, Eschsculoltz (1. c. p. 89; Taf. 11, Fig. 2).

Schirm halbkugelig, von 3 Linien Durehmesser. Magenstiel cylindrisch, etwas länger als der Schirmdurehmesser, sowohl oben als unten hegelförmig verdickt und unten in den conischen Magen übergehend, dessen Mundöffnung kurz vierlappig, nit rosenrothem Rande ungeben ist. Die 4 Genitalblitter sind fast dreieckig, eben so breit als lang, mit der gerade abgesehnittenen Basis dem Magenstiele, mit der abgerundeten Spitze dem Schirnırande zugekehrt, den sic fast berühren. Die Basen der rosenroth gefiirbten Genitalblätler berühren sich beinahe mit ihren Scitenecken. Die 4 Radialtentakeln sind ungefähr so lang als der Magenstiel.

Fundor t: In der Südsee in der Nähe des Aequators. Escnscioltz.

9. Liriope temirostris, Agassiz (1. c. p. 363).

Von dieser mit if Radialtentakeln rersehenen Art sagt Agassız. bloss, dass sie sich dureh den ausserordentlich langen und diunnen Magenstiel, der ".mal länger als der Schirmdurchmesser ist, vor allen andern Arten der Gattung auszeichnet. Die Jlöhe und der Münduñgsdurehmesser des Schirms betragen 1/2 Zoll, die Lüinge des Nagenstiels $2 \frac{1}{2}$ Zoll.

Fundort: Key West, Florida. Agassiz.

2. Genus: Glossocodon, IAeckel.

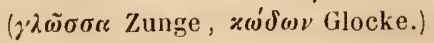

Gattungscharakter: Körper aus vier homotypischen Abschnitten zusammengesetzt. R Radialcanale. Keine blinden Centripetalcanale am Ringcanal. 8 Randblischen. foder 8 Tentakeln. Magenstiel in Form eines langen, soliden Gallertkegels ("Zungenkegels《) in die Magenhöhle hinein verlängert. 


\section{Sulggenus: Glossoconus, НаескеL.}

8 Tentakeln am Schirnırande des erwachsenen Thieres; it radiale, lang, schr beweglich, hohl, am Ende der Radialcanäle; in der Mitte dazwischen 4 interradiale, kurz, starr, solid.

\section{Glossocodon mucronatus, HaEGKel.}

Liriope mucronata, Gegenbaur (1. c. p. פ̈7; Taf. VIIl, Fig. 17). Eurybiopsis anisostyla, Gegenbaur (1. c. p. 247; Taf. VIII, Fig. 12). Liriope mucronata, Keferstens und Ehlers (Zoolog. Beitr. 1861, p. 92, Taf. XIV, Fig. 5, 6).

Glossoconus mucronatus (vergl. oben p. 22).

Schirm halbkugelig, von 4-6 Linien Durchmesser, glashell und farblos, wie das ganze Thier. Magenstiel cylindrisch, ungefïhr so lang als der Schirmdurchmesser, und in die Magenhöhle hinein als ein grosser, solider, kegelförmiger Zapfen (oZungenkegel () verlängert, der oft weit aus der Magenhölıle hervortritt. Die Mundöffnung ist ganzrandig, mit Nesselknöpfen gesiiumt, wellig gefaltet, oder mit 4. schwachen Ausbuchtungen versehen. Aus dem Grunde des Magensacks, der nicht scharf vom Magensticl abgesetzt ist, entspringen die \& Radialcanäle, welche die Basis des Zungenkegels umgeben und isolirt in Magenstiel emporsteigen. Die \& Genitalbliitter sind liinglich herzförmig, mit der Spitze gegen den Schirmrand gekehrt, den sie jedoch nicht erreichen, und liegen ziemlich weit auseinander. Die \& hohlen Radialtentakeln sind ungefähr so lang als der Magenstiel, rings mit Nesselwülsten besetzt. Die 4 soliden Interradialtentakeln sind viel kürzer und tragen nur an der Unterseite eine Reihe Nesselwarzen.

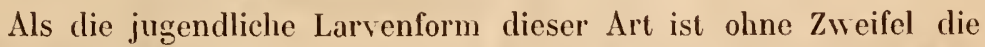
merkwürdige Meduse anzusehen, welche Gegexbaur ebenfalls bei Messina beobachtete und als Eurybiopsis anisostyla beschrieben hat. Vergl. darüber unten die Entwickelungsgeschichte von Glossocodon eurybit.

Fundort: Im Mittelmeer bei Messina. Gegenbaur, Keferstein und Ehlers.

2. Hossocodon catharinensis, НAEckeL.

Liriope callarimens's, Fritz Müller (l. c. p. 310 , Taf. XI, Fig. 1-25).

Glossocomes calharimensis (vergl. oben p. 22).

Schirm halbkugelig oder noch stairker gewölbt, von 3 Linien $\left(\ddot{z}-6^{\mathrm{mm}}\right)$ Durchmesser. Magenstiel cylinchisch, dünn, 2 $2^{\mathrm{mm}}$ lang, äusserlich nicht abgesetzt von dem ebenfalls cylindrischen, $1 \frac{1 / 2}{{ }^{m m}}$ langen Magen, in dessen Höhle hinein er sich als ein starker, solider conischer 
Zaplen ("Zungenkegele) verlangert. Die Mundöffinung ist ganzrandig, von Q १ blassröthlichen Nesselknöpfen umgeben. Aus dem Grunde des Magensacks entspringen die \& Radialeanäle rings um die Basis des Zungenkegels und steigen an der Oberfliiche des Magenstiels empor. Die 4 Genitalblitter sind oval oder elliptisch, stehen etwa um ihre eigene Breite von einander ab und reichen nicht bis zum Sehirmmond. Die \& hohlen Radialtentakeln sind röthlich gefirlot, in ausgedehnten Zustand vielmals linger als der Schirmdurchmesser. die 4 soliden Interradialtentakeln sind sehr kurz, starr, nach aussen und oben gerichtet und tragen an der Unterseite cine Reihe von 8 Nesselwarzen.

Ueber die merkwürdige Larvenform und Metamorphose dieser Art ist die treffliche Abhandlung Frutz MüLLer's nachzuseben.

Fundort: Im atlantischen Ocean an der brasilischen Küste bei Santa Catharina, sehr häufig. Fritz Müller.

\section{Subgenus: Glossocodon (sensu strictiori), Haeckel.}

4 radiale Tentakeln am Schirmrande des erwachsenen Thieres, am Ende der Radialcanäle. Die 4 interradialen Tentakeln, in der Mitte dazwischen, sind nur in der Jugend (im Larvenzustande) vorhanden.

\section{Glossocodon eurybia, Ilaeckel.}

Liriope eurybia, HaEckel (vergl. Jenaische Zeitschrift I. Bd. p. 329, Taf. XII. Fig. $11-23)$.

Die kurze Charakteristik dieser Art ist in der Jenaischen Zeitschrift I. Bd. p. 329 gegeben worden.

Fundort: Im Mittelmeer bei Nizza.

\section{Il. Unterfamilie: Carmarinida, Jieckel.}

Körper aus sechs homotypischen Theilen zusammengesetzt.

\section{Genus: Leuckartia, Agassiz (1. e. p. 364).}

Gattungseharakter: Körper aus sechs homolypischen $\Lambda$ Jschnitten zusammengesetzt. G Radialcanile. Keine blinden Centripetalcanile am Ringeanal. 12 Randblischen. 6 oder 12 Tentakeln. Magenstiel nicht in Form eines Zungenkegels in die Magenhöhle verlänğert.

\section{Leuckirtia brevicirrata, Hasckel.}

Medusu proboscidalis, Fonsкí (1. e. p. 108; Tal. 36, Fig. 7).

Geryonia proboscidalis, Escnscunotiz (1. c. p. 88).

Liriope proboscidalis, Lesson (1. c. p. 3331).

Schirm hallıkugelig, von $21 / 2$ Zoll Durehmosser, durchsichtig, farblos. Schirmsticl rein kegelformigy, so lang oder etwas länger als 
der Schirmdurchmesser, an der Basis dicker als ein Finger, ganz allmählich nach unten verdünnt. Magenschlauch flach glockig, ungefïhr 1/4 Zoll lang (odimidium unguem longa(i), mit sehr beweglicher, gefalteter, häutig musculöser Wand und einfacher, ganzrandiger, in 6 Falten gelegter Mundöffinung. Die 6 Radialcanäle steigen vom Magengrund aufwïrts in der Oberfliche des Magenstiels als 6 schmale lineare matt weissliche Streifen (nlineae obsoletae pallicliores(). In der Subumbrella gehen sie als Blattrippen mitten dureh die 6 Genitalblitter hindurch. Diese sind breit herzförmig, einen Zoll lang und ebenso lreit; die nach innen gerichteten breiten Basen der Ilerzen stehen nur sehr wenig von einander ab; die nach aussen gerichteten scharfen Spitzen berühren den Ringeanal und die Basis der 6 Radialtentakehn. Diese sind fadenförmig, sehr dünn, kürzer als der Radins des Schirms. Interradialtentakeln fehlen.

Diese Art ist die zuerst (177:3) beobachtete von allen Geryoniden. Wenn die Darstellung Forskíl's einigermaassen genan ist, so zeichnet sie sich vor allen andern Arten aus durch den sehr dicken Magenstiel, die sehr hreit herzformigen Genilabliatter und namentlich die sehr kumen Tentakehn, die nicht halb) so lang als der Magenstiel (bei den übrigen Camuariniden vielmals linger) sind.

Fundort: Nittelmeer. Fonskil.

\section{Lenckartia lougicirrata, НАескеL.}

Geryonia proboscidalis, Leuckant (I. c. p. 8, Taf. I, Fig̣. 3). Leucliartia proboscidalis, Agassiz (1. c. 1) 361).

Schirm halbkugelig, von 21/2 Zoll Durchmesser, glashell, farblos, wie das ganze Thier (mausgenommen die opaken Geschlechtsorgane(). Schirmsticl aus conischer Basis cylindrisch, ungef:ihr so lang als der Schirmdurchmesser, etwa einen halhen Finger dick (kaum lalls so dick, als bei $L$. brevicirvata). Magenschlauch schlank cylindrisch, in ausgestrecktem Zustand 1 Zoll lang, retrahirt halb so lang. Mundötfnung von (6 spitzen Lappen (oder Falten?) umgeben. Die 6 Radialcanäle steigen vom Magengrunde aufwärts als 6 sehr schmale lineare Streifen, und gehen, an der Subumbrella angelangt, als Blattrippen mitten durch die 6 Genitalblatter hindurch. Diese sind mattweiss, ungekelurt herzförmig; die nach innen gerichtete Spitze des Herzens reicht bis zur Basis des Magenstiels; die nach aussen gerichtete, tief ausgerandete Basis steht nur wenig vom Ringeanal ah. Die Zwischenrüume zwischen je 2 Genitalblittern sind mehrmals breiter als ein Blatt. Die 6 Radialtentakeln sind fadenförmig, mehrmals lïnger als der Schirmstiel (»können sich bis auf mehrere Fuss verlingern() und dicht mit ringförmigen Nes- 
selwülsten besetzt. Die 6 embryonalen Interradialtentakeln sind beim erwachsenen Thiere ganz kurz, rudimentiir, leicht zu ibsersehen und hornförmig nach oben gekriimmt.

Diese Carmarinide von Nizza zeiclnnet sich vor allen ubbrigen Arten dieser Subfamilie aus durch die umgekehrt herzö̈rmige Gestalt ihrer Genitalblitler, deren Basis nach aussen, die Spitze nach innen gerichtet ist, umgekehrt wie bei den übrigen. Auch der in 6 lange spitze Lappen gespaltene Mundsaum weicht sehr von dem der übrigen Arten ab. An eine ldentitit derselben mit der von Pénox bei Nizza gefundenen Geryoniu hexaphylla, oder mit der von mir ebendaselbst beobachteten Carmarina hastala kann daher wohl kaum gedacht werden.

Fundort: Im Nittelmeer bei Nizza. Levckart.

\section{Genus: Geryo nia, Péron et Lesueur (sensu mutato).}

Gattungscharakter: Körper aus sechs homotypischen Abschnitten zusammengesetzt. G Radialcanile. Vom Ringcanal gehen zwischen den Radialcanälen blind geendigte Centripetalcanaile in verschiedener Zahl aus. 12 Randbläschen. 6 oder 12 Tentakeln. Magenstiel nicht in Form eines Zungenkegels in die Magenhöhle verlängert.

\section{Geryonia umbella, НАЕскеL.}

Geryonia proboscidulis, Gegexbaur (1. c. p. 254; Taf. Vill, Fig. 16).

Schirm halbkugelig, von 2 Zoll Durchmesser, glashell, durchsichtig und farblos, wie der ganze Körper, die mattweissen Canäle und Anhïnge des Gastrovascularapparates ausgenommen. Magenstiel 21/2 Zoll lang, cylindrisch, nach unten allmählich verjüngt. Magenschlauch klein, rundlich, oft glockenförmig, meist gefaltet, mit ganzrandigem Mundsaum. Die 6 Radialcaniile entspringen getrennt aus dem Magengrunde, steigen' als 6 ziemlich breite weissliche Streifen in der Oberfliche des Magenstiels empor und gehen als Blattrippen mitten durch die 6 opaken Genitalblitter hindurch. Diese sind gleichsehenkelig dreieckig, die schnale Basis des Dreiecks ist nach innen gekehrt; die abgestumpfte Spitze erreicht fast den Ringcanal. Der Abstand zwischen je 2 Genitalblattern ist viel breiter, als ein solches Blatt. Vom Ringcanal entspringen zwischen je 2 Bliittern $\ddot{3}$ (bei jüngeren Individuen 3 ) blinde Centripetalcanäle, von denen der mittlere der lingste, die beiden seitlichen die kurzesten sind. Die 6 Radialtentakeln sind hohl, sehr beweglich, fadenförmig, lainger als der Magenstiel. Die 6 Interradialtentakeln sind dagegen sehr kurz. 
Das von Gegexbaur aus Messina mitgebrachte Originalexemplar dieser Art, das ich untersuchen konnte, wurde der vorstehenden Beschreibung mit zu Grunde gelegt. Es sieht meiner Carmarina hastata im Ganzen sehr ähnlich, unterscheidet sich aber durch die versehiedene Zahl und Form der Centripetalcaniile und durch den völligen Mangel des Zungenkegels, von dem in der anscheinend ganz unverletzten Magenhöhle keine Spur zu entdecken war. Von G. Jumgiformis unterselieidet sie sich durch den viel hleineren Magen und die viel schmäleren und anders geformten Genitalhlitter.

Fundort: In Mittelmeer bei Messina. Gegengaur.

\section{Geryonia fungiformis, НАЕскеL.}

Geryonia hexaphylla, Péron et Lesuetr (1. c. P. 329).

Geryonia hexaphylla, Milne Eowards (1. c. PI. 52, Fig. 3).

Geryonia proboscidalis, Escuschoutz. (1. c. p. 88).

Schirm halbkugelig, von 6-10 Centimeter (2-4. Zoll) Durchmesser, wasserhell, farblos, mit einigen schwachen Rosatinten. Magenstiel linger als der Schirudurchmesser, cylindrisch, seh" stark, Magenschılauch sehr gross, cylindrisch oder kegelförmig, gefalteı, mit einfacher, runder Mundölnumg. Die 6 Radialcanäle laufen als Streifen am Magenstiel empor. Die 6 Genitalblitter sind auffallend breit, lanzettförmig, so dass sie sich mit ihrer mach immen gerichteten Basis berühren, wihrend die iussere Spitze fast den Ringeanal erreicht. Zwischen je 2 Genitalblätern scheinen $;$ blincle Centripetalcanäle vom Ringeanal abzugehen. Die 6 Radialtentakeh sind sehr lang, mehrmals linger als der Schirmstiel. Interradialtentakeln fohlen.

Diese Art scheint von allen bisher beobachteten Carmariniılen der ron mir bei Nizza gefundenen Carmarina hastata am nachsten zu stelıen und ich wiüle beide für identisch halten und annelımen, dass der Zungenkegel, der woder in der Beschreiluung noch in der Abbildung erwähnt wird, iblersehen worden sei, wenn nicht auch die Form der Genitalbläter bei der von Péros bei Nizza gefunclenen Art ganz anders dargestellt wire. In der Abbildung erscheinen sie breit dreieckig und berühen sich mit ihren sehr breiten Basen, wihrend beị C. hastata die viel schmäleren, flügelförmig ausgezogenen Basen der spiessförmigen Genitalb]ätter weit von einander abstehen. Jedenfalls scheinen bei Nizza mehrere Garmariniden vorzukommen; denn auch die von Leuckant dort beobaditete und G. proboscidalis benannte Form (Lencliartia longicirrata) diufte weder mit der von Péron und Lesueur, noch mit der von mir bei Nizza gefumlenen $\Lambda \mathrm{rt}$ identisch sein.

Fu und l: In Mittelmeer bei Nizza. Péron et Lesueun. 
3. Gieryonia conoiles, H.ıекEL.

Geryonia hexaphylla, Braxdt (1. c. p. 389: Taf. XVIII, Fig. 1, 2).

Liriope proboscidalis, Lesson (1. c. p. 331 ).

Schirm kegelförmig, von 3 Zoll Durchmesser und ebenso viel Höhe, durchsichtig, farblos, bis auf die röthlichen Centripenalcanäle und einen rosenıothen Ring am Schirmmand. Magenstiel kegelfölmige, sehr stark, oben fingerdick. Das untere Ende sammt dem daram hefestigten Magen war an den einzigen Exemplare, das von MErtexs gefunden wurde, abgerissen und der Verlust durch einen kleinen unfurmlichen Stummel ersetzt. Die 6 grossen Genitalblatter sind gelblich, loeit lanzettoummig; das äussere abgestutzte Ende erreicht den Ringeanal; die innere breite Basis liuft mit abgerundeten Ecken in einen kur\%en stielihnlichen Fortsatz aus, der bis zur Basis des Magenstiels reicht. Die Zwischenriume zwischen den Blattbasen sind viel schmiler als diese selbst. Zwischen je 2 Blattern scheinen 9 blinde röthliche Centripelalcanäle rom Ringcanal abzugehen. Die 6 Radialtentakeln sind molımals linger als der Schirmstiel. Interradialtentakeln fehlen.

Diese Art ist jedenfalls von den andern $\ddot{5}$, siimmtlich im Mittelmeer beobachteten, Carmariniden specifisch verschieden. Ol) sie aber zu dieser orler zur folgenden Gattung gehört, lässt sich bei der Ungewissheit über dic Bildung des Magens und die Abwesenheit des Zungenkegels nicht entscheiden. Das untere Ende des Magenstiels sammt dem Magen lehlte bei dem einzigen beobachteten Individumm eben so vollstiindig, wie ich es auch bei Carmarima hastata oft gefunden habe. Der lange aus dem Schirm hervorhingende Magenstiel lockt elurch seine pendelnden Bewegungen wahrscheinlich als guter Köder die Fische an, die ihn dann abbeissen, oder er reisst auch wohl bei Angriften auf andere Scethiere al).

Fundort: Im grossen Ocean zwischen Japan und den BoninsInseln (36" nördlicher Breite, $211^{0}$ westlicher Linge). Mertens.

\section{Genus: Carmarina, Haeckel.}

("Carmarina" zusammengezogen aus Carne marina [See-Fleisch] nennen die Fischer in Nizza und an der Riviera ponente sowohl die grösseren Quallen, als auch andere gallertige durchsichtige pelagische Thiere.)

Gattungscharakter: Körper aus sechs homolypischen Abschnitten zusammengesetzt. 6 Radialcanile. Vom Ringeanal gehenzwischen den Radialcanilen blind geendigle Centripetalcanile in verschiedener Zall aus. Ig Rand- 
blaschen. 6 oder 12 (in einem gewissen Larvenstadium 18) Tentakeln. Magenstiel in Form eines langen soliden Gallertkegels ("Zungenkegelsa) in dic Magenböhle hincin verlingert.

1. Carmarima hastata, НАескет..

Geryonia hastata, Ilaeckel (vergl. Jenaische Zeitsehrift I. Bd. p. 327, Tal. XI. Fig. $1-10)$.

Die kmre Charakteristik dieser Art ist in der Jenaischen Zeitschritt 1. Bd. p. 327 gegeben worden.

Fundort: lm Millumeer bei Nizza.

\section{Anatomie ron Glossocodon eurybia (Liriope eurybia).}

(Hierzu Tall. II und III.)

\section{Körperform.}

Schirm (Mantel) und Schirmstiel (Magenstiel).

Der erwachsene Glossocorlom emybia, welcher in Fig. 11, 12, 15 hei schwacher, in ligg. 13, 14 hei stiirkerer Vergrösserung dargestellt ist, hat die Gestalt eines zicmlich flachen Ilıtpilzes, dessen Schirm auf einem langen dünnen Stiele sitzl. Der ganze Körper ist im Lehen vollkommen glashell, durchsichtig und farblos; nur die reifen Genitalblitter und bisweilen auch der Magen sind ein wenig opak, weisslich getribt. Nach sohr reichlicher Nahrungsaufnalıme erseheinen oft auch die simmtichen Can:ale des Gastrovascularsystems durch ihren lnhalt weisslich gefirht. Die letzteren Theile nehmen in der Regel auch einige Zeit nach dem Tode eine mattweisse Firhung an, sowie dann auch die mit Nesselzellen besetzten Theile, Mundsamm, Schimmand und Tentake]n in derschben Weise getribt werden. Eine röhliliche orler grünliche Firbung rinzelner Theile, wie sie bei andern Liriopiden häufig rotkommt, ist bei unserer Art niemals zu bemerken.

Der Schirm oder die I mhrella (Fig. II, I2 I) hat die Gestalt eines dicken Lhrglases und bildet ein zirmlich flach gewölbtes Kugelsegment, welehes nur im Ilomente der stirksten Contraction des Schimmandes (so bei den heftigsten Schwimubewegungen) sich der 
Halbkugelform mihest. Die sichirmwöbung des rubig im Wasser schwebenden Thices (Fig. 11) ist sche flach, so dass die Höhe des

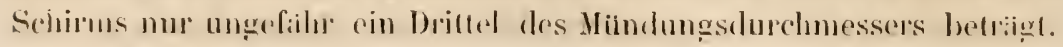

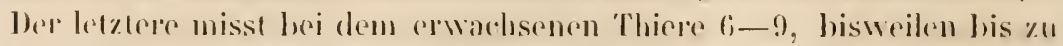

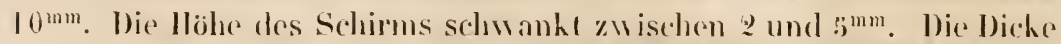
sciner hyalinen Galleutsubstanz oder des Mantols ist Wrecloselnd und scheint, wie bei Carmarima vergl. unten) ron der Menge des aufurenommenen Jahıung abhiingrg zu sein, so dass sir bei lange humgernden Thieren bedeutend abnimmt. In des Rogegel nimmt die Gallertsubstam\% (I) Jeg Emberla in der Hitle der Scheilue fast die Halfte, mindestens ein Drittel der Hölı ein, wihlıend sie sich nach lem Rande hin rasch verdionnt. Die Mantelgallerte ist durehaus homogen und structurlos mol schliesst, "wo bei Carmarina, niemals Zollen ein.' Dagegen ist sie, wir bu der lotzlepen, von zillhejelsen feinen, dichotom veristelton

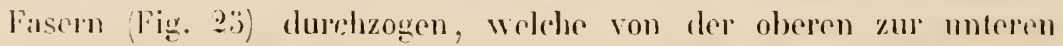
Schirmbiche zielsen und als festes Gerist der weichen Gallertmasse Halt verleilun (Fig. 87). Sie werlen unten in dem letzten Alsselmint nilier beschirichen.

Dieselben gabelspaltigren Fasern, wie in der lyalinen homogenen Schirmgallerte, sind auch in der grledehartigen Gallertsuldstanz des langen dimmen Sebirmstieles oder Magenstieles Podunculus, Fig. II, 12 p) machzuwejsen, welcher als eine solide lomogene stielformige Verlïngermug der Sehismgallerte aus der Mitle des unteren hohlen Schirmflache (Submubrella) entspringt und an seinem freien untern Ende den Magen trigh. Am Lrsprunge dick kegelförmigr, rerjiingt sich der Magrenstiel ziemlich raseh in einen sehlanken Cylinder, welcher sich nach mnten gegen den Magen lin mur noch wenig verduinmt, inmerhall, des Magens aber in den schlanken conisch zugespitzten Zungenkegel sich fortsetz. Dic ganze Liinge des Pedunculus von der Basis (in der Mille der Submmbrella) bis zur untern freien Spitze des Zungenkegels, hommut in dej Rogel ungefäh dem Jumbhmesser des kreisrunden Schirmandes gleich, oder übertrillt densellen nur wenig, wälsend er bei jüngeren Thieren hedentend dahinter zurückstolıt. Der liangrste, von mir gemessene Schirmstiel war $12 \mathrm{~mm}$ Jang, wihrend er gewoln-

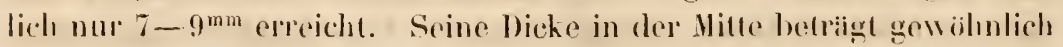
$0,: 3-0,8$, selten bis 1 mm. Die iussere Oberlliche des Galleptsticls ist bon den vier diumen linearen laingsmuskelbindern (Fig. I8-2I m) iiberyogen, wolehe mit den vier ungefible eben so bereiten, in der

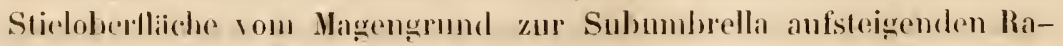
dialcaniblen (Fig. 18-21 r) alterniren. Wenn die letzleren stask mit Ninhrumgslliissigkeit gefüllt sind, springen sie über das Niveau der 
Muskelbinder derartig vor, dass die Cylinderform des Stiels zu einem vierseitigen Prisma wird und sein Querschnitt nicht mehr kreisrmnd, sonder'n quadratisch erscheint. Auf solehen Querschnitten quillt die Gallertsulostanz (1) des Sticls, wenu dic Muskoln (n) sich stark contraliten, oft hallıhugelig oder fast kugelig über die Schmittliache vor (Iig. 20).

l)ie $Z$ unge oder der $\mathrm{Zungenhegel}(\mathrm{z})$, wie ich die innerhall, des Magenschlauchs gelegene terminale Verlingerung̣ des Magronstiels nemne, ist ein solider gestreckt kegelfürmiger Gallertzapfen von $1 / 2-1$, höchstens von $2^{\mathrm{mm}}$ Liange, welcher bald ganz in die Magenhöhle zuriickgezogen und dann schwer zu erkennen ist (Fig. 11, 11, 19, 20 z), bald eine laingere oder büzere Strecke aus der Mundöthumg hervorgestreckt wird (Fig. 19, 13), letzteres besonders damn wenn der Magenschlanch sich nach aussen umstülpt (Fig. 13). Niemals habc ich den zuriickgezogenen Zungenkegel in der Weise knieförmig gehogen, geknickt orler zusammengalegt geselsen, wie man ihn bei Camarina (Eigy. 4 x) häulig beohaditen kann. Bei dieser letzteren hat er auch eine linger gestreckte Gylinderform, wihlrend er bei Glossocodon meistens rein kegelförmig erscheint. J)as untere Ende des Magensticles spitzı sich ganz allmälılich keggelfö̀nuig in den Zungenkegel zu und die Grenze zwischen beiden wird nur durch die Insertion des Magengrundes bestimuıt. Die solide Gallerturasse des kegels ist von einem sehr diunen Muskellseleg und darüher von einem Epithel überzogen. Durch Muskelcontraction kamn seine reine Kegellorm mehrfach modilieirt erscheinen. Fr kann nach verschiedenen Richtungen gelogen und wioder gestruckt, hisweilen fast halhkreislömmig gehriummt werden. Oefter ist er durch cine odler nchrere ringförmige Furchen der Quere nach eingeschnibl; namentlich ist die feine Spitze durch eine terminale Ringfurche oft fast knopfförmigg abgesetzt. Anderemale erscheint die Basis des Zungenkegels dünn zusammengesehnürt und die Spitze fast eiförmig angeschwollen, so dass er Kolbengestalt amnimmt. Bisweilen kamn man an lebenden Thieren, deren Magen kragenartig umgestülpt oder stark nach oben zurückgezogen ist, sehen, wie der Zungenkegel langsam hervorgestreckt und trige pendelnd, scheinbar tastend orler suchend, hin und her bewegt wird. Namentlieh wenn kleine in der Nibe des Mundes umhersehwimmende Thierehen mil dem Mundsaum in Beruhrung kommen oder einen Strudel in dessen Ungelung veranlassen, scheint der Gallerthegel wic ein 'Tentakel nach ihnen ansgestreckt zu werelen. Es scheint mir dahre von den Vermuthungen, die man sich ubber die function dieses, bis jetzt nur hei Carmarina und Glossocodon beobachteten seltsamen Organes bilılen kann, diejenige am 
meisten der Natur zu entspreclien, dass dasselbe zum Betasten, vielleieht aud, zum Schumecken der Nahıng dient und daher wohl als Z. unge bezeichnet werden darl'. Dass der Zungenkegel eine zum Verwunden oder Tödten der Bente dienliche Waffe sei, dagegon spricht einerseits die weiche Beschallenheit seiner Gallertmasse, andrerseits der Mang̣el von Nesselzellen in seinem Epithel. Ob der'Zungenkegel von C:Lssocodon eurybia in einer gewissen Lebensperiode als Knospenstork fungirt, wie bei Carmarina, kann ich nicht sagen, da ich nienals linospen an demselben ansitzend gefunden hale. Bei Glossocodon calharinensis dag̣egen scheint dies der Fall zu sein (rerghl. unten den VIll. Abschnitt).

\section{Gastrovascularsystem.}

Mund, Magen, Ernahrungseanäle und Geschlechtsorgane.

Der Magen (k) hingt bei dem ruhig̣ schwehenden Thiere als rin eylindrisches, glattwandiges, nicht gefaltetes Rohr (von $1-3$ min Limger 0, $2-0,6-I^{m m}$ Durchmesser) von dem Magenstiel herah, dessen Contour olne Grenze in die des Stiels übergeht, wihlrend die Suhstanz des letzteren durch seine vollkommene Durehsiehtigkeit sich von der oft etw as getribten dicken Magenwand alssetzl (Fig. 11). Am dicksten und trübsten ist der weissliche Hundsa um, der in gleichmissig geiflhetem Zustand meist ein regehmissiges Quadrat bildet (Fig̣. Ifij. Giewöhnlich ist der Mundrand des Magens mehr orler weniger weit manchellenartig nach aussen ungestiilpt, sehr hiufig sogar die ganze unter Itilfte der Magenwand, so dass der Mundsaum die Insertion des Magenrolırs am Stiele berührt oder noch dariiber hinaufragt (Fig. 19, 20). Nicht selten stiilpt sich dann der Mundsam nochmals nach rom um, so dass man dann anf einem Querschnitt 3 sich concentriseh umschliessende Magenblätter finden würde (Fig. 21). Scltener als diese doppelte Unstiilpung findet man den ganzen Magensack nach oben volistiindig zurürkgesehlagen, so dass der Zungenkegel in seiner ganzen liinge frei liegt und der Magen eine stiefelartige Scheide um den mntern Theil des Stieles bildel (Fig. 13). Wenn der Magen reichliche Nahrung aufgenommen hat, so kann er ein selır viel grösseres Volun und die versehiedensten Formen annehmen. Ebenso wedisehnd erscheint Form und Ausdohmung des quadratischen Mundsaums (ó). Bisweilen saugh sich das Thierchen fast mit der ganzen innern Magenwand auf der Glasplatte fest an (Fig. 1:5, 16) umd es erseheint der Hagen dann als eine ziemlich durchsichtige quadratisehe Platte, von deren i licken id diagonale Rinnen (d) noch der Mitle zu laufen, um sieh damn bis zmm Anfang der Radialeaniale an der Basis des Zungenkegeds fortzusetzen. dete Rinne erscheint als die 
Mittelrippe eines triben elliptischen Blattes (lig. lül, lid), das mit den itussern Ende die Quidhatecke herïhrt, und verhält sich zu diesen im Kleinen, wie jeder Radialeanal zu seinem Genitalblatt im Grossen. Dis Epithel unterseheidet sich von dem helleren der übrigen Magenwand dureh bedeutende Grösse, rundliche Form und dunkelkörnigen Inhalt der Zellen. Jede Zelle enthiilt ausser dem Kern cine Anzahl von dunheln, stark lichtbrechencten, wie Fett glinzenden Körnern. Ich vermuthe, dass diese Zcllen als cinzellige Drusen einen verdauenden Saft absondern und sche die Blitter (d) als Magendriisen an. Wenn der Mundsanm in der erwähnten Weise ausgedehnt ist, so erseheinen die Nesselzellen, welche den zusammengezogenen Mund als dicker Lippenwulst umgeben, ganz regehnassig auf :39 warzenfömnig vorragende paarweis verbundene Nesselknöp fe vertheilt (Fig. 103,16 , 1 \% o'); '2 Paar getrennte Nesselknöpfe hommen auf jede Seite des Quadrats, \& Paar auf jede abgestutzte Ecke desselben. Nicht selten wird jede Quadratseite des Mundsaums in der Mitte tief eingezogen, so dass derselbe dann deutlich vicrlappign erscheint, besonders wenn zugleich jeder Lappen noch in der Nitte kahnförmig zusammengefaltet wird, so dass der Rücken der Driisenrinne einen Kiel bildet und die heiden Iliblfen jedes Drisenblattes sich bis zur Berührung naihern (Fig. 13, 18, 21). In diesem Zustande glaubt man damn f ganz getrennte setbststindige Mundlappen vor sich zu haben, wie sie für viele Medusen-Arten als charaktcristisch gelten. Sobald aber die Falten sich ausgleichen und die liefe Einziehung der Quadratseitennitte aufhört, erscheint der Hundsaum wieder ganzrandig. Es geht hieraus hervor, wie wenig Werth aul die Gestalt und Lappenbildung des Mundes der Craspedoten zu legen ist, wenn man danach Arten oder war Gattungen unterscheiden will. Bisweilen sah ich den Mundsaum unseres Glossocodon sogar deutlich achtlappiga, indem statt der gewöhnlichen einfachen eine doppelte Einziehming jeder Quadratseite eingetreten war, und sowohl die Mitte der \& Quadratseiten als die \& Ecken in Form lappenförmiger Duplicaturen vortaten. Endlich sah ich bisweilen die doppelte Einzichung an gegenüherliegenden, die einfache Einziehung an den beiden andern Quadmatseiten, so dass der Mundsaum nur sechslappig ersehien I). Die Lappenbildung des Mundsaums findet auel bei umgestiulpten (Fig. 20) und sogar bei doppelt umgestiilptem Magenrand (Fig. 2I) nicht selten statt.

1) Offeubar ist es dasselhe wechselnde Verhattniss, welches Eschscuoltz und Lesson verleitete, ein einzelnes lndivifum von Liviope exigua generisch ron dieser zu trennen (vergl. oben die Beschreibung dieser $\mathrm{A} \cdot \mathrm{l}$ ). 
Die vier Radialcaniile (r) entspringen im Grunde des Magensaches, da wo derselhe an Magensticle sich inserirl, und wo milhin auch der Zungeuhegel entspringut. Sie öllnen sich an der Basis des letzleren in die Magenhöhle durch i runde Oeflinungen (i), die clureh einen Kreismushel völlị̣ von dieser ahgesehlossen werden könnon. flier nehmen sie zugleich das Ende der Rinnen aul, welehe von den 4 Drüsenblittern her wahrseheinlich den Verdaumng̣ssaft dem Magen-

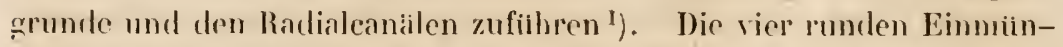
dungِsöffnunĝ̣n der Radialeamäle sind hisweilen (wenn sie wanz zusammengezogen und verstrichen sind) im Magenğrunde sehr schwer oder war nicht zu finden, wahrend sie anderemale solort in dic Augen fillm Fin. 11i, 16i, 19i). Aeusserst deutlich sah ich sie eimmal in geöflnetem \%ustande (Fig. I $\mathbf{i}$ ), als ein glitcklicher Zufall mir bei einem auf dem Rürken lieg̣enden Thiere, welches seinen Magenstiel emporrichtote und den Maq̣en weit öflihete, die volle Ansicht des Magenğrundes von unten vor Augen führte. Es arschienen die i geöflneten Mündungen der Radialennïle als 4 liinglich runde, durch ungefithr eben so breite Zwischenriume getrennte Löcher, welche in wanz yleichen Abständen den Zung̣enkeg̣el (der in Fig̣. 17 z stark verküzt erselieint), mngaben. Wie die Einmündungsstellen der Radialeanisle in den Mauengrund, so ist auch ihr Verlauf lings der Aussenfliche des Schirmsticles und lïngs der Unterfliche des Schirmes bald sche leicht und deutlich, bald sehr schwierig oder fast gar nicht wahrzunehumen. Bei lebenden Thieren nimblich, welche hungern oder nur sehr wenig Nahrung aufgenommen haben, rrscheinen sowohl die Radialeanäle als das sie verhindende Ringgefiiss vollhommen gh hashell und farblos und setzen sich fast gar nicht von der gallertigen Schirmsubstanz, die das Lichl ehenso bricht, ab. Hat dageegen das Thier reichliche Nahrung aufgenommen, so fiillen sich Radialgefiisse und Ringeanal mil sehr zahlreichen hleineren und grösseren, meist stark lichthrechenden und fettglinzenden körnchen und Blaischen, welehe als Verdauungsproducte des Magens von diesem in die Gefisse hineingetrieben und in diesen dureh flimmerbewegxung umbergefulht werden. Bisweilen erscheinen, nach iberreishlicher Nalırungsaufnahme, die Gefaisse strotzend mil solchen assimilirten

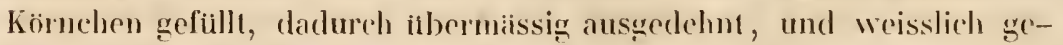
färbt, so dass sie sich nun sehr deutlich von der gulashellen larblosen Schirmsubstam\% absetzen. Elonso werden sie auch meistens kurze Zeit nach dem Tode weisslich getriilst; und dureh Anwemdung versthiedener

1) Bei Liriope ligurina beschreiht Leucksnт (I. c. P. 4) 4 ahnliche "Rinnen oder Spalten", deutet dieselben aber wohl irryg als die Oeffuungsspalten der Radialcanäle. 
Flissigkeiten, z. B. Mincralsäuren, welche in den lipithel oder in den Lımen der Gefaisse körnigge Niederschläge hervorhrinğen, kann man sich dieselben fast immer rasch zur Anschammg hringen. Das Lumen Aer Canbile scheint je mach der aufgenommenen Nabrumgsmenge oder Wassermenge sehr zu wechsehn, so dass man sie zu verschiedenen Zeiten von schr verseliedener Brejte findet. In ihrem Verlaule limgs der Oberllaiche des Magenstioles sind die Radialcanible (r) meist ebenso hreit, als die 4 linearen Muskelbincler $(\mathrm{m})$, durch welche sie voncinander getrennt worden (Fig. 13, 14, 18-21). Jis erscheinen dicselhen dam auf Quesschnitten des Magenstieles als die abgermdeten Ecken eines Quadrats (1ịg. 18-21). Meist treten auf solthen Querschnitten die klaflenden Lichtungen (૫) der durchschnittenen Ratialröhren sehr deutlich hervor, biswrilen schlost dann noch, wenn dic homogene Gallerte des durchschnittenen Magenstiels über dic Schnituliche halbkugeligg orler fast kugelig hervorgeguollen ist (Fig. :0 l). Man überzengt sich in letzterem Falle auf das Bestimmteste, dass tlej ganze Magenstiel von der homogronen Gallerte (I) gebilaled wird mul dass die 4 Radialröhren (r) sowie die fo sie tremenden Muskelbander (III) nur iusserlich auf seiner Oberlliche vorlaulen. Deullich setzen sich schon bei schwacher Vergrösserung, die Canible dadurch vor den fein lingsstreifig erscheinenden Muskehn ab, dass das eigenthimbliche subumbrale Epithel der Ganaile in sehr bestimmter Zeichnung hervortritt (Fig. Do). Dasselbe besteht aus sehr grossen und hohen polyedrisehen Ciglinderzellen, welehe sich durch sehr dicke Winde vor den ibrigen Epithelien des Geryonidenkörpers auszeiclnen. Die dicke Zellenwand ist benerkenswerth wegen eines auffallend murgelmissigen, gleichsam unterbrochenen Zeichmung ihres toppelten Ciontours, welehe vielleicht auf I’orencanale, die die Zwischenwinde durchbrechen, zu beziehen ist. (Tergyl. unten den letzten $\Lambda$ bschnitu iber alic Gewehe.)

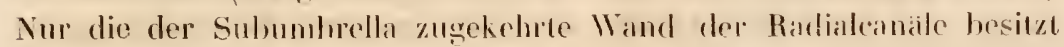
dieses dicke Gylinderepithel, während die umbrale, der Gallertsubstanz zugekehrte Wambl von rinem aus kleinen flachen Zellen gebildeten Pllasterepithel auscekleirlet ist.

Nachdem die a Ralialcanible langs der Aussenllache des Magensticls gleichbreit emporgestiegen sind, biegen sie sich, an der Subumbrella angelangt, um und erweitern sich ablsald zu den \& Hachen, breiteilömigen Taschen, in denen sich die Geschlechlsproducte entwiekeln (Fig. $11-1: 3 g)$. Diese 1 Genitalblatter sind bei den gyeschlechtsreifen Thieren von ansehnlicher Grösse, indem sic beinahe von der Basis des Magenstiels bis nahe an den Schirmand reichen, so dass ihre nach aussen gewendete Spitze den Girhcleanal erreicht oder sogar 
noch etwas in denselben hinein vorspringt (Fig. 13). Das entgegengesetzte innere (dem Nagenstiele zugewendete) Ende jedes Genitalblattes erscheint bald scharf abgerundet und ron dem Radialcanal abgeselzt (Fig. If), bahl geht es melır allınählich verschmiilert in denselben iber (Fig. 1:3); letzleres melır bei den männlichen, ersteres hei den weiblichen Thieren. Im Lebrigen ist die Form der Genitalien bei beilen Geschlechtern ganz gleich; doch kann man sie hïufig schon mil hlossem Auge daran unterscheiden, dass die Genitalblitter (I od e n) des Männehens stïker weisslich getrübt erscheinen ( Fïg. 1:3 $g^{\prime}$ ) als die helleren, mehr (lurchsichtigen Geschlechtstaschen (Eierstöcke) der Wribehen (Fig. 1'. $g^{\prime \prime}$ ). Der Abstand je zweier Genitalblitter voncinander an ihrer Basis ihertrift ihre eigene Breite bald um Weniges, bald um das Zwei- bis Dreifache. Die Geschlechtsprorlucte entwickeln sich hei beiden Geschlechtern aus dem subumbralen Epithel (rs), welches die untere (der Sehirmhöhle zugekehrte) Wand der blattoörmig flachen Ausstiilpung der Radialeaniile bekleidet. Beim Männchen entstehen durch fortgesetzte Theilung dieser Epithelzellen :üsserst zahlreiche und hleine kugelige Samen zellen von 0,00 q $^{\mathrm{mm}}$ Durchmesser, deren jede ein einziges stecknadelförmiges Zoosprerm zu entwickeln scheint. Das Köpfehen der Zoospermien ist rundlich, der missig lange Faden schr zart und dünn, sehr beweglich. Die Eier des Weibchens entwickeln sich durch Vergrösserung und fortdanernde Vermchrung jener Epithelzellen der unteren Taschenwand, so dass man bei gesehlechtsreifen Thieren bestimdiy Eier der versehiedensten Grössen nebencinander findel, alle in einer einzigen Ebene liegend. Hie grösseren Eier springen, indem sie die vorliegenden cireularen Wuskelfasern (ler Subumbrella auseinanderdringen, über diese Fbene als flache Buckel in die Schirmböhle hinein vor und werden schliesslich dureh Bersten des dünnen Leberzugs, den hier das flache Epithel der Sulumbrella noch ibber ihnen bildet, frei. So wenigstens habe ich bei $C a r-$ marina hastata (Fig. 71), bei Mitrocoma Annae und anderen Craspedoten die Eier direct anstreten sehen, wihrend dieselben in anderen Fällen wohl auch in die Strömung des Gastrovaseularsystems hincingerathen und durch den Magen und Mund entleert werden mögen. I)ie Möglichkeit dieser Ausführungsweise ist jerlenfalls dadureh qegeben, dass der Hohlraum der fhehen Geschlechtstasehen in der That hestiindig mit dem Lumen der Radialcanible in offener Communication heibt. Zwar hat es auf den ersten Blick den Anschein, als ob die nach dem Schirmmand gerichtete Fortsetzung der Radialcanile gacsehlossen mitten durch die Genitaltasche hindurehliefe, wie die Blattrippe dureh das Blatt (Fig. 13, 14); allein diese Tremung ist nur seheinhar mol da- 
dureh bedingt, dass das Ganalepithel in der Hitte der Blatter, wo an der sulumbralen Canalwand der Radialnerv (a r), von radialen Muskeln begleitet, vertauft, scinen urspriinglichen Chanathter behialt und kcine Geschlechtsproducte erzeugat. Von der oflenhleibenden Communication der Canalhöhle nit der rechts und links von ihr ausgehenden Ausstiilpung kann man sich leicht durch die Beohachtung der in den Gefissen cireulirenden Körnchen iiberzeugen, die häufigg auch zwiselsen die Simenzellen und namentlich zwischen die Eicr hincingelangen. Zwischen den einzelnen Eierhaufen eines jeden Blattes ist sogar hiufig, hesonders an theilweis entleerten ïleren Eierstöcken, eine Art lacunitren Gefiissnetzes bemerkbar, indem gewöhnlich die grössten und reifsten Eier einzeln oder zu wenigen vereint in bestimmten Abstimclen voneinander entfernt vorspringen; jedes von ihnen oder jedes Paar ist zunichst von einem Ilofe miltelgrosser Eier ungeben, zwischen alenen zahlreiche, ganz kleine und junge Eierchen liegen, und diese letheren bilden ausserdem einen peripherischen Ring um die ganze Eicraruple. Zwischen den so abgegrenzten Feldern bleiben nun hiufig schmillere oder breitere cicrfreie Zwisehenraiume übrig we wehe cine freicre Circulation des Chylus gestatlen (angedeutet in Fig. 1/, deutlicher bei Carmarina hastata in Fig. 1 und 3). Die reilsten und grössten Fier sind in der Regel durch gegenseitigen Druck polyedrisch abgeplattet und erreichen einen Durchmesser von $0,0 \ddot{3}$ bis $0,1 \mathrm{~mm}$. Hhr Dotterprotoplasma ist durch dichte Mengen feiner, dunkler Körnchen getribt (Fig. $86 \mathrm{~g} \mathrm{~d}$ ). Hhr Kern $(\mathrm{g} \mathrm{v}$ ) ist eine helle, kugelige Blase ron 0,02 bis $0,0: 3^{m m}$, welche einen sehr deutlichen kugeligen Nucleolus (g m) von $0,00: 3$ his $0,0 f^{\text {min }}$ zeigt. In diesem ist deutlich ein innerster Fleck (Keimpunet, Nucleolinus oder Punctum germinativum) zu unterscheiden (g p, Fig. 86). Thre Vlembran ist sehr' zalt und dinn und wird bei den jüngeren Eiern vollstandig vermisst. Diese stellen hiillenlose Protoplasmaklumpen dar, welche den kern umgeben. Die Menge des körnigen Protoplasma ist bei den jüngrsten Eiern minimal, so dass iliese fast nur aus dem Kerne mit seinem Nucleolus zu hestehen scheinen.

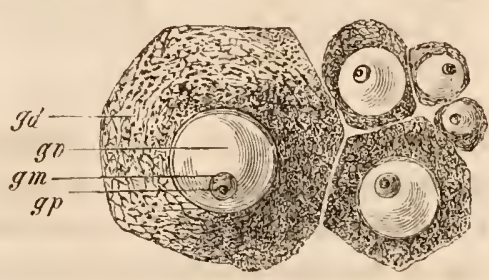

Fig. 86. Eier von Glossocudon eurybia. gr d. Protoplasma (Dotter). g v. Kieimbläschen (Nueleus). g m. Kieimflech (Nucleolus). g p. Reimpunct (Nucleolinus).

Das äussere spitze Ende der eiförmigen Genitalblätter erreicht, wie bomerkt, den breiten Cirheleanal (c), welcher die \& Radialcaniile am Schirmrande miteinander verbindel. Dieses Ringgeläss erscheint in der 


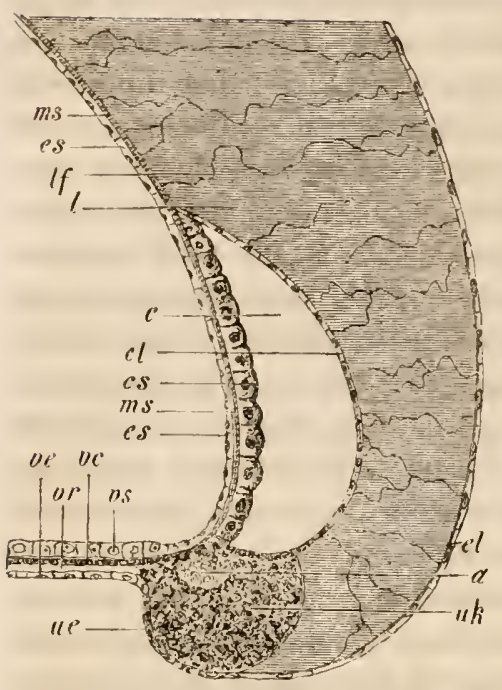

Fig. 87. Ein verticaler Radiatschnitt (Meridianschnith) durch den Schirmrand von Glossocodon curybia, zwischen 2 Randbläschen. a. Nervenring. c. Ringgelass. c l. Umbrales, e s. sulumbrales Epithel des Ringreliisses. e I. Epithel des Gallertmantels. es. Epithel der Subumbrella. 1. Gallertsubstanz des Mantels 1 1. Fasern in ter Gallertsubstanz. m s. Ringmuskeln der Subumbrella, u e. Epithel des Ringknorpels. u k. Kingknorpel. \. Velum. । e. Ringmuskelu, v e. unteres Epithel,v r. Radialmusheln, v s. oberes Epithel des Velum.

Reared sehr breit, oft fast hith so breit wic ein Genitablatt, oder elen so hreit als das Velum. Doch ist dis Lumen desselben ron selir weehselnder Ausdehnung, in prallgefuillten Zustande fast eylindrisch, hei geringer füllung dagegen flach tilschenförmig; im letzteren Falle liegen innere und aiussere Wand des Gefaissringes nahe ancinander, so dass derselbe auf dem radialen Querschnitt ein schr schmales Ovil oder eine Sichel darstellt (Fig. 87 (c). Auch an dem Ringeanale ist meist schon bei schwacher Vergrösserung die zicrliche feine nelzförmige 7eichnung selor deutlich (Fig. 13), welche durch die hohen und grossen dichwandigen Gylinderzellen des subumbralen Gefissepithels hervorgebracht wird (Fig. $8 \pi \mathrm{cs}$ ), wihlend das umbrate, der Gallertsulystan\% des Schirmes zugekehrte Epithel (Fig. $87 \mathrm{cl}$ ) auch am Cirkolgefisse nur aus flachen, diinnwandigen Pflasterzellen besteht. Die gewöhnliche fiorm des Randgeficses ist iibrigens bei cilossocodon eurybiu nicht wie hei den meisten Medusen ein lireis, sondern ein Polygon, bahl deutlicher viereckig, bald deutlicher achteckig. An dent unteren, dem Knorpelringe zugchehrten Rande des Cirkeleanals wird diese cekige Form durch die 8 einspringenden Winkel erzenget, wetehe hier die mten zu beschreihenden centripetalen Spangen der :iusseren Mantelfliche hervorbringen. Der entgegengesetzle obere Rand des Ringeanals dagegen wird dadured polygonal auggehuchtet, dass derselbe beim lehergange in die Genitalblitter ein wenig an deren Aussemwand hinaufliunft, wibluend er in der Hitte zwischen zwei Genitaltasehen cinen fist labllhreisformigen Vorsprung biledet, eine Andeutung fener hei Carmarince so entwickelten Centripetalcantile (Fig. 1:3).

Ausser den i Radialeanialen muinden in den Cirkelcanal, rechts 
neben den radialen Randblaschen, die í Canale cin, "relehe die Axe der Tentakchn ihrer ganzen Läng̣e nach durchzichen.

Dow Cirkeleanal bildet ibrigens nicht den cigentlichen liand des Schirmes, der denselben von dem Pelum abgrenzt. Dieser ausserste Schimmand wird vichehr ron dem sogleich zu beschreibenden, von

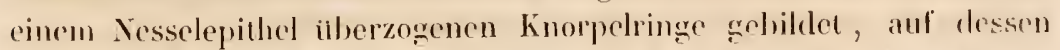
oberem Rande der Nervenring und der untere Rand des Cirheleanals ruhen.

\section{Skelet.}

knorpelring des Sehirmrandes.

So befremdend und so wenig passend es auf den ersten Blick seheinen mag̣, bed so weichen, wallertartigen und oft last zerfliesslichen Thieren, als es die meisten craspedoten Medusen und auch unsere Geryoniden sind, on oinem Skelete zu sprechen, so ist doch in der That in dem Körper der Geryoniden, wenigstens der beiden vor mir mntersuchten Reprisentanten dieser Fandie, cin Theil vorhanden, wcheler, olmohl ron heiner ansehnlichen Entwicklung, mir demnoch den Namen eines Skeletes vollkommen $z u$ verdienen scheint. Es ist dies ein tiinner, eylindrischer oder halbeylindrischer K norpelring (uk), welcher den untersten Theil des Schirmmondes bildet, so lass er mach aussen und unten frei ist, nach oben an den unteren Rand des Gallertmantels und des kingeanales, nach inmen an den Nervenring und den iursseren Rand des Velum stösst. Indem er zwischen diese versehiedenen Riinder eingeschaltet ist, dient er denselben wesentlich zur Stiitze und zur Insertion und griebt zugleich dem Manfelmande veruögege seiner mit grosser Elasticitait verbundenen Festigheil seine bestimmte und bleibende Kreisform.

Bei Glossucodon besehrinkt sich das rulimentiare. Skelet auf den Ringknorpel (lï. 38, 40, $114 \mathrm{k}$ ). Bei Carmarina dagegen ggehen von dem Knorpelringe des Schirmandes noch melrere kurze, hackenförnigy gebogene, fadendimne Ausliufer in Form solur schmaler Knorpelstreifen aus, welche in der Aussentliche des Gallortuantels in radialer Richtung emporsteigen, mol welche ich deshalh marginale oder centripetale Hantelspangen nemne $h)$. Lis sind leren eben so vicle als Randblaschen vorhanden und sie biegren sich von der Basis der Randblischen mach aussen und oben herum. Jede Mantelspange besteht nur aus einer einzigen Reihe von Knorpelzellen und biult von einem Mushelstreifen und cinem Nerven besteitet und von einem Streifen Nesselepithel iiberzogen, in der iusseren Mantellibche centripetal bis zu ıler Stelle empor, 
wo bei der Larve die intermadialen und die radialen Volententakeln frstsassen. Ilier selzle sich bei den Larven der Knorjelstreif direct in den viel dickeren Tentakelknorpel fort. Diese marginalen Mantolspangen mit inen Nerven, Muskeh und Epilhelstreifen sind zиar bei Cilossocorlon auch vorhanden. Lis felilt ihmen aber dis Knorpelsheled, durch welehes die Sipangen der Carmarina gestiuzt werden.

Von den fruberen Beobathern der Geryoniden ist der hinorpelring meistentheils gint ibbersehen, theils aber auch für einen Nervenring oder für cinen verdickten Epithedialsamm genommen worden. Dic letzlere Verwechslung war um so leichter möglich, als der Knorpelling von cinem Epithel iiberzogen ist, das zahloeiche Nesselhapseln entwickelt, und als die dunheln Yesselkapseln das Licht fast in demsellen Gade brechen wie die glinzenden Knorjelhöhlen, so dass ich selhst auch anfanglich oben das ganze Gebilde als Nesselsaum bezeichnet habe.

Der Knorpelring (Figg. 13, 1' 1 ; Fig. 38, 40,87 u k) des hleinen Glossocodon eurybiu ist sehr dün, aul dem verticalen Radialschnitu halbeylundrisch, nach unten convex. Er besteht aus dichtgedringlen Reihen rumder hleiner kinorpelzollen, welehe durch zienlich reichliche lntercellularsubstanz getremut sind. Am besten zu untersuchen ist er bei jüngeren Larven. wo erst wenige Zellenreilsen ubereinander liegen (Fig̣. 11). Ueber das topographisehe Verhiltuiss des Knorpelringes zu den Nachbartheilen ist der vorhergehende Ilolzsehnitt Fig. 8\%, sow ie die unten folgende Darstellung des Nervenringes zu vergleiehen. Bci Carmarina hastutu, wo das Knorpelskelet stäker entwichelt ist, werde ich dasselbe genauer beschreihen. Ueher die nibere Beschaflenheit des Medusenhnorpels, weleher sowohl seines histologischen, wie seines physikalischen und physiologischen Werhes wegen diesen Namen verdient, ist der letzte Abschnitt dieser Arbeit (iiber die Gewcbe der Geryoniden) zu veraleichen.

\section{MuskeIsystem.}

Tentakeln, Velum und Subumbralla.

Schrig unterball der Spitze jedes Genitalblattes entspringl ron den Schirmmonde ein selur contratiler, langer Faden, Tentah o l oder

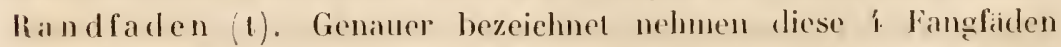
ihren Ursprung rechts neloen den radialen Ramdblisschen bei Betrachtung von aussen oder unten) und \%war oberhall, des Knorpolringes des Schimmandes, vou der Aussenfliche des Cirheleanals. von welchem aus sich rine Verbingerung als feine Röhre dureh die ganze liange des Tentakels hindurelı bis zu seinem blinden Eude forlsetz. Doch ist die 
Flimmerbewegung oder die Strömung des Chỵlus in dieser Höhlung des Fingfadens selten unt meist nur in der elweiterten Basis zn beobarliten, weit die der mikroskopischen Beobachtung zuginglich gemachten Fangfiden sich meist in einem Zustande schr starker Contraction befinden, bei weleher das Lumen des Tentakels ganz oder fast ganz rerschwindet, indem derselbe seinen flüssigen Axeninhalt in das kinggefiss zuricktreibt. In diesem stark zusammengezogenen Zustande gleichen die Tentakehn mit ihren wurmförmigen Bewegungen und ihrer dichten Ringelung gewissen Annelidenformen (Fị. 13, 11). Sie iibertreffen dann die Länge des Mag̣enstieles meist nur wenigg und erscheinen oft fast so breit als die Muskelbänder an Magenstiel. Ganz anders erscheinen sie bei dem frei in Wasser schwinmenden Thiere, welches sie nach allen Sciten wic Angeln verlingernd auswirft (Fig. 12), odpr bei dem ruhenden Thiere, bei dem síe in völlig erschlafftem Zustande bewegungslos herniederhaingen. Ilier übertrillt ihre Lïnge mehrmals die Lïnge des Magensticles und sie erschicinen-schon dem unbewaffneten Auge mit schr zahlreichen uud feinen Knoten besetzt, wic zierliche Perlenschniire. Jeder solcher Knoten oder jede Perle ergiebt sich vergrösser (Fig. $24 \mathrm{u}$ ) als ein ringförmigger dunhler Wulst, welcher dicht mit Nesselzellen gespickt ist. Während diese Nesselwülste bei den ganz lang ausgestreckten Tentakeh durch schniblere nesselzellenfreie Internodien getrennt sind, welche ihre eigene Liinge um das Drei- bis Vierfache ubertrefien, schwinden dagegen bei starker Contraction der Randfiderr diese Internodien vollstiindig, so dass nur Nesselring an Nesselring gereiht erscheint (Fig̣. 13, 14). Den grössten Theil der Tentakelsubstanz bilden mächtig entwichelte Laingsfaserbündel. Ihr feinerer Bau ist sehr schwierig zu erforschen, da Querschnitte und Längsschnitte, welche allein über denselben Auskunft geben können, nur selır schwer bei der geringen Dicke der Tentakeln zu crhalten sind. Was ich in dieser Bezichung ermitteln konnte, stimmt mit dem complicirten Bau der Tentakeln von Carmarina überein, der unten niher beschrieben werden wird. Sicher ist, dass auch hier bei Glossocodon keine quergestreiften Iuskeln, sondern nur glatte Fascrn die contractilen Tentakelelemente zusammensetzen.

Ganz verschieden von diesen í radialen Haupttentakehn, die sich durch ihre wurmförmigen krichenden und schliingehnlen Bewegungen auszeichnen, sind die 1 radialen Nebententakeln (s 1), welche oberhalb der ersteren von der Aussenseite des Schirmes entspringen, und die 4 interradialen Tentakeln (y). Beide gehen bei unserer $A$ rt noch vor der Entwicklung der Genitalien verloren, wiilrend sie (mindestens die interradialen) bei anderen Geryoniden zeitlebens persistiren, so bei Glos- 
socodon catharinensis und G. mucronalus und hei den oben in dem Subgenus Xamthea zusammengefassten Arten von Liriope. Diese 8 Larventontakeln, sowohl die radialen, mit einem Nesselhnopf verselienen (Fig. 39), als die interradialen, mit einer keilue von Nesselpolstern versehenen (Fig. 40) bestehen aus einem rylindrisehen Kinorpelstabe, der von einem dumnen Muskelschlauche iblerogen ist. Dieser ist nur aus longitudinal verlaufenden quergestreiften Muskelfasern zusaummosetzt und von einem cinfachen Epithelschlauche ilher\%ogen. Alle 12 Tentakeln, welche in einem gewissen Stadium der Entwicklung (Vig. 37) sich gleichzeitig zeigen, werden gebogen und verkiil»t durch Wirhung der longitudinalen Muskelfasern. Die Ausdehnung der verkürzten Tentakeln gesehicht bei den 4 radialen llauptlentakeln dureh Erection, nimblich durch Injection ron Emährungsflussigkeit aus dem Cirkeleanal in den Axeneanal des Tentakels, bei den ublrigen dagegen,

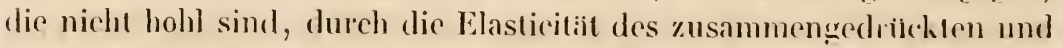
sich wieder ausclolmenden knorpelshelets.

Gleiche quergestreifte Mushelfasern, wie sie den Ueberzug der Larvententakehn bilden, setzen auch die Beweğungsorgane des Glossocodonschirmes, Velum und Sulmubrella zusammen. Das Velum (v) oder die Randmembran, welches ungefilhr so breit als die llöhe des Cirkelcanales ist, zeigt Fig. 87 im Quersehnilt. Es besteht aus ciner oberen stirkeren lage von Ringfasern ( $r$ ce und einer unteren sclwiicheren Lage von Radialfasem ( $\mathrm{v}$ r). Erstere ist oben von cinem Cylinderepithel ( $\mathrm{rs}$, letztere unten von einem Pllasterepithel (ve) bekleidet. Die circularen Muskelfasern des Velum setzen sich auch auf die $\mathrm{Sub-}$ a mbrella fort (lig. $87 \mathrm{~m} \mathrm{~s}$ ), wo sie aber viel schwicher entwichelt erscheinen und sich gégen die Basis des Vagensticles ganz verlieren. Sie sind von dem dünnen Pllasterepithel der Subunthrella (lig. 8 i es) äherzogen. Inter der dünnen Ringmushelschicht der Subumbrella finden sich noch 12 schmale longitudinale oder besser radiale Muskelbinder, von denen die 4 unpaaren in dor : iusseren Mittellinie der Radialcaniile. die Radialnerven bis zum Gimnle der Schirmböhle begleiten, wihrend die 8parigen stiitheren Mushelstreifen die Scitenrinder der \& Radialcanile siumen. An der Basis des Magenstieles treten dieselhen paarweise zur Bildung der Iong̣itudinalen Stielmuskeln (m) zusammen, welehe den Zwischonraum zwischen den Riwdialean:ilen linngs ihres Voplaufes am Maggenstiele ausfullen und unten in dir olerfliachliche laingsmushelselichl des lagens ibbergehen. 


\section{Nervensystem.}

Das Nervensystem habe ich bei Glossocodom emybia sowohl als bei Carmarina hastata mit verhibluissmitssig grösserer Dentlichkeit und Sicherheil nachzumeisen vermochl, als mil dies hei einer Anzahl anderer darauf untersuchter Hedusen aus den verschiedensten Familien möglich gewesen ist. Die Gergoniden scheinen in dieser Beziehung wikklich ein besomlers giinstį̣es Brobachtungsohject zu sein, weil sich deutliche nervöse Elementartheile hei ihnen isoliren lassen. Innmerlin ist aber auch hiep dor Nachwois derselhen krineswegs leicht. leh sehe mich daher mu so molı veranlasst, alles, was ich darüher durch sorgyfillige Untersuchung ermilteln konnte, hier anzuführen, als diesor Gegenstand olme Zweiled sowohl zu den wichtigsten als zu den schwierigsten in der Anatomir niederer Thiese wehört, und als gerade im gegenwirtigen Augenblicke die auflallendsten Widrespriiche darüber hei den verschiedenen Forschern zu finden sind. Ich schicke einige Worte über die hisherigen Angaben ïber das Nerrenșstem der Quallen roraus.

Ein Nervensystem bei Medusen wurde zum ersten Male ron Arassiz. ") beschrieloen und alugebilder, und zwar hej Sansia, Tiaropsis. Stanophora, am ausfiululiohsten hei Bouganuillia superciliaris. Es wirl als ein untelualb des Cirhelcamals verlaufender, aus Zellen bestolender Nervaning geschildert, welcher hinter der Eimmündungsstelle jedes dep 4. Radialeanile eine Anschwellung (Ganglion) bildet. Von diesen \& Knoten aus stejugen f. Fijlen an der Innenseite der Radialcantile empor und vereinigen sich im Grundr der Glockenwölloung, an der Lmbiegungsstelle der Radialeanaile zum Mag̣enstiele, durch einen zweiten Ring weldher in der Mitte zwischen je 2 Radialcanälen einen andern Faden, abormals an der Immenfliche der Sohimuhöle, liembschickt. Die \& letzleren Norvenfiden sollen aboe bloss bis zum Milte drep Glocke herabreichen. Als Elenentatheile dieser Nerrenliblen besclureibt Agassiz kernhaltige Zellen.

Der zweite Forscher, der fur das Nervensystrm der Medusen in die Schranken trilt, ist Frotz MëLesu, dessen Angaben zilıe! die Serven von Liriope calharincnsis (1. c. p. 313) ich hice wörllich anfülıre: "Un das Ringrgefiiss zieht sich ein ziemlich undurchsichtigol gell,licher Saum, der namentlich nach aussen scharf contouride rumbliche Zellen von

1) Agsssiz, Contributions to the history of the Acalephae of North America. (Memoirs of the American Academy of Arts and Sciences. Yol. IT. T. II. 1850.) 
0,00:3 his 0,008 mm Durchmesser zeigg und anf dem mehr oder wenigger reichliche Nesselzellen liegen. An der Basis der Tentakeln und in ther Mitte zwischen diesen Stellen zeigt er längliche Anselwellungen, denen die sogenaunten Randblisschen aufsitzen. Mil aller Wahrscheinlichheit ist er als Nerventing zu deuten; diffir spriclut ausser den Randlblisrhen tragenden $\Lambda$ nschwellungen, dass sich ron jeder dieser $\Lambda$ nschwellungen ein zarter, aber scharf begrenzter Strang mach oben verfolgen lïss, $\{$ zur Basis der Tentakel, 4 zu Puncten, an denen das jüngrere Thier dem erwadisenen meist vollstindig fehlende Tentakel getragen hat. " Einen ailnnlichen Nervenring nit 4 Knoten, von denen zalilreiche Fïlen (von jedem knoten gegen 20) zu handlörmigen Tentakiln ausstrahlen, fand Fritz. MëLlek "mit uherraschender Deutlichkeit auș̣eprigg “ bei 2 verschiedenen Arten der brasilianischen Charybleitlengattung Tamoya (T. quadrumana und T. haplonema) ${ }^{1}$ ).

Endlich spricht sich in der neuesten Zeit auch Lexckst ${ }^{2}$ z zu Gunsten eines besonderen Nervensystems der Medusen àus. Err überzeug̣te sich bei einer in ter Nordsee weit verbreiteten Eucope "aul das Bestimmteste von der Existenz eines besonderen nehen dem Ringgefiisse hinlaufenden Randfarlens. Die Anschwellungen, die dieser Faden an der Anhaftungsstelle der Randkapseh und Tentakel zeigt, bestehen aus Zellen von ziemlich indifferentem Charakter, wïhrend die dazwischen ausg̣espannten Commissuren eine Liingsstreifung erkennen lassen. “

Gegenüber diesen neueren bestimmten Angaben haben gleichzcitig andere Forscher, welche das Nervensystem der Medusen aufsuchten, es nicht gefumden, und die Existenz desselben eben so bestimunt

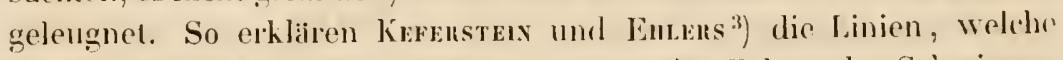
A gassiz als Nerrensystem beschreibt, "nur lür Falten des Schwimmsackes oder der Gallertgloche, oder liur die scharfen aus Zellen gebildeten Contouren der karliareanïle. " Auch die von Frıтz Mǘlek als Nervensystem beschriebene Bildung wird nicht von ilinen als solche anerkannt. Ehen so wenig ist Cuxs ${ }^{4}$ ) geneigl, den Medusen ein distinctes Nervensystem zuzugestehen. Er fand den ron Fratz Mäluzk beschriebenen Ring bei Medusen aus verschiedenen fanilien wieder, will ilun aber nicht als Nervenring getten lassen, um so weniger, "als es sich hier nicht un einen Gegensatz von Ganglienzellen und nach den einzelnen Organen ausstrahlenden Fasern handelt. "CLats lindet, mdass

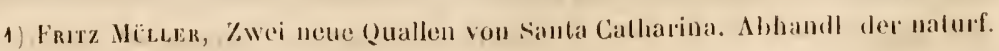
Gesellschall in Halle. Vol. Y. 1859.

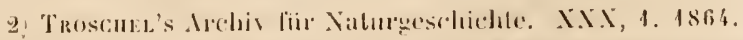

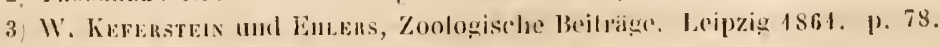

4) Zeilschr. fïr wisseuschalt. Zool, 1864. NII, p. 3s7. 
der dem Ringgefäss dicht anlicgende Strang 2 mehr oder minder scharf gesonderte Zellenlagen unterscheiden lässt, von denen die untere nur als Verdickung des Zellbeleges der Gefiisswand anzusehen ist, während die obere allein bei der Deutung als Nervenring in Betracht kommen könnte, « da sie die Randbläschen trägt und überall an der Tentakelbasis Anschwellungen bildet. Allein auch die Zellen dieses "vermeintlichen Nervenringes « miüssen als Theile des äusseren Epithels aufgefasst werden, da sie mit dem Epithel der Tentakeln continuirlich zusammenhängen und häufig Nesselkapseln erzeugen.

Von den Bildungen, welche ich in Folgendem beschreiben werde und als Nervensystem mit Sicherheit deuten zu durfen glaube, bemerke ich im Voraus, dass sie weder mit den von Agassiz, noch mit den (wahrscheinlich damit identischen) bei Liriope von Fritz MüLler als Nerven aufgefassten Theilen zusammenfallen. Nur die von letzterem bei Tamoya gesehenen und namentich die von Leuckart als Nerven beschricbenen Theile scheinen dieselben $z u$ scin, die ich bei den Geryoniden als solche habe nachweisen können. Der sichere Nachweis des Nervensystems ist immer erst möglich durch Darstellung nervöser Elementartheile, wie solche sich sowohl bei Glossocodon als namentlich auch bei Carmarina mit überzeugender Deutlichkeit aus den ungebenden Geweben herausschälen und isoliren lassen.

Bei lebendigen sowie bei frisch getödteten Individuen von Glossocodon eurybia ist das Nervensystem nur sehr schwer zu erkennen, da die lebende Nervensubstanz in ihrem Lichtbrechungsvermögen sich sehr wenig von den benachbarten Theilen, namentlich der hyalinen Schirngallerte unterscheidet, und ausserdem so vollkommen durchsichtig, farblos und wasserklar ist, dass sie sehr leicht ganz übersehen wird. Viel besser und leichter liisst sich das Nervensystem (ebenso wie das Gastrovascularsystem) bei Medusen verfolgen, die schon einige Zeit' todt sind, und bei denen die beginnende Zersetzung die verschiedenen Gewebe in verschicdenem Grade zu trüben beginnt. Auch durch vorsichtigen Zusatz verschiedener Reagentien, namentlich verdünnter Mineralsäuren, kann man sich die Medusennerven leichter zur Anschauung bringen. Doch ist auch dann die Erkenntniss derselben an verschiedenen Stellen durch mehrfache Hindernisse in verschiedenem Grade erschwert.

Das Nervensystem von Glossocodon besteht aus einem schmalen hellen längsstreifigen Ringe (a), welcher zwischen Ringcanal und Knorpelring längs des Schirmrandes verläuft und an der Basis der 8 Sinnesbläschen zu 8 aus kleinen Zellen bestehenden Ganglien von geringer Grösse anschwillt (f). Von jedem der 4 stärkeren radialen Ganglien, 
welehe unterhalb der Einmindungsstelle der 4 Radialeanäle in den Cirkeleanal unmiltelhar unter den radialen Randblischen liegen, gehen 4 Nervenfiden alb: 1. der erste und stärkste Xerv (a r) hegleitet den Radialeanal in sciner ganzen Lïnge rom Schirmrand bis zum Magen. 2. Ein selwwicherer (h $n$ ) geht durch die radiale Mantelspange (h) zur Basis des radialen Nebententakels. 3. Ein dritler welıt zum radialen Haupttentakel. 4. Der vierte hürzeste ist der breite bandförmige Sinnesnerv (n), welcher innerhalb des radialen Randblisehens verlïuft. Jedes der 4 schwidieren interadialen Ganglien, welche unterhalb der Basis der interradialen Larvententakeln, und unmittelbar unter dem interradialen Randbläschen liegen, gicbt nur 2 Nervenstrïnge ab, nämlich 1. den breiten Sinnesnerven, welcher innerhall, der letzteren verliuft

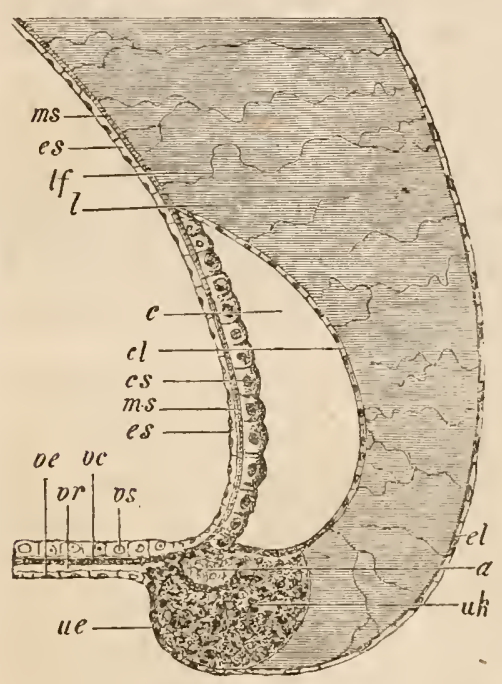

Fị̂. 87. Ein verticaler Radialschnitt (Meridiansehnilt) durch den Sclirmrand vou Glossocodon eurybia, zwisehen 2 Randhlaschen. a, Nervenring. c. Ringgefiiss. c l. Umhrales, c s. sulumbrales Epilhel des Riuggeliisses. e 1. Epithel des Gallertmantels es. Epithel der Subumbrella. l. Gallertsubstanz des Mantels. I f. Paser'n in der Gallertsulsstanz. III s. Ringunskeln der Subumbrella. u e. Epithel ales Ringknorpels. u k. Ringknorpel. v. Velum. v c kingmusheln, ve, unteres Epilhel, vr. Radialmuskeln, v s. oberes Epilhel des Velum. (n) und 2. den Spangennerven (h n), weleher dureh die marginale Mantelspange zur Basis der interradialen Knorpeltentakeln liiuft.

Ueber das genatiere Verhalten der cinzelnen Abschnille des Nervensystems konnte ich bei Glussocodon Folgendes eruittch. Ber Nervenring (Fig. 13, 14 a) ist ein sehr dimner, blasser und zarter hallbcylindriseher Strang, welcher mit seiner nach unten gekelırien Convesiliat grösstentheils in den oberen Theil des Ringknorpels ( $\mathrm{k}$ ) eingesenkt ist, wilırend sein oberer, flaeher und ziemlich ebener Rand in der Mitte zwischen dem unteren Rande des Cirkeleanals (e) und dem ausseren Rande des Velum (v) liegt, von ersterem zum Theil verdeckt (Fig. 87 a). Sein Durchmesser betrïgt nur efwa $1 / 6$ oder $1 / 4$ ron dem des Knorpelıinges. Da er gुleichsam in eine Rinne desselben theilweis eingeschlossen liegt, so ist er auf Flichenansichten nur mit grosser Miihe als ein heller, blasser Streif zu erkennen, um so schwieriger, als auch der dicke hyaline Gallertmantel, 
der das Licht fast ebenso wie der Ringnerv bricht, noch von aussen her den Seluirnmand ungreift und theilweis verdeckt. Nur bei jüngeren noch nicht geschlechtsreifen Thieren und bei Larven mittleren Alters kann man auch auf Flachenansichten, namentlich bei Betrachtung des Schirmrandes von innen, von der Schirmhöhle her, den Ringnerven deutlicher erkennen, besonders dann, wenn der Cirkelcanal leer oder stark zusammengezogen ist. Viel besser tritt or aber auf glucklich geführten und hinreichend diinnen Querschnitten des Schirmrandes hervor, welche allerdings selir schwierig anzufertigen, und nur selten und erst nach lingerem Bemühen in einiger Vollkommenheit zu erhalten sind (Fig. 86a). Was Futz Müller bei Liriope catharinensis (1. c. p. 314) als Nervenring beschreibt, yein ziemlich undurchsichtiger gelblicher Saum, der namentlich nach aussen scharf contourirte rundliche Zetlen von 0,00:̈-0,008 mm Durchmesser zeigt, und auf dem mehr oder weniger reichliche Nesselzellen liegen, " ist ohne Zweifel der Knorpelring. Der Nervenring enthiilt bloss unter den Randbläschen, wo er zu den Ganglien anschwillt, Nervenzellen, welche aber kleiner, blasser und zarter, ats dic des Knorpelrings sind (vergl. unten den Abschnilt ïber dic Gerrebe). Zwischen den Knoten erscheint die blasse zarte Substanz des Nervenringes nur fein längsgestreift (Fig. 38 a, 40 a).

Dic Ganglienknoten (f) des Nervenrings sind bei Glossocodon viel schwieriger als hei Carmarina nachzuweisen, da es bei ersterem nur mit der grössten Mïhe glïckt, himreichend klare Querschnitte, wie sie bei letzteren of schr schön gelingen (Fig. 63, 6i), durch den Schirmrand an den Stellen anzufertigen, wo die Randblaischen auf den Ganglienknoten aufsitzen. Dagegen gelingt es bisweilen beim Zerzupfen des Schirmrandes ein Randbläschen (b) im Zusammenhang mit dem zugehörigen Ganglion (f) zu erhalten (Fig. 22). Bei jüngeren Thieren kann man dasselbe auch auf Flichenansichten bisweilen als ein flachgewölbtes, noch nicht labkugeliges Polster erkennen, welches uber den Knorpelring hervorragt und das Blischen tright.

Von den verschiodenen Nervensträngen, die von den Ganglien des Nervenrings abgehen, sind am leichtesten die innerlablh der Randblaischen verlaufenden Sinnesnerven zu untersuchen (Fig. 22, 23, 40, 48). Ihr Verlauf wird sogleich bei den Simnesblischen beschriehen werden. Sehr sehwierig dagegen sind die 4. Nerven nachzuweisen, die zu den 4 radialen Ilaupttentakeln gehen. Viel leichter erkennt man die 8 Spangennerven (h n, Fig. 38, 40), wolche den mitleren Theil der 8 marginalen Mantelspangen (h) hilden und vom Ganglion aus in der Aussenfiache des Mantelrandes eentripetal his zu der Stelle emporsteigen, wo bei der Larve die 4 interradialen und die 4 radialen Neben- 
tentakeln festsassen. Die Mantelspangen sind auch schon von Fritz MüLler bei Liriope catharinensis gesehen und als Tentakelnerven gedeutet worden (1. c. p. 314, Fig. 7, 21). Jedoch entspricht nicht die ganze Spange dem Nerven. Der letztere verliuft vielmehr in der Mitte über dem breiteren darunter liegenten Muskelstrange (hm), der sich durch die Querstreifung seiner dunkleren Fasern deutlich von den helleren und bliisseren Nervenfasern unterscheidet. Beirle sind ausserdem nach aussen von dem Spangenepithel überdeckt, welches zerstreute Nesselzellen enthïlt.

Nerven, welche von den Ganglien zum Velum gehen, habe ich so wenig bei Glossocodon, als bei Carmarina nachweisen können. Dagegen sind die 4 starken Radialnerven auch bei ersterem ziemlich leicht zu erkennen und zu isoliren, namentlich bei geschlechtsreifen Thieren. Sie begleiten die 4 Radialcanäle in ihrer ganzen Länge rom Schirmrande bis zum Magen, wo sie sich über dessen Oberfliche auszubreiten scheinen. Sie erscheinen als 4 ziemlich breite und platte, lineare, fein längsstreifige Bänder, welche in der Mittellinie der :iusseren Wand der Radialeanile verlaufen und zwischen dem subumbralen Epithel und der Ringmuskelschicht der Subumbrella liegen. Das Verhalten der Radialcanäle bei ihrer Ausloreitung auf dem Magen blieb mir auch hier wegen der Undurchsichtigkeit und Dicke dieses Theiles unbekannt.

\section{Sinnesbläschen (Randbläschen).}

Gleich den übrigen Geryoniden besitzt Glossocodon eurybia doppelt so viele sogenannte Randhörper oder Randbliischen (besser Simmesbläschen genannt) als Radialcanäle. Alle 8 Sinnesblïschen verhalten sich hinsichtlich ihrer Grösse, Struetur und Lage gleich. Alle liegen eingeschlossen in dem unteren Rand der Mantelgallerte, zwischen dem unteren Rande des Cirkelcanals nach innen und der Basis der Mantelspange nach aussen. Die 4 radialen Sinnesbläschen sitzen unterhalb der Einmündung der \& Radialcanäle in den Cirkelcanal, links neben der Insertion der radialen Ilaupttentakeln (bei der Betrachtung des Schirms von aussen oder von unten). Die \& interradialen Randblischen sitzen in der Mitte zwischen jenen, gerade unterhalb der Basis der (beim erwachsenen Thiere abfallenden) interradialen Tentakeln. Die bisherigen Angaben über Lage und Struetur der Randbläschen bei den Geryoniden enthalten sehr viel Irrthümliches, und es erseheint daher ein nüheres Eingehen auf die wahren Verhïltnisse derselben besonders geboten; doch werde ich das Meiste, was ich hierüber ermitteln konnte, nicht hier, sondern bei Carmarina hastata anfülren, deren ausseror- 
dentlich grosse Randbläschen ein ganz vorziigliches Beobachtungsobject bilden. Ich beschränke mich daher hier auf Mittheilung nur des Wesentlichsten und auf Erginzung und Berichtigung der Angaben, welche Fritz Müllen über die Randbläschen der nahe verwandten Liriope catharinensis mitgetheilt hat.

Zunächst ist besonders hervorzuheben, dass die Sinnesbläschen von Glossocodon eurybia, wie von den anderen Geryoniden, nicht, wie man bisher angenoummen hat, frei auf dem Schirmrande aufsitzen, sondern in der Mantelgallerte des unteren Schirmrandes eingeschlossen liegen. Die bisher allgemein gültige, aber irrige Annahme, dass dieselhen frei auf der Aussenflïche des Schirms angebracht sind, wird auch noch von Frıtz Müllen getheilt, weleher in seiner Fig. 2' (1. c.) einen "schematischen Längssehnitt " durch den Schirmrand am Ursprunge eines interradialen Tentakels giebt. Hier liegt das Randbläschen nach anssen und oben von dem (als Ganglion gedeuteten) Knorpelring des Schirmrandes und die als »Tentakehnerv? "gedeutete marginale Mantelspange geht von oben und aussen nach unten und innen herab zum unteren Rande des Cirkeleanals, wobei sie an der inneren Seite von Bläschen und linorpelring vorbeigeht. In der That aber verliuft die marginale Hantelspange sammt dem eingeschlossenen Tentakelnerven ausserhałb der genamnten Theile, in der Aussenfliche des Mantels, und das Randbläsehen liegt, von dem untersten Randtheil der Schirmgallerte umhüllt, so auf dem Ganglion (f) des Nervenrings und dem Knorpelringe auf, dass es nach innen an den Cirkelcanal stösst, nach aussen von der Mantelspange bedeckt wird. Man kann sich von diesem Lagerungsverhältniss leicht auch auf Flächenansichten des Schirmrandes durch wechselnde Einstellung des Focus auf seine verschiedenen Schichten äberzeugen. Auf das Klarste und Unzweifelhafteste aber tritt dasselbe sofort bei Betrachtung solcher verticalen Radialschnitte durch den Mantelrand entgegen, wie ich sie von Carmarina hastata in Fig. 63 und 64 abgebildet habe. Ob diese verborgene Lage der Randbläschien in der Gallertsulsstanz des Mantels bei den craspedoten Medusen weiter verhreitet ist, müssen fernere Untersuchungen lehren. Sicher ist, dass sie nicht allgemein verbreitet ist, indem bei anderen Craspedoten z. B. Eucopiden, Trachynemiden, Aeginiden, etc. die Randbläschen frei, oft selbst mittelst eines kurzen Stieles, auf dem Schirmrande aufsitzen.

Die 4. radialen und die 4 interradialen Sinnesblisschen von Glossocodon eurybia sind von gleicher Bildung (Fig. 22, 23). Jedes stellt eine sehr zarte durchsichtige Kugel von 0,08 ${ }^{\mathrm{mm}}$ Durchmesser dar, welche mit der unteren, ein wenig abgeplatteten Fläche (Basis) auf der gangliösen Anschwellung (f) des Ringnerven, wie auf einem dicken kurzen Stiele 
aufsitzt. Die sehr dünne, doeh bei starker Verğrösserung doppelt contourirte Wand des Randblischens wirl von einer homogenen Membran gebildet, und ist innen von einem einfachen platten Pflasterepithel ausgekleidet. Der Innenraum des Bläschens wird von einer homogenen hyalinen Masse ausgefüllt, welche eine wässrige Fliissigkeit zu sein scheint. In diese ragt von oben, von der oberen freien Wollbung des Blïschens, ein hier mittelst eines kurzen breiten Stieles angeheftetes helles kugelig̨es Körperchen (Fig. 22, 23 s) hinein, dessen Durchmesser halb so gross, als der des unschliessenden Randbliischens ist, und welches einen oder mehrere kleine dunkle concentrisch geschichtete Concretionen (x) umschliesst.

Die genannten Theile sind von denjenigen Forschern, denen wir bisher die eingehendsten Beobachtungen über Geryoniclen verdanken, insbesondere von Gegenbacr, Leuckart, Fritz Müller gesehen und in verschiedener Weise gedeutet worden. Gegenüher der allgemeinen Aehnlichkeit, welche diese mit Flüssigkeit erfüllten und eine Concretion umschliessenden Bläschen mit den einfachen Gehörorganen der anderen niederen Thiere (Mollusken, Würmer ete.) zeigen, hebt schon Gegexbacr ${ }^{1}$ ) hervor, dass die Concretionen in den Randbläschen der Geryoniden, wie der anderen craspedoten Medusen, bewegungslos seien, und »dass die Concretion nicht frei in den Bläschen liegt, sondern durch einen kurzen Stiel mit der Wandung derselben verbunden ist, ja dass von diesem Sticle aus noch eine sehr feine Membran über die ganze Concretion sich hinwegzieht, und sie somil vollständig gegen das Lumen des Bläschens hin umschliesst. Bei wiederholtem Nachforschen sicht man dann zuweilen eine noch viel dickere Unhüillung der Concretion." Was die Deutung der Randbliaschen betrifft, so ist Gegexbacr geneigt, sie für » Sinnesorgane «, jedoch nicht bestimmt fuir "Gehörorgane « zu halten, da den im Bläschen eingeschlossenen Concretionen die freie Beweglichkeit abgeht, die sich sonst bei den analogen Otolithen niederer Thiere allgemein findet. Leuckart dagegen deutete die Randbläschen seiner Geryonia exigua (unserer Liriope ligurina), mit Bestimmtheit als "Gehörkapseln “ und beschreibt dieselben (I. c. p. 6, Taf. 1, Fig. 4) folgendermassen: "Die Gehörkapsel misst etwa 1/25"' und stellt cin sphïrisches Blischen dar, dessen hintere Flache etwas abgeplattet ist und von der Strömung des Ringgefiisses bespiilt wird. Die vordere Wand ist nicht unbetrachulich verdickt und trägt cin aweites kleineres Blibschen $\left(1 / 60^{\prime \prime \prime}\right)$, das in die Kapsel hinein-

1) C. Gegexbavk, Bemerkungen Wher die Randkörper der Medusen. Müllers Archiv 1836 p. 234 ; Taf. I.I, lïg. 3-5. 
hänğt. Dieses innere Bläschen enthält die Otolithen, einen grösseren Hauptotolithen ("/100 $\left.{ }^{\prime \prime \prime}\right)$ von sphärischer Gestalt und 2 hleinere Nebenotolithen, die demselben anliegen, so dass diese Gehörsteine ganz dasselbe Aussehen haben, wie die des umpaaren Gehörorgans von Monocelis unter den Tubbllarien.« Aehnlich beschreibt endlich auch Furz MüLten die Randbläschen von Liviope catharinensis (1. c. p. 31:; Taf. XI, Fig. 9-11): „Die rundlichen Blasen haben etwa $0,03 \mathrm{~mm}$ Durchmesser und zeigen cine doppelte Contour; am oberen Rande entfernt sich die innere ron der äusseren, eine Art breiten kurzen Sticl bildend, auf dem rine gelbliche Kugel von $0,02 \mathrm{~mm}$ Durchmesser aufsitzt. Diese, dem Stiel gegenüber leicht ausgehöhlt, umfasst hier cine kleinere, stark lichtbrechende Kugel. Haufiger bietet sich das Randblaischen dem Auge so dar, dass man die grössere Kugel als Haltmond der kleineren sich ansehliessend sieht, seltener so, dass sie als concentrische Hülle derselben erseheint. « Frıtz Mülzen theilt die Auffassung von AGassiz und erklirt die Randhlaschen der craspedoten Medusen "als Auge, die kugchige Concretion als Linse, dic grössere Kugel, in welehe diese eingebeltet ist, als $\mathrm{Seh} n$ erven«.

Wie man sieht, stimmen die 3 genannten Forscher in der anatomischen Beschreibung der Randblischen der Geryoniclen iiberein, wïhrend sie in der physiologisehen Deutung derselben weit auscinander gehen. Doch sind sowohl diesen drei, als auch allen anderen Beobachtern, die noch die Randbläschen von Geryoniden untersucht haben, mehrere höehst wesentliche anatomische Verhältuisse im Innern der Randblisehen entgangen, welche mir fiir ihre Deutung als Sinnesorgane von dem grössten Gewicht zu sein scheinen. Ich fand diese merkwürdigen Eigenthümlichkeiten der feineren Structur zuerst an den verhätnissmässig sehr grossen Randblischen von Carmarina hastata auf, bei welchen ich dieselben unten ausfibrlich besehreiben werde. Erst nachher konnte ich das Wesentliche derselben auch in den viel kleineren Randblaschen von Glossocodon eurybia wiederfinden, olnwolıl die geringe Grösse und vollkommene Durchsichtigkeit der Theile hier die Erkenntmiss sehr ersehwert. Die bezigglichen Structurverhältnisse, die bei den 4 radialen und den \& interradialen Randblischen ganz gleich sind ${ }^{\prime}$ ), bestehen kurz in Folgendem (Fig. \&2 ein Randblischen, hall, von aussen, hall, von der Seite, Fig. 23 ein Randbläschen, hall) von aussen, halb von oben gesehen).

1) Bei Liriope scutigera giebt Mc Crady (1. c. p. 208) an, dass die radialen und die interradialen Rambläschen verschieden seien, die ersteren doppelt, die lelzteren einfach. An der Basis jedes Radialtentakels befände sich danach na double 
Innen an der Basis des Randbliischens, wo dasselbe dem Ganglion (f) des Nervenringes aufsitzt, befindet sich ein flaches, wahrscheinlich mil dem letzteren in unmittelbarem Zusammenhange stehendes Polster (w) von länglich runder Form, zusammengesetzt aus rundlichen und spindelförmigen sehr blassen und zarten Zellen. Ich halte dasselbe für eine im Innern des Bliischens gelegene und unmittelbar mit dem ausserhalb darunter liegenden Nervenknoten verbundene Anläufung von Nervenzellen und bezeichne sie als Basalganglion (w). Auf beiden Seiten, rechts und links, (wenn man das Randblisschen en face, von innen oder von aussen betrachtet) verlängert sich das länglichrunde oder spindelförmige Nervenpolster in einen sehr platten, zarten und blassen, aber ziemlich breiten und deutlich (obwohl sehr fein) längsstreifigen bandformigen Strang, den ich für den $\mathrm{S}$ in nesnerven halte $\left(\mathrm{n}_{1}\right)$. Die beiden einander gegenüberstehenden Sinnesnerven laufen wie 2 halbkreisförmig gekrümmte Bügel, gleich den beiden Hälften eines Meridiankreises, an den beiden Seiten jedes Randbliischens, seiner lnnenwand eng anliegend, empor, um sich an dem oberen, der Basis entgegengesetzten Pole wieder in eigenthümlicher Weise zu vereinigen $\left(\mathrm{n}_{\text {,. }}\right)$. Hier nämlich scheinen sich die feinen Fäserchen, welche die beiden Nerrenbiigel zusammensetzen, zu durchkreuzen und zu einem Strange zu verflechten, der alshald in das kugelige, die Otolithenconcretion umschliessencle Körperchen eintritt, welches er mit der Bläschenwand verbindet und als dessen Stiel er erscheint. Dieses gewöhnlich kugelige, bisweilen auch unregelmässig rundliche Körperchen (Fig. 49-51), welches von Gegexbatr als „Lmhüllung der Concretion ", von Lecckart als "zweiles, kleines, inneres Bläschen«, von Fritz Müller als » Sehnerv ( bezeichnet ist, lıalte ich für einen zweiten inneren Nervenknoten, welchen ich kurzweg das S inn e s g a n gli on (s) nennen will. Es zeiggt sich dasselbe nämlich bei starker Vergrösserung als eine kugelige, seltener unregelnässig runde Kapsel von $0,04 \mathrm{~mm}$ Durchmesser, welche in einer zwar zarten, aber doppelt contourirten membranösen Umhüllung eine aus dichtgedrüingten kleinen Zellen zusammengesetzte Masse umschliesst. Diese Ganglienzellen sind schr zart und blass, aher nach Zusatz von Essigsäure nchst ihren Kern

capsule, consisting of two cysts, one above the olher, and connected by an intermediate (lubular?) thread apparently a continuation of the membrane of the cysts." Ich glaube diese auffallende Angabe einfach dadureh erkliren zu können, dass ich das untere der beiden radialen iber einander liegenden Blischen fur das (junge) Randblaselien halte, das obere dagegen für das Rudiment des radialen Nebentenlakels, und das die beiden Bläschen verbindende "mbermediate lubular thread " für die centripetale Mantelspange. 
deutlich zu erkennen. Mitten in diesen Zellenhaufen ist der sogenannte "Otolith « oder die » Linse « eingebettet, welche durch ihr starkes Lichtbrechungsvermögen am meisten von allen Inhaltstheilen des Bläschens in die Augen springt. Rings um dieselbe scheinen sich zwischen den umlagernden Zellen die Enden der gekreuzten Nervenfasern auszubreiten. Bei jüngeren Individuen, nicht selten auch bei erwachsenen (Fig. 49-51) sind statt einer einzigen solchen Concretion mehrere beisammen vorhanden, und die Entwicklungsgesehichte zeigt, dass bei den Larven dies die Regel ist und dass die grossen durch Verschmelzung mehrerer kleinerer entstehen (vergl. Fig. 44-48). Die Form dieser Concretionen ist bei Glossocodon ziemlich unregelmässig rundlich, oft fast höckerig. Gewöhnlich ist eine grössere birnförmige Concretion vorhanden, welche an einer Seite oder Ecke eine kleine Ilöhlung zeigt, in der meistens ein zweites kleineres Körnchen oder Steinchen liegt. Nicht selten umfasst dieses dann noch ein drittes. Bisweilen sind 2 grössere und daneben noch mehrere kleinere Concretionen vorhanden. Dann ist die rundliche Form des Sinnesganglion (s) auch sehr unregelmässig, fast zweilappig eingeschnürt (Fig. 49- 54). Die Concretionen sind sehr stark lichtbrechend, undeutlich concentrisch geschichtet und bestehen aus einer organisehen, mit phosphorsaurem Kalk (?) verbundenen Grundlage.

Was die Deutung der Randkörperchen nach Feststellung dieses complicirteren Baues anlangt, so wird zunächst ihre allgemein gültige Stellung als Sinnesorgane dadurch nur befestigt. Was aber die speciellere Feststellung der Sinnesqualitit betrifft, so scheint mir diese dadurch nach keiner Richtung hin bestimmter bezeichnet zu werden. Im Gegentheil glaube ich, dass damit nur die wesentliche Differenz dieser Randbläschen von anderen ahnlichen Sinnesorganen niederer Thiere, z. B. von den meist zunächst damit verglichenen Gehörbläschen der Würmer und Mollusken, noch mehr bestätigt und ausdrücklich hervorgehoben wird. Da das concentrisch geschichtete Concrement, welches gewöhnlich als Otolith gedeutet wird, ganz in der zelligen, von mir als Sinnesganglion gedeuteten Blase eingeschlossen ist, und ausserdem die Nervenfasern rings um dasselbe innerhalb jener Zellenmasse auszustrahlen scheinen, so springt die auffallende Verschiedenheit dieses Organs von den mit frei beweglichen Otolithen versehenen Gehörblïschen anderer niederer Thiere sofort in die Augen. Weder die morphologischen noch die physikalischen Verhältnisse jenes Apparates lassen eine directe Vergleichung mit diesen letzteren zu. Noch weniger freilich als die von den meisten Autoren angenommene Deutung der Randbläschen unserer Medusen als Gehörorgane kann die von Agassiz und Fritz 
MüldLer vertretene Ansicht befriedigen, dass dieselben Augen seien. Abgeschen von dem völligen Mangel jeden Pigmentes, der allerdings auch bei unzweifellsaften Augen einiger niederer Thiere bisweilen vorkommt, ist jedenfalls die Deutung der Coneretion als »Linse ganz unhaltbar. Bei Gilossocodon eurybia wenigstens hat dieses Concrement keineswegs eine regelmässig abgerundete, sondern eine ziemlich unregelmaissige, bei den verschiedenen Individuen selır verschiedene For'm. Bald ist es kugelig, bald ellipsoid, bald uneben und höckerig, sehr häufig birnförmig oder fast kegelförmig. Meistens ist an der einen (und zwar gewöhnlich an der (ler Eintrittsstelle des Nerven zugewendeten) Scite eine zweite, viel kleinere, unregelmässige Concretion mit der grösseren verbunden, und zwar gewöhnlich gleichsam in ein Grübchen au der letzteren Oberfläehe halb versenkı. Anderemale ist dies Grübehen allein leer vorhanden. Bisweilen finden sich neben der grossen Concretion auch $2-3$, selten noch mehrere, kleinere, welche ehenfalls der Oberflïche der grösseren anliegen. Solche hat auch Levckant bei Liriope ligurina gesehen und als "Nebenotolithen " beschrieben. Endlich ist noch die Lage der Concretion weehselnd, bald ganz im Innern des Sinnesganglion eingeschlossen, hald an einer Stelle der Innenfliiche seiner Wand anliegend, gewöhnlich der unteren Wand, welehe der Eintrittsstelle der Nerven entgegengesetzt ist. Alle diese Verhältnisse sind mit der Deutung der Concretion als "Linse « und des sie umsehliessenden Sinnesganglion als » Sehnerv « durchaus unvereinbar. Auch die Lage der Randbläschen gerade hinter den Mantelspangen, welche sie von aussen her verdecken (Fig. 40) wiirde zu ihrer Auffassung als Augen schlecht passen.

Die Deutung der Sinnesorgane niederer Thiere gehört ohne Zweifel zu den sehwierigsten Objecten der vergleichenden Physiologie und ist der grössten Unsicherheil unterworfen. Wir sind gewohnt, die von den Wirbelthieren gewomnenen Anschaumgen ohne Weiteres auch auf die wirbellosen Thiere der verschiedenen Kreise zu übertragen und bei diesen analoge Sinnesempfindungen anzunehmen, als wir sellsst besitzen. Und doch ist es viel wahrscheinlicher, dass hier wesentlich andere Sinnesempfindungen zu Stande kommen, von deren eigentlicher Qualität wir uns keine bestimnte Vorstellung machen können; wie es z. B. sehr wahrseheinlich ist, dass die Limpfindung der Lichtund Schallwellen, fiir welehe bei den höheren Thieren versehiedene Organe differenzirt sind, bei den niederen an ein und dasselbe Sinnesorgan, natürlich in unvollkommener Ausbildung, gebunden vorkommen. Als ein solehes "gemischtes Simnesorgan", über dessen eigentliche Function wir uns natürlich vorläufig jeder bestimmteren Ver- 
muthung enthalten müssen, möchte ich auch die Randkörper eines grossen Theiles der Mfedusen, und namentlich die sogenannten » Randbläschen« bei den Geryoniden, Trachynemiden etc. betrachtet wissen.

Dass ein ähnlicher Bau der Randbläschen, wie ich ihn hier von den Geryoniden beschrieben, auch bei anderen craspedoten Medusen verbreitet ist, zeigen mir Beobachtungen an einzelnen Repr:isentanten anderer Familion, wie namentlich an mehreren bei Nizza beobachteten Trachynemiden, Aeginiden und Eucopiden. Doch scheint bei diesen meistens der Nerv, welcher dic Wand des Randblisschens durchbohrt, als ein einfacher ungetheilter Strang, gewöhnlich als ein kurzer Cylinder, in das kugelige oder cilörmige, mit wenigen Zellen erfüllte Sinnesganglion einzutreten, welches die Concretion umschliesst. So finde ich es z. B. sehr deutlich bei Rhopalonema umbulicatum (Calyptra umbilicata), wo das eiförmige Sinnesganglion frei in die Mitle des geräumigen Randblïschens vorragt und auf dem die Bläschenwand von unten her durchbohrenden Sinnesnerven wie auf einem Stiele aufsitzt. Die Concretion ist in dem oberen, der Nerveneintrittsstelle entgegengesetzten Ende des Ganglion wandständig eingeschlossen. Aehnlich bildet auch V. Hexsen gelegentlich in seinen ausgezeichneten Studien über das Gehörorgan der Decapoden die Randblisschen einer nicht näher bestimmten Eucope ab ${ }^{1}$ ) und bemerkt (lazu: )Hier fand sich in den zahlreichen Otolithensiicken an der centralen Seite eine verdickte Stelle, als verdickte Epithelschicht zu deuten. Von hier aus sah man sehr feine Haare nach einem Steine zu strahlen, der in der Mitte des Sackes lag. Der Stcin war abcr in einer inneren Blase, die er nicht ganz ausfültte, und an die eine Seite dieser Blase gingen auch wieder Haare heran. Die Hiäarchen waren sehr blass und wenig lichtbrechend. "Wenn ich dic Abbildung (1. c. Fig. 24 B) mit jenen oben erwihnten Bildern der Randblïschen mehrerer von mir in Nizza beobachteten Eucopiden (namentlich Phialidium viridicans und ferrugineum) und Trachynemiden (Rhopalonema velatum und umbilicatum) vergleiche, so finde ich zwischen beiden die grösste Aehnlichkeit und zweifle nicht, dass dic von Hexsex als » Iäärchen " aufgefassten feinen blassen Linien die Fasern des Sinnosnerven sind und die beiden äussersten »Häirchen « die Contouren des Nerven, der wie cin Stiel das die Concretion unschliessende Sinnesganglion (die sinnere Blase (t) tigt.

Dic Theilung des in das Randblaischen eingetretenen Sinnesnerven in 2 an entgegengesetzten Seiten des Randbläschens aufsteigende und sich oben vor dem Eintritt in das Sinnesganglion wiecler vereinigende

1) Zeitschr. für wissenschafll. Zool. XIlI, 1863, p. 355, Anm. 
Aeste, oder, wenn man lieber will, die Existenz eines der Innenwand des Randblischens anliegenden Nervenringes, gebildet aus 2 halbkreisförmigen Nervenbïgeln, die von entgegengesetzten Seiten des Basalganglion unten ausgehen und oben sich mit ihren Fasern durchkreuzen, - diese höchst merkwürdige Bildung scheint den Geryoniden eigenthümlich zu sein, und ist von mir bei keiner andern Meduse wicder gesehen worden.

Dass die Sinnesorgane im Allgemeinen mehr als andere Körpertheile einer weitgehenden Differenzirung und Abänderung durch Anpassung unterworfen sind, und auch bei sonst nächstverwandten Thieren bedeutende Modificationen erleiden können, ist eine wichtige und weitverbreitete Erscheinung. Unsere Geryoniden liefern davon ein neues auffallendes Beispiel. Wie im IX. und X. Abschnitl dieser Untersuchungen gezeigt werden wird, ist die Familic der Aeginiden mit derjenigen der Geryoniden durch unmittelbare genealogische Verwandtschaft auf das Engste verbunden: Cunina rhododactyla entsteht als Knospe auf der Oberflächeder Zunge in der Magenhöhle vo $n$ Carmarina hastata. Diese beiden anscheinend so sehr verschiedenen Medusen gehören demnach als verschicdene Generationen dem Formenkreise einer einzigen Species an. Ihre Uebereinstimmung in inneren Baue ist weit grösser, als es die sehr versehiedene äussere Körperform errathen lïsst. Mehr aber als alle anderen Körpertheile sind bei beiden Medusenformen die Sinnesbläschen in Zahl, Lagerung, Grösse, Form und feinerem Bau verschieden.

\section{Metamorphose von Glossocodon eurybia (liriope eurybia).}

\section{(Hierzu Taf. III.)}

Dic Fortpflanzungs- und Entwickelungsverhältnisse der Geryoniden waren vor weniger als 10 Jahren noch völlig unbekannt. Man hiclt sie für einfacher als diejenigen der meisten andern Medusenfamilien. Doch lernte man, nachdem zuerst Levckart 1856 an seiner Geryonic exigua (Litiope ligurina) die Existenz eines Larvenzustandes nachgewiesen hatte, die Jetamorphose der Larven einer vierzïhligen Geryonide genau kennen dureh die treflliche Darstellung, welche fritz Müller $18: 9$ von den "Formwandelungen der Liriope catharinensis « lieferte. Die Abkunft dieser Larven aus dem befruchteten Ei konnte nicht festgestellt werden; doch zweifelte man nicht daran, da man cine ungeschlechtliche Vermehrungsweise niemals bei den Geryoniden beobachtet 
hatte. Erst 1861 veröffentlichte Kronn gelegentlich eine kurze Notiz, nach welcher er bereits im Jahre 1843 eine Geryonia beobachtet hatte, die, obwohl geschlechtsreif, im Magen eine aus dichtgedrängten Knospen zusammengesetzte Aehre trug. Mir fiel cliese in einer Anmerkung versteckte wichtige Notiz erst in die Hande, als bereits die ersten drei Abschnitte der vorliegenden Monographie gedruckt waren, weshalb ich die im Ende des zweiten Abschnittes enthaltene Angabe, dass noch niemals ungeschlechtliche Fortpflanzung bei den Geryoniden beobachtet worden sei, zu entschuldigen und zu verbessern bitte. Unmittelbar nachher hatte ich selbst Gelegenheit mich auf das Bestimmteste von der Richtigkeil der Krous'sehen Angabe zu überzeugen, indem ich auch im Magen mehrerer Individuen meiner Carmarina hastata eine dichte Knospenähre aus dem Zungenkegel hervorsprossend vorfand. Nur sind diese Knospen nicht, wie Krons glaubte, die Embryonen der Carmarinide, sondern einer ganz davon verschiedenen achtstrahligen Meduse, wie im VIII. Abschnitte gezeigt werden wird. Es scheinen demnach die Fortpllanzungserscheinungen der Geryoniden weit verwickelter zu sein, als man bisher annahm.

Bei Glossocodon eurybia habe ich niemals einen ihnlichen Knospungsvorgang bemerkt. Namentlich zeigte von mehreren hunder't untersuchten Individuen kein einziges in der Magenhöhle eine ähnliche Knospenähre wie die Carmarina, obwohl der Zungenkegel bei beiden gleich entwickelt ist. Die Möglichkeit einer : :hnlichen ungeschlechtlichen Fortpflanzung und eines damit verbundenen Generationswechsels ist jedoch dadurch keineswegs ausgeschlossen, vielmelor aus anderen Gründen wahrscheinlich, wie im X. Abschnitt gezeigt werden wird. Es muss deshalb noch zweifethaft bleiben, ob die Larven, deren Metamorphose in Glossocodon ich durch alle Stadien hindurch verfolgte, ungeschlechtlichen Ursprungs sind oder aus den befruchteten Eiern dieses Thieres hervorgegangen. Künstliche Befruchtungsversuche, die ich anstellte, blieben leider sämmtlich ohne Erfolg. Alle Larven, die ich beobachtete, habe ich frei schwimmend pelagisch gefischt.

Die Metamorphose der Larve von Glossocodon eurybia erfolgt, geringe Abweichungen ausgenommen, in derselben Weise wie bei der von Fritz Müller beobachteten Liviope catharinensis, so dass ich die Darstellung dieses trefflichen Forschers nur in Bezug auf das feinere Detail der Vorgänge und insbesondere in Bezug auf den feineren Bau der Larven wesentlich zu erginzen vermag. Die jüngsten Larven, welche ich fing (Fig. 26-28), stellten kleine hyaline Gallertkugeln von 0,3 bis $0,4 \mathrm{~mm}$ dar, deren Oberfliche fein punctirt erschien. Die Puncte stellen sich bei stärkerer Vergrösserung als die regelmässig ver- 
theilten Kerne des Epithels dar, welches als cinfache Zellenschicht die Oberflïche der homogenen Gallerthugel uberzicht, dessen hüllenlose Zellen sich aber noch nicht von einander sondern lassen, sondern zu einem Coe nepithel verschmolzen sind (vergl. den letzten Abschnitt). Da von Tentakeln, Randbläschen oder anderen Anhïingen, sowie ron Theilen des Gastrovascularsystemes noch keine Spur zu bemerken ist, so besehränkt sich die cinzige an diesen vollkommen durehsichtigen und wasserklaren Gallertkügelchen wahrnehmbare Organisation auf die erste Anlage der Schirmhöhle und des Velum. Die Schirmhöhle, welche als eine kleine grubenförmige Vertiefung an einer Stelle der Oberflïche auftrit, fand ich bei verschiedenen Embryonen, deren Kugel den gleichen Durchmesser von 0,3 bis $0,4^{\mathrm{mm}}$ zeigte, von ziemlich verschiedener Ausdehnung; bald erschien sie nur als ein ganz flaches Grübchen, wie eine napfförmige Vertiefung auf einem bestimmten kleinen runden Felde der Kugeloberfläche; hald drang sie tiefer in deren Gallertmasse ein und dehnte sich dabei halbkugelig oder fast kugelig aus. Doch erreichte auch dann ihre Ilöhe höchstens 1/3 der Schirmhöhe. Das kreisrunde Grübchen wird zu einer kammerartigen Ilöhle alogeschlossen dureh das V el um oder die Randınemluran (v), welehes als eine sehr zarte häutige Platte wie ein Diaphragma uber die Grubenöfnung weggespannt ist, so dass es die unterbrochene Kugelform des Gallerthörpers wieder herstellt. Die Epithelzellen sowohl, welche die Innenfläche der kleinen Schirmhöhle auskleiden, als diejenigen, welche das Velum zusammensetzen, sind ziemlich dickwandige Cylinderzellen, dicker, körniger und undurehsichtiger als das hlare, zarte Pilasterepithel der Schirmoberfliche. Letzteres repräsentirt die Zellenschicht des Ectoderms, während die seharf davon geschiedenen Epithelien des Velum und der Schirmhöhle das Entodernı zusanmmensetzen. Aus diesem, dem Entoderm, scheinen alle die verschiedenen Biłdungen hervorzugehen, die wir nun in der Schirmhöhle und von dem Velum aus sich entwickeln sehen, während das Ectoderm auf die :inssere Oberfliichenbedeckung des Gallertschirmes beschrïinkt bleibt. Von dem Eetoderm wird wahrscheinlich auch vorzugsweise oder allein die hyaline, vollkommen structurlose Gallerte abgeschieden, welehe beide Zellschichten voneinander trennt und die IIauptmasse des kugeligen Embryonalkörpers bildet.

Die jüngsten Embryonen, welche Fratz Mülden von Liriope calharinensis beobachtete, sind den oben besehriebenen sehr ähnlich, " von kleinzelligem Gelïge, und zeigen cine geschlossene Ibüle, die etwa $1 / 3$ des Durchmessers einnimmt und excentrisch dicht unter der Oberfliche der Kuged gelagert ist. An dieser Stelle zeigt letztere eine die 
innere Ilöhle etwas überragende und üher das Niveau der Kugel unbedeutend sich erhebende minder durehsichtige Platte. Der nächste Fortsehritt ist die Eröffnung der inneren Ilöhle durch Bildung eines Lochs in dieser Platte, die sich bald dureh ihre Contractionen als Velum zu erkennen giebt. « Bei den ähnliehen kugeligen Embryonen von Liriope eurybia habe ich mich ron der wirklichen Praeexistenz einer gesehlossenen Schirmhöhle niemals mit Sicherheit überzeugen können. Ich sah nimlich mehrmals, dass Embryonen, deren Velumplatte bereits die mittlere Eingangsöflinung in die kleine Schirmhöhle deutlich zeigte (Fig. 27 und 28), kurze Zeit nachher eine völlig geschłossene Höhle, ohne Spur einer Oefinung im Velum zeigten (Fig. 26). Es hatie sich das Velum langsam so vollständig zusammengezogen, dass seine Oeffnung völlig verstrichen war. Durch wiederholte Untersuchung eines und desselben Individuums zu verschiedenen Zeiten iberzeugte ich mich, dass die Thierchen abwechsehnd die Höhle durch Relaxation des Velum weit öffnen und dann wieder durch ganz vollständige $\mathrm{Zu}-$ sammenziehung desselben so verschliessen können, dass keine Spur von der völlig verstrichenen Eingangsöffuung mehr zu erkennen ist. Es ist mir daher zweifelhaft geblieben, ob die Schirmhöhle im Inneren des kugeligen Embryonalkörpers durch exeentrische Aushöhlung und nachherigen Durchbruch der einschliessenden Platte (V'elum) entsteht, oder viehmehr durch Exeavation eines Grübehens von der äusseren Oberfliche der Kugẹl aus, in welehem Falle das Velum dureh Verdickung und eentripetales Wachsthum des kreisförmigen Grubenrandes entstehen würde. Im erstern Falle würde der Durchbruch des Velum dieses erste Entwichlungsstadium in zwei Absehnitte trennen, den ersten mit geschlossener, den zwciten mit geöfineter Schirmhöhle.

Das zweite Entwicklungsstadium (Fig. 29 und 30 ) von Glossocodon eurybia wird dadurch charakterisirt, dass in Umkreise des Velum die ersten Anhänge, näimlich 4. gleichweit voneinander entfernte kleine Wärzchen hervorsprossen, die rasch zu kurzen Gylindern mit einem endständigen Nesselknopfe und einer darauf gesetzten Geissel adswachsen (Fig. 29 und $30 \mathrm{st}$ ). Wir bezeichnen diese primordialen Anbänge, welche in den Ebenen der später auftretenden Radialcanäle hervorkeimen, als radiale $\mathrm{Nebententakeln}$ oder embryonale Radialtentakeln (st). Dieselben treten entweder alle 4. zusammen gleichzeitig auf, oder, was der häufigere Fall zu sein scheint, es treten bloss 2, in einer Meridianebene cinander gegenüberstehende Tentakeln auf und zwischen diesen entstehen erst nachträglich die beiden andern: welche in der zweiten, auf jener ersten senkrechten Merilianebene liegen. Dasselbe Gesetz, das paarweise Erscheinen der in 
Vierzahl vorhandenen Theile, wiederholt sich nit bemerkenswerther Constanz auch bei den folgenden später sich entwickelnden Anlaängen, so dass von je \& zusammengehörigen Tentakeln, Randbläschen u. s. w. zuerst nur ein Paar gegenständige erscheint und erst nachlser zwischen jene sich das andere Paar einschaltet.

In der Structur und in den Bewegungserscheinungen gleichen die radialen Nebententakeln (Fig. 38 st und Fig. 39) wesentlich den demnächst auftretenden interradialen Tentakeln (I) und unterseheiden sich dagegen sehr von den zuletzt erscheinenden radialen Haupttentakeln ( $t$ ). Die letzteren sind hohl und sehr beweglich, die beiden ersteren solid, starr und sehr wenig beweglich. Jeder radiale Nebententakel (Fig. 39) besteht aus 3 Stüeken, nämlich I. dem dicken eylindrischen, unteren Hauptstück, II. dem mittleren kugeligen Nesselknopf, und III. dem dünnen cylindrischen, oberen Geisselanhang. Der letztere ( $\mathrm{f}$ ) ist anfangs fast eben so lang, später aber kaum lialb so lang, oder selbst mehrmals kürzer, als das $3-$ bis 4 mal so dicke basale Ilauptstick. Er ist aus sehr kleinen polyedrischen Zellen zusammengesetzt und läuft bald nach der Spitze geisselartig verdünnt aus, bald endigt er dort in eine kolbenförmige Anselwwellung, welche an einer Seite ganz oberfliichlich eine geringe Anzahl ( 1 bis 8) grössere, stark lichtbrechende, durch gegenseitigen Druck polygonal abgeplattete Körperchen enthält (Fig. 39). Meistens erscheint der fatenförmige Geisselanhang mehrfach gebogen oder geschlängelt. Der dicke kugelige Nesselknopf ( $\mathrm{s} u$ ), aus dessen Mitte er hervortritt, besteht aus radialgestellten, dicht aneinander gedrïngten Nesselzellen und ist fast doppelt so dick, als das eylindrische basale Ilauptstück. Dieses hat wesentlich den Bau der interradialen Tentakeln und besteht aus einer einfachen Reihe von etwa 6 his 12 kurzeylindrisehen Zellen derjenigen Art, die wir unten als Medusenknorpel beschreiben werden ( $\mathrm{sk}$ ). Der so entstehende Cylinder ist von einer sehr dünnen Lage longitudinaler quergestreifter Muskelfasern überzogen ( $\mathrm{s}$ ) und diese wiederum von cinem ziemlich lockeren kleinzelligen Epithelials chla u che umhüllt (s e). Wie in der Structur, so gleichen auch in den Bewegungen die radialen Nebententakeln den eben so starren interradialen Tentakeln. Bald werden sie in schneller Zuckung an den Schirm hinauf- und wieder an das Velum herabgeschlagen, bald beschränkt sich ihre Bewegung auf unbedeutende, S-förmige Biegungen und auf ein allmälıliches Ileben und Senken. Bald findet man sie ganz aufgerichtet und der äussern Schirmfliche angedrückt, bald völlig nach innen geschlagen und an die Aussenfliche des Velum angelegt, bald von dem Schirmrande wie Quasten herablıängend. Sie wachsen nur sehr langsam und nur ungefilır bis 
zu, dem Zeilpuncte, wo die ersten Randblisshen sich entwickeln. Allerhöchstens erreichen sie die halbe Lïnge des Schirmradius, und gehen nach dem Auftreten der letzten Randb]iischen bald verloren, indem sie zuerst verkïmmern und dann abfallen.

Gleichzeitig mit der Entwickelung der 4 ersten Tentakeln und ihres Nesselknopfes bildet sich auch der schmale Kn orpelring, welcher das gleichartige Epithel der Schirmhöhle (Subumbrella) und des Velum voneinander abgrenzt. Die an der Grenze beider befindlichen Zellen vergrössern sich und scheiden Intercellularsubstanz ab.

Bald nach dem ersten Auftreten der radialen Nebententakeln sprossen zwischen ihmen am Aussenrande des Velum 4 andere Höckerchen hervor, welche rasch zu bedeutend längeren Anhängen, den in ter radialen Tentakeln (y) sich entwickeln. Thre Anwesenheit bezeichnet das dritte Stadium der Entwickelung (Fig. 31 bis 34 ). Sie sind ebenfalls solid, cylindrisch, anfangs fast gleich dick von der Basis bis zur abgerundeten Spitze, späterhin dagegen an der Basis etwas kolbenartig verdickt (Fig. 40). Bei der vollkommenen Durchsichtigkeit dieser wasserhellen Cylinder lässt sich ihre Struetur weit leichter als bei den radialen Iaupttentakeln ermitteln. Die Hauptmasse jedes interradialen Tentakels wird aus einer ziemlich beschränkten Anzahl von sehr grossen, wasserklaren Zellen des unten näher zu beschreibenden Medusenknorpels gebildet (Fig. $40 \mathrm{yk}$ ). Bei jüngeren Tentakeln sind deren nur 5,10 bis $1 \ddot{3}$ ron gestreckt cylindrischer Form vorhanden, welche in einer einzigen Reihe hintereinander liegen. Späterhin vermehren sich dieselben nicht allein durch Bildung von Querscheidewänden, sondern auch durch Entstehung von longitudinalen und schräg verlaufenden Zellenwänden, jedoch nur in der unteren Hïlfte des Tentakels, wodurch sich diese etwas kolbenförmig verdickt. Doch findet man auch dann auf einem Querschnitt durch die Tentakelbasis meist nur 2 , höclistens 3 bis 4 solcher Knorpelzellen nebeneinander. Diese solide Zellenaxe, welche die Form und Grösse des Tentakels bestimmt, ist ibjerzogen von einer continuirlichen einfachen Lage quergestreifter Muskelfasern (y m). Doch ist dieser cylindrische Muskelsehlauch nur sehr diinn und besonders bei lebenden Thieren sehr leicht zu übersehen, da er nur aus einer einzigen Schicht von longitudinalen Muskelfasein besteht, welche sehr regelmässig, eine neben der andern gelagert, von der Basis des Tentakels bis zu seiner Spitze verlaufen. In Fig. 40 sind dieselben nur an dem basalen Theile dargestellt. Transversale (circulare) oder schrig verlaufende Muskelfasern fehlen den interradialen Tentakeln durchaus. Die Streckung der durch Contraction aller longitudinalen Muskelfasern etwas verkürz- 
ten und verdickten Tentakeln geschieht lediglich durch die Elasticität des knorpelskelets. An den beiden Profils:indern der Tentakeln (am scheinbaren Lingsschnitt) liisst sich die sehr geringe Dicke der Muskelsehicht messen. Sie betrigt nur 0,002 mm. Sie erseheint hier als ein matt glïnzender gelblicher Streifen, welcher das Licht nur wenig ander's bricht, als der innere daran liegende Knorpel und als der äussere daran liegende Epithelial überzug ( $\mathrm{g}$ e). Dieser letztere ist an den gerade ausgestreckten Tentakeln mit erschlatfter Musculatur, welche er schr straff anliegend überzicht, schwer zu erkemmen, leichter an den stark gebogenen oder theilweise zusammengezogenen Tentakeln, wo er sich an der concaven Seite in Falten legt (Fig. 40 y e). Er besteht aus einer einzigen Lage kleiner, heller, polygonaler Pflasterzellen mit Kern. An der unteren oder inneren Seite der Tentakeln, welche aber bei den gewöhnlich aufwärts gekrummten Tentakeln nach aussen gerichtet ist, entwickeln sich in diesem Epithelialüberzuge an bestimmten Stellen Gruppen von Nesselzellen, welche eine Anzahl polsterförmig gewölbter, elliptischer Nesselballen oder Nesselpolster (y u) zusammensetzen. An den ganz jungen Interradialtentakeln, welehe eben erst als kurze, dicke Cylinder aus dem Umkreise des Velum hervorgesprosst sind, bildet sich erst nur ein einziger solcher, fast kugeliger Nesselballen an der abgerundeten Spitze. Unmittelbar neben diesem nach unten erscheint dann ein zweiter; bald folgt bei dem rasch fortschreitenden basalen Wachsthum des Tentakels ein dritter und vierter nach und schliesslich ist an den ganz entwickelten Tentakeln eine Reihe von 6 bis 8 , höchstens 10 hintereinander liegender Nesselballen zu bemerken. Je jünger dieselben sind, desto weiter sind sie voneinander entfernt, desto weniger springt ihı Polster iilser die Unterfläche des Tentakels hervor, desto geringer ist die Zahl der in ilnen zusammengestellten Nesselzellen und desto näher liegen sie der Tentakelbasis. Die jüngsten, der letzteren am nächsten stehenden Ballen sind ganz flache, nur ein paar Nesselkapseln enthaltende llügel, deren Abstand voneinander ihren eigenen Durchmesser ubertrifft. Die Basis der ilteren Interradialtentakeln, mindestens das untere Drittel, oft mehr als die Hälfte, ist ganz frei von Nesselballen.

Die interradialen Tentakeln sprossen gewöhnlich, wie die zuerst angelegten radialen Haupttentakeln, paarweise hervor (Fig. 31). Das jüngere Paar erscheint erst dann, wenn die beiden älteren gegenständigen sehon 1 oder 2 Nesselpolster gebildet haben. Diese letzteren sind daher dann auch spiiter noch eine Zeil lang daran zu erkennen, dass sie 1, seltener 2 Nesselballen fmehr zeigen als die beiden zwischen ihnen stehenden jüngeren. Später verwischt sich dieser Unterschied. Die 
Bewregungen der starien Interradialtentakeln gleichen denen der radialen Nebententakeln. Bald schnellen sie in plötzlicher Zuckung empor und werden eben so plötzlich wieder nach unten geschlagen; bald krümmen sie sich langsam und werden ganz allmählich gehoben und gesenkt. Verkürzen können sie sich nur sehr unhedeutend, so weil es die Elasticitat ihres Kinorpelskelets erlaubt. In diesen Bezichungen gleichen sie den ähnlichen starren Tentakehn der Trachynemiden und Aeginiden. Meistens werden sie vollkommen nach aufwärts gekrümmt getragen, so dass ihre untere mit Nesselballen besetzte Flïche nach aussen sieht (Fig. 33 bis $3: 3$ ).

Wenn die interradialen Tentakeln etwa 4 bis 6 Nesselpolster entwickelt haben und wenn ihre Liinge den grössten Schirmdurchmesser erreicht hat, so dass sie die Länge der radialen Nebententakeln un das Drei- oder Vierfache übertriff, so beginnt die erste Anlage des Gastrovascularsystemes sich zu zeigen. Es differenzirt sich nimlich das bis dahin aus vollkommen gleichartig aussehenden Zellen zusammengesetzte Epithel des Entoderma, welches die Schirmhöhle als Subumbrella auskleidet und das Velum überzieht, in der Weise, dass am Schirmrande, an der Grenze von Velum 'und Subumbrella, ein breiter Streif (die Anlage des Girkelcanals) erscheint, der aus grösseren und dickwandigeren Zellen zusammengesetzt isı. Gleichzeitig differenziren sich in der Flache der flach gewölbten oder hallskugeligen oder fast kugeligen Subumbrella selbst 2 eben solche breite Streifen, welche sich rechtwinklig in der Mitte der Subumbrella kreuzen und je 2 gegenständige radiale Nebententakeln paarweise verbinden. Dies sind die Anlagen der. Radialcanäle, welche, wie der sie aussen verbindende Cirkelcanal, anfangs so breit sind, dass zwischen ihnen nur \& rerhältnissmässig enge Quadrantenfelder der Subumbrella frei bleiben, welche mit einem blasseren und flacheren, aus kleineren und dünnwandigeren Zellen bestehenden Epithel bekleidet sind. In der Mitte der Schirmböhlenwölbung, wo die 4 Radialcaniile sich kreuzen, wird nun auch bald eine kleine runde Oeffnung, der $\mathrm{Il} u \mathrm{nd}$, sichthar, welcher unmittelbar in die sich aushöhlenden Canäle hineinfiihrt. Von einem eigentlichen Magen und Magenstiele ist noch keine Spur vorhanden. Der Schirm, welcher um diese Zeit meist zwischen $0,, 5$ und $0,8{ }^{\mathrm{mm}}$ Durchmesser hat, zeigt meistens noch die ursprüngliche Kugelform oder ist nur wenig abgeflacht, ebenso die relativ noch sehr kleine Schirmhöhle, deren Höhe höchıstens $1 / 4$ bis $1 / 3$ von der des Schirmes beträgt.

Der vierte Abschnitt der Entwickelung (Fig. 33 und 36) ist charakterisirt durch das A uftreten der Sinnes organe, und zwar 
der 4 interradialen $R$ andbläschen (b) i). Es erscheinen diese erst bei Larven von ungefähr 0,8 bis I bis $1,3 \mathrm{~mm}$ Durchmesser, bei denen das Gastrovascularsystem bereits angeleg̣t ist und deren 1 bis $1,3 \mathrm{~mm}$ lange interradiale Tentakeln bereits 4 bis 6 Nesselpolster entwickelt haben. Es besteht hier ein kleiner Untersehied ron Glossocodon catharimensis, dessen erste Randbläschen schon früher auftreten, nimlich schon bei Larven, deren interradiale Tentakeh erst die Länge des Schirmradius erreicht und erst 1 bis 2 Nesselknöpfe entwickelt haben (l. c. p. 317). Auch die Simnesblischen erscheinen, wie die Tentakeln, paarweise und zwar trill das erste Paar an der Basis der beiden alteren, zuerst hervorgesprossten interradialen Tentakeln auf. Zwisehen dem untersten Ende von deren Basis und dem Knorpelring der Velumperipherie, auf dem jene aufsitzen, erscheint ein helles Knöpfehen, aus Zellen zusammengesetzt (Fig. 44). Bald dehnt sich dies zu cinem kugeligen Bläschen ans, in dessen Höhlung ein zweites kugeliges, holles, zelliges Körperchen wandständig eingeschlossen ist (Fig. 45). In letzterem, der Anlage des Simnesganglion, treten dann nachlier 1, 2 bis 4, bisweilen selbst 6 bis 8 kleine, unregelmässige, dunkle, stark lichtbrechende Körperchen auf (Fig. 46), welche erst secundär zu ciner einzigen oder 2 grösseren otolithischen Concretionen verschmelzen (Fig. 48). Gleichzeitig sammelt sich eine grössere Menge von Flüssigkeit zwischen dem Sinnesganglion und der umschliessenden Blase an, und an der Wand der letzteren werden die beiden bignelfömigen Sinnesnerven sichtbar, welche von dem Anheftungspuncte des Sinnesganglion zu der gegenüberstehenden Bläschenbasis (am Knorpelring) verlaufen (Fig. 47 und 48). Gewöbnlich erst nach der vollstïndigen Aushildung des ersten gegenständigen Paares der interradialen Randblisschen erscheint das damit alternirende zweite Paar derselben, welches sich ebenso an der Anheftungsstelle des jüngeren Paares der interradialen Tentakeln entwickelt.

Die weiteren Veränderungen, welche die Larve in dieser vierten Periode während der Entwickelung der 4 ersten Sinnesbläschen aufweist, bestehen vorzuglich in der En $t$ wi ckelung des Magens und in der stärkeren Ausdehmung der Schirmlıöhle. Letztere nimmt eine halbkugelige oder noch flacher gewölhte Form an und ihre IJöhe beträgt ungefiihr die flitfte der ganzen Schirmhöhe. In ihrem Grunde erscheint der Magen als eine flache, breite, abgestulzt kegelförmige Hervorragung, gleich einem niedern Trichter mit abgeschnittener Spitze. Er entwickelt sich durch röhrenförmige Verlingerung des wulstig verdickten runden Nundsaums, der mun auch häufig schon eine deutlich viereckige form zeigt oder in contrahirtem Zustande selbst in 4 kreuzweise stehende Lappen (Falten) ausgezogen erscheint. In 
Grunde der ganz niedrigen, flachen Magenhöhle (dic sich jetzt ganz gleich derjenigen der Aequoriden und namentlich der Aeginiden verhält) ist um diese Zeit fast regelmässig cine sehr stark lich(l)rechende, fettglänzende Kugel zu bemerken, welche in einer weniger glänzenden, concentrischen Kugel (von dreimal so grossem Durelmesser) eingeschlossen ist. Ein gleiches Gebilde habe ich constant im Magrengrunde jüngerer Indivichuen von Rhopalonema umbilicatum (Calyptra umbilicata) beobachtet.

Mit der Ausdehnung der Schirmböhle ist auch ein rasches Wachsthum des Velums, sowie des anliegenden Knorpelringes am Schirmrande verbunden. Die Oeffnumg des Velums, welche den Eingang in die Schirmhöhle bildet, erweitert sich bedeutend (Fig. 36).

Endlich wird auch in diesem vierten Alsschnitt der Entwickelung die Anlage des Nervens y tems zum ersten Male deutlich sichtbar, dessen eigentliche Differenzirung allerdings vielleichı schon in eine frühere Zeit fällt, aber wegen der ausserordentlichen Feinheit dieses Gebildes sehr schwer zu constatiren ist. Auch jetzt noch während der Entwickelung der 4 exsten Randblaischen erscheint das Nervencentrum nur als ein ausserst blasser und zarter, feinstreifiger, schmaler Ring oberhalb des Knorpelringes am Schirmrande, zwischen diesem und dem Cirkelcanal. Leichter und deutlicher sind die 4 kurzen, blassen Nervenfäden zu verfolgen, welche von dem Nervenringe aus zu der Basis der 4 radialen Nebententakeln verlaufen und sich um so melu verlängern, je weiter jetzt die letzteren von ihrer anfinglichen $\Lambda$ nheftungsstelle am Schirmrande sich entfernen und an der Aussenfliiche des Schirmmantels emporsteigen. Es entstehen so in letzterer die 4. centripetalen Spangen, welche oben beschrieben sind, theils rerursacht durch die Ausdehnung der Schirmöfinumg und das Wachsthum des Schirmrandes, theils dadurch, dass die Tentakeln, indem sie sich von dem Schirmrande entfermen, die für sic bestimmte Portion von Nesselzellen, Muskelfasern und Nervenfasem in Form eines schmalen Stranges, eben jener centripetalen Spange (h), mit heraufuchmen.

Dic Larve von Glossocodon im vierten Stadium der Entwickelung hat die grösste Aehnlichkeit mit denjenigen Medusen, welche von Escuscmoltz als Eurybia exigua (1. c. p. 118) und ron Gegevbaur als Eurybiopsis anisostyla (1. c. p. 247) beschrieben worden sind. Namentlich letztere ist ohne Zweifel als die Larve von Liriope mucronatu anzusehen. Die Larven lieben es in diesem Stadium, sich häufig̣ in cigenthünlicher Weise zusammenzuzichen, wie dies schon von Fritz Mülter bei seiner Liriope catharinensis beschricben ist. "Das Velum wird fast bis zu völligem Verschlusse contrahirt und glcichzeitig die die Radiär- 
- gefiisse begleitenden Muskeln, wodurch die Schirmböhle eine vicrlappige Gestalt annimmt; die Tentakeln werden durch diese Contractronen nach innen geschlagen und schnellen dann plötzlich wieder nach aussen. « Diese plötzlichen zuckenden Bewegungen habe ich sowohl an den radialen Nebententakeln als an den interradialen nicht selten mehrere Male hintereinander walngenommen, wenn ich das bewegungslose, starre Thierchen plötzlich aus seinem Ruhezustande aufstörte. Sic stehen in eigenthümlichem Contraste zu den langsamen, pendelartigen Bewegungen und Kriummungen, deren diese star'ren, soliden Tentakeln ebenfalls fithig sind.

Die fünfte Periode der Formwandelung von Glossocodon eurybia (Fig. 3i) ist ausgezeichnet durch das parweise Erscheinen der fradialen Haupttentakeln (t), welche spatcrhin, beim erwachsenen Thiere, von allen 12 Tentakeln allein iilrig bleiben. Die Larven, bei denen man sie zuerst hervorsprossen sieht, haben einen Durchmesser von 2, 21/2 bis $3 \mathrm{~mm}$. Das elste Paar erscheint unterhalb des iilteren gegenstïndigen Paares der radialen Nebententakeln, das zweite, nit dem ersten alternirende, unterhalb des jüngeren Paares der letzteren. Bisweilen treten alle 4 fast gleichzeitig auf, andere Male aber auch das zweite Paar viel später, nachdem das erste schon eine beträchtliche Länge erreicht hat. Die radialen Haupttentakeln erscheinen zuerst unmittelbar ibler dem Kinorpel- und Nervenringe als kurze, dicke, kegelförmige Ilöckerchen (Fig. 38 t), welche eine hohle Ausstiilpung des Cirkeleanals nach aussen darstellen. Die Höhlung des letzteren setzt sich unmittelbar in das Lumen des Tentakels fort, wic die Nesselwülste des letzteren mit dem Nesselepithel des Schirmrandes in genetischen Zusammenhange stehen. Die radialen Haupttentakeln liegen nicht in derselben Meridianebene mit den, entsprechenden, itber ihnen befindlichen Nebententakeh. Ihr Ursprung liegt nämlich constant schrig neben den centripetalen Spangen, welehe von den einspringenden Winkeln des Schirmrandes zu der Basis der letzteren hinauflaufen. Ebenso liegt er später schief neben dem radialen Randbläschen, das sich an dieser Stelle entwickelt. Betrachtet man den Schirm von aussen oder von unten, so liegt dic Ausstiilpung des Ilaupttentakels aus dem Ringgefäss stets rech ts von der zugehörigen Spange und vom Randbläsehen. Die radialen Haupttentakeln wachsen ziemlich rasch, so dass sie häufig schon vor dem Auftreten der radialen Randblisshen die intermalialen, und in ausgedehntem Zustande sellost den Schirmdurchmesser, an Linge übertreffen. Das jüngere Paar bleibt of lange Zeit hedeutend kürzer als das ältere (Fig. 3i).

Wiilrend sich die radialen Hauptlentakeh so ansbilden, beginnen 
die interradialen, deren Nesselpolster an Zahl zunehmen, in gleicher Weise an der Aussenfläche des Mantels emporzusteigen, wie es vorhin von den radialen Nebententakeln beschrieben wurde. Sie bleiben also nur noch dureh eine eentripetale Mantelspange mit dem Schirmrande in Verbindung. Zugleich wïehst auch der Magen beträchtlich dureh Verlängerung seiner Wände und geht aus der flachen Kegelform in die Gestalt einer gleichweiten eylindrischen oder fast vierseitig prismatiseh abgeflachten Röhre über, welehe in der Schirmhöhle bisweilen ungefähr bis zum Niveau des Velum berabhïingend gefunden wird. Ferner werden an dem wulstig verdicklen Mundsaume des Magens erst 4, daun 8, zuletzt 16 Paare von warzigen Nesselzellengruppen sichthar (Fig. 17). Endlich erseheint um diese Zcit oft sehon im Grunde der Magenhöhle die erste Anlage des Zungenkegels als ein spitzes, conisches oder eiförmiges Ziipfehen ( $\mathrm{Fig} .42 \mathrm{z}$ ). Die Canäle des Gastrovaseularapparates werden relativ sehmailer, indem die Subumbrella zwisehen den Radialeanälen schneller als diese selbst wächst.

In dem seehsten Entwickelungsstadium gelangt die progressive Hetamorphose von Glossocodon eurybia zum Abschluss, indem nun auch noch die 4 radialen Sinnesbläsehen erseheinen und indem aus einer Verlängerung des Zungenkegels der $\mathrm{Nag} \mathrm{c} \mathrm{nstiel} \mathrm{her-}$ vorgeht. Es ist diese Verwandelung schon an Larven von 3 bis $3 \frac{1}{2} \mathrm{~mm}$ Durchmesser bemerkbar. Die 4 radialen Sinnesbliischen (b r) entwickeln sich meistens ebenso parweise, wie die interradialen, links neben den radialen Ilaupttentakeln und gerade unterhalb der radialen Nebententakeln, in einer Meridianebene mit diesen, und am unteren Ende der centripetalen Iantelspange, welche letztere mit dem Schirmrande verbindet. Das erste Paar der Randbläschen erscheint an der Basis des älteren, das zweite an der des juingeren Paares. Der Vorgang der Entwickelung ist ganz derselbe, wie bei den interradialen Randbläschen (b i).

Der II a g en s tiel oder Schirmstiel (p) entsteht nun dadurch, dass der Zungenkegel $(\mathrm{z})$, welcher bisher als ein ganz freier Kogel vom Grunde der Magenhöhle in dieselbe hineinragte, allmählich den Magengrund ganz ausfüllı, und indem er sich in einen unten conisch zugespitzten Gylinder auszieht, ringsum mit dem basalen Theile der Magenwand dergestalt verwächst, dass nur die 4 Löeher frei bleiben, durch welche die 4 Radialcanäle in die Magenhöhle münden (Fig. 42). Diese Löeher ziehen sich dann beim weiteren Wachsthume des cylindrischen Zungenkegels zu 4 Röhren aus, welche in der Oberfliiche des letzteren liegen und aus dem Magen zur Subumbrella aufsteigen. Indem hierbei gleichzeitig der mit dem Zungenkegel verwachsene Magen von dem 
Grunde der Schirmhöhle abgehoben und schliesslich aus dieser hinausgeschohen wird, bildet sich der juingere, aus dem Grunde der Sehirmhöhle inmer weiter nachwachsende Theil des Zungenkegels, in dessen Oberfläche die \& aufsteigenden Radialeanäle liegen, zum späteren Magenstiele aus. Der cylindrische Basaltheil des jungen Magensticles crscheint bei scinem raschen Wachsthume anfinglich oft dünner, als der bisweilen fast kolbenförmig angeschwollene, conisch zugespitzte, freie Theil, der als Zungenkegel in dic Yagenhöhle hineinragt (Fig. 13). Späterhin jedoch wird dieses Verháltniss umgekehrt, so dass der cylindrische Magenstiel an sciner Basis im Grunde der Schirmhöhle weit dicker, als am unteren freien Theile erscheint.

Die weileren Verïinderungen, welche in der sechsten Periode noch zu bemerken sind, erseheinen von mehr untergeordneter Art und beziehen sich hauptsächlich auf beträchtliche Verläng̣erung der radialen Haupttentakeln, sowic auf die anschnliche Abflachung des Schirmkörpers, verbunden mit Erweiterung der Schirmböhle. Hauptsächlich ist es das überwiegende Wachsthum des Schirmrandes, wodurch diese Verinderungen bewirkt werden. Dasselhe bewirkt auch die Verlängerung der Radialcanäle, welche jetzt relativ schmäler erscheinen, sowic die weitere Verlängerung der 8 centripetalen Mantelspangen, welche von den 8 einspringenden Winkeln des Schirmrandes aus in der äusseren Mantelfliche zu der Basis der 4 interradialen und der 4 radialen Nebententakeln hinaufsteigen. Dadurch werden die 8 letzteren immer weiter an der Aussenflache des Sehirmmantels heraufgedrängt, so dass sie zuletzt oft fast auf halber llöhe des Schirmes aussen aufsitzen. Die radialen Ilaupttentakeln dagegen entfernen sich nicht weiter vom Sehirmrande. Die radialen Nebententakeln gehen bereits ihrem Untergange entgegen, indem sie ihre Nesselknöpfehen verlieren. Auch die interradialen, welche mit der Ausbildung von 8 bis 10 Nesselpolstern ihre höchste Höhe der Entwickelung und cine Länge von etwa $2^{\mathrm{mm}}$ erreicht hahen, wachsen nun nicht mehr.

Glossocodon eurybia erscheint jetzt auf der Iöhe seiner morphologischen Ausbildung angelangt. Das Thierchen (meist von ungefihr $4 \mathrm{~mm}$ Durchmesser) besitzt 12 Tentakeln in 3 Kreisen, 8 Sinnesbläschen und alle anderen Theile, welche sich am erwachsenen Thiere vorfinden, mit einziger Ausnahme der Geschlechtsorgane. Auch diese beginnen in seltenen Ausnahmsfillen sehon sich zu entwickeln. Derartige geschlechtspeife Individuen mit allen 12 Tentakeln habe ich 2 oder 3 Mal beobachtet. Als ich das erste von diesen fand, war ich versucht, dasselbe fiir eine hesondere Gattung und Art der Geryonidenfamilie zu halten, bis ich mich späterhin von der grossen Variabi- 
lität der Entwickelung in dieser Familie überzeugte. Diese gestattet sehr hetrichtliche Variationen in der Aufeinanderfolge und der Zeit des Erscheinens der einzelnen Theile; so dass sich im Eimzelnen viele und bedeutende Abweichungen von dem hier gegebenen die Regel darstellenden Schema nachweisen lassen.

Die weiteren Veränderungen, welche nun noch die im sechsten Stadium der Entwickelung angelangte Larve durchläuft, bestehen nicht allein in der Entwickelung der Geschlechtsorgane, sondern auch in einer regressiven Metamorphose der Tentakeln, nach welcher man noch zwei weitere Entwickelungsstadien unterscheiden kann. Die siebente Periode der Verwandelung wïrle dureh das Verschwinden der 4 radialen Nebententakeln charakterisirt sein, welche zuerst von allen 12 Tentakeln abfallen, wie sie auch zuerst erschienen sind. Schon in den vorhergehenden Perioden hatten dieselben ein verkümmertes Aussehen angenommen, waren sehlaff und welk geworden und hatten ihren Nesselknopf verloren. Jetzt fallen dieselben an ihrer Basis ab und zwar entweder alle 4 gleichzeitig oder ein Paar nach dem andern, wahrscheinlich zuerst das altere, zuerst erschienene Paar und erst nach ihm das jüngere, damit alternirende Paar.

Ebenso würde der achte $A$ bschnitt.des Larvenlebens durch den Wegfall der 4 in teradialen Tentakeln bezeichnet sein. Diese scheinen in der Regel alle 4 zusammen gleichzeitig abzufallen; seltener heobachtete ich erwachsene Individuen, an denen nur noch die Rudimente von 2 gegenstiundigen interuadialen Tentakeln (wahrscheinlich des jüngeren Paares) vorhanden waren, während die beiden anderen, mit ihnen alternirenden (vermuthlich das altere Paar) schon abgefallen waren. Auch hei den interradialen Tentakeln scheinen, wie bei den radialen Nebententakeln, dem völligen Verschwinden derselben mehrfache Veränderungen vorherzugehen, welche eine allmähliche Rückbildung bezeichnen. Die Tentakeln werden schlaff, faltig, welk, verlieren ihren eigenthümlichen starren und vollen Habitus, und werden nicht mehr so steif aufrecht getragen. Namentlich biegt sich die erschlaffte Spitze zuerst um, wie denn uberhaupt diese regressive Metamorphose von der Spitze der interradialen Tentakeln beginnt und allmählich nach der Basis zu fortschreitet. Die abgewelkte Spitze scheint oft stückweise abzufallen, wie die abnehmende Zahl der Nesselpolster lehrt. Endlich hat die Rüekbildung auch ihre Basis ergriffen ; diese fällt cbenfalls ab, und es besitzt nun das erwachsene Individuum mur noch die 4 bleibenden radialen Haupttentakeln.

Die Entwickelung der Geschlechtsorgane beginnt in der Regel erst, wenn die 8 Larvententakeln abgestreift sind. In seltenen 
Fällen, wie schon bemerkt, erscheinen dieselben bereits im sechsten Stadium, wenn noch alle 12 Tentakeln gleichzeitig vorhanden sind. Viel häufiger ist der Fall, dass dieselben bereits in der siebenten Periode sich zu entwickeln beginnen, wenn zwar die 4 radialen Nebententakeln abgefallen, die 4 interradialen Tentakeln aher noch vorhanden sind. Doch ist auch dies immer nur als eine, wenn auch nicht seltene, Ausnahme zu betrachten, als Regel dagegen, dass die Geschlechtsreife erst nacl dem Abfalle aller 8 Larvententakeln eintritt. Die Entwickelung der Genitalien geschieht bei beiden Geschlechtern in gleicher Weise und beginnt damit, dass die 4. linẹaren, gleich breiten Radialeanäle in der Mitte ihres Verlaufes an der Subumbrella sich ein wenig erweitern oder vielmehr in der Fläche der letzteren austehnen. Diese anfangs schmal lanzettförmige Verbreiterung wird allmihlich breiter und breiter, dehnt sich auch entlang des Radialeanals aus und wird so zuletzt zu der ovalen, blattförmigen Tasche, welche das fertige Genitalorgan darstellt. An der unteren, der Schirmhöhle zugekehrten Fläche der taschenförmigen Ausbuchtungen entwickeln sich beim Männchen die Samenzellen, beim Weibehen die Eier.

\section{Inatomie von Carmarina hastata (Geryonia hastata).}

Hierzu Taf. I, IV, V.

\section{Körperform.}

Schirm (Mantel) und Schirmstiel (Magenstiel).

Die erwachsene Carmarina hastata, welche in Fig. 1, 2 und 3 in natürlicher Grösse dargestellt ist, gehört zu den grössten und ansehnlichsten craspedoten Medusen, indem der Durchmesser ihres flach gewölbten Schirmes 50 bis $60 \mathrm{~mm}$, die IIöhe desselben 30 bis $4.0 \mathrm{~mm}$ und die Länge des Schirmstieles oder Magenstieles sogar 60 bis $90^{\mathrm{mm}}$ erreicht. Der grösste Theil des hutpilzförmigen Thieres ist farblos, wasserklar und durchsichtig; nur die Genitalien unterscheiden sich durch ihr opakes, matt weissliches Aussehen, das in manchen Fällen, jedoch nicht constant und in verschiedenem Grade, auch das gesammte Gastròvascularsystem zeigt. Einige Zeit nach den Tode nimmt diese weissliche oder gelbliche Trübung zu, so dass dann der Cirkeleanal sowie die radialen und centripetalen Caniile selur deutlich hervortreten. Bei den meisten erwachsenen Thier'en dieser Art, die ich beobachtete, waren bestimmte Körpertheile röthlich gefärl)t, namentlich die reichlich 
mit Nesselzellen und mit Muskelfasern versehenen Organe, wie Mund, Magen, die 6 Muskelbander an Magenstiel, der Nesselsaum am Schirmrand, die radialen Tentakeln und in geringerem Grade bisweilen auch das Velum. Die intensivste Fäbung zeigten Magen, Nesselsaum und Tentakeln. Die Intensitit der Färbung war sehr verschieden; meist matt rosenroth, bisweilen kaum bemerkbar. Ein einzelnes Individuum zeichnete sich durch fast Iẹbhaft purpurrothe Färbung aus; andere, sonst nicht verschiedene, waren aber auch fast farblos, so dass diese oft sehr auffallende Färbung für den Speciescharakter von keinem Gewicht ist.

Die Form des Schirmes oder der Umbrella (Fig. 1 und 2) ist bald fast halbkugelig, bald aber flacher gewölbt, so dass die Höhe des Schirmes bald fast $2 / 3$, bald kaum $1 / 3$ des Durehmessers betragt. Die Dicke des Gallertmantels (1) betright bald $1 / 4$, bald fast die lliilfte der Schimhöhe. Wechsel der Manteldicke, der Schirmhöhe und Schirmwölbung scheinen in unmittelbarem Zusammenhange zu stehen und zum Theil von der aufgenommenen Nahrungsmenge abzuhängen. Zwei sehr wohlgenährte Individuen mit sehr dickem Gallertmantel und hochgewölbtem Schirme, welche ich bै Tage lang in reinem Seewasser ohne alle Nahrung bielt, hatten wihrend dieser Zeit bedeutend an Manteldicke und Schirnwölbung eingebüsst und erschienen viel flacher und dünner. Nach dem Schirmıande zu nimmt die Dicke des Gallertmantels allmählich und gleichmässig ab (Fig. I und 2). Im Zustande der stärksten Contraction, bei den heftigsten Schwimmbevegungen nimmt die eigentliche Wölbung des Schirmgipfels nur wenig $z u$, da vorzugsweise die unteren und mittleren Theile der Glocke, oft fast cylindrisch, zusammengezogen werden. Fig. 2 stellt cin Thier in diesem Momente dar, bei welchem der im höchsten Grade contrahirte Schirm sich eben wieder zu dilatiren beginnt und das erschlaffende Velum durch den mächtigen Stoss des ausgetriebenen Wassers nach unten vorgetrieben wiled.

Aus der Mitte der Unterflache des Schirmes entspringt mit breit kegelförmiger Basis der dicke, solide, cylindrische Schirm stiel oder Magenstiel (Pedunculus, Fig. 1 und 2 p), welcher 60 bis $90 \mathrm{~mm}$ lang, also eben so lang oder um die IIälfte länger als der Schirmdurchmesser ist und sich sehr allmihlich gegen den Magen hin kegelförmig verdiunnt (Fig. $99 \mathrm{p})$. In der Mitle beträgt seine Dicke gewöhnlich 5 bis $8 \mathrm{~mm}$. Wenn die in seiner Oberfläche aufsteigenden 6 Radialcanaile sehr prall gefüllt sind, erscheint er oft auf dem Querschnitt fast sechseckig. Der Raum zwischen diesen 6 Ganälen wird von 6 halb so breiten oder eben so breiten Muskelbädern eingenommen. Abgesehen 
von diesem Ucherzuge der Oberfliche besteht der Magenstiel aus derselben hyalinen, rollkommen homogenen Gallertsubstanz wie der Schirmmantel selbst, dessen Fortsetzung er ist. Die schmalen veristelten, unten im letzten Abschnitt niiher zu beschreibenden Fasern, welche bei Glossocodon diese Gallerte durchzichen, scheinen bei Carmarina noch weit zahlreicher und mehr verästelt zu scin (Fig. 88 l f). Auf Querschnitten des Magenstiels quillt die Gallertmasse oft halbkugelig oder fast kugelig vor (Fig. : 1 I).

Die Gallertmasse des Magensticls setzt sich beiCarmarina ebenso wie bei Glossocodon, unmittelbar nach seinem Eintritt in den Magen, in die $\mathrm{Zunge} \mathrm{oder} \mathrm{den}$ Zungenkegel (Fig. 2, \& und $5 \mathrm{z})$ fort, der hier im Verbältniss noch stiriker entwickelt ist als bei Glossocodon. Die Gestalt des Zungenkegels ist bei Carmarina mehr gestreckt eylindrisch und erst nach dem fein zugespitzten unteren Ende zu allmählich kegelförmig verdünnt (Fig. $4 \mathrm{z})$. Doch ist bisweilen auch die Basis ein ziemlich dicker Kegel (Fig. : $\mathrm{z}$ ), wïhrend andere Male der Magenstiel sehr plötzlich in den viel dünneren Zungenkegel zusammengezogen erscheint. Bisweilen ist die untere feine Spitze spindelförmig ange-

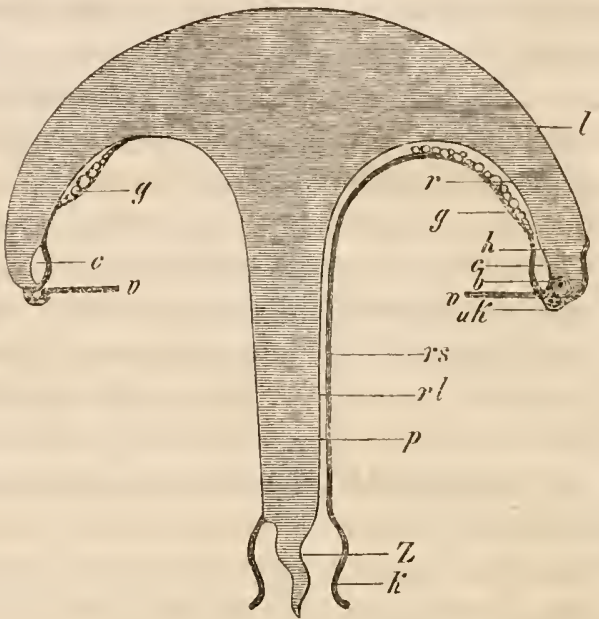

Fig. 99. Schema eines radialen Verticalschnittes dureh eine erwaclssene geschlechtsreife Carmarina hastala, rechts durch einen Radialcanal in seiner ganzen Länge, links durch den Seitenflïgel eines Genitalblattes in einer interradialen Ebene gefiihrt. b. Randblisschen. c. Ringgefass. g. Geschlechtsproducte. h. Mantelspange. k. Magen. l. Gallertmantel. p. Magenstiel. r. Radialcanal. r l. Umbrales, r's. subumbrales Epithel des Radialcanals. u k. linorpelring. v. Velum. z. Zunge. schwollen (Fig. 3). Die Gallertsubstanz des Kegels ist überzogen ron einem einschichtigen Epithel, das aus polygonalen kernhaltigen Zellen von zweierlei $\Lambda \mathrm{rt}$ zusammengesetzt ist (Fig. 6). Diese sind in der Weise auf 6 Paare alternirender bandförmiger Lïngsstreifen vertheilt, dass 6 breitere Streifen, die aus kürzeren mul breiteren Zellen bestehen, abwechseln mit 6 schmialeren Streifen, die aus lingeren und schmaileren Zellen zusammengesetzt sind. Die 12 alternirenden Bänder laufen in langgezogenen Spirallinien um die $\Lambda$ xe des Kegels (Fig. 6). Unter 
dem Epithel befindet sich eine sehr dünne Lage von longitudinalen Muskelbändern. Vermöge seiner Contractilitiat kann der Zungenkegel weit aus dem Munde hervorgestreckt werden (Fig. 5), wilhrend er auch vollstiindig in die Magenhöhle zurückgezogen werden kann. Im letzteren Falle wird er mehrfach knieförmig oder wellenförmig gebogen und zusammengelegt (Fig. 4). Bei dem ruhenden, bewegungslos in Wasser schwebenden Thiere ist dann of keine Spur von dem Zungenkegel wahrzunehmen (Fig. 1); sobald aber das Thier gereizt und in lebhafte Bewegung versetzt wird, oder wenn ein anderes vorbeischwimmendes Thier in die Nähe des Mundes kommt, streckt es den Zungenkegel weit aus der Nundöffinung hervor und bewegt ihn wie tastend hin und her (Fig. 2). In einer gewissen Lebensperiode fungirt der Zungenkegel als Knospenstock (Fig. 75), worüber unten der VIll. Absehnitt zu vergleichen ist.

\section{Gastrovascularsystem.}

Mund, Magen, Ernähungscanäle und Geschlechtsorgane.

Der Magen (k) erscheint von dem unteren Ende des Magenstieles deutlich abgesetzt, theils durch seine trübere opake Beschaffenheit und das of runzelig gefaltete Aussehen seiner Wände, theils dureh seine spindellörmig oder glockenförmig erweiterte Gestalt. Doch ist die letztere sehr wechselnd, bald mehr kegelförmig oder cylindriseh, bald mehr sechsseilig-pyramidal oder prismatisch abgeflacht. Ebenso wechselnd ist auch das Verhalten des Magens zum Munde und die Gestalt des letzteren. Der Mund (o) bildet bald bloss die trichterartig erweiterte und mit einem verdickten Saum ungebene Ausmündung der Magenhöhle, welche stärker gefaltet und gerunzelt ist als die eigentliche Magenwand (Fig. 5); bald ist die Mundhöhle als eine besondere trichterförmige Cavität durch eine enge Einschnürung von der darüber gelegenen kugeligen oder spindelförmigen Magenhöhle getrennt (Fig. 1, 2 und 4). Die Wände sowohl der Mund- als Magenhöhle sind iusserst contractil und können sich cbenso bei Aufnahme grosser Nahrungskörper enorm ausdehnen, oft um das Mehrfache ihrer ursprünglichen Durchmesser, als sie, im entgegengesetzten Falle, auf einen sehr kleinen unansehnlichen Körper sich zusammenziehen können. Die Wände bestehen aus einer sehr entwickelten ausseren longitudinalen und inneren circularen Muskelfaserschicht. Bei der geringen Durehsichtigkeit und der bedentenden Dicke der Winde ist der Verlauf der Muskelfasern auf Fliichenansichten schwer zu verfolgen, wihrend sieh auf Quersehnitten 
(Fig. 73) die innere dicke Ringfaserlage ( $\mathrm{k}$ c) von $0,00 \mathrm{3}^{\mathrm{mm}}$ scharf von der iiusseren dünnen Liingsfaserlage ( $k 1)$ von $0,002^{m m}$ absetzt. Am leichtesten lassen sich cinzelne Bündel ron Längsmuskeln isoliren. Der meist in zahlreiche grössere und kleinere Falten gelegte Mundtrichter ist von einem verdickten rötllichen Nesselsaum (Fig. $4 o^{\prime}$ und $\ddot{z} o^{\prime}$ ) umgeben, der aus schr zahlreichen warzenförmig vorspringenden Nesselpolstern zusammengesetzt ist (Fig. 89). Jedes halbkugelige Polster enthält eine Gruppe von radial gestellten Nesselzellen. Da die Contractions- und Faltungszustainde des Mundes noch mehr als dic des Magens wechseln, so ist auch die Form der Mundöffnung sehr variabel und kann auch hier, wie dies bereits bei Glossocodon nachgewiesen wurde, nicht zur systematischen Charakteristik benutzt werden. Bald erscheint die Mundöffnung sehr weit, kreisrund und fast glatt, bald einfach sechscekig, bald sternförmig in 6 oder selbst in 12 Falten gelegt, bald scheinbar in 6 lange Lappen getheilt (Fig. 74), die aber bei näherer Betrachtung sich ebenfalls als einfache Duplicaturen ergeben. Der scheinbar tief sechstheilige Mundsaum kann plötzlich wieder zu einer ganzrandigen kreisrunden Oeffnung verstrei-

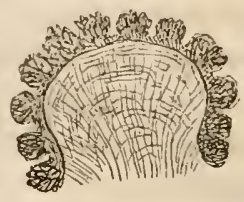

Fig. 89. Ein rundlich zusammengezogenes stiickelien des Mundsaums von Carmarina hastata mit der marginalen Reihe von Nesselknöpfen. chen. Vom Mundrande aus ziehen zum Magengrunde 6 bandförmige D rüsenblätıer, bestehend aus zahlreichen büschelförmigen Gruppen grosser einzelligger Drüsen (Fig. $73 \mathrm{~d}$ ), deren dunkelkörniger Inhalt oft schr deutlich sich absetzt ron den helleren und blasseren Zellen des geschichteten Cylinderepithels (Fig. $73 \mathrm{k} \mathrm{i}$ ), das die innere Magenfliche auskleidet. Diese 6 Magendrüsen scheinen sich ähnlich, wie die 4 Drüsenblätter im Magen von Gilossocodon zu verhalten, sind jedoch hicr noch schwieriger zu untersuchen.

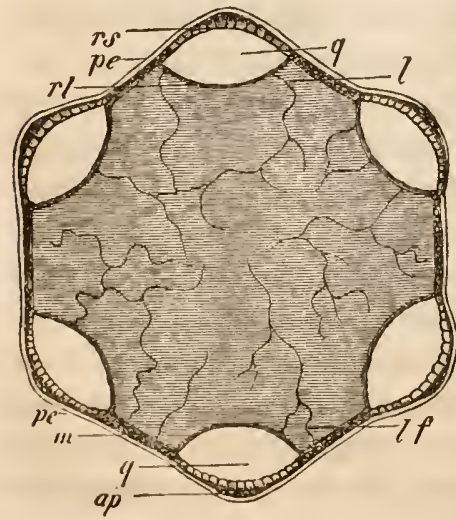

Die sechs Radialcanäle (r) entspringen im Grunde des Magenschlauches, unmittellsar über der Strictur, durch welche der Magen sich mehr oder weniger deutlich vom Magensticle absetzt, und umgehen so den

Fig. Ss. Horizontaler Querschnitt dureh den Magenstiel von Carmarina hastata. a p. Rafialnerv. I. Gallertsubstanz des Schirmstiels. 1f. Fasern in der Gallertsubstanz. m. Längsmuskeln. pe. Epithel des Magenstiels. r I. Umbrales, r s. subumbrales Epithel der aufsleigenden Radialcanäle. 
Ursprung des Zungenkegels (Fig. 4). Die 6 kreisrunden oder linglich runden, durch einen Schliessmuskel völlig gegen die Magenhöhle abschliessbaren Ursprungsöffnungen der Canäle sind bisweilen in geöflnetem Zustande sehr deutlich sichtbar (Fig. 4. i). Auf dem Querschnilte des Magenstiels (Fig. 4 und 5) erscheinen die durchschnittenen Gefässe $(q)$ meist als querelliptische Löcher (Fig. $88 q$ ); wenn sie durch reichliche Nahrungprall gefült und ausgedehnt sind, anch wohl kreisrund; anderseits ist das Lumen, wenn sie entleertund zusammengezogen sind, oft kaum wahrnehmbar; die Canäle erscheinen dann als platte Bänder. Danntritt auch in der Mittellinie der Aussenflache jedes Canals sehr dentlich die rinnenförmige Einzichung hervor, in deren Grunde der absteigende Theil des Radiahnerven verläuft (Fig. 4 a" ). Die kleinen, oft dichotom getheilten Querfalten, welche von dieser Längsrinne ausgehen, bergen vielleicht Seitenäste des Nerven, die zu den Muskeln gehen. Nach unten setzen sich die 6 Längsfalten der äusseren Canalwände auch auf die Magenoberfläche fort, sind hier ebenso mit gespaltenen Querästchen besetzt und enthalten vielleicht die Fortsetzung der 6 Radialnerven zu Magen und Mund (Fig. 4). Von ihrem Ursprunge an Magengrunde an bleiben die Radialcanäle in ihrem ganzen Verlaufe bis zum Cirkelcanale fast gleichbreit, mit Ausnahme der taschenförmigen Erweiterungen bei geschlechtsreifen Thieren. Von den 6 ebenso breiten oder nur halb so breiten röthlichen Muskelbändern (m), durch welche sie längs ihres Verlaufs auf dem Magenstiele getrennt werden, setzen sie sich durch weissliche opake Färbung meist scharf ab, auch durch den Mangel der feinen Längsstreifung, welche erstere oft schon dem unbewaffneten Auge zeigen (Fig. 1 und 2). Bei schwacher Vergrösserung markiren sie sich ausserdem durch das fein netzförmige Aussehen, das die dickwandigen grossen Zellen ihres Epithels hervorbringen (Fig. 5 r r). Auch hicr ist es, wie bei Glossocodon, nur das subumbrale, nach aussen gelegene Epithel der-Radialcanäle (Fig. $88 \mathrm{rs}$ ), welches aus diesen hohen derbwandigen Gylinderzellen besteht, während das umbrale, der Gallertsubstanz zugekehrte Epithel (Fig. 88 r l) nur aus zarten, flachen Pflasterzellen besteht. Im Grunde der Höhlung des Schirmes angclangt, biegen sich die 6 Radialcanäle auf dessen Unterfläche (Subumbrella) um, und erweitern sich nun alsbald zu den flachen taschenförmigen Geschlechtsorganen.

Die 6 Geschlechtsorgane oder G e n ital b lät ter (g) der erwachsenen Carmarina hastata zeigen eine Form, welche für cliese Art sehr charakteristisch ist (Fig. 1 bis $3 \mathrm{~g}$ ). Waihrend nämlich bei jüngeren Individuen, deren Genitalien sich eben erst entwickeln, jedes Genitalblatt die Form eines langgezogenen gleichschenkligen Dreiecks hat, dessen Höhe 
die Breite seiner nach innen gerichteten Basis um das Doppelte übertrifft und dessen Spitze bis nahe an den Cirkeleanal reicht, ziehen sich späterhin die beiden Ecken der Basis in flügelförmige, dreieckige, seitliche Anbinge aus; zugleich wiichst die Mitte der Basis mehr nach innen hinein; die beiden Seitenränder oder Schenkel des Dreiecks aber - treten in der Mitte ein wenig banchig erweitert vor, und die nach aussen gerichtete Dreiecksspitze runclet sich ab. So erhält jedes Blatt eine charakteristische Spiess- oder Spontonform, nach der ich dieser Species ihren Namen gegeben habe und welche tlieselbe leicht von den velwandten Carmariniden (auch ahgesehen von dem Zungenkegel) unterscheiden lässt (Fig. I bis $3 \mathrm{~g}$ ). Der Abstand zwischen beiden einander zugewandten Spitzen je zweier benachbarter Genitalblitter ist bei vollkommen geschlechtsreifen Thieren ungefilhr ebenso gross als der Abstand der beiden Seitenspitzen jedes einzelnen Genitalblattes. Die Spitze erreicht den Girkeleanal nicht ganz, wenigstens in der Regel. Die Form und Grösse der Genitallhlitter ist bei beiden Geschlechtern nicht verschieden, doch kann man dieselben schon mit hossem Auge oft dadurch unterscheiden, dass die Hoden des Männchens (Fig. $2 \mathrm{~g}^{\prime}$ ) feiner und gleichmässiger punctirt und dadurch stïrker weisslich getrübt erscheinen, als die gröber körnigen, in Ganzen helleren und durchsichtigeren Ovarien des Weiljchens (Fig. 1 und $3 \mathrm{~g}^{\prime \prime}$ ). Ihrer Entstehung nach sind die Genitalblïter nichts anderes als sehr flache seitliche Ausstülpungen der Radialcanïle, mit deren Lumen ihre niedrige taschenförmige Iöhlung auch bestindig in offener Commnnication bleibt. Die Geschlechtsproducte, sowohl die Samenzellon des Männchens als die Eier des Weibchens, entwickehn sich nur aus dem Epithel der unteren, subumbralen, der Schirmhöhle zugekehrten Wand dieser Taschen und gelangen, nachdem sie die circularen Muskelfasern der Subumbrella auseinander gedrïngl, unmittellar nach aussen. Das Bersten des diunnen Epithelialïberzuges der Subumbrella, welche durch die grossen reifen Eier zu einer iusserst zarten Platte ausgedehnt wird, unil der Austritt aus deren Spalt sind bisweilen direct zu beobachten. In allen diesen Beziehungen verhalten sich die Genitalien der Carmarint nicht wesenthich von denen des Glossocodon verschieden. So bilden namentlich auch hier die reifen Eier halbkugelige Vorsprünge über die Oberlliche der Subumbrella nach innen (Fig. il g) und auch hier sind die Eier meistens dergestalt gruppirt, dass in bestimmten $\Lambda$ bstinden vertheilte grössere Eier von Gruppen kleinerer hofarlig umgeben sind, und dass zwischen diesen rundlich polygonalen Eierhaufen wandungslose Ilohlriume ïbrig beiben, die mit dem in der Mitte dureh das Genitalblatt offen hindurch tretenden Radialeanal bleibend in freier Com- 
munication stehen und von ihm aus Nahrungssaft zugeführt erhalten. Die sehr kleinen kugelrunden S a m e n zellen, deren jede ein einziges stecknadelförmiges' Zoosperm zu entwickeln scheint, laben 0,006 bis $0,008^{\mathrm{mm}}$ Durchmesser. Die Ei er sind sehr grosse, kugelige oder polyedrisch alggeplattete Klumpen von 0,1 bis $0,1:$, bisweilen selbst von 0, $2 \mathrm{~mm}$ Durchmesser. Aus ihrem dunkeln, hörnigen Dotter-Protoplasma (Fig. $7 \mathrm{~g}$ d) tritt der grosse, helle, kugelige Kern oder das Keimbläschen (von 0,04 bis $0,06^{\mathrm{mm}}$ ), oft deutlich doppelt contourirt, sehr seharf hervor. In dem sehr grossen Nucleolus desselben (Keimfleck) (von 0,01 bis $0,01 . \mathrm{mm}^{\mathrm{mm}}$ ) ist constant ein ansehnlicher Keimpunct (Nucleolinus, Punctum germinativum) (von 0,001 bis $0,003^{\mathrm{mm}}$ ) nachzureisen. Eine den Dotter unselıliessende Membran fehlt mindestens den jüngeren Eiern vollständig und ist auch an den alteren höchstens als eine sehr zarte Ilaut, vielleicht nur eine festere Rindenschicht des Dotters vorhanden.

Der Cirkelcanal (c), weleher die durch die Mitte der Genitalblätter hindurchgetretenen 6 Radialcanäle aufnimmt, ist bei der erwachsenen Carmarina ungefihr so breit, oft aber auch kaum halb so breit als das Velum, und wie dieses, im Verbältniss zu dem grossen Schirm, weit schmailer als bei Glossocodon. Meist ist er von gleicher Breite mit den Radialcanälen (Fig. 1 und 3). Wie bei diesen, ist sein Lumen je nach dem verschiedenen Fülhungszustande mit Nahrung sehr verschieden, bald bandförmig eng, diunn und hoch, bald fast cylindrisch ausgedehnt. Daher erscheint er auf Querschnitten bald sehr dünn und schmal, bald melsr oval oder fast kreisrund (Fig. 71 c). Auch hier besitzen die beiden Canalwände ganz verschiedenes Epithel (Fig. 63, 64 und 71), indem das umbrale (innere) aus flachen zarten Pflasterzellen (e I), dagegen das subumbrale (ïussere, der Gallertsubstanz abgewendete) aus hohen dickwandigen Cylinderzellen besteht (c s). Nach unten grenzt der Cirkeleanal an den Knorpelring und den Nerrenring. Nach oben sendet er die centripetalen blindgeendigten Fortsätze aus, welche für die Gattungen Carmarina und Geryonic so charakteristisch sind.

Die erwachsene geschlechtsreife Carmarina hastata besitzt zwischen je zwei Radialcanälen sieben blinde Centripetaleanäle, so dass deren im Ganzen 42 vorhanden sind. Demnach muinden in den Cirkeleanal, wenn man noch die 6 Axencanäle der Tentakeln und die 6 offenen, vom Magen kommenden Radialeanïle dazuzïhlt, nicht weniger als 5.4 Gefaisse ein (Fig. I und 3). Die 4.9 Centripetalcanäle entwickeln sich nicht alle gleichzeitig; vielmehr treten zuerst nur 6 auf, je einer in der Mitte zwischen 2 Radialeaniilen (Fig. 5i); dann treten 12 andere auf, in der Mitte zwischen letzteren und jenen ersteren 
(Fig. 58 und 59; ; zuletzt endlich treten in der Mitte $z w$ ischen den nun vorhandenen 24. Gefiissen gleichzeitig elenso viele andere auf. Diese letzten 24. Centripetalcanïle erreichen nur ungefiblur die lliafte oder 2 Drittel der 18 ersten, so dass also zwischen je 2 Radialcanïlen sich 3 längere und 4 kürzere blinde Centripetaleanaile vorfinden. Die lingeren reichen mit ihren Spitzen his zwisehen die seitlichen Spitzen der Genitalblitter hinein. Die blinden Enden sind meistens stumpf, seltener zugespitzt (Fig. 1 und 3 e).

\section{Skelet.}

Knorpel des Schirmrandes und der Mantelspangen.

Der Ringcanal bildet bei Carmarina, ebenso wie bei Glossocodon, nicht den Schirmrand selbst. Vielmehr findet sich unter denselben noch ein eigener, dicker, wulstiger Reif, weleher die eigentliche Grenze zwischen Schirmrand und Velum bezeichnet. Es ist dies ein sehr entwickelter $\mathrm{K} n$ or pelring $(\mathrm{uk}$ ), der von einem Nesselepithel überzogen ist und ein stuitzendes Skelet für das ganze Thier bildet, wie dies schon bei Glossocodom bemerkt wurde. Zwischen ihm und dem unteren Rande des Cirkelcanals liegt der Nervenring (a). Ausserdem stehen auch die Sinnesblischen, die centripetalen Mantelspangen und die Tentakehn durch ihre Lage und Insertion zu dem Schirmrande und dessen verschiedenen ringförmigen Organen in der engsten Beziehung. Es erscheint mir deshalb dieser Theil des Medusenkörpers von besonderer Wichtigheit und ich selıe mich um so mehr veranlasst, hier auf dessen anatomische Verhïlnisse genaner cinzugehen, als dieselben bisher trotz ihrer hohen Bedeutung ganz vernachlissigt worden sind und als sich infolge dessen theils nur ganz unvollstindige, theils sehr unrichtige Angaben über die hier beisammenliegenden Theile vorfinden.

Der einzige Forscher, der dem wichtigen Baue des Schirmrandes bei den Geryoniden bisher einige Aufmerksamkeit geschenkt hat, ist Frutz MüLler, der auch allein den vortheilhaften Gedanken gehabt hat, durch Querschnittsdarstellungen die Lagerungs- und Verbindungsverhiiltnisse der hier beisammenliegenden Theile aufzaklären. Doch sind die beiden Querschnitte des Mantelrandes, die er von seiner Liriope catharinensis giebt (1. c. Fig. 24. und 9:5), ganz schematisch gehalten, wie er auch selbst angiebt. Wahrscheinlich sind dieselben nur aus Flichenbildern abstrahirt. Schwerlich sind sie durch directe Anschaumng gewonnen, da die Lagerung der versehiedenen Theile des Schirmrandes nicht der Natur entspricht und daher auch ihre Deutung irrig ausgefallen ist. 
Uebrigens ist auch jene Geryonidenart so klein, dass es wohl sehr sehwer sein würde, vom Mantelrande derselben befriedigende Querschnitte anzufertigen. Querschnitte können hier aber allein zum Ziele führen. Ein vorzigliches Oliject zur Anfertigung derselben bot mir nun meine grosse Carmarina hastata und zahlreiche, sehr klare und demonstrative Schnitte, welche ich durch ihren verhiiltnissmässig dicken Mantelsaum an verschiedenen Stellen anfertigen konnte, haben mir die ziemlich schwierigen anatomischen Verhältnisse desselben so weit klar gelegt, dass ich die folgenden Angaben mit voller Sicherheit vertreten zu können glaube. (Vergl. Fig. 63, 64 und il nebst deren Erklïrung.) Allerdings habe ich nur in Salzlösungen aufbewahrte Thiere zu den Schnitten benutzt, da ich am lebenden Thiere derglcichen zu versuchen versäumt hatte; indess waren die wesentlichen Verhailtnisse an den gut conservirten Thieren doch vollkommen klar und sicher zu erkennen und zahlreiche von dem lebenden Thiere entnommene Flächenansichten kamen mir dabei wesentlich erliuternd und bestatigend zu Hülfe. (Vergl. Fig. 63 bis 66.)

Der eigentliche Mantels a m des Schirmrandes von Carmarina hastata, d. h. der untere zugeschärfte, freie Rand der Gallertscheibe oder der homogenen gallertigen Mantelsubstanz (e), erseheint schon für das blosse Auge nach unten ringsum abgeschlossen und namentlich von dem Velum abgegrenzt dureh einen dicken, wulstigen, kreisförmigen Reifen oder Ring, der sich durch seine undurchsichtige Beschaffenheit und meistens auch durch röthliche Färlbung von dem weniger opaken und weisslichen darüberliegenden Girkelcanal unterseheidet (Fig. 1 bis $3 \mathrm{u}$, Fig. 63 bis $66 \mathrm{u} \mathrm{k}$ ). Dieser dicke, wulstige Ring hat von allen Theilen des Mantelsaums die bedeutendste Dicke, Consistenz und Festigkeit und bildet eigentlich die feste Grundlage, das Skelet des Schirm randes, welches vermöge seiner Resistenz und Elastieitiit demselben auch bei der stärksten Contraction des Velum seine Kreisform wahrt. Von früheren Beobachıern ist dicser wulstige, kreisrunde Saum des Schirmrandes hier, wie bei anderen Medusen, als der Nervenring betrachtet worden. Er enthilt aber keine nervösen Elemente, sondern besteht wesentlich aus einem cylindrischen oder halbeylindrisehen Knorpelringe ( $\mathrm{uk}$ ), umhïllt von einer Epithelialschicht, deren cylindrische Zellen namentlich an der äusseren Seite zahlreiche Nesselkapseln entwickeln (u e). Ich habe daher oben den ganzen Ringwulst als Nesselsaum (u) bezeichnet. Doch ist dieser Name besser auf den sehmalen Ringstreifen von Nesselepithel zu beschränken, der den Knorpelring überzieht. Die membranlosen Zellen (Fig. $70 \mathrm{uk}$ ) des Knorpelringes sind kleiner und mehr rundlich als die Knorpel- 
zellen in den marginalen Mantelspangen und namentlich als die sehr grossen Kinorpelzellen der embryonalen Larvententakeln. Dagegen ist ihre Intercellularsubstanz (Fig. $70 \mathrm{u} \mathrm{k}_{\text {ul }}$ ), die Knorpelgrundsubstanz, reichlicher entwickelt, als dic der letzteren (Fig. 70). Die Cylinderepithelzellen (Fig. 63 bis 66 u e), welehe den Knorpelring in einer einfachen Lage iblerziehen, entwickeln Nesselkapseln hauptsíchlich an der nach aussen gekehrten, weniger an der unteren Seite des Ringknorpels, wilhrend sie nach innen flacher werden und in das Epithel der unteren Fliche des Velum ( $\mathrm{v}$ e) übergehen.

Die relative Lagerung der dem lingknorpel zunächst anliegenden und ihn von oben lier bedeckenden Theile ist nun der $\Lambda \mathrm{rt}$ (Fig. 63, 64 und 71 ), dass die obere Flaiche des Knorpehings (wihrend die untere convexe frei nach unten und aussen sieht) nach innen anstösst an die Basis des Velum ( $v$ ), nach aussen an den Mantelrand, d. h. den untersten verdünnten Rand der Schirmgallerte (1) und in der Mitte zwischen diesen beiden an den unteren Rand des Cirkeleanals (c). Der Nervenring (a) liegt unmittelbar nach innen und unten von dem letzteren. Auf Querschnitten durch den Mantelrand zwischen 2 Tentakehn (Fig. 71 ) erschcint daher der Nervenring (a) als das Centrum, um welches sich die anderen Theile anlagern; und zwar liegt dann die Basis (der angewachsene Aussenrand) des Velum ( $v$ ) an der inneren, der untere Rand des Cirkelcanals (e) an der oberen, der untere Rand des Gallertmantels (l) an den iusseren und die obere ebene Fliche des Ringknorpels an der unteren Fliche des Nervenrings. So an allen Stellen des Mantelrandes zwischen den Tentakeln und den Randbläsehen. Wird dagegen der Querschnitt dureh clie Basis eines Tentakels oder noch besser durch die Insertion eines Randbläschens geführt, so wird das Lagerungsverhailtniss etwas geändert (Fig. 63 und 64). Das Randbläschen (b) ist nämlich in dem unteren Rande der Schirmgallerte eingesehlossen, wird hier nach aussen von der centripetalen Mantelspange (li), nach innen von dem unteren lande des Cirkelcanals (e) begrenzt, und driingt den letzteren hier so nach innen, dass derselbe sich vom Ringnerven entfernt, und dass die obere Seite des Nerven, der hier zu einem Ganglion (f) anschwillt, unmittelbar unter dem Randbläsehen liegt.

Als Resultat dieser anatomisehen Untersuchung des Schirmr a nd e s ergiebt sich also, dass derselhe nicht, wie bisher angenommen wurde, bloss ans dem unteren lande des Cirkeleanals und einen Zellen- oder Nervenringe gebildet wird, sondern dass in die Zusammensetzung desselben nieht weniger als 6 verschiedene ringförmige 
Theile eingehen, nimlich: 1. der Knorpelring $(\mathbf{u k})$, 2. der mit Nesselzellen versehene Epitheliberzug desselben oder der Nesselring (ue), 3. der Nervenring (a), f. der Gefäs sring oder Cirkelcanal (c); nach innen stösst an diese Theile \%. der iussere ringförmige Rand des Velum (v), mach aussen und ohen endlich 6. der untere ringförnige, verdünnte Rand der Gallertscheibe (I) oder der Mantelrand.

Ebenso wenig als der Schirmrand haben bisher die marginalen centripetalen Mantelspangen, welche bei den Geryoniden vom Schirmrande zur Basis der Larvententakeln in der Aussenfläche des Mantels emporsteigen, eine genigende Beachtung gefunden. Und doeh verdienen sie diese wegen ihrer Beziehung zu jenen embryonalen Tentakeln in hohem Grade. Der Einzige, ler diese wichtigen Gebilde erwähnt, ist Frotz Müller. Der Beschreibung des Schirmrandes von Liriope culharinensis fügt er hinzu: ") Mit aller Wahrscheinliehkeit ist er als Nervenring zu deuten; dafür spricht ausser den Randbliischen tragenden Anschwellungen, dass sich von jeder dieser Anschwellungen ein zarter, aber scharf begrenzter Strang nach oben verfolgen lässt, 4 zur Basis der Tentakeln, \&u Puneten, an denen das jingere Thier dem erwachsenen meist vollstandig fehlende Tentakeln gotragen hat « (1. e. p. 214). In der Abbildung (Fig. 2i), wo dieser Strang irrig an die innere Seite des Randbläschens und des Mantelsaums verlegt wird, ist derselbe als »Tentakelnerv? « bezeichnet.

Die Gebilde, welche ich marginale oder centripetale Mantelspangen « $(h)$ nenne, sind in der gleichen Anzahıl wie die Randblisschen vorhanden, bei Carmarina also 12. Sie verlaufen in der Aussenflaiehe des Mantelsaums oder des unteren Randes des Gallertmantels und steigen hier von der Basis der 12 Randbläschen in radialer (centripetaler) Richtung empor zu der Basis der 6 interradialen Tentakeln (y) und zu der Basis der 6 radialen Nebententakeln $(s t)$. Die radialen Mantelspangen sind von den interradialen nicht wesentlich verschieden. Beim erwachsenen Thiere sind beide fast von gleicher Länge, während bei der Larve die älteren radialen Spangen an Liinge die erst später sich vertängernden interadialen Spangen bedeutend ibertreffen. Die Mantelspangen eignen sich bei Carma ina hastata wegen der beträchtlichen Grösse dieses Thiers besonders für eine nähere Untersuchung, wobei wieder Querschnitte durch den Mantelrand von besonderem Werthe sind (Fig. 63 und 64). Jede centripetale Mantelspange ist wesentlich eine Fortsetzung orler ein Ausliufer des Schirmrandes, in welche alle Theile desselben, mit Ausnahme des Gastrovascularcanales, eingehen. Es ist also in jeder Spange ein Knorpelstreif, ein Muskelbeleg, ein Ner- 
venstrang und ein Epithelialsaum mit Nesselzellen zu unterseheiden (Fig. 63 bis 6:5). Die feste und formgebende Grundlage, das Skelet jeder Spange, liefert, wie im Schirmrande selbst, der Medusenknorpel. Allerdings bildet derselbe nur einen schmalen Streifen, aus einer einzigen Reihe sehmaler, langgestreekter Knorpelzellen bestehend (Fig. 63 $\mathrm{h} \mathrm{k}$ und $6 \mathrm{~h} \mathrm{~h} \mathrm{k})$. Indessen reieht die Festigkeit ihrer derben Grundsubstanz oder der Knorpelkapseln doeh hin, um der Mantelspange auch bei den versehiedensten Contractionszustinden des Sehirmes ihre eharakteristische Form zu wahren. Diese ist bei Carmarina hastatu in der Weise hornförmig oder verkehrt S-förnig gekrümmt, dass die untere Hailfte eine starke Convexitait nach aussen, die obere eine eben so starke Vorwölbung nach innen (in die Mantelgallerte hinein) zeigt (Fig. 1 und $2 \mathrm{~h}$ ). Die Spange ist von unten nach oben allmählich verdünnt, so dass sie an der Basis, wo sie vom Mantelrand ausgeht, am dieksten ist. Dem entsprechend nehmen die Knorpelzellen von unten nach oben allmählich an Dicke ab, an Länge aber gleichzeitig zu; die untersten sind daher fast münzenförmig abgellacht, die mittleren Cylinder von gleicher Länge und Dicke, die olseren langgestreckte Cylinder, welche oben convex, unten concav sind. Wie bei den interradialen Tentakeln und bei den radialen Nebententakeln ist das Knorpelskelet zunächsı umhüllt von einem continuirlichen Muskelrohre (h m), dessen quergestreifte Fasern sämmullich longitudinal verlaufen. An der inneren Seite, wo die Mantelspange der äusseren Fläehe des unteren Schirmrandes angewachsen ist, folgt nun unmittelbar das sehr dünne, grosszellige Plattenepithel des Ectoderm. An der :iusseren Seite des Spangenmuskels $(\mathrm{h} \mathrm{m}$ ) dagegen liegt der zarte, hlasse Nervenstrang an (h $n)$, weleher von dem Ganghion des Ringnerven zur Basis des Larvententakels emporsteigt. Dieser endlich ist überlagert von demselben Cylinderepithel, das den Knorpelring umkleidet, und das, wie dort, zahlreiche Nesselzellen entwickelt (he).

Die Mantelspange ist also ihrem Baue nach wesentlich als ein A usläufer des Schirmrandes zu betrachten und diese Auffassung wird durch die Entwickelungsgeschichte vollkommen gereehtfertigt. Die Mantelspangen entstehen dadureh, dass die Larvententakeln, sowohl die interradialen als die radialen Nebententakeln, welche ursprünglich unmittelbar aus dem Mantelrande hervorkeimen und diesem aufsitzen, sich späterhin von demselben entfernen und, durch Wachsthum des gallertigen Mantelrandes, eine Strecke weit an dessen Aussenfliche hinaufsteigen. Dabei nehmen sie von den benachbarten, für sie brauchbaren Theilen ein Stück mit fort, zichen gewissermaassen einen Zipfel des Schirmrandes nach sich, der so zu der centripetalen 
Spange sich verlängert. So entsteht aueh der einspringende Winkel an der Basis der Spange, weleher durch eine Einziehung des Schirmrandes bedingt ist. So lange die Larvententakeln existiren, ist die wesentliche Function der Mantelspangen darin zu suchen, dass sie den centripetalen Nerven vou dem Nervenring zur Tentakelbasis hiniiberführen. Der Nerv bleibt auch späterhin, nach dem Abfall der Larvententakeln, noch bestehen, und strahlt wahrscheinich seine Fäden über die Mànteloberfläche aus.

\section{Muskelsystem.}

Tentakeln, Velum und Subumbrella.

Curmarina hastata besitzt als crwachsenes und geschlechtsreifes Thier nur 6 radiale Tentakeln (Haupttentakeln), indem die 6 interradialen Tentakeln und die 6 radialen Nebententakeln, welche die Larve auszeichnen, noch vor dem Eintritt der Geschlechtsreife (wie bei Glossocodon eurybia) verloren gelien. Diese letzteren werden daher unten in der Entwickelungsgeschichte beschrieben werden. Die 6 radialen Ilaupttentakeln, welche uns hier allein beschäfigen, sind aussen am Schirmrande, schrïg gegenüber der Einmindungsstelle der 6 Radialcanile in den Cirkelcanal, befestigt, entspringen jedoch (ebenfalls wie bei Glossocodon) nicht ron dieser Einmündungsstelle selbst, sondern neben derselben, aufder rechten Seite (bei der Betrachtung des Schirmrandes von aussen oder von unten). Oft sind sie um mehr als das Doppelte ihrer eigenen Breite von jener Einmündung entfernt. Die Insertion der Tentakeln am Schirmrande ist ferner oberhalb des Knorpel rings, so dass der Canal, den das Ringgefiiss in jeden Tentakel hincin sendet, und der diesen bis zu seinem blinden Ende durchläuft, die ganze Dicke des Gallertmantels oberhalh des Knorpelringes durchbrechen muss (Fig. 98).

Die Tentakeln der erwachsenen Carmarina sind im Verhältniss zur beträchtlichen Grösse des Thieres sehr dünn (verhältnissmässig viel dünner als bei Glossocodon), aber zugleich sehr lang. Wenn sie in vollkommen erschlafftem Zustande von dem Mantelrande des bewegungslos im Wasser schwebenden Thieres herabhängen (Fig. 1), erreicht ihre Länge oft über 1, selbst bis 2 Fuss, so dass sie die Länge des Magenstiels bisweilen um melır als das Vierfache ubertreffen. Jeder Tentakel erscheint dann wie eine zierliche Perlenschnur, da die sehr zahlreichen ringförmigen, röthlichen Nesselwülste, welche in gleichen Abstiinden den Tentakel besetzen, durch 3 - bis 4mal so lange, dünnere, farblose, nesselfreie Internodien voneinander getrennt sind. Doch bedarf es nur 
einer geringen Reizung, z. B. einer leisen Berührung der Tentakeln oder des Schirmes nit der Nadel, um die Tentakeln zur Yerkürzung zu bewegen, wobei sich die Perlenschnüre in der zierlichsten Weise langsam aufrollen, indem die einzelnen Perlen durch Contraction der Internodien geniihert werden. Bei heftigerer Reizung, z. B. beim Abschneiden cines Tentakels, gerathen die Fiden in sehr lebhafte Bewegung, und wihrend das erregte Thier mit zusammengezogenem Schirme kriftige Schwimmstösse auslühr', bewegen sich die langen, feinen Fälen, wie ein Knäuel von viclen rerschlungenen Anneliden, im buntesten Spiel wild durcheinander und gewïhren mitunter ein höchst anzichendes Schauspiel. Namentlich rerschling̣en sich mehrere Tentakeln dann oft zu dicken Knoten, welche wahrhaft unentwirrbar erscheinen (Fig. 2). Wie ein Convolut zahlreicher dïnner Wiumer kriechen und schlingeln sich die verschiedenen Fïlen durcheinander, bis dann plötzlich wieder dic Lösung des scheinbar unauflöslichen Knotens eintritt und die cinzelnen Fäden fiei sich durch das Wasser schlang̣eln. Auch die abgerissenen Stiicke der Fäden zeigen noch grosse Beweglichkeit und kriechen wie Würmer umher. Bisweilen sind auch die ruhig herabhängenden Fälen in Knoten verschlungen und hängen dann in zierlichen Bogen zusammen, wie das in Fig. 1 von 3 Tentakeln dargestelit ist.

Die radialen Ilaupttentakeh von Carmarina hastata zeichnen sich durch eine iiberraschende Complication ihrer Structur aus, die wahrscheinlich bei allen Geryoniden in gleicher Weise wiederkehrt, die aber bis jetzt den Beobachtem völlig̣, entgangen ist. Schon bei der iusserlichen Betrachtung der Tentakeln bei schwacher Vergrösserung gewahrt man eine Anzahl von abwechselnd helleren und dunkleren Liingsstreifen, die namentlich an den durchsichtigen nesselfreien Internodien sehr deutlich hervortreten. Versucht man nun, durch Anfertigung von Querschnitten sich genauer uber die Anordnung und Bedeutung dieser longitudinalen Bänderung zu unterrichten, so wird man auf gut gelungenen Querschnitten durch ein iusserst zierliches Bild überrascht, welches in Fig. 60 bei schwacher Vergrösserung (70) dargestellt ist, wihhrend Fig. 61 einen radialen Ausschnitt desselben bei stïkerer Vergrösserung (300) zeigt. Während es noch ziemlich leicht gelingt, leidliche Querschnitte zu gewinnen, so ist digegen die Anfertigung von hinreichend dümnen Lïngsschnitten mit sehr grossen Ilindernissen verbunden, und auch wenn diese ziemlich gelungen sind, so ist dennoch die Deutung des eigenthümlichen Baues, der nur aus der Vergleichung der durch longitudinale und transversale Schnitte crhaltenen Bilder sich feststellen lisst, mit ausserordentlichen Schwierigkeiten rerknüpft. Obwohl ich wochenlang diese Tentakeln auf Liings- und Querschnitten und mit 
Hülfe versehiedener Reagentien untersucht habe, und obwohl ich über die wesentliehen Eigenthümliehkeiten ihrer Structur jetzt klar zu sein glaube, so muss ich dennoch auf eine bestimmte Deutung derselben verzichten. Es ist dies hauptsiichlich dadurch bedingt, dass die musculösen Elementartheile der wurmförmig sich zusammenziehenden Tentakeln ganz andere sind, als diejenigen, welche die anderen Muskeln des Körpers zusammensetzen.

Auf gelungenen Querschnitten durch einen radialen Il a upttentakel, die eine kreisrunde Scheibe darstellen. (Fig. 60 und 61) gewahrt man von innen nach aussen folgende \& Schichten: 1. ein inneres, die Centrallıöhle des Tentakels begrenzendes Cylinderepithel ( $\mathrm{e}$ ); 2. einen aus hellen, eoncentrischen, kreisrunden Streifen zusammengesetzten Ring ( $\mathrm{e}$ ); 3. eine dicke Mittelschicht, welche aus ungefíhr 60 Paaren von abwechselnd bellen und dunkeln radialen Streifen zusammengesetzt ist ( $\mathrm{l}$ und $\mathrm{t} \mathrm{m})$; 4 . cin ausseres, zahlreiche

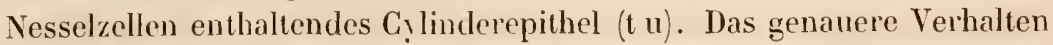
dieser 4 concentrischen Lagen ist folgendes: I. das innere $\mathrm{Cy}$ linderepithel ( $\mathrm{t}$ e) von 0,0:3 ${ }^{\mathrm{mm}}$ Dieke besteht aus einer einzigen Lage von hohen, schmalen, çlindrischen Zellen mit Kern, welche wahrseheinlich Flimmercilien trạen und das Lumen des hohlen Tentakels unmittelbar umgeben. 2. Die zweite concentrische Lage $(\mathrm{t} \mathrm{c})$, der ganz durchsiehtige, glasholle, fast strueturlose Ring, weleher im Mittel $0,03 \mathrm{~mm}$ breit ist und das Canalepithel als ebenso diekwandiger IIohlcylinder umfasst, zeigt sich bei sorgfailtiger Untersuchung aus kleineren concentrischen, hyalinen, kreis runden Ringen von $0,01 \mathrm{~mm}$ Breite zusammengesetzt. 3. Die dritte, sehr mäehtige, ringförmige radialgestreifte Sehicht $(\mathrm{t} 1$ und $\mathrm{t} m$ ), die ungefihr $4-$ bis 6 mal so breit, als jede der beiden ersten ist (im Mittel 0,1 bis $0,15 \mathrm{~mm}$ breit), erseheint zusammengesetzt aus ungefähr 60 hellen, hyalinen Radialstreifen und ebenso vielen damit alternirenden dunkleren, scharf davon abgesetzten Streifen. Die Zahl dieser abwechsehnden radialen Streifenpaare ist in versehiedenen Lebensaltern versehieden und nimmt mil dem Alter zu. Bei erwachsenen Thieren finden sieh deren meistens zwischen 50 und 60 , selten bis gegen 70 Paare vor. Die glasartig durehsiehtigen, hellen Streifen ( I ), welche aus derselben Substanz wie die coneentrischen Ringe der zweiten Lage ( $t$ e) bestehen, erscheinen meist ganz strueturlos, oder nur sehr undeutlich und zart gewürfelt oder gepflastert, wie aus schr kleinen, rundlieh-polygonalen Körperehen zusanmengesetzt. Die meisten hellen Radialstreifen sind linear, gleich breit vom inneren bis zum äusseren Ende. Das letztere ist convex abgerundet, während sich das innere Ende kaum von der 
gleichartigen hyalinen Substanz der zweiten Lage abgrenzt. Einige helle Radialstreifen sind bisweilen nach aussen hin gabelig getheilt, indem gewöhnlich nicht alle dunklen Streifen durch die ganze Dicke der dritten Sehicht ron aussen nach innen durehgehen, sondern einige meistens nur eine gewisse Strecke weit von aussen nach innen hineinragen (Fig. 60 und 61). Diese dunklen Radialstreifen ( $\mathrm{m})$ sind nicht gleichbreit linear wie die hellen mit ihnen alternirenden Streifen, sondern von aussen nach innen allmïhlich verschmalert, so dass sie innen in eine stumpfe Spitze auslaufen, während sie aussen mit breiterer Basis in die unterste Schicht der vierten Lage unmerklich übergehen. Jeder dunkle Radialstreifen ist zusammengesetzt aus 2 unregelmässigen nebeneinander verlaufenden Reihen von glïnzenden, runden oder länglichrunden, bisweilen auch hurch gegenseitigen Druck etwas polygonal abgeplatteten Körperchen von 0,003 bis $0,01 \mathrm{~mm}$ Durchmesser, welche durch eine scheinbar feinkörnige dunkle Zwischenmasse, bestehend aus kleineren und grösseren dunklen Körnchen, getrennt șind. Sowohl diese $Z$ wischenmasse, als die beiden Reilıen glïinzender Körperchen sind chemisch verschieden von der hyalinen Substanz der hellen Radialstreifen. Jede der beiden Reihen glänzender Körperchen bildet häufig einen ziemlich regelmässigen Saum um den Rand des ihr anliegenden hellen Radialstreifens und umsïumt auch noch das iuussere, oft nach aussen vorquellende Ende des letzteren, indem sie in die nächste Reihe des benachbarten dunklen Streifens übergeht, welche den entgegengesetzten Rand des hellen hyalinen Streifens säumt. An dem inneren Ende des dunklen Radialstreifens sind die glïzenden Körperchen meist kleiner und durch zahlreichere dunkle Körperchen feineren Kalibers getrennt. In der radialen Mittellinie jedes dunklen Radialstreifens nehmen die kleineren dunkleren Körperehen nach aussen hin eine breitere Zone ein und gehen endlich unmerklich iber in die feinkörnige dunkle Substanz, welche aıch in der tiefsten Lage der vierten und iussersten Schicht des Quersehnitts sich findet. 4. Diese vierte concentrische Lage endlich wird gebildet durch das iussere Gylinderepithel ( $t$ u) des Tentakels, welehes in den nesselfreien Internodien ungefihr so hoch wie das innere Epithel $(0,03 \mathrm{~mm}$ stark), in den damit alternirenden Nessehwiilsten aber 2- bis 3mal so stark $\left(0,06\right.$ bis $0,08^{\mathrm{mm}}$ hoch $)$ und aus mehreren, mindestens 3 verschiedenen Schichten zusammengesetzt ist (Fig. 91 A). Die innerste Lage, welche ich die Sehicht der Büsehelzellen nenne, wird aus sehr dünnen, fast fadenförmigen Cylinderzellen zusammengesetzt, wolche büschelweis auf dem convexen Aussenrand der hyalinen Radialstreifen sitzen und oft mehrfach verbogen, bisweilen fast wellenförmig geschlingelt 
erscheinen. Jedes Büschel (Fig. 9/ B) besteht aus etwa 5 bis 10 dünn cylindrischen, in der Mitte einen langlichen Kern enthaltenden Zellen (Fig. 9| C), welehe eine central stehende kegelförmige dicke Zelle (Fig. 9| D) umfassen. Die nach aussen gekehrte Basis der Kegelzelle scheint vertieft zu sein zur Aufnahme des unteren oder inneren dünnen Endes einer ähnlichen legelzelle der zweiten oder mittleren Epithelschicht. Diese mittlere Lage nenne ich Schicht der Flaschenz ellen, woil sie grossentheils aus sehr eigenthümlichen, einer lang-

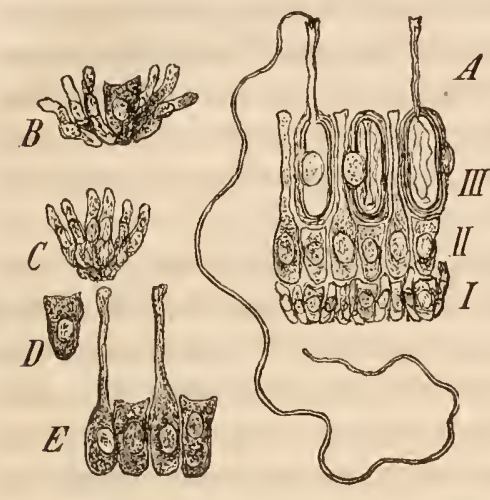

Fig. 91. Epithelzellen aus einem Nesselwulst der radialen IIaupttentakeln von Carmarina hastata. A. Ein Stuick des Epithels in sciner ganzen Dicke, aus 3 Schichten bestehend: I. Schicht der Büschelzcllen. II. Schicht der Flaschenzellen. 111. Schicht der Nesselzcllen. Aus 2 Nesselzellen der obersten Schicht ist der Nesselschlauch, aus einer zugleich der Nesselfaden hervorgetreten. B. Eine Kiegelzelle der ersten, tiefsten Schicht, von Büschelzellen umgeben. C. Eine Gruppe von Büschelzellen der ersten Schicht. D. Eine Kegelzelle der ersten Schicht. E. Zwei Kegelzellen und zwei Flaschenzellen der zweiten, mittleren Schicht. halsigen Weinflasche ähnlichen Zellen besteht (Fig. $91 \mathrm{E}$ ). Der lange, oft an Ende knopfförmig verdickte Hals der letzteren liegt in der dritten oder nesselnden Epithelschicht und füllt die Zwischenriume zwisehen deren Nesselzellen aus, während der dickere cylindrische Flaschenkörper, weleher den Zellenkern einsehliesst, zwisehen den dicken kernhaltigen Kegelzellen (Fig. 91 E) der zweiten Schicht liegt. Die nach aussen gekehrte Basis der letztgenannten Kegelzellen, welehe etwas grösser als die der untersten Schicht sind, scheint vertieft zu sein zur Aufnahme des inneren convexen Endes der Nesselzellen (Fig. 68), welche zusammen mit den Ilälsen der Flaschenzellen die dritte ausserte Lage des äusseren Tentakelepithels, die Schicht der Nesselzellen bilden. Die unter den Nesselzellen gelegenen Kegelzellen zweiter und erster Ordnung dienen vielleicht, indem sie von innen nach aussen nachrücken, zum Ersatz der Nesselzellen, welche (hureh Sprengung der Nesselkapseln verloren gehen.

Lïsst man auf einen derartig zusammengesetzten Querschnitt eines radialen Tentakels verschiedene chemische Reagentien, z. B. verdünnte Säuren, einwirken, so scheint derselbe für die oberfläehliche Betrachtung nur aus zweierlei versehiedenen Substanzen zu bestehen, nämlich 
aus den epithelialen Bildungen (innerem und iusserem Epithel), welche durch die Siuren getruibt werden, und aus der hyalinen structurlosen Substanz. (zwcite Lage und helle Radialstreifen der dritten Lage), welche zwischen den beiden Epithelschichten liegt und durch Siuren nicht getruibt wirl. Die dunhlen Radialstreif'n der dritten Schicht sehen wie Fortsiitze aus, welche das iussere Epithel in die hyaline mittlere Substanz hineinschicht. Namentlich hat das Bild, welches gute, genau senkrecht zur Tentakelaxe geführte und diunne Querschnitte geben, auffallende Aehnlichkeit mil demjenigen, welches gewisse drüisige Apparate auf Fiachenschnitten mancher Schleimhäute licfern. Die dunklen Radialstreifen sehen wie schlaudhformige Drüsen aus, die von dem ausseren Epithel nach innen eingestiilpt sint. Die beiden Reihen glianzender Körperchen ( $\mathrm{m}$ ) gleichen dem Epithel ciner lingasdurchschnittenen Schlauchdriise (Fig. 61).

Die Lägsschnitte der radialen II a pttentakeln sind, wie schon bemerkt, in geniigend dünnen und durchsichtigen Schichten nur sehr schwierig und unvollkommen auszuffihren, und dennoch ist ihr genaues Studium unerliisslich, mm iiber die Bedeutung der oben beschriebenen merkwürdigen Querschnitsbilder eine richtige Ansicht zu erhalten. Dic blosse Betrachtung der Tentakeln von aussen erliatert so gut wie nichts, da das dicke und undurchsichtige äussere Epithel die innere Structur verdechl. Im Allq̣emeinen liefern die besten Aufschlüsse die tangentialen Lïngsschnilte, und namentlich diejenigen, welche ungefähr durch die Mitte der dritten (radial gestreiften) Schicht oder noch niher der Aussenfliche derselben geführt werden. Auf solchen $t a n g e n t i a l e n$ Längschnitten durch die radial gestreifte Schicht (lig. 62) erblickt man weitcr nichts, als eine Anzahl von regelmässig alternirenden dunkleren und helleren parallelen Lïngsstreifen. Die hellen Streifen sind fast alle ron der gleichen Breite (im Mittel $0,01 \mathrm{~mm})$; dagegen die mit ihnen abwechselnden dunklen Liingsstreifen von verschiedener Breite: ist der Tangentialschnitt durch die Mitte der dritten Schicht gegangen, so sind sie eben so breit, als die hellen Streifen; ist der Schnitt durch den ausseren Rand der dritten Schicht gegangen, so sind sie doppelt so breit; ist er dureh den innern land gegangen, so sind sie nur halb so breit als die bellen Streifen. Bei genauerer Untersuchung zeigen sich die hellen Longitudinalstreifen entweder ganz structurlos und hỵalin, oder sie lassen nur eine äusserst zarte und blasse longitudinale Streifung erkennen; sie sind der Lïnge nach spalthar und es gelingl brim sorgfiltigen Zerzupfen, sie in ausserst blisse und zarte, sehr lange und schmale Fasern zu zerlegen. Diese sind durchaus homogen und lassen auch nach Behandlung mit 
Säuren etc. keine Kerne entdecken. Dagegen gelingt es ziemlich leiclit, die dunklen Längsstreifen, welche im Ganzen betrachtet eine sehr unregelnässige und feine longitudinale Streifung zeigen und von zahlreichen länglichrunden Kernen durchsetzt sind, in ihre Bestandtheile zu zerlegen. Beim sorgfailtigen Zerzupfen mit Nadeln zeigt es sich, dass sie ganz vorwiegend, fast ausschliesslich aus parallel verlaufenden und eng verbundenen sehr langen Striingen bestehen und jeder dieser letzteren ist wiederum aus langen und starken spindelförurigen Fasern zusammengesetzt. Diese Fasern sind in Mittel 0,1 mn lang, nach beiden fein zugespitzten Enden hin almïhlich verdünnt und in der Mitte bis zu einer Dicke von 0,003 bis $0,008^{\mathrm{mm}}$ angeschwollen. Jede Faser entspricht ciner selr verläingerten spindelförmigen Zelle und umschliesst in der Mitte einen ellipsoidischen oder ovalen Kerı von $0,00:$ bis $0,012 \mathrm{~mm}$ Länge und 0,002 bis $0,006 \mathrm{~mm}$ Breite. Häufig bildet der dicke Kern an einer Seite der Zelle eine bauchige Vorwölbung. Im Uebrigen ist die Substanz dieser spindelförmigen, kernhaltigen Faserzellen durchaus homogen, und lässt keine Spur von einer Querstreifung erkennen. Sie bricht das Licht in :ihnlicher W'eise wie die dunkeln glianzenden Nesselkapsehn, wesshalb auch auf Querschnitten ihr Durchschnitt sehr leicht mit Spitzenansichten der letzteren verwechselt werden kann. Vicl schwächer lichtbrechend ist die Substanz der blassen kernlosen Fasern, die sich auch in ihrem Verhatten gegen chemische Reagentien wesentlich von den dunkeln kembaltigen Faseinn unterseheidet. Auch diese blassen Fasem sind durchaus homogen; niemals erscheinen sie quelgestreift, wie etra die Muskehn des Velum, der Subumbrella oder der knorpeligen Larvententakeln. Eine eigenthümliche Querstreifung tritt an denselben nach Maceration in verlünnter Salpetersiure allerdings auf. Es ziehen dann sehr feine und gedraingte, aber unregelmaissige Querlinien über die ganze Breite der aus den blassen Fasern zusammengesetzten hellen Längstreifen hinweg (Fig. 62 rechts). Isolitt man aber die cinzelnen Fasern durch Zerzupfen, so zeigt sich, dass diese Querstreifung nicht bedingt ist durch eine Differenzirung der Substanz, wie bei den echten quergestreiften Muskeln, sondern vielmehr durch eine eigenthümliche Schrumpfung der blassen Fasern, an deren Oberfliche sich viele übereinanderliegende ringförmige Rinnen bilden, die durch scharfe vorspringende Rifle getrennt sind (Fig. 62 rechts unten). Die dunkeh kernhaltigen Fasern werden durch verdünnte Salpetersäure nicht in dieser Weise verändert, dagegen durch verdünnte Essigsäure werden sie körnigg getrübt, während die Substanz der hyalinen Lingsstreifen ganz hell hleibt. Die spindelförmigen Zcllen worlen der 
Länge nach zu langen Bändern vereinigt durch ein Minimum einer feinkörnigen Kittsubstanz.

Ra diale Läng s s chnitte der Tentakeln, welehe durch die Längsaxe derselben gehen, werden nur selten durch einen glücklichen Zufall in einiger Vollkommenheit erhalten. Heistens fallen die so versuchten Schnitte der Lïngsaxe parallel oder schicf gegen sie gerichtet. Die besten radialen Längsschnitte, welche ich erhielt, zeigten alle stets dasselbe Bild, nämlich eine Zusammensetzung aus den folgenden Schichten: 1. Zu innerst, unmittelbar das Lumen des Tentakelcanals umschliessend, findet sich ein Cylinderepithel ron $0,03 \mathrm{~mm}$ Miichtigkeit, ganz gleich der entsprechenden ersten Schicht des Querschnitts (t e). Q. Die zwcite Schicht bildet eine hyaline gallertihnliche Substanz von $0,03 \mathrm{~mm}$ Breite, welche zahlreiche feine, senkrecht (radial) zur Tentakelaxe gerichtete Querstreifen zeigt ; letztere sind nichts anderes, als die Grenzen der übereinander liegenden concentrischen Ringe der zweiten Schicht des Querschnitts (t e) ; ferner lässt sich an denselben oft auch eine ausserst zarte Zeichnung wahrnchmen, als ob jeder Querstreif aus einer Reihe nebeneinander liegender rundlich-polygonaler Körperchen bestünde; dies sind die Querschnitte der einzelnen langen hyalinen Fasern, die die concentrischen Ringe zusammensetzen. 3. Die mächtigste, dritte Schicht, von 0,1 bis $0,15^{\mathrm{mm}}$ Breite, lässt sich an etwas dickeren radialen Längsschnitten in mehrere übereinander liegende longitudinalradialgestellte, abwechselnd dunklere und hellere Blitter zerlegen. Jedes dunkle Blatt zeight sich ausschliesslich zusammengesetzt aus zahlreichen parallel verlaufenden, sehr langen bandförmigen oder cylindrischen Strängen von 0,003 bis $0,006^{\mathrm{mm}}$ mittlerer Breite. Jeder Strang lisst sich isoliren und ziemlich leicht zerlegen in eine Anzahl der oben beschriebenen kernhaltigen spindelförmị̣en Faserzellen. Ifat man diese Schicht von der Schnittläche des radialen Liingsschnittes entfernt, so gelangt man auf die hyaline, durchsichtige, entweder ganz lonogene oder fein längsstreifige Lage, welche sich beim Zerzupfen in blasse kernhaltige Fasern ( $\mathrm{t}$ ) zerlegen lässt. Unter dieser kommt wieder cine Lage von dunkeln kernhaltigen Liingsfasern u. S. w. 4. Endlich die äusserste und vierte Schicht wird gebildet durch das äussere Tentakelepithel ( $\mathrm{u}$ ), dessen innerer Grenzcontour geradlinig, der iussere regelmässig und tief wellenförmig gebogen ist. Die Wellenthiiler entsprechen den nesselfreien Internodien, die Wellenberge den ringförmigen Nesselwiilsten des Tentakels. An letzteren zeigrt das-Epithel dieselbe Zusammensetzung aus 3 Schichten wie auf dem Querschnit.

Iläl man :nun die so gewonnenen Bilder der Querschnitte und der fangentialen und radialen Längsschnitte zusammen, so ergiebt sich für 
den Bau der radialen Haupttentakeln folgendes Resultat. Jeder Tentakel bestelıt aus 3 concentrisch sich umschliessenden Hohlcylindern, einem inneren und :iusseren Epithelialcylinder und einen dazwischen befindlichen, zum grossen Theile museulösen Gylinder von sehr zusammengesetzter Structur. Es besteht der letztere aus einem inneren concentrisch geschichteten und einem ausseren radial geschichteten Theile. Der innere concentrisch geschichtete Theil (die zweite Lage unserer Querschnitte und radialen Längsschnilte) besteht aus einer einzigen Substanz, angeordnet in Form theils sich einschliessender, theils übereinander gelagerter Ringe. Jeder ling ist zusammengesetzt aus vielen unregehmässigen, sehr langen und schmalen kernlosen Fasern von cylindrischer oder spindelförmiger Gestalt. Alle verlaufen in transversalen Ebener, die senkrecht zur Tentahelaxe stehen.

Der iussere radial geschichtete Theil des mittleren Tentakeleylinders (die dritte Lage unserer Querselmitte und radialen Längsschnille) bietet der genaueren Untersuchung die groissten Schwierigkeiten. Er ist zusammengesetzt aus einer grossen Anzahl (meistens 120) radial gestellter dümner Bliitter, die durch die ganze Läng̣e des Tentakels von seiner Wurzel bis zu seiner Spitze ununterbrochen hindurchlaufen. Diese radialen Bliitter sind von zweierlei Art, hellere, mehr homogene, kernlose, und dumklere, mehr differenzirte, kernreiche. Ilelle und dunkle Bläter sind stets in gleicher Anzahl vorhanden und wechseln regelmaissig mitcinander ab. Beide sind in der Mitte der Schicht von ungefïlı gleicher Dicke. Die hellen Blätter sind überall von gleicher Dicke $\left(0,0 \mathrm{fm}^{\mathrm{mm}}\right)$; die dumklen Blätter sind von aussen nach innen keilförmig zugeschïrft. Die hellen Bliitter bestehen aus zahlreichen innig verbundenen, parallel verlaüfenden, longitudinalen Fasern, welche sich in längere oder kürzere, unregelmässige, spindelförmige, kernlose, hyaline Fasern auflösen lassen, ganz gleich denjenigen, welche die concentrischen Ringe der zweiten Schicht zusammensetzen. Die dunklen Blätter, welche scharf von den hellen geschieden sind, bestehen ebenfalls aus zahlreichen innig verbundenen und parallel neheneinander verlaufenden longitudinalen Fasern. Diese sind aber mit zahlıcichen Kermen besetzt und zeigen sich zusammengesetzt aus zahlreichen der Lïnge nach aneinander gelegten, gestreckı spindelförmigen, glatten Faserzellen, deren jede einen ellipsoiden Kern in der Mitte umsehliesst. Jedes dunkle Radialblatt besteht eigentlich aus zwei besonderen in dieser Weise zusanmengesetzten Blaittern, welche durch ein wenig feinkörnige Zwisehensubstanz getrennt sind, wie aus dem Querschnitte (Fig. 60 und 61) hervorgeht.

So viel lisst sich also thatsächlich über den merkwürdigen und 
complicirten Bau der radialen IJaupttentakeln feststellen. Eine bestimmte Deutung aller Elementartheile vermag ich aber nicht zu geben; namentlich gilt dies von den betlen, schwach lichtbrechenden, kernlosen Fasern, welche'als Ringfasern dic zweite, concentrisch gestreifte Schicht ( $\mathrm{t}$ c) und als Lïingsfasern die hellen Radialblitter der dritten, radial gestreiften Schicht (I) zusammensetzen, sowie von den dunkeln, stark lichtbrechenden, kernhaltigen Fasern, welche die dunkeln Radialblitter ( $\mathrm{tm}$ ) derselben bilden. Jedenfalls isi wenigstens das eine dieser Elemente musculöser Natur, vielleicht auch das andere, wenn dies nicht vielleicht zur Gewebsgruppe der Bindesubstanzen gehört. Ob aber die dunkeln Fasern Muskeln und die hellen Fasern Bindegewebe sind, oder ob das Umgekehrte der Fall ist, oder ob beide Faserarten Muskelfasern von verschiedenem Bau und Werth sind, dariiber muss vorlaiufig das Urtheil desshalb ganz ungewiss bleiben, weil beide Faserarten, sowohl die hellen kernlosen, als die dunkeln kernhaltigen Fasern ausschliesslich in den radialen Haupttentakeln der Geryoniden vorkommen, wiihrend sie im übrigen Körper feblen. Die motorischen Elemente des übrigen Körpers, namentlich des Velum, der Subumbrella und der Knorpeltentakeln der Larven, bestehen aus quergestreiften Muskelfasem, welche weder zu den hellen noch zu den dunkeln Fasern der Haupttentakeln irgend eine bestimmte Beziehung erkennen lassen. Allerdings ist auch ein grosser Theil der Magenwände (Fig. 73) aus glatten Muskelfasern zusammengesetzt. Allein die Aehnlichkeit derselben mit den hellen kernlosen Stringen der Tentakeh scheint bloss eine oberflichliche zu sein, da sie nicht, wie die letzteren, beim Zerzupfen in clie oben beschriebenen spindelförmigen Fasern, sondern in Bündel ron äusserst schmalen und langen Fibrillen zerfallen.

Erwägt man die ausserordentliche Contractilitä der radialen Haupttentakeln, und namentlich den Umstand, dass dieselben sich nicht allein schr bedeutend verkürzen, sondern auch stark der Quere nach l'ingförmig einschniren können, so erscheint es natürlicher; die contractilen Elemente in den blassen kernlosen Fasern zu suchen. Es würde dann eine starke innere Ringmuskelfaserschicht ( $\mathrm{c}$ ) vorhanden sein, wihrend im entgegengesetzten Falle, wenn nur die dunkeln kernhaltigen Fasern contractiler Natur wïren, Ringmuskeln ganz fehlen wiirden. Die longitudinalen Muskelziige würden in beiden Fïllen gleich entwickelt erscheinen, da die Summe aller hellen und aller dunkeln Radialblïtter der dritten Schicht ungefilhr greich sein wird. Vergleicht man die beiderlei Fasern mit den glatten, nicht quergestreiften Musholn anderer Thiere, so finden sich den hellen kernlosen Fasern ahnliche Muskelb:inder vielfach bei Mollusken, während die dunkehn 
kernhaltigen Fasern den contractilen Spindelzellen der glatten Muskeln von Wirbelthieren sehr ähnlich sehen. Zur Vergleiehung der beiderlei Fasern mit den glatten Muskelelementen anderer Coelenteraten fehlt es jetzt noch an genügenden Anhaltspuneten. Es sind sowohl kernlose als kernhaltige homogene Fasem als Muskelzellen bei versehiedenen Coelenteraten beschrieben worden.

Offenbar steht der eigenthïmliche Bau und die Zusammensetzung der radialen Haupttentakeln aus diesen glatten Muskelzellen in ursäehlichem Zusammenhang mit ihrer eigenthünlichen Bewegungsweise. Ihre wurmförnigen Contractionen erfolgen nicht so plötzlich und momentan, balten aber anch länger an, wie bei den quergestreiften Muskeln des Velum, der Subumbrella und der Larvententakeln. Bei diesen letzteren verläuft die Contraction gewöhnlich momentan in einer energischen Zuckung, auf welche sofort die Erschlaffung folgt, während bei jenen ersteren die Zusammenziehung in der Regel in keiner beftigen Zuckung, sondern allmählicher erfolgt und längere Zeit andauert. Die beiderlei contractilen Elemente unterscheiden sich durch ihre Wirkung in ähnlicher Weise, wie die glatten und quergestreiften Muskeln der Wirbelthiere.

Die quergestreiften Iuskeln der Carmarina bilden einen sehr dimnen, nur aus Längsfasern zusammengesetzten schlauchförmigen Ueberzug über die cỵlindrischen Knorpelskelete der interradialen Tentakeln (Fig. 64. y m) und der radialen Nebententakeln (Fig. 6.5 $\mathrm{s} \mathrm{m}$ ) der Larve, sowie über die Knorpelstibe der 12 centripetalen Mantelspangen (h), welche am Schirmrande zu jenen hinführen (h m). Ausserdem setzen sie beim erwachsenen Thiere die Locomotionsorgane zusammen, von denen die Subumbrella das schwächere, das Velum das stiirkere ist.

Das Velum (v) oder die Randmembran der erwachsenen Carmarina ist im ersehlafften Zustande 5 bis $8^{\mathrm{mm}}$ breit, im stark contrabirten noch nicht ein Drittel so breit. Seine Dicke betrigt $0,04 \mathrm{~mm}$. Das Velum besteht in seiner ganzen Ausdehnung aus 4. übereinanderliegenden Sehichten (Fig. 63, 64 und 71 v). Die der Schirmhöhle zugewandte obere Fliiche ist von einem mässig dicken Cylinderepithel ( $r$ s) überzogen, dessen fast kubische kernhaltige Zellen $0,018^{\mathrm{mm}}$ hoch sind. Unter diesem Ueberzuge folgt die sehr entwickelte Ringmuskelschicht $(\mathrm{v}$ e), deren Mächtigkeit $0,007 \mathrm{~mm}$ beträgt. Unter diesen eireular verlaufenden Fasern liegen die etwas schwächeren Radialmuskeln ( $\mathrm{r} r$ ), die eine Lage von $0,005 \mathrm{~mm}$ Dicke zusammensetzen. Die untere Fläche dieser Radialmuskelschicht endlich ist von einem Pflasterepithel ( $\mathrm{r}$ e) 
überzogen, dessen breite kernhaltige Zellen kaum hally so hoch, als dic des oberen Epithellagers sind, nur etwa 0,009 $\mathrm{mm}$ hoch.

Die verschicdenen Schichten des Velum setzen sich nur theilweis auf die Subumbrella fort (Fig. 63, 64 und 71 ). Das untere Epithel des Velum ( $\mathrm{v}$ e) geht aussen in das dickere Epithel des Knorpelrings über ( $\mathrm{u}$ e). Das obere Epithel des Velum (v s) setzt sich continuirlich in das flachere Epithel der Subumbrella (e s) fort, dessen blasse kernhaltige Pflasterzellen sehr niedrig sind. Ebenso setzt sich die obere, aus den Circularfasern bestehende Muskelschicht des Velum ( $\mathrm{v} \mathrm{c}$ ) unmittelbar in die schwichere Ringsmuskellage der Subumbrella (m s) fort, deren concentrische Faserringe gegen den Grund der Schirmhöhle hin immer diunner und schwächer werden und an der Basis des Magenstieles sich ganz verlieren. In den Zwischenrïumen zwischen den Radialeaniblen liegen die Cirkelfasem der Subumbrella zum grossen Theil unmittelbar auf der Gallertsulsstanz des Mantels, nach unten gegen den Rand hin auf dem subumbralen Epithel des Cirkeleanals (c s). An der Innenfliiche der Radialcanäle dagegen und in deren nächster Uingebung finden sich unter den eircularen auch theilweis noch einzelne Züge von longitudinal oder vielmelır radial verlaufenden Muskelfasern der Subumbrella, welche man als partielle Fortsetzungen der Radialmuskelschicht des Velum ansehen kann. Von solchen Radialmuskeln der Subumbrella lassen sich 18 einzelne Bäder deutlich unterscheiden. Es verlaufen 6 schmale unpaare Radialmuskeln in der Mittellinie der Radialcanäle zwischen ihrem subumbralen Epithel und der Ringmuskelschicht. Sie verlieren sich an der Basis des Magenstiels, während die von ihnen begleiteten Radialnerven (a r) sich in der Mittellinie der Aussenfliache der Radialcanile bis zum Magen fortsetzen (Fig. 88). Die 12 paarigen Radialmuskeln der Subumbrella sind etwas breitere Bänder, welche unmittellar an den beiden Seitenwïnden cines jeden Radialcanals wie längsstreifige Säume desselben verlaufen und namentlich bei jüngeren Thieren, deren Radialcanäle sich noch nicht zu den Genitaltaschen ausgebuchtet haben, sehr deutlich hervortreten. Iḿ Grunde der Sehirmhöhle, wo die Radialeanäle auf den Magenstiel umbiegen und sich dabei so sehr nähern, dass nur noch Zwischenrïume von ihrer eigenen Breite zwischen ihnen übrig bleiben, werden die letzteren vollständig von den Muskehn ausgefüllt, inden je 2 convergirende benachbarte Radialmuskeln (der rechte Muskelsaum von einem jeden Radialeanal und der linke Muskelsaum von dem rechts daneben gelegenen Canal) zusammentreten zur Bildung eines einzigen starken Muskelstreifen, der nun als Laingsmuskellband (Fig. 4 und $5 \mathrm{~m}$ ) bis zum 
Maggengrunde herabsteigt und dort in die longitudinale Muskelschicht des Magens sich fortsetzl.

\section{Nervensystem.}

Das Nervensystem lïst sich bei der grossen Carmarina hastata mit noch grösserer Sicherheit nachweisen als bei dem kleinen Glossocodon eurybia. Die Nervenstrïnge sind hier grösser, deutlicher und leichter von den Nachbartheilen zu isoliren, als bei dem letzteren, namentlich bei Larven mittleren Alters; von besonderer Wichtigkeit aber ist es, dass es mir hier gelang, unzweifelhaft nervöse Elementartheile

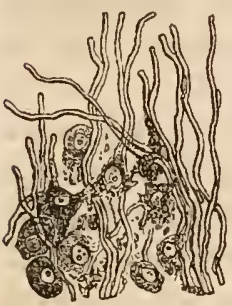

Fig. 92. Nervenfasern und Ganglienzellen von Carmarina hastata, aus dem Nervenring an der Austrittsstelle aus einem radialen Ganglion entnommen. mit vollkommener Sicherheit in den Nervensträngen nachzuweisen (Fig. 92). Ueber die Ganglienzellen und die mit ihnen in Verbindung stehenden Nervenfasern werde ich unten in dem Abschnitt, der von den Geweben handelt, besonders berichten. Hier will ich bloss die anatomisehe Verbreitung des Nervensystems in dem Körper der Carmarina so darstellen, wie ich mich nach vielen mühsamen Präparationsversuchen endlich von ihr sicher überzeugt zu haben glaube. Ich bemerke dabei, dass mir die oben schon, bei Beschreibung des Mantelrandes erörterten Querschnitte die grössten Dienste leisteten. Bei Larven mittleren Alters kann man auch auf Flächenansichten die Nervenstränge und ihre Ganglien ziemlich leieht erkennen (z. B. Fig. $ّ 6,65$ und 66). Bei ïlteren Thieren dagegen ist es ohne Quersehnitte des Mantelrandes, namentlich an den Stellen, wo die Randb]äschen aufsitzen und die Tentakelnerven al)gehen, kaum möglich, z" einer klaren Anschauung des Nervenrings und der von ihm abgehenden Nervenstrïinge zu gelangen.

- Der Nervenring (a) an Sehirmrande von Carmarina hastata liegt so verborgen zwisehen Cirkeleanal, Knorpelring und Velum, dass es nur selten und mit Mülıe bei der Betrachtung von blossen Fläehenansichten des erwachsenen Thieres gelingt, sich von seiner Anwesenheit bestimmt zu überzeugen. Viel leichter und sicherer gelingt dies dureh das Studium von Querséhnitten des Schirmrandes. Hier erseheint der Ringnerv als ein eylindrischer, auf dem Quersehnitt kreisrunder, oder von oben nach unten etwas abgeplatteter Strang (Fig. 71 a), dessen Durehmesser nur etwa $1 / 4$ bis $1 / 6$ von dem des Knorpelrings beträgt. Wie schon bei Beschreibung des Sehirmrandes erwähnt, liegt der Ringnerv unmittelbar auf der oberen Fläche des Knorpelringes, so dass er 
in verticaler Richtung den Knorpelring ron dem unteren Rande des Cirkeleanales trennt. Ebenso ist er in horizontaler Richtung zwischen Aussenrand des Velum und unteren Rand des Gallertmantels eingeschaltet. Nirgends liegt also der Cirkelnerr frei an der Oberfliche, und diese versteckte Lage erklärt zur Genüge, warum er bisher übersehen wurde. Oben wird derselbe vom Ringgefiss, unten rom Ringknorpel, aussen vom Gallertmantel und innen rom Velum verdeckt. Auf Querschnitten erscheint er vollkommen als Grenzmarke für diese 4 verschiedenen ringfömigen Theile, zwischen welche er eingeschaltet ist. An den Abgangsstellen der Tentakehn wird er ausserdem noch an der äusseren Seite von diesen letzteren und von den centripetalen Mantelspangen, an der oberen von den Randbläschen bedeckt (Fig. 63 und 64).

Der Nervenring von Carmarina ist in 12 Ganglien (f) angeschwollen, welche unnittellbar unter der Basis der 12 Randbläschen liegen, und auf denen diese, wie auf einem Polster, aufsitzen (Fig. 63 bis 66). Die Ganglien erscheinen als ziemlich unregelmässige rundliche Knoten oder flache rundliche Hügel, die 6 radialen etwas starker gewölbt und umfangreicher als die 6 interradialen. Unten und theilweise auch seitlich sind dieselben von dem oberen Theile des Ringknorpels umschlossen und verdeckt, der bei Larven mittleren Alters hier eine spindelförmige Anschwellung bildet (Fig. 66). Yon jedem der 12 Nervenknoten geht nach oben ein starker Nerv ab, welcher sofort durch das Basalganglion (w) in das Innere der Sinnesblisschen (b) hineintritt und lier in die beiden gegenständigen Sinnesnerven sich theilt, die an der Innenfliche desselben verlaufen $\left(\mathbf{n}^{\prime}\right)$. Ausserdem schickt jedes der 12 Ringganglien einen Spangennerven (h n) ab, welcher nach aussen und oben zur Basis der 19 knorpeligen Larvententakeln verliuft. Jeder radiale Knoten giebt ausserdem noch einen Nerven ab, der das entsprechende Radialgefiss begleitet, und einen zweiten, welcher den zugehörigen radialen Haupttentakel versorget.

Die 6 stärksten Nervenstränge des Schirmes nächst dem Ringnerven sind die Radialnerven (a r), welche als platte, breit lineare Bänder, begleitet von den 6 unpaaren radialen Muskelbändern (ler Subumbrella, in der Mittellinie der unteren (der Schirmhöhle zugekehrten) Wand der Radialcanäle verlaufen (Fig. 72 a r), so dass sie hier nur von dem dünnen Ringmuskelbelege $(\mathrm{m} s)$ und dem zarten Epithel der Subumbrella bedeckt sind. Sie lassen sich längs des Verlaufs der Radialeanäle bis zum Magen herab verfolgen, wo ihr weiteres Verhalten wegen der Undurchsichtigkeit dieses Theils nur mit grosser Unsicherheit verfolgt werden kann. Auch über die Oberlliche des Magen hin- 
weg scheinen sie noch als 6 getrennte Faden $\mathrm{zu}$ verlaufen und dort in die oben bezeichneten Furchen (Fig. ' 4 " ${ }^{\prime \prime}$ ) eingeschlossen zu sein. Vielleicht bilken sie um den Mund einen zweiten Ring. Am leichtesten zu beobachten und zu isoliren ist derjenige Abschnitt der Radialnerven, der in Begleitung des Radialmushels in der Mitte der 6 Genitalblätter verlatuft (Fig. 1 bis 3 a $\mathrm{r}$ und Fig. 63 a r).

Weit schwieriger als die 6 Radialnerven sind die $12 \mathrm{Sp}$ a $\mathrm{ng}$ e $\mathrm{n}-$ nerven (h n) zu verfolgen, welche von den 12 Ganglien aus zu der Basis der 6 interradialen (y) und zu der Basis der 6 radialen Nebententakeln ( $\mathrm{s} \mathrm{t}$ ) verlaufen (Fig. 63). Diese sind viel schmäler und an Fasern irmer als die Radialnerven und ausserdem bei ilurem blassen, zarten Aussehen auf Flächenausichten der Spangen schwer wahıunehmen. Auf Quersehnitten dagegen iberzeugt man sich leichter von ihrer Anwesenheit. Sie liegen unmittelbar unter dem mit Nesselzellen versehenen Epithel der Mantelspangen, zwischen diesem (b e) und zwischen dem Muskelrohre (h $\mathrm{m}$ ), welehes die Knorpelspange umgiebt. So lange die Larvententakeln noeh rorhanden sind, seheint sich der grösste Theil der Spangennerven in die letzteren fortzusetzen. Syaterhin, nach dem Abfallen derselben, strahlen ihre Fäden von dem Ende der Mantelspange ïber die Manteloberfläche aus. Die radialen Spangennerven sind sehwächer als die interradialen.

Von den Ganglien des Nervenringes, entweder bloss von den 6 radialen oder von allen 12 , gehen höchst wahrscheinlich auch Fäden in das Velum hinein. Doch ist es mir ebenso wenig bei diesen gelungen, mich durch unmittelbare Beobachtung sicher von ihrem Verlaufe zu überzeugen, als bei den 6 Nervenfiden, welche von den 6 radialen Ganglien aus zu den 6 radialen Haupttentakeln zu gehen scheinen. Sehr leicht und sicher lassen sich dagegren die Simmesnerven innerhalb der 12 Sinnesbläschen verfolgen, welche sogleich bei diesen beschrieben werden sollen.

\section{Sinnesbläschen (Randbläschen).}

Die Sinnesbläschen oder Randbläschen (b) der Carmarina hastata gehören zu den grössten, die bei craspedoten Medusen vorkommen. Sie eignen sich wegen dieser betrichtlichen Grösse ganz besonders für eine genauere Untersuchung, zumal eine mit vollkommener Durchsichtigkeit verbundene scharfe Abgrenzung der einzelnen Bestandtheile den feineren Bau dieser interessanten und wichtigen Organe bier besser, als vielleicht bei den meisten anderen craspedoten Medusen zu erkennen erlaubt. (Vergl. Fig. 7, 8, 63 b r, 64 b i und 66 b i.) Bei dieser 
Art entdeckte ieh zuerst die beiden hallokreisförmig gebogenen Sinnesnerven $\left(n^{\prime}\right)$, welehe von einem an der Basis des Randbliischens gelegenen Ganglion (w) ausgehen, an entgegengesetzten Seiten des Blisschens emporsteigen und oben sich mit ihren Nervenfasern durchflechten, während sie in ein mit Zellen gefülltes und ein Concrement $(\mathbf{x})$ umschliessendes kugeliges Sinnesganglion (s) eintreten. Erst nachdem ich diesen complicirten Nervenapparat im Inneren der Randbläschen von Carmarina erkannt hatte, fand ich denselben nachher auch bei dem kleineren Glossocodon eurybia wieder, bei welchem seine wesentlichen Eigenthïmlichkeiten oben bereits kurz beschrieben worden sind. Ebendaselbst sind auch die Angaben der früheren Beobachter über die Randbläsehen der Geryoniden-Medusen miteinander verglichen und gezeigt worden, dass wir diese Körper zwar mit voller Bestimmtheit als eigenthünliche Sinneswerkzeuge, aber mit Sicherheit weder als Gehör- noch als Gesichtsorgane bezeichnen dürfen. Es scheint daher vorläufig am sichersten, den neutralen Namen »Sinnesbläschen « für dieselben beizubehalten.

Die 6 radialen und die 6 interradialen Randbläschen von Carmarina hastata sind ron gleicher Grösse und Struetur. Sie liegen nicht frei an der Aussenseite des Schirmrandes, wie man bisher annahm, sondern, wie die Querschnitte (Fig. 63 und 64) auf das Deutlichste zeigen, eingeschlossen in den unteren Randtheil der hỵalinen Mantelgallerte, an der inneren Seite der Basis der 12 centripetalen Mantelspangen, welche an ihrer Aussenseite in der Aussenfliche des Gallertmantels emporsteigen. Ihre Innenseite berihrt den unteren Rand und den untersten Theil der umbralen Wand des Cirkeleanals. Ihre Unterseite oder Basis ruht auf einem Ganglion (f) des Nervenringes (á), welches in dem inneren oberen Rande des Ringknorpels (u k) theilweis eingesenkt liegt.

Jedes Sinnesblisehen stellt eine durchsichtige Kugel von $0,2 \mathrm{~mm}$ Durchmesser dar, deren umhüillende bomogene Membran (b) ziemlich derb und resistent, doppelt contourirt und an der Innenfliche von einer einzigen sehr diinnen Schicht Pflasterepithel ausgekleidet ist. Die grossen, hetlen, sehr platten, polygonalen Zellen desselben, die einen flachen, lïnglich runden Kern umschliessen, treten namentlich bei jüngeren Thieren sehr deutlich hervor, während sie bei iilteren oft schwer zu erkennen sind. An der innem Seite der Basis des Randblüschens, wo dasselbe auf dem Kinoten (f) des Nervenringes wie auf einem flachen Ilügel aufsitzt, erhebt sich ein flaches, rundliches, wahrsclieinliclı unmittelhar mit letzterem in Zusammenhang stehendes P'olster (w), das Basalganglion, welches aus rundlichen und spindel- 
förmigen Zellen mit Kern zusammengesetzt erscheint. Die beiden entgegengesetzten Enden desselben, rechtes und linkes, lanfen in die beiden Sinnesnerven $\left(n^{\prime}\right)$ aus, welche bei dieser Art so scharf von den Nachbartheilen abgegrenzt, so gross und so deutlich aus feinen, parallel nebeneinander gelagerten Fasern zusammengesetzt sind, dass wohl jeder Zweifel an ihrer nervösen Natur schwinden muss. Man braucht nur vorsichtig und mit Vermeidung jeden Druckes die Randblisschen aus dem Rande auszuschneiden und unter dem Mikroskope nach verschiedenen Seiten zu rollen, um sich auf das Sicherste von dem nachstehend beschriebenen Verhalten der beiden Nerven zu überzeugen.

Die beiden Sinnesnerren sind halbkreisförmig gebogene Strïinge, welche cinander gegenüher an der Innenwand des Randbläschens dergestalt emporsteigen, dass beide zusammen einen vollständigen Ring oder Meridian bilden, und an dem oberen, freien, der basalen Anheft!ming entgegengesetzten Pole des Bläschens sich wieder berühren und durchkreuzen. Die Ebene dieses Meridianringes steht senkrecht auf der Ebene des Velum und zugleich senkrecht auf einem in der letzteren liegenden Radius, den man von der Basis des Randbläschens zu dem idealen Centrum des Velumkreises zieht. Es ist demnach die Convexitit der beiden halbkreisförmigen Nervenbügel den beiden benachbarten Randbläschen zugewendet, so dass man bei der Ansicht der Randbläschen von aussen nur den schmalen Rand der bandförmig platt gedrückten beiden Stringe zu sehen bekommt. Der letztére Unstand diurfte wohl hauptsächlich Schuld daran sein, dass die beiden ansehnlichen Nervenbügel den bisherigen Beobachtern völlig entgangen sind, zumal die Dicke der bandförmigen Bügel eine selır geringe ist, so dass sie sich bei der Profilansicht (Fig. 66) nur wie eine starke Verdickung der Bliischenwand ansnehmen (vergl. auch Fig. 8). Die beträchtliche Breite $\left(0,04^{\mathrm{mm}}\right)$ der Nervenbügel wird man erst gewahr, wenn man das Blaischen rollt, so dass man erstere von verschiedenen Seiten sieht (Fig. 8 halb von aussen, halb von oben, Fig. 7 halb von aussen, halb von der Seite). Am deutlichsten aber tritt jeder Simnesnerv auf verticalen Radialschnitten des Mantelrandes hervor, wobei man das Randbläschen von der dem benachbarten Blaischen zugewandten Seite und den Nerren somit in seiner ganzen Breite als einen gleich breiten Strang zu sehen bekömmt, der scheinbar senkrecht von dem basalen unteren zu dem freien oberen Pole des Bläschens emporsteigt (Fig. 63 und 64. $\left.\mathrm{n}^{\prime}\right)$. Die Nerven des ganz unveränderten aus dem lebenden Thiere herausgeschnittenen Randbliischens (Fig. 7) erscheinen zwar sehr blass und zart, wasserhell und farblos, lassen jedoch sowohl die seitlichen 
Grenzlinien als auch eine feine fibrilläre Längssstreifung deutlich erkennen. Letztere tritt sehr scharf hervor nach Behandlung der Bläschen mit rersehiedenen die Nervensubstanz trübenden Reagentien, z. B. verdünten Mineralsïuren und Sublimat (Fig. 8). Es werden dann àuch zahlreiche feine, stäbchenförmige Kerne siehtbar, welche die parallelen Längsstreifen stellenweise unterbrechen und der Nervenring zeigt nun ein Aussehen, welches keine andere Deutung als eine Zusammensetzung aus feinen, parallel nebeneinander verlaufenden und stellenweise mit kleinen Kernen besetzten Fasern zulässt. Eingeselıaltete Ganglienzellen sind während des Verlaufes der Nervenfasern an der Bläschenwand nicht zu erkemnen.

An dem freien, d. h. an dem nach oben gewendeten und dem Basalganglion entgegengesetzten Pole des Randbläsehens angelangt, biegen sich die beiden gegenständigen Nervenbügel, noch ehe sie sich berühren, wieder ein wenig nach unten um und gehen dann, indem sie sich mit ihren pinselförmig ausstrahlenden Fasern kreuzen und durchflechten, in eine eigenthümliche Art von $\mathrm{Ch}$ i a sma ein. Diese Durchkreuzung gesehieht, während die beiden Nervenbügel in das Sinnesganghion eintreten, welches mittelst der ungebogenen und gekreuzten Nervenstränge, wie durch einen kurzen, dicken Stiel, an der oberen Wölbung des Randbläsehens befestigt ist.

Das Sinnesganglion (s) ist eine weiche, helle Kugel, deren Durehmesser $(0,1 \mathrm{~mm})$ halb so gross, als der des Randbläschens ist, und die von einer doppelt contourirten, aber sehr zarten und zerreisbaren hellen, homogenen Membran umschlossen wird. Den Inhalt dieser membranösen Kapsel bilden dicht aneinander gedrangte, gleich grosse und durch gegenseitigen Druck polygonal abgeplattele Zellen, welehe an dem frischen Randblisschen oft kaum zu erkennen sind oder nur als ganz helle, homogene Körperchen erseheinen (Fig. 7). Nach Zusatz von Sublimat oder von verdünnten Säuren treten aber sofort die Grenzen und die Kerne der einzelnen Zellen selır scharf und deutlich hervor (Fig. 8). Bald in der Mitte des Sinnesganglion, bald mehr excentriselı, bald der membranösen Wand desselben anliegend, ist darin das $\mathrm{C}$ on ereme $\mathrm{nt}(\mathrm{x})$ eingeschlossen, welches gewöhnlich als "Otolith « bezeichnet wird. Meistentheils scheint dasselbe wandstandig in dem unteren freien Theile des Sinnesganglion zu liegen, weleher der oberen Eintrittsstelle des Nerven entgegengesetzt ist. In der Regel ist diese Concretion bei Carmaina eine ansehnliche Kugel, deren Durchmesser $\left(0,0: \mathrm{mm}^{\mathrm{m}}\right)$ die Iälfte von dem des Sinnesganglion und $1 / 4$ von dem des Randbläschens betriggt. Seltener ist die Form derselben unregelmässig rundlich oder höekerig. Bisweilen findet sich, der Oberfliche 
derselben aufsitzend, oder in eine kleine Vertiefung derselben flach eingesenkt, noch cine zweite kleinere Concretion ("Nebenotolith(s). Der Otolith ist verkalkt, stark lichtbrechend, dunkel glinzend und zeigt deutlich seine Zusammensetzung aus zahlreichen concentrischen Schichten. Diese bleibt auch an der organischen Substanz noch sichtbar, welche zurückbleibt, wenn man durch verdünute Säuren die Kalksalze entfornt. Der Kalk scheint an. Phosphorsäure gebunden zu sein und löst sich in Sïuren ohne Entwickelıng von Gasbläschıen.

Dasjenige Structurverhältniss, welches an den Randbläschen am schwierigsten festzustelten ist und dessen Erkenntniss doch von dem gröossten Interesse wäre, ist die Endigungsweise der in das Sinnesganglion eingetretenen Nervenfasern. Die beiden Sinnesnerven kreuzen und durchflechten sich, während sie von oben her in das Sinnesganglion eintreten und scheinen dann ihre gekreuzten Fasern in der Weise zwischen den Zellen des Kapselinhaltes pinselförmig auszustrahlen, dass die obere Ilitfte des Concrementes von einem kegelförmigen, nach unten oflenen Fasermantel umgeben ist (Fig. i). Vielleicht stehen die Enden der Nervenfasern mit den Zelten in Zusammenhang. Doch habe ich mir darüber keine Gewissheit verschaffen können. Andere Male hatte es mehr den Anschein, als ob die Nervenfasern nach ihrem Eintritt in das Sinnesganglion zunächst rings um einen abgestutzten Kegel sich ausbreiteten, dessen breite Basis den oberen Pol des kugeligen Concrementes umfasst. Bisweilen schien das ganze Concrement von einer Faserhülle ungeben $\mathrm{zu}$ sein. Es ist aber bei der Zartheit der nervösen Gebilde sehr schwer, diese Verhältnisse festzustellen, um so mehr, da jeder Druck und jede Zerrung bei der Beobachtung ver'mieden werden muss und eine mechanische Präparation, z. B. Freilegung und Ausschälung des Sinnesganglion aus dem Randbläschen, gar nicht auszufuhren ist. Sowohl die Zellen des Sinnesganglion, als die Fasern der Nervenbügel sind so äusserst weich, zart und verletzbar, dass der leiseste Druck genügt, ihre Structur unkenntlich zu machen.

\section{Vil. Metamorphose von Carmarina hastata (Geryonia hastata).}

(Hierzu Taf. IV).

Die Entwickelungsgeschichte und die Formenwandlungen der Carmariniden oder seclıszähligen Geryoniden waren bisher nicht bekannt. Larven der Carmarima hastata von sehr verschiedenen Entwickelungsstufen, welche ich in Nizza gleichzeitig mit den erwachsenen Thieren 
fischte, gaben mir Gelegenheit, den Verwandlungsgang dieser Art im Zusammenhange darzustellen. Die Metamorphose von Carmarina hastata folgt im Grossen und Ganzen denselben Gesetzen, wie die oben beschriebene Verwandelung des Glossocodon eurybia. Nur ist natirlich überall der Unterschied durchgreifend, dass bei dem letzteren alle Organe in Vierzahl oder im Multiplum von Vier sich entwickeln, während bei Carmarina alle Organe in Sechszahl oder im Multiplum von Sechs auftreten. Doch finden sich auch ausserdem noch mancherlei Abweichungen, namentlich im feineren Baue der Larvenorgane, vor, die immerhin eine gesonderte Betrachtung dieser Entwickelung rechtfertig̣en.

Die Herkunft der Larven blieb mir bei Carmarina leider ebenso wie bei Glossocodon unbekannt, da sie simmtlich von der Oberfliche des Meers weggefangen wurden. Versuche, aus befruchteten Eiern Larven zu ziehen, schlugen auch hier fehl. Ich bedaure dies um so mehr, als die im nächsten Abschnitt zu beschreibende Knospenbildung in der Magenhöhle der Carmarina gänzlich verschiedenen Mełtusen den Ursprung giebt und die Fortpflanzungsweise dieser Species mit einem Generationswechsel der merkwürdigsten Art verknüpft sein lissst.

Zunächst ist im Allgemeinen von unseren Larven zu bemerken, dass bei Carmarina nicht das ungleichzeitige Auftreten der alternirenden homotypischen Theile eines und desselben Kreises zu beobachten ist, welches bei Glossocodon so sehr die Regel ist, dass wir danach jedes Stadium der Larvenentwickelung des letzteren in zwei untergeordnete Abschnitte eintheilen konnten. In jedem der drei Tentakelkreise von Glossocodon, sowie in den beiden Kreisen von Sinnesblischen (radialem und interradialem Kreise) erscheinen regelmissig zuerst nur zwei gegenüberstehende homotypische Theile, denen dann das zweite damit alternirende Paar erst später nachfolgt. Dieses ungleichzeitige Auftreten liisst sich an den Tentakeln oft noch lingere Zeit hindureh an der ungleichen Liinge der alternirenden Paare wahrnehmen. Nur ausnahmsweise treten hier alle 4 homotypischen Organe gleichzeitig auf. Bei den Larven von Carmarima dagegen scheint das gleichzeitige Erscheinen aller homotypischen Theile eines jeden Kreises die vorherTschende Regel zu sein. Wenigstens habe ich keine Larven beobachtet, bei denen nur 3 (oder nur 2 oder 4) homotypische Tentakeln oder Randblïschen entwickelt gewesen wiren und die anderen noch gefehtt hïtten. Nicht einmal geringe Unterschiede in der Lïnge gegenständiger oder alternirender Tentakeln, oder merkbare Differenzen in der Grösse correspondirender radialer oder interradialer Randbläselien eines und desselben Kreises, welche eine ungleichzeitige'Entwickelung derselben 
verathen hätten, liessen sich jemals mit Bestimmtheit nachweisen. Es scheinen also stets alle sechs homotypischen Theile eines jeden Kreises gleichzeitig hervorzusprossen.

Die zeitliche Aufeinanderfolge in der Entwickelung der verschiedenen Organe ist bei Carmarina hastata fast dieselbe wie bei Glossocodon eırybia, so dass also die verschiedenen Anhänge des Schirms und die Simnesbläschen auch hier die gleiche Reihenfolge des Erscheinens einhalten, nämlich: 1. die radialen Nebententakeln; 2. die interradialen Tentakeln; 3. die interradialen Randbläschen; 4. die radialen Haupttentakeln; 5. die radialen liandbläschen. Ebenso verschwinden von den beiden nur der Larve zukommenden Tentakelkreisen zuerst die radialen Nebententakeln und dann die interradialen Tentakeln. Es liessen sich also auch hier die oben bei Glossocodon unterschictenen acht Perioden der Metamorphose nachweisen. Da wir bei jener Liriopide bereits dieselben ausführlich geschildert haben, so möge hier von der Carmarinide eine kurze Charakteristik der einzelnen Stadien genügen, mit besonderer Erwähnung der Abweichungen, welche der Entwickelungsgang der Carmarina gegenüber dem der Liriope zeigt.

Die jüngste von mir beobachtete Larvenform der Carmarinu hastata ist in Fig. 54 dargestellt. Es entspricht dieselbe nicht dem ersten, sondern dem zweiten Entwickelungsstadium, das ich von Glossocodon beobachtet habe, indem der kugelige förper bereits mit dem ersten Kreise der Anhinge, mit den 6 radialen Nebententakeln besetzt ist. Es maass diese kugelige Larve, die mir nur in einem einzigen Individuum zu Gesicht kam, ungefähr $1^{\mathrm{mm}}$ im Durchmesser. Der grösste Theil des Körpers besteht aus einer durchaus homogenen und structurlosen Gallertmasse: An der einen Seite hefindet sich eine kleine napfförmige Aushöhlung, die erste Anlage der Schirmhöhle, ausgekleidet mit einem trübkörnigen, grosszelligen Epithel. Der Höhlenrand ist wulstig verdickt, diunkel und setzt sich áls kreisrunder breiter Ring in eine horizontal rorspringende Membran fort, welche zeitweise (im Zustande höchster Contraction) ganz geschlossen, zeitweise von einer weiten kreisrunden, centralen Oeffinung, wie ein Diaphragma, durchbrochen erscheint. Es ist dies das gut entwickelte Velum, welches in dieser Periode die Stelle des Mundes vertritt, sowie die gesammte Schirmhöhle anstatt des noch fehlenden Gastrovascularsystemes zu functioniren scheint. Das dunkle, körnige, aus dickwandigen Cylinderzellen bestehende Epithel der Schirmhöhle ist das einzige Emährungsorgan. Der verdickte Rand des Velum, in welchem schon die erste Anlage des Knorpelringes sich erkennen lasst, ist besetzt mit 6 gleichweit voneinander entfernten, noch selır kurzen, dicken, cylindrischen Tenta- 
keln, die vollkommen den radialen Nebententakeln der Larven von Glossocodon entsprechen.

Dic nächstälteren Larven der Carmarina, welche mir zur Beobachtung kamen, entsprachen der dritten Entwickelungsperiode des Glossocodon. Eine solche ist in Fig. 55 halb von oben, halb von aussen dargestellt. $\mathrm{Zu}$ den 6 radialen Nebententakeln treten jetzt noch 6 interradiale hinzu, die mit denselben alterniren. Die Form des Schirmes beträgt etwa $3 / 4$ einer Kugelfliche ron $2 \mathrm{~mm}$ Durchmesser, welche unten durch die Ebene des Velum, ron etwa 1 1/2 mm Durehmesser, abgeschnitten ist. Die Schirmhöhle findet sich sehr bedeutend erweitert, so dass die Gallertmasse des Schirms beträchtlich reducirt ist. Die Schirmhöble übt nicht mehr die Function einer verdauenden Cavität und das sehr ausgedehnte, mit weiter Oeffnung versehene Yelum nieht mehr die Function des Mundsaumes. Vielmehr ist die Anlage des Gastrovascularsystems bereits vorhanden in Form von 6 ziemlich schmalen, flach bandförmigen Canälen, welche von dem Mittelpuncte der unteren Schirmfläche (Subumbrella) ausgehend, in derselben radial nach dem Rande zu verlaufon und sich hier in einem schmalen Ringgefiiss vereinen. Den centralen Vereinigungspunct der 6 Radialeandile bildet eine ganz flache, in die Ebene der Subumbrella eingesenkte Magentasche, welche sich durch eine sechseckige, von einem verdickten Lippenwulst ungebene Mundöffnung in die Schirmhöhle öffnet. Bei geöffnetem Munde springen die 6 Ecken desselben scharf ein gegen den Abgang der Radialcanäle. Sowohl die radialen als das circulare Gefiiss sind noch sehr schmal, nur ungefähr so breit als die interradialen Tentakehn, deren Auftreten diese dritte Periode charakterisirt. Unmittelbar unter dem unteren Rande des Ringgefässes, wo zugleich der untere Rand des Gallertmantels an den iusseren Rand des Vehum grenzt, markirt sich jetzt sehärfer der dunkle, glänzende Streif, der schon bei der ersten Larve (Fig. 54) als erste Anlage des Knorpelringes erkennbar ist.

Die 12 Tentakeln, welche die Larve in cliesem und im nächstfolgenden vierten Stadium besitzt, sind dergestalt vertheilt, dass die 6 interradialen jüngeren unmittelbar dem ausseren Rande des Knorpelringes aufsitzen, wihrend die 6 mit ihnen alternirenden radialen Nebententakeln bereits vom Rande an die Aussenflïhe des Schirmes hinaufgestiegen sind, und mit dem Knorpelringe nur noch durch eine centripetale Mantelspange zusammenhängen. Die 6 radialen Nebententakeln haben oft schon in diesem Stadium den höchsten Grad ihrer Entwickelung erreicht und erscheinen als ansehnlich dicke Cylinder, doppelt so stark als die interradialen, hinter denen sie allerdings an Liinge bald becleutend zurückbleiben. 
Die 12 Larvententakeln der Carmarina fehlen wie bei Glossocodon dem erwachsenen Thiere völlig und sind also wesentlich als vorübergehende Larvenorgane zu betrachten. Sie sind in Bau und Verrichtung völlig verschieden von den erst später auftretenden radialen Haupttentakeln, die dem geschlechtsreifen Thiere allein ubrig geblieben sind. Während die letzteren hohle, wurmförmig bewegliche Cylinder sind, die den oben ausführlich geschilderten, eigenthümlichen und complicirten Bau zeigen, sind dagegen die radialen Nebententakeln (s l) und die ebenso gebauten interradialen Tentakeln (y) der Larven von Carmarina starre, solide Cylinder, die völlig von jenen in der Structur und in den Bewegungserscheinungen abweichen (Fig. 64 und 65). Sie bestehen wesentlich aus einem cylindrischen Knorpelstreifen, welcher von einem Schlauche quergestreifter longitudinaler Muskelfasern umschlossen und über diesem aussen von einem Epitheliallager umhüllt ist. Der Medusenknorpel, welcher die formgebende Grundlage und die Hauptmasse der 12 Larvententakeln bildet, besteht an den radialen Nebententakeln der Carmarina aus einer einzigen Reihe sehr dickwandiger, kurz cylindrischer Knorpelzellen, die wie die Münzen einer Geldrolle übereinander liegen (Fig. $6.3 \mathrm{~s} \mathrm{k}$ ). Ihre Zahl beträgt bei den längsten und böchst entwickelten Tentakeln höchstens 10 bis 15. Dagegen sind die Knorpelzellen der interradialen Tentakeln weit zahlseicher und grösser, aber auch viel dünnwandiger und liegen nicht in einer, sondern in mehreren Reihen neben- und hintereimander (Fig. 64. y k). Sie sind durch gegenseitigen Druck polygonal abgeplattet. Auf Querschnitten durch einen ganz entwickelten interradialen Tentakel würde man an der Basis etwa 6 bis 10 , in der Mitte 3 bis 6 , im äusseren Ende 2 bis 4 Zellen nebeneinander finden. Der Muskelschlauch, welcher den Knorpelcylinder ummittelbar umschliesst, besteht nur aus einer einzigen, sehr dünnen Lage von quergestreiften Muskelfasern, die regélnässig und sehr dicht nebeneinander gelagert, der Länge nach verlaufen. Circulare oder radiale Muskeln fehlen gänzlich. Zwischen dem Muskelschlauch und dem Knorpeleylinder, streckenweis auch zwischen Zellen des letzteren, verläuft an den interradialen Tentakeln ein dünner Nerv, die Fortsetzung des Spangennerven (Fig. 6 \& y n). Er erscheint als ein dümer, blasser, feinfaseriger, mit einzelnen spindelförmigen (Ganglien?) Zellen durchsetzter Strang, der an die einzelnen Nesselpolster Aeste abgiebt. Der Epithelialüberzug, der das Muskelrohr sehr locker anliegend umschliesst, so dass er bei starker Verkürzung der Tentakeln sich in circulare Falten legt (Fig. 64 y e und $65 \mathrm{~s}$ e), besteht aus einer einfachen Lage ziemlich grosser, flach gewölbter Zellen, welche an bestimmten Stellen Nesselkapseln entwickeln. An den 
radialen Nebententakeln sind die sämmtlichen Nesselzellen in einen einzigen grossen, kugeligen Knopf radial dergestalt zusammengestellt, dass ihre verlängerten Axen sich im Centrum der Kugel treffen würden. Der Durchmesser des Knopfs ist fast doppelt so gross als derjenige des darunter befindlichen äusseren Tentakelendes. Der Nesselknopf trägt einen kurzen und sehr dünnen peitschenförmigen Anhang, aus kleinen, hellen, polyedrischen Zellen zusammengesetzt. An den interradialen Tentakeln sind die Nesselzellen auf eine Anzahl concav-convexer kreisrunder Polster vertheilt, welche mit ihrer concaven Fläche höchstens ein Drittel von der Oherfliche des cylindrischen Muskelschlauchs umfassen. Die Nesselzellen sind in diesen Polstern derart radial zusammengestellt, dass ihre verlängerten Axen sich in der Cylinderaxe schneiden würden. Die Polster sitzen sämmtlich an der unteren oder inneren, subumbralen (gewöhnlich am aufwärtsgeschlagenen Tentakel nach aussen gekehrten) Seite des Tentakels in der Art in einer Reihe hintereinander, dass sie durch ungefihtr ebenso breite Zwischenräume voneinander getrennt sind. Die Zahl der Nesselwarzen nimmt mit dem Alter der Larve zu. In Zustande der höchsten Entwickelung besitzt jeder interradiale Tentakel von Carmarina bis zu 12 Nesselpolster hintereinander (Fig. 58 und 59).

Sowohl die interradialen als die radialen Nebententakeln entwickeln sich sämmllich vom Schirmrande aus, mit dem sie auch späterhin, wenn sie an der Aussenfläche des Schirmes in die Höhe gerückit sind, durch die centripetalen oder marginalen Mantelspangen ( $h$ ) noch in continuirlicher Verbindung bleiben. Es setzen sich daher auch sämmtliche Gewelosschichten des Mantelrandes auf die Mantelspangen und von da auf den Schirm fort, und die Mantelspange gleicht in ihrem Baue, wie bereits oben gezeigt wurde, wesentlich einem Larvententakel. Der dünne, cylindrische, aus einer einzigen Zellenreihe bestehende Knorpelstreif, welcher die Grundlage der Mantelspange bildet, geht vom Knorpelring des Mantelrandes aus und verbindet denselben continuirlich mit dem knorpeligen Cylinder der Larvententakeln. Der cylindrische Muskelbeleg der letzteren setzt sich ebenso continuirlich als unmittelbare Umhüllung auf die Knorpelspange und von deren Basis auf den Aussenrand des Velum fort. Der radiale Nerv, welchen die Mantelspange vom Randganglion zur Basis des Tentakels führt, setzt sich unmittelbar auf letzteren fort, und endlich das Nesselzellen fülırende Epithel des Tentakels hängt durch den ebenso gebauten Epithelialüberzug der Spange continuirlich mil dem gleichen Ueberzuge des Ringknorpels zusammen.

Die Zahl der Nesselpolster an den interradialen Tentakeln steigt 
noch während der dritten Entwickelungsperiode, in der sie zuerst auftreten, von einem bis zu 3 bis 4 . In dem darauf folgenden Stadium steigt sie auf 5 bis 6 und die Länge der Tentakeln kommt nun ungefähr (lem Schirnradius gleich (Fig. 56). In dieser vierten Periode treten die ersten Sinnesbläschen auf und zwar die 6 interradialen Bläschen (Fig. 66 und $64 \mathrm{~h} \mathrm{i}$ ). Sie erscheinen zuerst als helle halbkugelige Wuilste, welche mittelst eines kleinen, dunkeln, feinkörnigen Knotens auf einer stark spindelförmig verdickten Stelle des Knorpelrings aufsitzen; dieser Knoten (Fig. $66 \mathrm{f}$ ) ist die Anlage des Randganglion; denn auch das Nervensystem, welches vielleicht schon früher angelegt ist, tritt nun deutlich erkennbar hervor. Der Nervenring (Fig. 66 a) wird als schr feiner, blasser, längsfaseriger Streif hinter dem oberen Rande des Ringknorpels sichtbar, ebenso der Radialnerv an der unteren Wand des Radialcanales. In den homogenen glashellen Sinneskörperchen wirl bald eine. Differenz zwischen einer äusseren Hülle (b) und einem cingeschlossenen hellen, kleineren Körperchen (s) sichtbar, den Sinnesganglion; und im letzteren tritt bald die dunklere Concretion deutlich hervor. Das Blïschen dehnt sich kugelig aus und hebt sich mehr und mehr von dem darunter liegenden Knoten (f) ab.

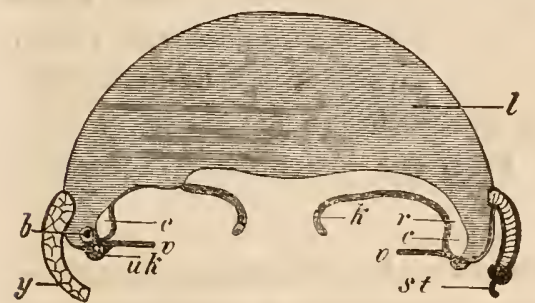

Fig. 97. Schema eines radialen Verticalschnittes durch eine Larve von Carmarina hastata (aus der vierten Entwichelungsperiode), rechts durch einen radialen Nebententakel, links durch eineu interradialen Knorpeltentakel gefuilirt. b. Randbiäschen. c. Ringcanal. h. Mantelspange. k. Magen. 1. Gallertmantel. r. Radialcanal. s t. Radialer Nebententakel. u k. Knorpelring. v. Velum. y. Interradialer Tentakel.

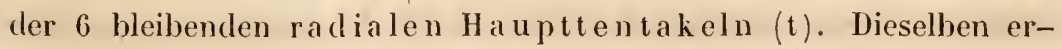
scheinen zuerst als ganz kleine, runde Warzen an der Aussenfliche des Schirmes, welche wie kurze taschenförmige Ausstulpungen des Ringgefïsses nach aussen oberhalb des Knorpelringes hervorragen. Sie treten hier (von aussen oder unten betrachtet) rechts neben der Basis der 
benachbarten marginalen Mantelspange hervor, welche von dem Schirmrand zu dem darüber gelegenen radialen Nebententakel emporsteigt. Die radialen Haupttentakeln unterscheiden sich also nicht allein im Bau und den Bewegungserscheinungen, sondern auch in der Entwickelungsweise wesentlich von den radialen Nebententakeln ( $\mathrm{t}$ ) und den interradialen Tentakeln (y). Die beiden letzteren sind von Anfang an solide Fortsaitze oder Ausläufer des Schirmrandes, dessen verschiedene Elemente (Knorpel, Muskeln, Nerv, Nesselepithel) in ihre Zusammensetzung eingehen. Die radialen Haupttentakeln dagegen zeigen sich von Anbeginn an als holıle, blindsackförmige Ausstülpungen des Cirkelcanales, dessen Epithel sich in ihren Axencanal fortsetzt (Fig. 98 1).

Während nun die radialen Ilaupttentakeln rasch wachsen, beginnt auch das Gastrovascularsystem in der fünften Periode sich weiter zu entwickeln. Der Magenschlauch, welcher bisher als ganz flache Tasche in die Mitte der Subumbrella eingesenkt lag, verlängert sich zu einem dickwandigen Cylinder, der bis zur halben Höhe der Schirmhöhle herahhängt und an der erweiterten Nundoffinung oft in 6 Falten gelegt, fast sechslappig erscheint. Im Grunde des Magensackes verlingert sich die Gallertsubstanz des Mantels in ein frei vorragendes conisches Zïpfchen, die Anlage des Zungenkegels. Die ersten Centripetaleanäle treten als zungenförmige Blindsäcke in der Mitte zwischen je 2 Radialeanälen deutlicher hervor, nachdem sie schon in der vierten Periode durch Vorwölbung des Cirkelcanals über der Basis der interradialen Tentakeln angelegt worden waren.

In der sechsten Periode bringt das Erscheinen der 6 radialen Randbläschen die progressive Entwickelung der Carmarina zum Abschluss (Fig. 58). Dieselben bilden sich in gleicher Weise wie die interradialen und erscheinen zuerst als helle, halbkugelige Knöpfchen an der Basis der radialen Mantelspangen, links neben der $\mathrm{Ab}$ gangsstelle der radialen Ilaupttentakeln. Die letzteren haben durch rasches Wachsthum schon eine ansehnliche Lainge erreicht, welche den Schirmdurchmesser bedeutend übertrillt, der jetzt ungefialır $8 \mathrm{~mm}$ betrïgt. Der Schirm wird flacher gewölbt, indem namentlich der Schirmrand stark nach aussen wïchst und die Schirmhöhle sich auf Kosten der Gallertsubstanz des Mantels ausdehnt. Dadurch werden auch die Mantelspangen länger ausgezogen, während die 12 knorpeligen Larvententakeln an der Aussenfliche des Schirmes in die Ilöhe steigen. Von den letzteren gehen die radialen Nebententakeln wun schon ihrem Ende entgegen, indem sie ihren Nesselknopf verlieren und als schlaffe Füiden herabhängen. Auch das Wachsthum der interradialen Tentakeln, 
welelie jekt 10 bis 12 Nesselpolster an der subumbralen Seite tragen, schliesst jetzt ab.

Das Gastrovaseularsystem zeigt seine weitere Ausbildung in der sechsten Periode einmal durch die Ausbildung neuer Centripetalcanäle und sodamn namentlich durch das Ileranwachsen des Magenstieles. Neben jedem Centripetalcanale erster Ordnung (Fig. $98 \mathrm{e}$ ) (der einer interradialen Mantelspange entspricht) tritt rechts und links, in der Mitte zwisehen ihm und dem benachbarten Cirkeleanale, ein neuer kürzerer Blindsack als Ausstülpung des Cirkelcanals nach obęn hin auf,

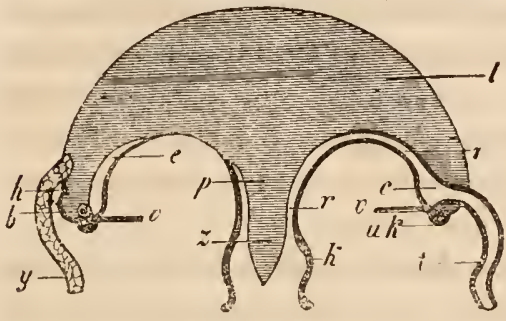

Fig. 98. Schema eines radialen Verticalschnittes durch eine Larve von $\mathrm{Car}$ marina hastata (aus der seclisten Entwickelungsperiode), rechts durch einen radialen hohlen Haupttentakel, links durcli einen interradialen linorpeltentakel gefülnt. b. Randblischen. c. Ringcanal. e. Centripetalcanal. li. Mantelspange. k. Magen. I. Gallertmantel. r. Radialcanal. i. Raclialer Haupttentakel. uk. Knorpelring. v. Velum. y. Interradialer Tentakel. z. Zunge. so dass jetzt die Larve im Ganzen schon 18 blinde Centripetalcanäle besitzt. Der Magenstiel entsteht dadurch, dass der Zungenkegel (Fig. $98 \mathrm{z}$ ), der schon in der vorigen Periode als ein kurzer conischer Zapfen von der Mitte des Schirmhöhlengrundes aus in die Magenhöhle hineingewachsen war, sich nun betriichtlich verliingert und ringsum mit der Magenwand verwächst, so dass bloss dic 6 Radialcanäle oflen bleiben. Während diese vorher gemeinsam in die flache Magentasche mündeten, laulen sie nun getrennt an der Oberfliiche des Magenstiels herab, um erst an dessen Ende in die eigentliche Magenhöhle zich zu öffnen. Diese erscheint an der in Fig. 58 abgcbildeten Larve nur als eine sehr kleine, flache Glocke, deren Mundsaum in 6 Zipfel ausgezogen ist und in deren Ilöhlung die kurze freie Spitze des Zungenkegels verborgen liegt.

Carmarina hastata ist jetzt, am Ende der sechsten Periode, bei einem Schirmdurchmesser von $8^{\mathrm{mm}}$, mit verschiedenartigen Anhängen weit reicher ausgestattet als das erwachsene geschlechtsreife Thier, indem sie nicht weniger als 3 verschiedene Kreise von je 6 Tentakeln trïgt. Die weiteren Veränderungen, welche das Thier nun noch zu durchlaufen hat, bestehen einestheils in der Ausbildung der Genitalien und der noch fehlenden Centripetalcanäle dritter Ordnung; anderntheils in einer Reduction der Tentakelanhänge, von denen zuerst die 6 radialen Nebententakeln und dann auch die 6 interradialen Tentakeln abfallen, so dass schliesslich nur die 6 bohlen radialen Haupttentakeln 
übrig bleiben. Man könnte demgemïss noch 2 Stadien der Verwandelung unterscheiden.

Das siebente Stadium, durch den Wegfall der radialen Nebententakeln (s l) charakterisirt, ist in Fig. 59 dargestellt. Die radialen Haupttentakeln sind bei diesen Larven, deren Schirmdurchmesser $12 \mathrm{~mm}$ beträgt, schon bedeutend linger geworden. Die interradialen Tentakeln treten dagegen sehr zurück, werden sehlall und welken ab. Oft löst sich auch ihre freie Spitze mit den oberen Nesselknöpfen sçon stiickweis ab. Der Magenstiel verliingert sich bedeutend, ebenso auch seine untere feine Spitze, welche als Zungenkegel aus der Magenhöhle vortritt. Die Centripetaleanïle dritter Ordnung fehlen noch, so dass zwischen 2 radialen inuer noch nur 3 centripetale sichtbar sind. Bisweilen fangen schon in diesem Stadium, bei einem Schirmdurehmesser von $10-1: 3 \mathrm{~mm}$, die Gesehlechtsorgane als seitliche Ausstülpungen der Radialcaniile sich zu entwickeln an.

Der achte Als schnitt des Larvenlebens endlich wird durch das Verschwinden der interradialen Tentakeln und durch die Entwickelung der noeh fehlenden Centripetaleanäle dritter Ordnung bezeichnet. Von den letzteren sprossen je 4 in dem Zwischenraum zwischen je 2 Radialeanilen aus dem Cirkeleanale hervor. Sie erreichen aber nur die Hälfte oder höchstens \% von der Länge der Centripetalcanäle erster und zweiter Ordnung, mil denen sie alterniren. Der Schirmrand des Thicres wächst nun noch bedeutend. Dabei nimmt die Wölbung des Schirmes und die Dicke seines Gallertuantels verhailtnissmaissig ab. Der Magenstiel und die 6 radialen liaupttentakeln, welehe jetzt allein noch von allen 18 Randanhängen iibrig sind, nehmen an Länge noch betrichtlich zu, ebenso auch der Zungenkegel und der Magensack, in welchem der letztere verborgen ist.

Die Entwickelung der Geschlechtsorgane, mil welcher das Thier seine volle Reife erlangen sollte, tritt dennoch bei Carmarina, ebenso wie bei Glossocodon, oft schon lange vor dem Abschlusse des Wachsthums cin. Sehon kleine Carmarinen von $15-20 \mathrm{~mm}$ Sehirmdurehmesser zeigen die heginnenden Ausbuchtungen an den Seitenrändern der in der Subumbrella verlaufenden Radialeaüle, welche sich zu den flachen Seitentaschen erweitern, aus deren subumbralem Epithel sich die Geschlechtsproducte entwickeln. Ausnahmsweise treten dieselben schon im siebenten Stadium auf, wenn die interradialen Tentakeln noch vorhanden und erst 18 Centripetalcanaile ausgebildet sind. Sehr selten dagegen (und ich habe dies nur cinmal gesehen), begegnet man Carmarinen, welche noch alle 18 Tentakeh tragen und dennoch schon die beginnende Ausbuchtung der Radialeanaile zu den Genital- 
blättern erkennen lassen. Die für Carmarina hastata charakteristische Spiessform nehmen die Genitalblätter erst spaiterhin, bei ganz erwachsenen Thieren, an, während sie bci jüngeren noch als gleichschenklige Dreiecke mit schmaler Basis erscheinen, deren Ecken sich erst später allmählich flügelförnig ausziehen und verbreitern.

\section{Kuspenbildung in đer Mageuhöhle (an der Zunge) von Carmarina hastata.}

$$
\text { (Hierzu Taf. VI Fig. 74-77.) }
$$

Wenn die Erkenntniss der thierischen Fortpflanzungsverhältnisse durch die Fülle überraschender Entdeckungen, welche die Arbeiten der letzten Decennien bei den niederen Thieren zu Tage gefördert haben, einer der interessantesten Zweige der Zoologie geworden ist, so gilt dies ganz besonders mit Bezug auf die umfangreiche Abtheilung der Coelenteraten und namentlich die Classe der Hydromedusen. Fast alle denkbaren Möglichkeiten der geschlechtlichen und ungeschlechtlichen Fortpflanzung, des Generationswechsels und des Polymorphismus scheinen in dieser merkwürdigen Thierclasse erschöpft zu sein; und dennoch liefert fast jede genauere Untersuchung einer einzelnen kleineren Gruppe oder selbst einer einzigen Species und ihres Formenkreises neue überraschende und seltsame Entdeckungen. Auch die eingehende Untersuchung der sechszähligen Geryoniden sollte in dieser Beziehung nicht ohne Erfolg sein.

Während Carmarina hastata Geschlechtsproducte entwickelt, aus denen wahrscheinlich die sechszähligen Larven hervorgehen, deren Metanorphose im vorigen Abschnitte dargestellt wurde, erzeugt dasselbe Thier gleichzeitig auf ungeschlechtlichem Wege achtzählige Knospen, die zu einer ganz verschiedenen Medusenform sich entwickeln. Sowohl die gänzliche Verschiedenheit dieser achtzähligen Medusenknospen von dem sechsstrahligen Mutterthicre und dessen Larven, als auch das Hervorknospen derselben in zahlreichen Gesellschaften aus dem Zungenkegel - innerhalb der Magenhöhle des Mutterthieres, - lassen diese neue Form des Generationswechsels als eine der seltsamsten Complicationen auf diesem an abenteuerlichen Verwickelungen so reichen Gebiete erscheinen.

Schon vor mehr als 20 Jahren wäre dieser merkwürdige Vorgang beinahe von einem Beobachter, der sich um die Entwickelungsgeschichte der niederen Thiere dic grössten Verdienste erworben hat, von August 
Krons, entdeckt worden. Bei Mittheilung seiner »Bemerkungen utber den Bau und die Fortpllanzung der Eleutheria ${ }^{1}$ ), welehe in geschlechtsreifem Zustande Knospen treibt, bemerkt Kroux (I. c. p. 16\%. Anınerkung): "Während meines Aufenthaltes in Messina, im Jahre 18 \$3, kam mir ein weibliches Exemplar von Geryonia proboscidalis zu Gesicht, dessen wie bei Liriope frei in die Magenhöhle hinabreichendes Stielende mit Sprösslingen von ungleicher Entwickelung dicht besetzt erschien. Die minder entwickelten nahmen den oberen, die weiter vorgeschrittenen den unteren Theil desselhen ein. An jenen licssen sich bloss Sehirm und Stiel unterscheiden, diese hatten nicht nur schon die sechs Fangfäden oder Tentakeln, sondern auch die Randkörper entwickelt. Alle diese Sprösslinge sassen mit dem Scheitelpunete ihres Schirmes dem Stielende des Mutterthieres fest auf. So befremdend es auch sein mag, Knospen innerhalb eines Organs hervorkeimen zu sehen, das zugleich zur Aufnahme und Verdauung der Nahrung bestimmt ist, so darf doch nicht übersehen werden, dass dieselbe Erscheinung bereits an einer andern Meduse beobachtet ist. Es ist die Aegineta prolifera von Gegenbaur ".

Dieser wichtigen, aber nicht weiter verfolgten Beobachtung des verdienstvollen Квонм schliesst sich cine ähnliche, ebenfalls gánz vereinzelte Beobachtung von Fritz Müller an, welche in demselben Bancle ${ }^{2}$ ) des Archivs f. N. mitgetheilt ist und die ich wegen ihrer Wichtigkeit ebenfalls wörtlich anführe. Sie betrifft Liriope cutharinensis. Er sagt (1.e. p. 51): „Zu Anfang dieses Jahres (1860) fing ich cine Liriope catharinensis, der ein langer blassgelblicher Zapfen aus dem Munde hervorhing. Bei näherer Untersuchung ergab sich derselbe als eine aus dichtgedrängten Quallenknospen bestehende Aehre, deren Ende die Liriope verschluckt hatte (Fig. 30). Der frei vorhängende Theil hatte $1,75 \mathrm{~mm}$ Länge und $^{-}$ die grössten Quallenknospen fast $0,5 \mathrm{~mm}$ Durchmesser. Sie waren fast halbkugelig und die gewölbte Fläehe sass mit kurzem Stiele an der gemeinsamen Axe fest. Am freien Rande erhoben sich acht halbkugelige Randbläschen mit kugliger Coneretion; etwa in der Mitte zwischen Rand und Scheitel sprossten abwechselnd mit den Randbläsehen acht kurze plumpe Tentakel hervor. Auf der freien ebenen oder flach gewölbten Fläche der Knospe zeigte sich ein grosser ganzrandiger Mund, der in einen flach ausgebreiteten Magen führte. Alle diese Eigenthümlichkeiten stimmen mit der achtstrahligen Form von Cunina Köllikeri, während nicht die entfernteste Aehnlichkeit mit irgend einer an-

1) Archiv für Naturgeschichte, 1861. XXVII, 1. p. 168.

2) Archiv für Naturgeschichte, 1861. XXVII, 1. p. 51. 
dern der in Laufe von 4 Jahren hier von mir beobachteten Quallen besteht."

Obwohl die letztere Bemerkung wahrscheinlich vollkommen richtig ist, so wird sich doch durch Vergleichung mit den folgenden Mittheilungen fast mit Gewissheit ergeben, dass diese aus Quallenknospen bestehende Aehre nicht von der Liriope verschluckt war, sondern dass sie als ein Product derselben, durch Knospenbildung im Magen selbst entstanden, aufzufassen sei, wie es bei jener von Krouv beobachteten Geryonia der Fall war. Diese Vermuthung ist auch bereits von Leuckant ausgesprochen, der in seinem Jahresbericht für 1861 den von KRoHN und den von Fritz Müller beobachteten Fall neben einander stellt und bemerkt, dass der letztere sich »aller Wahrscheinlichkeit nach « durch den ersteren erkläre. ${ }^{1}$ )

Sowohl Krouv's als Fritz Müller's Beobachtung war mir unbekannt, als ich in Mär'z und April 1864 bei Nizza zahlreiche Exemplare von Carmarina hastata untersuchte und die Fortsetzung des Magenstiels in die Magenhöhle hinein beobachtete, welche ich oben als Zungenkegel oder Zunge beschrieben habe (Fig. 4, ren fand ich in dem Mageninhalte, gemischt mit Crustaceen, Sagitten und anderen kleinen pelagischen Organismen, welche die Carmarinen gefressen hatten, einen etwa $\breve{b}-8^{\mathrm{mm}}$ langen und $2-3^{\mathrm{mm}}$ dicken, trüben, blassgelblichen cylindrischen Zapfen, welcher einem IIaufen von Fischeiern glich und aus kleinen runden Körnern von ungleicher Grösse (die grössten von $1 \mathrm{~mm}$ ) zusammengesetzt war. Unter das Mikroskop gebracht, gab sich dieser Körnerzapfen als eine aus zahlreichen (über 50) kleinen Quallenknospen zusammengesetzle Aehre zu erkennen. Die kleinen Medusen waren mit ihrer Schirmwölbung (dem Aboralpol) an einer centralen cylindrischen Axe befestigt. Die ältesten Knospen (von $1 \mathrm{~mm}$ Durchmesser) zeigten einen flach scheibenförmigen dicken Schirm, dessen der Anheftungsstelle entgegengesetzte Unterfläche in der Mitte in einen kurzen cylindrisehen Magen mit runder platter Mundöffnung verlängert war. In der Peripherie der Seheibe zeigten sich 8 kurze Tentakeln und in der Mitte zwischen diesen, an 8 vorspringenden Lappen des Schirmrandes, 8 Randbläschen.

Da ich bei den beiden Carmarinen, in deren Magen ich diese Quallenähren beobachtete, dieselben scheinbar vollkommen frei in der Magenhöhlung gefunden hatte und da beide (gleichzeitig gefangene) Individuen auch ausserdem dieselben Nahrungsbestandtheile, die gleichen Arten von Gopepoden, Sagitten und Würmerlarven im Magen enthielten,

1) Archiv für Naturgeschichte, 1864. XXX, 2. p. 165. 
118 VIII. Kuospenbildung in der Magenhöhle (an der Znuge) ron Carmariua hastata.

so zweifelte ich nicht, dass auch jene seltsimen Medusenähren, deren Ursprung ich auf keine der mir bekannten Medusenartèn zurückzuftihren vermochte, vor den beiden Carmarinen mit der anderen Beute zufällig verschluckt worden seien. An einen genetischen Zusammenhang der achtstrahligen Ḱnospen nit den sechszähligen Geryoniden konnte ich um so weniger denken, als ich damals schon die Metamorphose der sechszaluligen Larven von Carmarina beobachtet hatte. Erst als mir nach meiner Rückkehr von Nizza die von Krohx und Frıtz Müllek beobachteten beiden Faille bekannt geworden waren, dachte ich daran, dass wohl auch jene beiden scheinbar verschluckten Aehren möglicherweise in gleicher Art von der Carmarina abstammen könnten. Ich untersuchte sorgfältig alle aus Nizza mitgebrachten und in Salzlösung sehr wohl conservirten Exemplare der letzteren und war nicht wenig überrascht und erfreut, im Magen von mehreren geschlechtsreifen Thieren, sowohl von Männchen, als von Weibehen noch vollkommen wohlerhaltene Knospenähren anzutreffen (Fig. 74, 75).

Die Anzahl der conservirten geschlechtsreifen Exemplare, die ich nachtriglich untersuchen kounte, betrug 2:3. Von diesen besassen nicht weniger als 9 einen verstummelten und theilweise in Reproduction begriffenen Magen $\left.{ }^{1}\right)$. Von den 14 ubrigen geschlechtsreifen Carmarimen zeigten die 2 grössten Exemplare, mit einem Schirmdurelımesser von $50-60^{\mathrm{mn}}$, in ihren Magen keine Spur von Knospenbildung, eben so wenig auch 5 jüngere Individuen, deren Schirmdurchmesser nur zwischen 15 und $2.5 \mathrm{~mm}$ betrug, und bei denen eben erst die Bildung der Genitalblätter als seitlicher Ausbuchtungen der Radialcanäle begann. Die 7 übrigen Exemplare, mit einem Durchmesser von $30-40 \mathrm{~mm}$, zeigten sämmtlich in ihrem Magen eine Knospenïhre, und zwar gehörten die knospentragenden Mägen beiden Geschlechtern an, indem 4 von jenen 7 Thieren weiblich, die 3 andern männlich waren. Das eine Weibchen trug 2 Knospenähren im Magen, was ich für eine zufallige Abnormitat, bedingt vielleicht durch ursprüngliche Spaltung des Zungenkegels, halte. Larven und jüngere Individuen von

1) Dieser ausserordentlich häufige Verlust des Magens, welcher den Carmarinen nichts zu schaden und sehr rasch ersetzt zu werden sehcint, crklärt sich, wie ich glaube, dadurch, dass der lange Magenstiel, welcher von den sehwimmenden sowohl, als von den ruhig im Wasser sehwebenden Thieren wie ein Pendel langsam hin und her bewegt wird, die Fische wie cin Köder anlockt, und oft von diesen abgebissen wird. Auch reisst wahrscheinlich der verhälıissnässig dunne Magenstiel leicht ab, wenn die Carmarina, wie es bisweilen geschehen mag, ein ihr an Kraft überlegenes Thier mit dem Magen erfasst und verschluckt hat, welches noch innerhalb desselben heftige Bewegungen auszuführen vermag. 
Carmarina, bei denen noch keine Entwickelung der Genitalien bemerkbar war, zeigten auch keine Spur von Knospen im Magen. Bei allen 7 knospentragenden Individuen enthielten dic Genitalblätter zwar vollkommen reife Geschlechtsproducte, zeigten aber doch nur einen mittleren Grad der Entwickelung, indem sie schunale gleichschenkelige Dreiecke darstellten, noch olne die flügelförmige Auslsreitung der Basis, welche sie bei ganz erwachsenen Thieren annehmen (Fig. 1).

Die Knospenahren (Fig. 7. $)$ ) waren im Mittel etwa $1-8 \mathrm{~mm}$ lang, und $1-2$, höehstens $3^{\text {"mu }}$ breit. Sie erfülten bald nur den mittleren Axenraum, bald den grössten Theil der Höhlung des stark zusammengezogenen Magens (Fig. 7i). Sie lösten sich sehr leicht, schon bei leiser Beruihrung, ron dem Grundr des der Länge nach aufgeschnittenen Magens ab, so dass sie frei in demselben zu liegen schienen. Die eylindrisehe Form der Aehre wurde durch die an der Oberfläche in ungleicher Vertheilung vor:pringenden grösseren Knospen etwas unregelmaissig. Zwischen den grösseren und mittleren Knospen sassen überall sehr zahlreiche heinere und hleinste vertheilt, so jedoch, dass die letzteren mehr an dem oberen, die ersteren mehr an den unteren Theile angehauft waren. ln allgemeinen Ilabitus gliehen die jüngeren, kleineren Aehren der von Futz. Yüunen abgrebildeten knospen:̈hre. An 2 der grössten Achren hahe ich dic Knospen gezihlt. Ich vertheilte die knospen nach ihrer Grösse in :3 Chassen: Grosse, deren Sehirmdurchmesser $0,8-1$ mm betryg, mittere, mit einem Durelmesser $z$ wischen $0, \ddot{z}$ und $0,8 \mathrm{~mm}$ und kleiue, mit einem Durchmesser von $0,1-0, \ddot{3}$ mm. Die kleinsten knospen, unter 0,1 mus 1 urden gar nicht mitgezihlt. Die eine jener beiden Achren, von einem Minnchen producirt, trug nicht weniger als 85 Knospen, nämlich 11 grosse, 21 mittlere und 53 kleine. Die andere, von einem Weibchen erzeugte Achre trug 71 Knospen, nämlich 7 grosse, 18 mittlere und 46 kleine. Bei der in Fig. 7\% abgebildeten Aehre, die ebenfalls zu den grössten gehörte, mag die Zahl der Knospen gleichfalls gegen hundert bet'agen, die kleinsten gar nicht einmal eingerechnet. Die kleineren Achren mochten ungefahr zwischen 20 und 50 Knospen tragen. Auch hier sind die kleinsten, unter 0, ${ }^{\mathrm{mm}}$ Durchmesşer, nicht mit gerechnet. Sämmtliche Knospen sassen so dichtgedrängt neben und durch einander, dass die Oberflïche der gemeinsamen Zapfenaxe zwischen ihnen fast nirgends sichtbar war.

Bei der genaueren Untersuchung zeigte sich, dass die gemeinsame Axe der Aehre, an welche sämmtliche Medusenknospen mit der Mitte ihrer aboralen Schirmflaiche angeheftet waren, nichts anderes, als dic

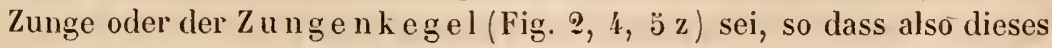


seltsame Gebilele, welches spaiterhin nur als Tastorgan und vielleicht zugleich als Geschmacksorgan benutzt zu werden scheint, in einem gewissen Lebensalter ler Carmarina, zur Zeit der mittleren Geschlechtsreife(?), als $\mathrm{K} n$ os pen s t ock fungirt. Die Structur der Zunge sehien mir, soviel ich an den in Salzlösung conservirten Thieren erkennen konnte, nicht verschieden zu sein von derjenigen des ganz erwaclısenen Thieres. Namentlich erschien mir die Zunge auch jetzt als ein durchaus homogener und solider Gallertzapfen, der als unmittelbare Fortsetzung des soliden Magenstiels heine Ilöhlung enthielt.

Schon die erste oberflächliche Betrachtung der Knospen, noch mehr aber die genauere Untersuchung ihres Baues führte zu den iuberraschendsten Resultaten. Es war mir dabei sehr werthroll, dass ich einen der ersten Medusenkenner, meinen Freund Gegexbaur als Zeugen herbeiholen und sich von diesen paradoxen Verhiltnissen mit eigenen Augen über'zeugen lassen konnte. Zunäclıst ist hervorzuheben, dass sammtliche Knospen ohne Ausnahme aus acht gleichen Theilen zusammengesetz $t$ waren, wilhrend alle Carmarinen, die ich im erwachsenen Zustande beobachtete, und ebenso alle im VII. Abschnitte gesehilderten Larven derselben, ohne cine einzige Ausuahme, aus sechs gleichen Abschnitten bestanden. Die iussere Körperform, der innere Bau, die Bildung der Anhänge des Körper's u. s. w. sind dahei so durehgreifend, sowohl von den entsprechenden Verhältnissen der erwachsenen Carmarina, als auch von denen ihrer sechszähligen Larven verschieden, dass man an einen genetischen Zusammenhang der beiderlei Formen nimmermehr denken wiirde, wenn man sie nicht eben in continuirlichem materiellen Zusammenhange erblickte.

Die En $t$ wickelung der K nospen aus der Oberfliche der Zunge liess sich mit befriedigender Sicherheit durch alle Stadien hindurch verfolgen, trotzdem die Knospen dureh die Aufbewahrung in Salzlösung sehr undurchsichtig geworden und dabei so brüchig und weich waren, dass sie selbst bei sehr schonenden Präparationsversuchen sogleich in Stücke zerfielen. Nach möglichst sorgfältiger Untersuchung und Vergleichung einiger hundert Knospen glaube ich die folgende Darstellung verbürgen zu können (Fig. 9.4 A-E, 95̆, 76, 77, 75).

Di e erste Anlage der Knospe zeigt sich auf der glatten Oberfliche der Zunge als eine klcine kreisrunde Scheibe von ungefaihr $0,0 \ddot{-0,08}{ }^{\mathrm{mm}}$ Durchmesser, welche nichts Anderes als cine locale Wucherung des Zungenepithets ist. Wiahrend dieselbe anfinglich aus ganz gleichartigen Zellen besteht, tritt alsbald eine Differenzirung derselben in zwei versehiedene Blatterschichten ein (Fig. 94 A), 
eine iussere hellere, welche der Zungenoberfläche unmittelbar anliegt (ec), und eine innere dunklere, welche anfäglich nur als ein sehr

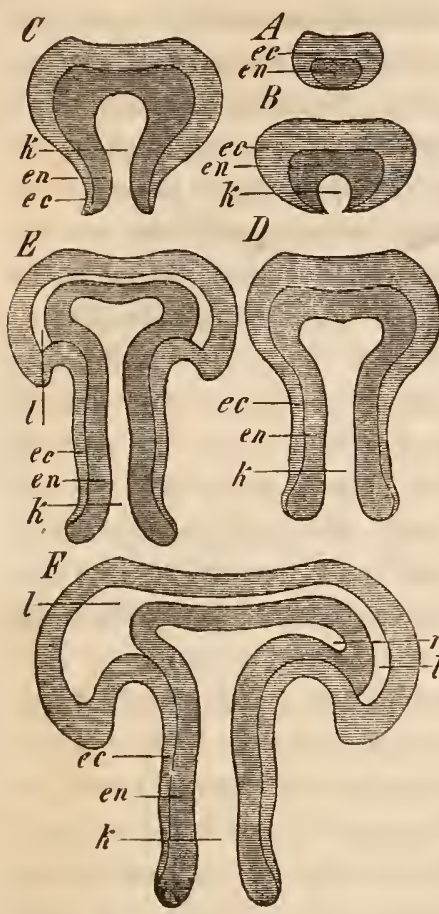

Fig. 94. A. Anlage ciner Zungenknospe von Carmarina hastata, in 2 Blätter differenzirt: ec Ectoderm, en Entoderm. Schematischer Meridianschnitt. B. Junge Zungenknospe von Carmarina hastata, mil der geöffneten Anlage der Magenhöhle ( $k$ ). ec Ectoderm, en Entoderm. Schematischer Meridiauschuitt. C. Junge Zunyenkilospe von Carmarina hastata, bei der das llagenrohr $(k)$ sich zu verlangern beginnt. ec Ectolerm, en Entoderm. Schematischer Meridianschnitt. D. Zungenknospe von Carmarina hastata, nit verlängertem Magenrohr ( $k$ ) und Verdickung des Entoderms (en) am Mundsanme, wo sich das Ectoderm (ec) verdünt absetzt. Schematischer Meridianschnitt. E. Zuıgenknospe von Curmarina hastala, bei welcher sich der Schirm von dem Magenrohr (k) alszusetzen und in dem Schirm der Gallertmantel abzuscheiden beginnt. ec Ectoderm, en Entoder'm. Schenatischer Meridianschuitl. F. Aeltere Zungenknospe von Carmarina hastata, bei welcher der Grund der Magenhohle (k) sich in die 8 Radialtaschen $(\boldsymbol{r})$ auszusliulpen beginnt. I Gallertsubstanz des Mantels. ee Ectoderm, en Entoderm. Schematischer Meridianschnitt.

kleines rundes Scheibchen in der Mitte der erstern sichtbar ist (en). Dieses dunklere centrale Scheibchen wird nicht allein an der dem Zungenkegel zugekehrten Flaiche, sondern auch an seinen Seitenwänden ringsum von der ausseren helleren Schicht umsehlossen. Beide Zellenschichten sind ungefähr von gleieher Dicke. Die dunklere innere Schicht (en) ist das Entoderm und liefert weiter Nichts, als das Epithel des gesammten Gastrovascularapparates, welches die innere Oberfläche des Mundes, des Magens und alle damit im Zusammenhange stehenden Canile und Hohlräume auskleidet. Die hellere iussere Schicht, welche zwischen der ersteren und der Zunge liegt, bildet als Eetoderm den Schirm der Meduse und alle übrigen Theile ihres Körpers, mit Ausnahme des Gastrovascularepithels.

Die nächste Veränderung der Knospe besteht darin, dass in dem bisher soliden Körper, und zwar in der inneren dunklen Zellenschicht, dem Entoderm, eine Höhlung entsteht, die ersle Anlage der Mage nhöhle (Fig. 94 B.). Der Durehmesser dieser kugeligen Höhle $(k)$ ist anfänglich nur so gross, als die Dicke eines der beiden Epithelblätter. 
Auch hier, wie bei den juingsten beobachteten Larven von Glossocodlon, kann ich aus eigener Anschauung nicht mit Sicherheit sagen, ob die Höhlung sich als eine geschlossene excentrische entwickelt und erst nachher nach aussen (lurchbricht, orler ob sie sich von aussen her als kleines Grübehen in der Oherfläche der soliden Scheibe aushıöhlt.

Die Knospe (Fig. 94 B) im Meridianschnitt stellt jetzt ein planconvexes kreisrundes, ringsum abgeflachtes Polster dar, dessen Iöhe (Dicke) etwa $2 / 3$ von dem äquatorialen Durchmesser betrigt, welcher letzlere ungefilh $0,1 \mathrm{~mm}$ misst. Die ebene oder etwas vertiefte Fliiche bleiht mit der Oberflïche der Zunge verhunden. Die :iussere convexe Fliche zeight in der Mitte eine kleine Oeffnung, den M und, der in die bloss von dem Entoderm eingeschlossene enge kugelige Magenhöhle hineinführt. Der die Nundöllmung umgebende äusserste Theil der polsterförmigen Knospe fïngt nun an stirker zu wachsen, und verlängert sich in eine eylindrische Röhre, deren Linge bald dem iquatorialen Querdurchmesser des Polsters gleich kommt und ihn dann übertriffi. Anfangs ist der äusserste, die Mundöffnung umgebende Rand dieses Magenrohrs verdiunnt oder selbst zugeschärft (Fig. 94. C); bald jedoch wird er wieder dicker, so dass die Magenwand in ihrer ganzen Linge gleich dick oder selhst am hundrande etwas wulstig verdickt erscheint (Fig. 94 D, E). Doch betriflt diese gleichmissige Dicke nicht die beiden Blitter, welche die Magenwand zusammensetzen. Am Ursprunge des Magenrohrs, wo dasselbe von dem Polster (der Schirmanlage) abgeht, sind beide Blaitter allerdings noch gleich dick. Gegen den Munt lin nimmt jedoch die Diche des dunkleren, die Magenhöhle auskJeidenden Entorlerms bestiindig zu, wihrend die Dicke des helleren, die Magenoberlliche bedeckenden Eetoderms entsprechend abnimmt, so dass das letztere aussen am Mundrande scharf zugespitzt endet (Fig. 94 D, E. F). Die beulen Blitler gehen also hier nicht in einander über; vielmehr ist ihre Trennung hier so scharf, wie in ihrer ganzen Beriihrungsfliche, und stets durch eine feine aber scharfe Linie auf Durchschnittsansichten deutlich ausgezeichnet (lig. 94 D).

Das eylindrische Magenrohr, welches anfänglich olme :inssere $\mathrm{Ab}$ grenzung in das nunmehr kugelförmig angeschwollene Polster des eigentlichen Knospenkörpers ïbergeht (Fig. 94 D), set\%t sich nun von letzterem auch iusserlich scharf dadurch ab (Fig. 94 E), dass rings un die Abgangsbasis des cylindrisehen Magenrohres sich der :iussere Rand des scheiluenförmigen Polsters in Gestalt einer dicken R ing la lt e nach aussen erhebt. So entsteht eine ringförmige, nach aussen oflene, halbcylindrisehe linne rings un die Basis des Magenrohrs, welche die erste Anlage der Sehirmbühle ist. Her dicke scheibenlörmige 
Sehirmliörper setzt sich so anch iusserlich seharf von dem Mageneylinder ab, dessen Querdurchmesser jetzt nur noch 1/3, höchstens die Hailfte von dem des ersteren betriggt.

Diese grössere Ausdehnumg des scheibenförmigen Schirms in die Breite, kommt nicht dureh die zunehmende Verdickung beider zelligen Blither zu Stande, sonderu theilweis dadurch, dass der innere erweilerte Grund der Magenhöhle sich ringsum zu einer flachen kreisrunden 'Tasche atsdehnt, theilweis dadurch, dass zwischen den beiden Blitlem die Ablagerung der Gallertsubstan\% des Mantels beginnt Fig. 9 i El). Dieselbe erscheint zuerst nur als ein sehr heller Streif zwischen den beiden Blättern, der sich von der oberen Wölbung des scheibenförmigen Schirms kappenartig nach seinem Rande linüberzieht und dort scharf abgeschnitten endet, ohne sich zwischen die beiden Bliilter des Magenrohrs forlzusetzen.

Dic nächste Verinderung des Emblyo besteht num darin (Fig. 94.F), dass der flache Grund der Magenhöhle sich seitlich ausdehnt und an 8 yleichweit von cinander enternten P'uncten seiner Peripheric in 8 kurze blinde Ausstülpungen in radialer Richtung sich auszieht. Dies sind die ersten Anlagen der Radialcan ile (Fig. !f F r), und zwischen ihnen lagerı sich eine mächtigere Masse von Gallertsubstanz ab(1), indem die beiden Lamellen des gefalteten äusseren Blattes weiter von einander weichen.

Die Ablagerung der Gallertsulsstanz (I) nimmt num noch beträchtlich zu, so dass die beiden Blatter noch weiter von einander weichen und der Schirm sich verdickt, wihrend gleichzeitig das lange Magenrohr (k) sich verkürzt (Fig. 77, 78, 95). Die Magentaschen (r) dehnen

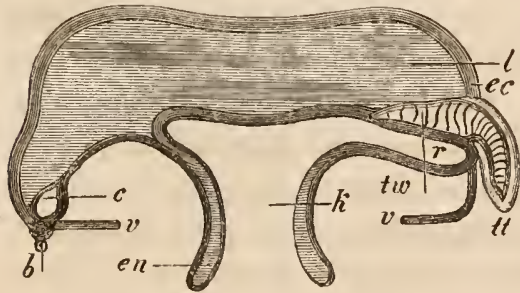

Fig. 95. Schemalischer Meridianschuill duıch eine der grössten und ältesten Zun:enknospen von Carmarina hastata, von 1 mm Durchmesser. b Randbläschen nebst Gang̨lion. c. Ringcanal. ec. Eetoderm (Epithel der Schirmoberllache). en. Entoderm. k. Magen. I. Gallertmantel. r. Radialcanal. t t. Tentakel. $t$ w. Tentakelwurzel. v. Velum. Vergrösserung: 50. sich bis zum Schirmmande hin aus, wo sie sich duredr einen engen Ringreanal (c) verbinden. Unterhall des letzteren wird die Anlage des kingknorpels (uk) sichtbar. Der gesammte Schirmrand verlangert sich nach unten in Gestalt von 8 luablokreis- oder rundbogenlörmigen Lappen, an deren Spitze je ein kleines Knöpfehen hervorsprosst, das sich bald zum Gangylion mit dem Randblaschen (b) differenzirt. Die Zwischenriume zwischen den Láppen werden von einer diinnen Haut, dem Velum (v) ausgefüllt, wel- 
ches nach unten und innen noch iiber den Schirmrand yorwichst. Nun erheben sich anch deutlich von der Mitle des dicken Seitenrandes des scheibenförmigen Schirms die 8 Te n takeln ( 1 ) deren conische W urzel (tw) schon üher der Mittellinie der oberen Wand jedes Radialeanals sichtbar wurde. Der freie Theil jedes Tentakels erscheint anfangs nur als ein dickes und kurzes conisches Wirzehen mit stumpfer Spitze, in der Mitte des Einschnitts zwischen je 2 Randlappen. Sie wachsen nach dem IJervortreten rasch, werden länger, schlanker conisch und durchsichtiger, und lassen hald eine hellere fein quergestreifte Axe rrhennen, welche aus einer einzigen Reihe sehr flacher münzenförmiger Zellen besteht. Diese ist überzogen von einer diunnen dunkleren Schicht (von Längsmuskeln) und über der letzteren liegt wierler als Ueherzug cin aus grösseren und helleren Zellon gebildetes dickes Epithel. In den Zellen sowohl dieses Epithels, als desjenigen des Schirmirandes, werden kleine kugelige, stark lichtbrechende Körperchen sichthar, in denen sich die ersten Anlagen von kleinen kugelrunden Nesselkapseln erkennen lassen. Sie sind unregelmässig über die Oberfläche der Tentakeln zerstreut.

W:ahrend diese Veränderungen in dem Körper der achtstrahligen knospen immer deutlicher hervortreten, erreicht ihr Schirm einen Durchmesser von 1 "'m. Bis zu diesem Stadium der Entwickelung habe ich sie, am Zungenkegel der Carmarima festsitzend (Fig. 75) verfolgen können. Sie lösen sirh nun von demselhen ab und treten aus $\mathrm{dcm}$ Magen des sechsstahhligen Stammthieres hervor, un ausserhally desselben ihre Entwickelung weiter fortzusetzen. Eine der ältesten von der Zunge abgelösten Knospen ist in Fig. $76 \mathrm{im} \mathrm{Profil,} \mathrm{in} \mathrm{Fig.} 77$ von unten dargestellt. Der dieke scheibenformige Gallertschirm ist nur wenig gewölbt, im Ganzen fast linsenförmig. Yon der Mitte seines Randes hängen die 8 Randlappen herab, zwischen dencn der obere Theil des Velum ausgespannt ist, wihrend der untere Theil nach innen vorspringt und die kleine enge Schirmhöhle von unten her grossentheils zudeckt. Aus dieser tritt das lange und dicke cylindrische Magenrohr (k) hervor. An der Spitze jedes Rindlappens sitzt ein kurzgestieltes Sinneshläschen aussen frei auf. Aus der Tiefe des Einsehnittes zwischen je zwei Lappen entspringt ein kurzer, plumper, solider eniseher Tentakel, in die Schirmgallerte eingesenkt mittelst einer eonischen hellen Wurzel, die auf der oberen Fliche des zugehörigen breiten Radialcanals aufliegt. Jedes der 8 unter sich gleichen Körpersegmente enthält also einen Radialcanal, einen Tentakel, zwei halbe Randlappen und zwei halbe Simnesblischen.

In Form und Bau sind diese ätesten achtstrahligen Knospen so 
sehr von Carmarina hastata verschieden, dass es selbst angesichts des continuirlichen materiellen Zusanmenhanges Beider schwer hält, sich von ihrer Zusanmengehörigkeit zu üherzengen. Es giebt nur eine Quallenfanilie, welche die Grundzuige des Baues mit den Knospen der Carmarinu theilt, und dies sind die Acginiden. In Gesellschaft der Carmarina hastata, und zwar als constante Begleiterin derselben, habe ich bei Nizza eine Aeginidle in zahlreichen Exemplaren gefischt, welche ich als Cunina rhododactyla beschrieben habe"), und deren juingste beobachtete Individuen (von $3 \mathrm{~mm}$ ) so sehr nit den altesten beobachteten Knospen der Carmarina (von I mm) iibereinstimmen, dass ich an der Identitat beider Formen nicht melır zweifeln kann, so paradox diese Bchauptung auch klingen mag. Ich lasse daher in nächsten Abschnith die genaue Anatomie dieser Meduse folgen und werde dann in einem besonderen Abschnitt durch eingehende Vergleiehung beider Formen die innige Verwandtschalt der Geryoniden und Aeginiden begrinden.

\section{Inatomie von Cuniua rhollodictyla.}

(llierzu Taf. VI. Fig. $78-83 \%$ )

\section{Körperform.}

Der Körper des ruhig im Wasser schwebenden Thieres (Fig. 79) zerfiallt für die oberflächliche Betrachtung in zwei Theile, einen oberen wasserbellen, planconvexen, gewöhnlich halbkugeligen soliden Gallertmantel (1) und einen unteren, schmalen kragenähnlichen Saum, welcher in eine Anzahl $(8-16)$ rundlicher Lappen tief gespalten ist, und aus dessen Einschnitlen die 8-16 Tentakeln alggehen. Dieser Kragen ist nach unten flach trichterförmig erweitert, so dass er iber den unteren Rand des Gallertmantels nach unten und aussen vorspringt. Der untere freie Kragenrand kann aber auch so zusamnengezogen werden, dass die Lappen sich nit ihren Seitenrändern decken und nach unten und innen bis fast zur Beruhrung sich einschlagen, wobei das ganze Thier beinahe eine Kugelform annimmt. Anderemale erscheint dasselbe flacher gewölbt und in flach ausgebreiteten Zustande selbst fast scheibenförmig. Die Körperform wechselt ausserordentlich, theils nach dem Contractionsgrade, theils nach dem Ernährungszustande.

Der Durchmesser des ganzen Schirnes, mit flach ausgebreiteten Kragen, beträgt bei den jüngsten beobachteten Individuen, welche 8 homolypische Abschnitte zeigen, $3-\{$ mm, bei den ältesten, deren

1) Jenaische Zeilschrift 1, 1864, p. 333 
Segmontmahl anf $1 \ddot{3}-16$ gestiegen ist, $10-11$ mon. Jio Molue ales ruhigg ausgehreiteten Schirmes betrig̣t bei crsteren ungefahr ?, bui betzleren 1. ligen Gallertsehirm orlor Mantel, dessen gesammle Gallertmasse von einer ziemlichen Anzahl sehr feiner diehotom veristelter Fasern durehzogen, ausserdem aher volthommen homogen, wasseklar und larblos ist, und einen ziemlich berluntruden Consistenzğand zeigt. Am liande setzt sich der plamıonvexeGallemmantel in dielappen deskmgens fort, deren jeder seiney Hauphuasse nach aus einer dumnen halbhreisformiggen Gallertscheibe besteht, deron heicic flichen ehenfalls durdo foine, die Gallert durchziehende Fasern (Fig. 82 I f) verbunden sind.

Die untere Fliche des hallkllggeligen Gallertmantels (1) ist last oben oder nur sehr wenig rerlielt, hisweilen in der Nille sogar etwas conves nach unten volgew ̈blbt, und ringes hermu dann stitrherverticft $(\mathrm{lig} \underset{\mathrm{s}}{\mathrm{s}} .78,79)$. Fast die ganze Interllicle von dem llachen, lasehenliormigen Magen (k) eingenommen, dessen Emkreis in $8-16$ (meistens $10-12)$ sehr hreite und flache Radialcanäle ausläuft $(\mathbf{r})$, welche bisher irrig für blinde Tasehen grehalten wurden. Sie reichen bis zur Einselnüurung des Schimsaumes zwischen zwei Kragenlappen hinaus

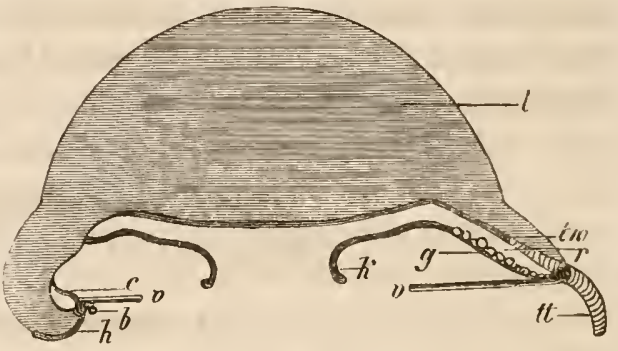

lïg. 96. Schema eines Verticalschniltes 'lurch eineerwachsene Cunina rhododactyia, rechts durch eine radiale, links dureh eine interradıale Verticalebene geführt. b. Randbläschen. $\quad$. Ringeana!. g. Genitalproducte. h. Mantelspange. h. Magen. 1, Gallertmantel. r. Radialcanal. It. Tentakel. «w. Tentakelwurzel. v. Velum.

und sind hier durch cinen engen, zusammenhängenden, liings des Lappensaumes hinlaufenden Kingeanal (c) verbunden. In der liefen Einschnitrung zwischen je zwei Kragenlappen nimmt ein kurzer cylindrischer Tentakel seinen Ursprumg, der höchstens die Liinge des Schirmmalius preicht (11) und mil einer in dem Galleptmantel eingeschlossenen 11 แrzel ( $W$ ) auf deroberen Fliche einer radialen Magentasche angewachsen ist. Die Randblas chen (b) sind in sehr grosser, mit dem Mller zuuchmender $\Lambda$ nzahl vorhanden und sit\%en aul dem vorspringenden Rande dor Krigenlappen, an dor Spitze einer kobbenförmigen manginalen

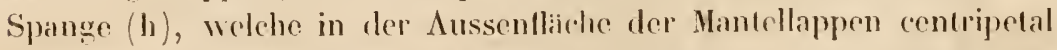
verliaft, und welche wit als $M$ antelspange bezeichnen wollen. Bei jiingeren Thieron kommen auf jeden Lappen $1-2$, hei äleren 1 - 8 Randblaschen. Das breite Velum (v) fïllt die Zwischenraume zwi- 
schen den Randlappen aus und springt ausserdem noch uber deren Rand hinaus nach innen vor.

Der ganze Körper der Cunina rhododactyla kann demnach in zwei sehr verschiedene Itauptheile zeilegt werden, nimlich in den planconvexen einlachen, halbkugeligen Gallertmantel, der die Hanptmasse dẹs Körpers ausmacht und an dessen Unterfliche der kreisrunde flache Magen, in der Mitte mit einfacher Mundöffnung liegt; und in den breiten, in mehrere Lappen gespaltenen Kragen, an dem sämmtliche übrigen Organe angebracht sind und der aus mehreren homotypiscisen radialen Theilen zusammengesetzt ist. Jeder homotypische Theil enthiilt eine radiale Magentasche, einen Tentakel und die beiden angrenzenden IIalften der beiden Kragenlappen, welehe den Tentakel zwischen sich nehmen. Auf jedes homotypische Radialsegment kommen ferner 1-8 Randbliisehen und ebensoviele Mantelspangen.

Die homolypisehe Grundzahl nimmt mit dem Alter des wachsenden Thieres allmählich zu und steigt ron acht bis auf 16. Doch ist die Körpergrösse nichı immer der Zahł der radialen Körpersegmente entsprechend. Unter 32 genauer beobachteten Individuen befanden sich 1) drei ganz jugendliche Individuen von 2-3 m in Durchmesser, mit 8 Segmenten; 2) vier junge Individuen von $3-4^{\mathrm{mm}}$, mit () Segmenten; 3) elf Individuen von $4-6 \mathrm{~mm}$, mit 10 Segmenten; 4) (hei Thiere von $5-8^{\mathrm{mm}}$, mil 11 Segmenten; $\ddot{)}$ sieben Thiere von $6-9^{\mathrm{mm}}$, mit 12 Segmenten; 6) kein Thier mil 13 Segmenten; 7) ein Thier von $10^{\mathrm{mm}}$, mit 14 Segmenten; 8) zwei Thiere von $11 \mathrm{~mm}$, mit $1: 3$ Segmenten; 4) ein Thier von $11^{\mathrm{mm}}$ Durchmesser, mil 16 Segmenten. Es wurden also alle homotypischen Grundzahlen von 8 bis 16 , mit alleiniger Ausnahme von 13, beobachtet. Fig. 78 stellt eins der jiingsten Individuen mit 8 , Fig. 79 ein ailteres mit 10 Segmenten dar. Die obere Iliilfte der Figur 80 ist einem Individum mit 10, die untere Iälfte dem grössten beobaclıteten, mit 46 Segmenten entlehnt. Siimmtliche homo!pisehe Radialsegmente des Körpers sind gleichartig gebildet, jeloch oft von ziemlich versehiedener Grösse. Bei jüngeren Individuen mit 8-10 Segmenten ist meist auch die Zahl der Randbläsehen an den verschiedenen Lappen gleich (je ein oder zwei); bei den :ilteren dagegen wird diese sehr variabel.

Mit Ausnahme der constant rosenfarbenen Tentakeln ist ler iibrige Körper meistens farblos, höchstens noch der Saum der Kragenlappen, seltener diese sellsst schwach röthlich gefürbt. Die Rosenfarbe der Tentakeln ist an der Spitze intensiver, of fast hell purpur und nimmt nach der blassen fleischfarbenen Basis hin allmählich ab. 


\section{Gastrovascularsystem.}

Der Magen der Cumina rhodoductyla ( $\mathrm{k}$ ) erscheint zu verschiedenen Zeiten von sehr veränderter Ausdehnung und Form. Gewöhnlich stellt er eine sehr flache, fast ebene oder nur selır wenig vertiefte kreisrunde Tasche dar, welche den grössten Theil der Subumbrella einnimmt und im Unkreise mit den $8-16$ radialen taschenförnigen Ausbuchtungen besetz ist. Obere und untere Magenwand liegen meist, wenn nicht Nahrungsmassen den Magen erliillen odler ausdehmen, unmittelbar an einander. In der Mitte der unteren Wand befindet sich die einlache kreisruncle Mund offnung, welche aber in Bezug auf Lage, Gestalt und Grösse zn verschiedenen Zeiten die üherraschendsten Verschiedenheiten darbietet. Selten ist der Mund vollkommen verschlossen, so dass uan in der Mitte der unteren Magenfliche Nichts sieht, als einen dunklen centralen Punct, von welchem viele feine radiale Falten nach allen Seiten ausstrahlen. Audrerseits kann er so ausserordentlich weit, durch Contraction der radialen Muskelfasern der unteren Magenwant, geöllnet werden, dass der Durchmesser des Mundes sogar den des Velum übertriflt, und dass die ganze eigentliche Magenlıöhle sammut den Anfangsstücken der radialen Nebentaschen völlig entblösst und offen gelegt wird. Der geöffnete Mund liegt meist central, kann aber auch excentrisch nach verschiedenen Richtungen hin verschoben erscheinen. Die Fornı des geöffneten Mundes ist bald kreisrund, bald unregelmässig rundlich oder polygonal, nicht selten viereckig oder achteckig. Sehr häufig̣ ist sie kreuzförmig oder sternförnig ausgerogen. Seltener erscheint sie als eine schmale lange, von zwei Lippen eingefasste Spalte. Der Mundsaum ist wulstig verdickt. Bisweilen - und dies ist besonder's wichtig in Hinblick auf den röhıenfö̀migen oder trichterförmigen Magen der aclitstralıligen Carmarina-Knospen (Fig. 75, 76) - springt der Mund aus der Mitte der unteren Magenfläche in Form einer kurzen weiten Röhre vor, welche seltener einen kurzen Cylinder, meist einen nach oben kegelförmig erweiterten Trichter, mit unterer enger Mundöffnung, darsstellt.

Die $8-16$ breiten und flachen Radialcanaile (r), welche von der Peripherie des Magens in gleichen Abstinden entspringen und welche bei den Aeginiden gewölnolich als Magentaschen bezeichnet werden, liegen nicht mit der centralen Magenhöhle in einer und derselben Ebene, sondern bilden mit ilır einen sehr stumpfon Winkel und steigen sanft geneigt nach aussen unt unten herab (Fig. 79). Sie sind noch dacher, als die centrale Mağenhöhle sellsst. Die Form der Taschen ist bald mehr quadratisch, bald mehr biruförmig oder keulenförmig nach 
aussen erweitert. Am schmalsten sind sie kurz nach ihrem Abgang vom Magen. Die Taschen erscheinen gewöhnlich ungefähr so lang als breit, und meist elsenso breit, als die hyalinen Scheidewände von Gallertmasse, durch wolche sie getrennt werden, und welche nach innen in Gestalt dicker radialer Septa mit gewölbtem Innenrande in die Magenhöhle hinein vorspringen (Fig. 78-80).

Die Geschlechtsproducte entwickeln sich bei beiden Geschlechtern in der unteren Wand des Magens, aus deren Epithel, jedoch nur an bestimmten Stellen, nämlich an den Intervallen zwischen je zwei Radialcanälen und an dem Aussenrande dieser letzteren selbst. Die Zahl der Hoden und Ovarien richtet sich demgemäss nach der homotypischen Grundzahl. Jedes Geschlechtsorgan stellt einen halbmondförmigen, nach aussen concaven Wulst dar, und unfasst mit seiner Concavität das Gallertseptum des Mantels, welches zwischen je zwei Magentaschen in die Magenhöhle hinein vorspringt. Ein weibliches Thier mit Eiern wurde nur ein einziges Mal beobachtet und zwar war dies zugleich das einzige Individuum, welches 14 Körpersegmente zeigte, von $10^{\mathrm{mm}}$ Durchmesser. Die rosenrothe Färbung der Tentakeln war bei ihm nur angedeutet. Die Eier waren gross und sassen in ziemlich geringer Anzahı an den Rändern der radialen Magentaschen vertheilt, so dass auf jede Tasche durchschnittlich nur 5 - 10 Eier kommen mochten. Viel häufiger waren geschlechtsreife Männchen, deren halbmondförmige Hoden bei einigen Individuen bloss den frei vorspringenden Rand des Gallertseptum zwischen je zwei Radialtaschen umfassten, bei anderen dagegen die ganzen Aussenränder der Taschen säumten und bis in die Tiefe ihres Grundes hinabreichten. Die Hoden waren mit stecknadelförmigen Zoospermien erfüllt. Etwa $2 / 3$ oder $3 / 4$ von den beobachteten Individuen zeigten noch keine Geschlechtsorgane.

Die-flachen taschenförmigen $R$ a dial can äle ( $r$ ) werden gestützt und ausgespannt erhalten durch die kegelförmigen T en ta k elwurzel n ( $\mathrm{w}$ ) welche mil ibrer dicken Basis in dem Einschnitte des Mantelkragens zwischen je zwei Randlappen, am unteren (äusseren) Ende der Magentasche befestigt sind, und in der Mittellinie der oberen Wand der letzteren centripetal nach innen oder oben verlaufen, wo sie an der Einmundung der radialen Taschen in die centrale Magenhöhle, oder etwas nach innen ron dieser Einmündungsstelle, fein zugespitzt enden. In der ganzen Länge ihres Verlanfes ist die untere Wand der Tentakelwurzel mit der oberen Wand der Magentasche (r I) fest verwachsen, wovon man sich auf radialen Querschnitten leicht überzeugt (Fig. 81). Es kann daher eine Ausdehnung der Magentaschen niemals 
in der Länge, in radialer Richtung, stattfinden; und da auch eine seitliche Erweiterung durch die gallertigen Radialsepta, die zwischen je zwei Taschen vorspringen, nur in sehr geringem Grade gestattet wird, so kann eine betrichtlichere Erwoiterung der Taschenhöhle nur durch Ausdehnung der unteren freien Wand zu Stande kommen.

Das Epithel, welches die centrale kreisrunde Magentasche und deren radiale Ausstülpungen auskleidet, ist ganz versehieden an der oberen, umbralen und an der unteren subumbralen Wand der verdauenden Cavititen. Das erstere besteht aus einer sehr dünnen einfachen Lage von hellen flachen Pflasterzellen, die unmittelbar die untere ebene Fliche des Galler'mantels überziehen. Das Epithel der unteren Wand dagegen, wolches wohl als das eigentlich verdauende zu betrachten ist, besteht aus einer viel dickeren, wie es scheint mehrfachen Schicht ron dunkleren Cylinderzellen, welche die innere Fläche der starken Muskelhaut des Magens bekleiden (Fig. $81 \mathrm{r}$ s). Aus Theilen dieses Epithels entwickeln sich auch an den Grenzen zwischen je zwei Radialcanälen und an deren Rande die Geschlechtsproducte. Es ist also hier dieselbe Differenzirung des Epithels der beiden Magenflichen und ihrer radialen Taschen, wis an den Gastrovascularcanälen der Geryoniden nachzuweisen. Dasselhe gilt auch von dem Epithel des Ringgefisses, welches den Grund der Radialtaschen verbindet (Fig. $81,82)$.

Es ist bisher allgemein als der wesentlichste Charakter der Aeginiden angesehen worden, dass von ihrer centralen Magenhöhle nicht, wie bei den übrigen craspedoten Medusen, radiale Canäle ausgehen, welche durch ein am Schirmrande verlaufendes Ringgefäss verbunden sind, sondem bloss breite nud flache radiale Taschen, welche nach aussen geschlossene Blinddaime darstellen und nicht mit einander zusammenhängen. Der Mangel des Kinggefïsses ist sogar neuerdings so sehr hervorgehohen worden, dass man darauf gestutzt die Aeginidenfamilie ganz von den craspedoten Nedusen zu trennen versucht hat (vergl. unten Abschnitt $\mathrm{X}$ ). Nun ist aber in der That dennoch ein am Schirmrande verlaufendes Ringgefiss vorhanden, welches die äusseren Enden der Magentaschen verbindet, so dass diese keineswegs blind geschlossen sind, sondern als vollkommen gleich den Radialcanilen der ubrigen Craspedoten sich ausweisen. Wenigstens liisst sich bei unserer Cunina rhododactyla dieses Verbiiltniss init der grössten Deutlichkeit nachweisen. Dass das Ringgefüs den bisherigen Beobachtern völlig entging, liegt wohl hauptsächlich an dem geringen Volum desselben, welches allerdings, namentlich gegenuber den colossal erweiterten Radialcanälen, sehr unbedeutend ist. 
Ein verticaler Radialschnitt durch den Rand eines Mantellappens der Cuninarhododactyla (Fig. 81, 82) zeigt in der Zusammensetzung und den Lagerungsverhältnissen der verschiedenen Theile auffallende Uebereinstimmung mit einem gleichen Schnitt durch den Rand von Geryoniu hastata (Fig. 7 I), und noch mehr von Glossocodon eurybia (Fig. 86). Ein wesentlicher Interschied zwischen Beiden besteht eigentlich nur in der verschiedenen Lagerung der (auch different gebauten) Randbläschen, welche bei den Geryoniden in der Gallertsubstanz des Mantelrandes eingeschlossen, bei der Cunina ausserhalb desselben, frei auf der Oberfläche liegen. Sonst gewahrt man bei der letzteren elsenso, wie bei den ersteren, zunächst das klafiende Lumen des durchschnittenen Ringgefässes (e), dessen inncre (umbrale), der Mantelgallert zugekehrte Wand (c l) nur aus einer sehr dünnen Lage von Pflasterepithel, dagegen die äussere (subumbrale) Wand (e s) aus einer dicken Schicht von Gylinderepithel besteht. Der untere Rand des Ringgefisses grenzt an den äusseren Rand des Velum (v) und nach aussen von diesem an 'einen soliden cylindrischen, dunklen Strang $(u)$, der die ausserste Grenze des Mantellappens bildet, und, wie bei den Geryoniden, einen dünnen Knorpelring ( $\mathrm{u}$ k) darstellt, auf dessen oberer Fläche der dünne Nervenring (a) liegt. Doch lassen sich diese einzelnen Theile des Schirmrandes hier viel schwieriger als bei den Geryoniden nachweisen. Auf dem vorspringenden Rande des Mantelsaumes (u) sitzen äusserlich, frei zwischen unterer Fläche des Velum und Aussenfläche des Gallertmantels die hügelförmigen Ganglien (f) auf, welche die Randbläschen (b) tragen. Von jedem der letzteren geht eine steife mehr oder weniger gekrümmte Spange (h) aus, welche in der Aussenfläche des Mantelrandes radial (centripetal) aufwärts steigt und sich sehr ähnlich den Mantelspangen der Carmarina verhält. Der Unterschied, welchen die Durchschnittsansichten des Mantelrandes von Cunina (Fig. 82) und von Carmarina (Fig. 71, 63) sonst noch darbieten, beruht nur auf dem ganz unwesentlichen Unstande, dass bei ersterer die Gallertsubstanz des Mantels zwischen Ringgefäss und Mantelspangen weit mächtiger entwickelt ist, so dass die Spange einen grösseren Bogen beschreiben muss.

Auf Fliichenansichten (Fig. 81), bei starker Vergrösserung betrachtet, zeigt das dicke stark wandige Gylinderepithel, welches die subumbraleWand des Ringgefässes der Cumina bekleidet (c s), ganz dasselbe ckarakteristische Aussehen, wie das von Carmarina (Fig. 65) oder Glossocodon (Fig. 38). Das Ringgefäss der Cunina folgt natürlich, da es stets seharf am Rande des gelappten Schirmes verläuft, allen Ausbuchtungen desselben. Der Zusammenbang des Ringgefässes mit den 
Magentaschen (Radialcanälen) ist desshalb sehwer zu sehen, weil diese Einmundungsstelle gerade unterhalb des Abgangs der Tentakeln von ihrer Wurzel liegt, und von den beiden dunkeln halbmondförmigen Wülsten (Fig. $81 \mathrm{tx}$ ), beleckt wird, welche diese Abgangsstelle umfassen. Das durchsehnittliche Lumen des Ringgefässes misst $0,1 \mathrm{~mm}$.

\section{Skelet.}

Auch bei Cumina ist, wie bei den Geryoniden, ein rudimentäres Knorpelskelet vorhanden, welches zwar am Schirme selbst dürftiger entwickelt und schwieriger nachzuweisen ist, als das der letzteren, aber dennoch in Lagerung, Structur und Function wesentlich mit ihm übereinstimmt. Es bildet auch hier der Medusenknorpel erstens einen zusammenhaingenden Knorpelsaum, weleher unmittelbar unter dem Ringgefäss an äussersten Rande des Mantels verläuft, und zweitens centripetale Spangen, welche in der äusseren Mantelfläche vom Schirmrande aus emporsteigen und unter rechtem Winkel von dem Knorpelringe abgehen. Endlich wird auch die Hauptmasse der Tentakeln, welche in ihrem Baue vollkommen den soliden Larvententakeln der Geryoniden entsprechen, aus Knorpel gebildet.

Der Ringknorpel (Fig. 82, 84 u k) ist bei unserer Cumina, wie der ganze Schirmrand, ungleich sehwicher entwickelt, als bei Geryonia und Liriope. Er erscheint als ein sehr schmaler cylindrischer oder etwas plattgedrückter Strang von ungefiuhr $0,03^{\text {m }}$ m Durchmesser, welcher an deı untersten Rande des Gallertmantels unmittelbar unter dem unteren Rande des Ringgefaisses (c) liegt und diesem zur Stuitze, wie dem äusseren Rande des Velum (v) zur Insertion dient. In einer Rinne im oberen Rande des Ringknorpels, zwischen diesem und dem unteren Rande des Ringgelisses, liegt der Ringnerv (a). Die Knorpelzellen des Ringknorpels sind sehr klein, eng zusammengedrängt und durch viel geringere Mengen von Intercellularsubstanz getrennt, als diejenigen in den Knorpelringen der Geryoniden.

Die centripetalen oder marginalen.Mantelspangen (Fig. 81, 82, 84 h) erscheinen bei der Cunina rhododactyla zahlreich und stark entwickelt. Es sind ihrer so viel als Randl,läschen vorhanden, mindestens also acht, bei erwachsenen Thieren dagegen zwischen fünfzig und hundert. Es sind cylindrische gekrummte Stäbe, welche an der Insertion jedes Randbläschens unter rechten Winkeln von dem Knorpelringe abgehen und in der Aussenfläche des Gallertmantels emporsteigen. mit dessen Oberfläche ihre innere Seite verwachsen ist. lhre Krammung entspricht daher auch der, je nach dem Contractions- 
zustande wechselnden, Krümmung der Mantellappen. Meist sind sie dabei etwas unregelmässig verbogen und an dem oberen Ende stark kolbenförnig angeschwollen und abgerundet (Fig. 81, 82 h). Die Nantelspangen bestehen, wie bei den Geryoniden, aus einem cylindrischen Knorpelstreifen, der von einem dünnen Muskelrohre, und aussen von einem Epithel überzogen ist, dessen regelmaissige polygonale Zellen zum grossen Theile dunkel glänzende kugelige Nesselkapseln entwickeln (Fig. 84 h). Der Knorjelstab verleiht den marginalen Mantelspangen einen hohen Grad von Festigkeit, verbunden mit Elasticitat, so dass sie, wenn der Mantelrand durch starke Contraction des Velum nach innen gezogen oder bei Erschlaffung desselben umgeklappt wird, nur bis zu einem gewissen Grade nachgeben und das Sinnesganglion, auf dem das Randbläschen sitzt, stets etwas nach atussen gewendet erhalten. Dic marginalen Mantelspangen theilen also auch hier, wie bei Carmarina, den Bau der knorpeligen soliden Tentakeln. Aehnliche Spangen sind auch von Fratz. Müller bei Cumina Köllikeri als "Nesselstreifen beschrieben worden. Anderen Aeginiden scheinen dieselben dagegen zu fehlen.

Die radialen Tentakeln ( 1 ) sind in den Einschnitten des Mantelkragens, zwischen je zwei Lappen, befestigt und bestehen aus einem kurzen conischen, im Mantel eingeschlossenen Theile, der Wurzel, und aus einem langen iusseren freien Theile, dem Stamme. Die Tentak elwurzel (Fig. $81(w)$ ist ein gestreckt kegelförmiges Knorpelstück, so lang als eine Magentasche oder etwas länger. Von ihrer breiten Basis an, welche in den äusseren freien Tentakeltheil ubcrgeht, verschmälert sie sich allmählich bis zu ihrem inneren feinzugespitzten conischen Ende, welches gewöhnlich etwas hakenformig nach einer Seite gekrümmt ist. Die Tentakelwurzel ist ringsum von der Gallertmasse des Mantels umschlossen, mit Ausnahme der unteren Fläche, welche in ihrer ganzen Lïnge an der obcren Wand der radialen Magentasche aufgewachsen ist. Sic verläuft gerade gestreckt in deren Mittellinie und reicht mil der Spitze bis zu ihrem Ursprunge aus dem Magen oder noch etwas weiter. Die Tentakelwurzel besteht aus wenigen $(10-15)$ hyalinen Knorpelzellen welche in einer einzigen Reihe hintereinander liegen

Fig. 93. Ein Stuck einer Tentakelwurzel von Cumina rhododactyla. A Kern. B Protoplasma der linorpelzellen. C Intercellularsubstanz (Knorpelkapseln). D Wässrige Fliissigkeit innerhalb des Protoplasmaschlauchs.

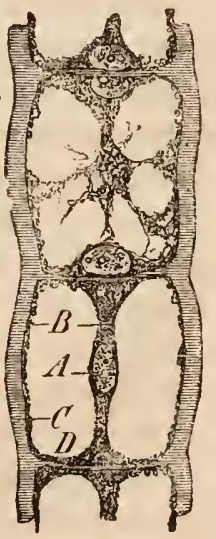


und durch quere (tangentiale) Septa getrennt sind. Die Grösse der Knorpelzellen nimmt von aussen nach innen zu ab. Die Kerne derselben sind gewöhnlich entweder in der Mitte eines cỵlindrischen Protoplasmastranges eingeschlossen, welcher in der Längsaxe der Zelle verläuft, oder von einem strahlenden sternförmigen Protoplasmahofe umgeben. Die Knorpelkapsehn Intercellularsubstanz) sind meist dünnwandiger als an dem Tentakelstamme.

Der längere freie äussere Theil des Tentakels oder der Tentakelst a mm (Fig. 81 t 1, Fig. 8.3) besteht ans einem soliden, ziemlich dicken cylindrischen Knorpelstabe, der von einem dünen Muskelschlauche ibberzogen und aussen von einem Epithelialrohre umhüllt ist. Dieser Theil des Tentakels hat also denselben Bau, wie die interradialen und die radialen Nebententakelu der Geryoniden und gleicht denselben auch vollkommen durch seinen starren llabitus und die eigenthumliche $\mathrm{Be}-$ wegungsweise. Die Bewegungen bestehen theils in plötzlichen Zuchungen, theils in sehr langsamen Biegungen. Verkürzen können sich die Tentakeln nur sehr wenig, soweit es die Elasticitat der Knorpelzellen gestattet, welche auch bei Nachlass der Muskelcontraction den gekrümmten und verkiirzten Cylinder wieder streckt. Gewöhnlich werden die Tentakeln von dem ruhig im Wasser schwebenden Thicre (Fig. 79) nach unten gerichtet und mit der Spitze concay nach einwärts gekrümmt getragen. Bei mechanischer Reizung werden sie gewöhnlich ganz nach innen eingeschlagen (Fig. 78, 80). Seltener werden sie nach aussen und oben in die lföhe gekrümmt. Die freien Tentakclstämme sind ungefähr so lang als der Radius der Gallertscheibe. Es sind sehr schlanke, dünne Cylinder, welche nach der stunıpf abgerundeten Spitze zu sich allmählich etwas verdünnen. An der etwas angeschwollenen Bisis, wo sie sich mit der Tentakelwurzel rerbinden, besteht ihr Knorpelstab aus mehreren neben einander liegenden Reihen von polygonalen Zellen (Fig. 81), wáhrend der grösste Theil der knorpeligen Axe nur aus einer Reihe flach münzenförmiger binter einander liegender Zellen besteht, deren transversale Scheidewände den Tentakel schon bei schwacher V'ergrösserung zierlich quergestreift erscheinen lassen. Die Knorpelkapseln bilden ziemlich breite Streifen ron homogener Intercellularsubstanz (Fig. $83 \mathrm{sk}^{\prime \prime}$ ). Das Protoplasma kleidet dic Knorpelhöhlen als eine zusammenhängende, sehr dünne, feinkörnigge Schicht aus und liuft ausserdem durch die Mitte (Axe) der Zelle als ein dicker cylindrischer Schleimstrang, der sich nach beiden Enden conisch rerdickt und in der Mitte, wo er an dünsten ist, einen rundlichen Zellenkern einschliesst. Die Summe dieser in der Axe der hintereinanter liegenden scheibenförmigen Knorpelzellen verlaufenden 
Protoplasmastränge stellt einen dunklen Streifen dar, der die gesanımte Tentakelaxe durchzieht, leicht mit einem Centralcanal verwechselt werden könnte, und in der That als solcher in den meisten Beschreibungen von Aeginiden figurirt. Der Mushelschlauch, der den Knorpelstab der Tentakeln uberzieht, ist sehr dünn; dicker ist die dritte und äusserste Gewehsschicht, das Epithel, welches aus einer einzigen Lage von sehr kleinen polygonalen kernhaltigen Zellen besteht, die an zahlreichen ganz unregelmässig zerstreuten Stellen kleine kugelrunde Nesselkapseln in sich entwiekeln. Diese Nesselkapseln sind ganz gleich denen der Mantelspangen und zeichnen sich durch eine dicke, sehr stark lichtbrechende, dunkelglänzende Wand aus. Nach der Spitze zu sind sie stärker gehäuft. Hier ist auch die rosenrothe Färbung der Tentakeln intensiver, als an Grunde.

\section{Muskelsystem.}

Das hauptsäehlichste Bewegungsorgan der Cumima ist das sehr starke und breite Velum (v). Dasselbe ist von eben so wechselnder Breite und eben so ausserordentlicher Dehnbarkeit und Contractilität, als die untere musculöse Magenwand. Bald erscheint es breiter, bald schmäler als letztere. Da sein Innenrand eine kreisrunde Oeffnung bildet, wahrent sein Aussenrand überall mit dem Mantelsaume des Schirmrandes verwachsen ist und allen Einschnitten desselben folgt, so muss es natiirlich an verschiedenen Stellen eine sehr wechselnde Breite besitzen. Am schmälsten ist es gegeniber der atm meisten vorspringenden Mitte der Kragenlappen: am breitesten gegenüber der Tentakelinsertion. Das Velum besteht aus einer olseren starkeren Lage von circularen und einer unteren dünneren Schicht von radialen Muskelfasern. Bei überwiegender Contraction der letzteren und Erschlaffung der ersteren wird das Velum verschmälert und an den gelappten Mantelsaum herangezogen, dessen Einbuchtungen es folgt, so dass seine Ehene wellenförmig gehogen wird. Bei starker Contraction der Ringmuskeln dagegen wird der Mantelsaum ganz nach innen gezogen und das Velun in ciner einzigen Horizontalebene ausgebreitet. Das Epithel der oberen Velumfläche besteht aus grösseren, höheren Zellen.als das der unteren.

Die Subumbrella ist bei Cunina sehr beschrinkt entwickelt, da die grosse Magenscheibe sanmt ihren breiten Radialtaschen den bei weitem grössten Theil der unteren Schirmfläche einnimmt. Man kann daher eigentlich als Subumbrella nur die sehr schwache und dunne Schicht von unterbrochenen Ringmuskeln, sowie eine Anzahl von zer- 
streuten, wenig entwickelten radialen Nuskelhändern bezeichnen, welche die untere Fläche des Gallertmantels zwischen je zwei radialen Magentaschen und an den Randlappen bekleiden.

Die Muskeln, welche ausser dem Velum und der Subumbrella sich noch vorfinden, sind bereits erwähnt. Es sind dies der cylindrische aus Längsfasern gebildete Muskelschlauch, welcher die knorpeligen Tentakelstainme überzieht, der ̈̈hnliche Muskelschlauch, welcher die marginalen Mantelspangen umhïllt, vor allem aber die schr stark entwickelten radialen und circularen Muskeln der unteren Wand des Magens und seiner Radialtaschen.

Besonderer Erwähnung werth sind die ausserordentlich versehiedenen Formen, welche Cumina rhododactyla bei verschiedenen Contractionszuständen des Velum, der Subumbrella und der Spangennuskehn annchmen kann. Man glaubt oft ganz verschiedene Thiere vor sich zu haben. Sehr häufig wird der Rand der Mantellappen stark nach innen gezogen, so dass die Spangen radial von aussen nach innen zu den nach innen vorspringenden Randblischen zu laufen scheinen (Fig. is links, 80 rechts). Ausserdem wirl häufig dann noch der Lappenrand nach oben (und zugleich wieder nach aussen) eingeschlagen, so dass num die Spangen einen rücklaufenden Bogen machen und der untere das Randbläschen stülzende schmale Spangentheil in der That oberhall, des oberen, in den abgerundeten Kolhen auslaufenden Spangentheils liegt (Fig. 78 rechts, 80 links, 79). Andere Male zieht sich das Thier vollkommen kuggelig zusanmen, so dass die Ränder der Kragenlappen sich decken und die Randbläschen sich beinahe in einem unteren Mittelpuncte beruliren.

\section{Nervensystem.}

Die Nerven sind hei Cunina weit unsicherer und schwieriger, als bei Carmarima nachuweisen. Am deutlichsten und leichtesten kann man sie anch hier wieder (wie bei der letzteren) an den Sinnesbläsehen erkennen. Durch die Axe jedes eylindrischen Randbläschens (Fig. 83) geht cin sehr heller und blasser cylindrischer Strang, etwa $1 / 4$ so hreit, als das Bläschen selbst $(11)$. Oben beruihrt er die Concretion, unten setzt er sich fort durch die Axe des conischen Ganglicnhiigels (f). Auch bei anderen Aeginiden finde ich diesen blassen eyllindrischen Axenstrang ebenso wieder. Ich halte ihn für den Sinnesnerven.

Weit schwieriger ist es, sich von der Existenz des Ringnerven zil ibberzengen, den ich auch hier, wie bei den Geryoniden, in einem hellen hlassen frin lingsgestreiften Strange zu finden glaube, der 
zwischen Ringgefass und Knorpelring, in einer Furche des letzteren liegt (Fig. 82 a, 8: a). Nach innen grenzt er nahe an die Insertion des Velum. Itn zu isoliren ist mir nicht gelungen. Auf Flächenansichten Fig. 84) verbirgt sich der Ringnerv leicht hinter dem Gefüse oder dem Knorpelringe. Mas Fratz. Mürler bei Cuninn köllikeri als Ringnerv beschreibt, halte ich fü den Knorpelring. Ausserdem glaubt der letztere dem Nervensystem auch noch nein paar ansehnliche, zicmlich undurchsichtige Wülste an der Basis jedes Tentakels, die scharf contourirte Zellen enthalten «, zurechnen zu müssen.

Diese "Wuijste " finden sich auch bei unserer Cunina rhodoductyla vor (Fig. 78-80, Fig. $81 \mathrm{t} \mathbf{x}$ ). Es sind zwei dicke concav-convexe rundliche Polster, welche in dem Einschnitte zwischen je zwei Randlappen sitzen und den Tentakelstamm an seinem lebergange in die Wurzel von beiden Seilen her umfassen. Die beiden Polster sind dunkel glainzende dünnhäutige, scheinbar geschlossene Blasen, prall angefüllt mit dichtgedrängten, kugelig̣en sehr stark lichtbrechenden Zellen. Den Eindruck von Nervenzellen machen letztere nicht. Was sie aber sonst sein mögen, vernag ich auch nicht zu sageu. Vielleicht gehören sie zum Knorpelringe.

Für Ganglienknoten halte ich die hügelförmigen, flach conischen Polster, auf deren Höhe die Randbläschen, wie auf einem kurzen dicken Stiele flach aufsitzen. (Fig. 84, 83 f). Es sind ihrer so viele als Randbläschen vorhanden. Mit ihrer breiten flachen Basis ruhen sie unmittelbar auf dem Nervenringe, theilweise auch auf dem Knorpelringe und dem unteren dünen Ende der marginalen Mantelspange. Der Inhalt besteht aus sehr hellen und blassen kugeligen Zellen, älnnlich denen im Randbläschen selbst, aher kleiner. Durch die Axe des kegelförmigen Ganglienhügels geht der Sinnesnerı, welcher von dem Nervenringe sich abzweigt. Das sehr verdünnte untere Ende der marginalen Mantelspange scheint sich noch über die aussere Fläche des Ganglion bis zur Basis des Randbläschens selbst fortzusetzen (Fig. 84). Wahrscheinlich dient der in der Spange liegende Muskel auch zur Bew egung (zum Aufrichten und Niederlegen?) des Randb)ischens. Der Ejpithelialuberzug der Nervenknoten hesteht aus sehr hleinen kernhaltigen polygonalen Zellen. Jede der'selben scheint ein sehr langes und feines, starres Borstenhaar zu tragen, welches ungefähr ebensolang oder länger, als das Randbläschen selbst ist (Fig. 80̈). An der Basis ist jede Borste ein wenig verdickt, am freien Ende läult sie in eine kaum sichtbare feine Spitze aus. Da die starren Fadenborsten nach allen Seiten von der. Oberfläche des Ganglion ausstrahlen, bilden sie zusamınen ein kegellörmiges, nach aussen oflenes Wimperbüschel, in dessen Axe das 
Randblischen sitzt. Aehnliche slarre Wimperborsten auf den Hugeln, welche die Randbliischen Iragen, sind von Gegraxacr bei legimelu sol maris, von Kefenstem und Emlans bei leyineta coroma beschriehen worden. Ich halte sie für 'T a stborsten. Vielleicht stelien sie unnittelbar mit Nervenenden in Zusammenhang.

Aehnliche Tastborsten, welche frei in das Wasser vorragen, fiude ich auch bei anderen Medusen wieder. Bei Rhopalonema umbilicalum Culyptra umbilicata) sitzen drei kirinze von solchen langen Tastborsten unmittelbar über einander giurtelförmig an der knopfartig rerdichlen Spitze der starren interradialen Tentakeln, welche aus einem von lipithel iiberzogenen Knorpelstabe bestelien. Jeder Kranz bestcht aus 20 bis 30 sehr langen und feinen Borsten von $0,1^{\mathrm{m} m}$ Läng̣e. Die Borsten der drei Gürtel alterniren mit einander. Sie stehen von der Nlitte der kolbig angeschwollenen Tentakelspitze in einer Horizontalebene ab, rechtwinklig zur Tentakelace. Die Tentakelspitze kann aber in der Weise nabelförmig eingezogen werden, dass die Borstenkrïnze an das äusserste Ende des Tentakels selbst zu liegen kommen und hier einen nach aussen divergirenden conischen Büschel bilden.

\section{Sinnesbläschen (Randbläschen).}

Die Zahl der Randblasschen steigt, wie schon früher benerkł wurde, bei Cunina rhododactyla von acht auf fünfzig bis hunder.. Bei den juingsten beobachteten Individuen, von $3^{\mathrm{m} m}$ Durchmesser (Fig. 78) sind nur 8 Blaischen an der Spitze der 8 Randlappen vorhanden, welche mit den 8 Tentakeln alterniren. Späterhin wiichst diese Zahl, indem neue Randbläschen in unbestimmter Reihenfolge neben den alten entstehen. Individuen mit 10 Tentakeln lragen in der Regel auf jedem Lappen $2-3$ Randblaschen, ältere mit 12 Tentakeln $4-6$ Bläschen. Das Maximum der Blischenzahl auf einem Lappen seheint $\Lambda$ cht zu sein. Bei einem der grössten beobachteten Individuen, von $11^{\text {w m }}$ Durchmesser, mit if Randlappen, zeigten sich die 89 Randblisschen in nachstehender Reihenfolge auf den Lappenkranz vertheilt: $\ddot{3}, 6,7,8, \ddot{3}, 6$, $4,5,6,8,4,6,7,4,8$. Die lintermung der Randblaschen von einander ist daher auch an verschiedenen Stellen eine ungleiche.

Dic Randbläschen sitzen frei aul den oben beschricbenen conischen Ganglienknoten auf, welche zwischen der umteren Fliche der VelumInsertion und dem unteren verdiunten Ende der marginalen Nantelspangen von dem Knorpelringe ( $1 \mathrm{~h}$ ) und dem Vervenringe (a) sich erheben (Fig. 82, 81). Die Form der Randblisshen ist eylindrisch, am freien Ende abgerundet und in der Nitte mehr oder weniger ring- 
formig eingeschnitrt (Fig. 8̈̈). Ihre Länge beträgt $0,05 \mathrm{~mm}$ und ist 2 -3mal so gross, als die Breite. Die Wand des Ramdblisschens wird von einem Epithel gebildet, das aus sehr flachen Pflasterzellen besteht. Den Inhalt bilden dichtgedrïngte wasserhelle polyedrische Zellen. In der Axe des Randbliischens verliuft der diinne blasse cylindrische Strang, der hereits oben als Sinnesnerr beschrieben worden ist und $1 / 3-1 / 4$ so breit, als das Bläschen selbst ist. Das :iussere Ende, oft die ganze ciussere Hälfte des Bläschens, nimmt ein Krystall ein, bis zu dessen Peripherie der Nerv zu verfolgen ist. Seltener sind statt eines Krystalls zwei hintereinander licgende vorhanden, und mehrere Male wurde eine Reihe von drei Krystallen beobachtet, von denen der oberste des grösste war. Die Krystalle scheinen ihrer Form nach dem rhombischen Krystallsysteme anzugehören. Da übrigens sonst die sogenannten Otolithen in den Randblaschen der Craspedoten stets nicht krystallinische Concremente, und nur in denen der Acr"aspeden Krystalle sint, so bietet in dieser Beziehung unsere Cunina eine schr bemerkenswerthe Ausnahme dar.

\section{Verwandtschaft unıl Generationswechsel zwischen den Geryoniden unil leginiden.}

Eine unbefangene Vergleichung der ältesten beobachteten Knospen von Carmarina hastuta mit den juingsten Individuen der Cumina thodoductyla lässt keinen Zweifel ihrig, dass letztere in der That nichts Anderes ist, als ein weiter entwickelter Zustand der Ersteren. Die ailtesten, am weitesten entwickelten Knospen derZunge von Curmarimu hustuta, mit einem Schirmdurchmesser von 1 mm , hesitzen einen aus acht gleichen homotypischen Abschnitten zusammengesetzten Körper (Fig. 76 im Profil, Fig. 77 von unten). Der Rand des scheibenförmị̣en Körper's ist in acht pundliche Lappen gespalten, deren Spitze ein lrei aul kurzem Stiele vorragendes Sinnesbläschen trïgt. Der Zwischenraun zwischen den Lappen wird von dem oberen Theile des Velıum ausgefüllt. Entlang des Randes der Lappen verliuft, auf einen diunnen Knorpelring gestützt, ein zusammenhängendes enges Ringgefäss, welches in der Tiefe der acht Randeinschnitte mit acht breiten flachen taschenförmigen Radialgelässen zusanmenhängt, die von der Perijherie des centralen lachen und weiten Magens ausstrahlen. In dem Grunde 
jedes Randeinschnittes, zwischen der Basis je zweier benachbarter Lappen, ist ein solider cylindrischer Tentakel befestigt, welcher mittelst einer kegelföruigen knorpeligen Wurzel in die Scheibensubstanz eingesenkt und auf der oberen Fläche der entsprechenden radialen Magentasche in deren Mittellinie angewachsen ist. Der Tentakel seibst besteht ans einer soliden e?lindrischen Axe, aus einer einzigen Zellenreihe gebildet, und ibberzogen von einem diinnen Mushelschlauche, iber welchem ein Nesselepithel liegt.

Alles, was ich hiermit von den ('harakteristischen und wesentlichen Structurverhältuissen der ältesten, auf dem Zungenkegel der Carmorince aufsitzenden knospen (Fig. 76, ii) ausgesagt habe, gill "örtlich gan\% ebenso von den jüngsten, frei in Hecre gefischten Individuen der Cunina rhododactyla, von 3 mm Durchmesser (Fig. 78 ). Es ist in der' That nicht eine einzige wesentliche Organisationsdifferenz zwischen Beiden vorhanden.

Die einzigen Unterschicde, welche die Zungenknospe der Carmarina Fig. 75) und dic jüngste freie Form der Cunina (Fig. 78) zeigen, sind folgende. Der Gallertschirm der Zungenknospe ron Curmarina ist eine dicke, ziemlich flach gewölbte Scheibe von $1^{\text {m m }}$ Durchmesser, derjenige der Cunina eine meist stärker gewölbte, oft fast halbkugelige Scheibe von $3^{\mathrm{mm}}$ Durchmesser. Die Tentakeln der CarmurinuKnospe sind plumper, dicker und kürzer; als die längeren und schlankeren der Cunina. Dagegen ist das eylindrische Mundrohr oder Magenrohr der ersteren im Verhältniss weit länger, als der sehr kurze, kaum iiber den flachen Magen vorragente Mundrand der letzteren. Ausserdem sind natürlich alle Theile der Curmurinu-Knospe in entsprechendem Verhialtniss kleiner, die Gallertsubstanz des Mantels weniger entwickelt, als bei der Cuninu.

Es bedarf keines weiteren Beweises, dass diese Diflerenzen sämmtlich yanz unwesentliche sind, die sich beim fortschreitenden Wachsthum der Knospen von 1 z $13^{\mathrm{m} m}$ ganz allmählich verwisehen werden. Der zunächst an meisten auffallende Unterschied, nimlich das lange Magenrohr der Carmarina-knospe gegenüber dern kurzen Mundrand der Cunina, macht in der That nicht die geringste Schwierigkeit, da wir hercits von einel anderen Cuninu wissen, dass das reife Thier gar hein ror'springendes Magenrohr, der Eubryo desselben dagegen ein ausserordentlich langes und diunnes eylindrisches Magenrohr besitzt. Es ist dies die Cunima octonaria Mc. Crudy, welche in crwachsenem Zustande. unserer Cumina rhododactyle sehr ihulich ist, dagegen als Embryo oder Larve noch ein weit liingeres Mayenrolu zeigt. Ich hann daher nicht mehr das geringste Bedenken bagen, die pelagisch gefischte Cunina 
rhodorlactyla mit den achtstrahligen Knospen, welche auf der Zungenoberfläche der geschlechtsreifen Carmarina hastata hervorsprossen, für itlentisch zuerkliren. lch kann un so weniger an dieser Identitit zweifeln, als die Cumina rhododaclyla im Golfe von Nizza stets nur in der unmittelbaren Gesellsebaft und Umgebung der Carmarinu hestala zu finden war. Beide Medusen-Arten erschienen während meines siebenwöchentlichen Aufenthalts an jener Küste nur an drei oder vier Tagen, an diesen aber in grossen Schwarmen. Doch waren die Carmarinen weit spirlicher vorhanden, als die Cuninen, welche sie in allen rischiedenen Entwickelungsstadien massenhaft begleiteten.

Die Cumina rhododactyla, eine frei schwimmende und Geschlechtsorgane entwickelnde achtstrahlige Meduse aus der Aeginiden-Familie, wird also auf ungeschlechtlichem Wege, und zwar durch Knospung an der Zungenoberfliche in der Magenhöhle, von der Carmarina hastuta cryengt, einer scheinbar weit davon entfernten und ganz verschiedenen sechsstrahligen Meduse aus der Geryoniden-Familie, einer Meduse, welche ebenfalls frei umherschwimmt und Geschlechtsorgane producirt, und welche sich ausserdem durch eine complicirte Metamorphose aus einer sechsstrahligen Larve entwickelt, die sowohl der erwachsenen Curmarina, als der Cunima sehr unähnlich ist!

Diese Thatsache, welche ich nicht mehr bezweifeln kann, ist in der That so fremdartig und wunderbar, entspricht so wenig allen bekannten Verhältnissen der heterogenen Fortpflanzung, dass ich es Niemand verargen will, wenn er vorläufig meinen Angaben kein Vertrauen schenkt. lch wïrde selbst daran zweifeln, wenn ich nicht die leiblichen Thatsachen unmittelbar vor Angen sïhe. Wir sind durch die viclen trefllichen Untersuchungen, welche in den letzten Decennien ulber dir Naturgeschichte derllydromedusen angestellt worden sind, mit cinerausserordentlichen Mannichfaltigkeit der merkwürdigsten Fortpflanzungsverhältnisse in dieser interessanten Thierclasse bekannt geworden. Alle denkbaren Formen der geschlechtlichen und ungesclilechtlichen Fortpflanzung, des Generationswechsels und des Polymorphismus, seheinen hier realisirt zu sein. Medusoide und polypoide Formen haben sich in der mannichfaltigsten Weise combinirt gezeigt. Hier aber liegt eine Thatsache vor, die sich keiner irgend bekannten Form des Generationswechsels anzuschliessen und eine ganz neue Form der Fortpflanzung zu begründen scheint.

Leider bin ich nun nicht im Stande, aus dem vorliegenden Materiale weitere Aufschlïsse über den ferneren Verlauf dieser höchsı merkwürdigen Zeugungsform zu gewinnen, und eine del vielen und wichtigen Fragen zu beantworten, die sich angesichts dieser wunderbaren 
Thatsache unwillkurlich aufdrängen. Auf welche Weise schligit die achtstrahlige (und zuletzt sechzehnstrahlige) Cunina wieder in die Formı der sechsstrahligen Carmarina zurück? Wo kommen die sechsstrahligen Larven der letzteren her? Was wird aus den Geschlechtsproducten der beiden anscheinend so weit verschiedenen Medusen? Zeugen auch die Cuminen ungeschlechtlich? Als die verhältnissmässig einfachste Lösung des Räthsels würde noch diejenige erscheinen, dass sowohl aus der geschlechtlichen als aus der ungeschlechtlichen Zeugung der Carmarina hastata dirselbe Cumina rhododactyla herrorgeht, und dass sowohl aus der geschlechtlichen, wie aus der ungeschlechtlichen Zeugung der letzteren wieder die Carmarina entspringt. Oder pflanzt sich die Cunima nur als Cumina fort, während die Carmarina gleichzeitig auf geschlechtlichen Wege ihres Gleichen, auf ungesshlechtlichem aber Cunina producirt?

Auf diese und viele andere Fragen werden erst kunftige Untersuchungen Antwort geben. Inmerhin bin ich schon jetzt durch eine möglichst genaue vergleichende anatomische Untersuchung beider Yedusen in den Stand gesetzt, wenigstens von einer Seite her diese merkwürdigen Verhältnisse etwas aufklären zu können und sie weniger wunderbar erscheinen zu lassen, als dies im ersten Augenblicke der Fall ist. Es hat sich nimlich aus einer sorgältigen Vergleichung des anatomischen Baues der Geryonide und der aus ihr hervorknospenden Aeginide ergeben, dass die beiden Medusen-Familien, denen sie angeliören, weit näher verwandt sind, als dies allgemein angenommen wird.

Da es bei einem so ausserordentlichen und von den gewohnten Vorgängen so alweichenden Vertuälnisse, wie das vorliegende, jedenfalls gerathen ist, in der Erklärungsweise die grösste Vorsicht anzuwenden, und alle, auch die entferntesten Möglichkeiten in Betracht zu ziehen, so mögen zuvor ein par Worte über die Frage eingefügt werden, ob wir es nicht möglicherweise hier mit einem Parasitismus zu thun haben? Dieses Verhiltniss ist unter den Vedusen überhaupt äusserst selten. Durch Квону haben wir die merkwürdige Mnestra parasites kennen gelernt ${ }^{1}$ ), eine kleine Meduse aus unbestinmter Familie, welche stets an derselben Körperstelle eines Weichthieres, und zwar der Phyllirhoe bucephuhu, iusserlich angesaugl gefunden wird. Viel wichtiger für unseren Fall ist der seltsame Parasitismus, der neuerdings von einer Aeginide durch die trefllichen Untersuchungen Mc. Crady's 
bekannt geworden ist ${ }^{\text {) }}$. In der Mantelhöhle einer Oceaniden-Meduse aus dem Hafen von Charleston, der Turritopsis mutricola. fincien sich in Menge und in verschierlenen Entwickelungszustainden die Larven einer frei schwimmenden Aeginide vor, der Cunima octonaria Mc. Crady. Die jüngsten flimmernden Larven bilden einen kleinen keulenförmigen Kïrper, der mittelst des dünn auslaufenden Stieles in der Mantelhöhle der Turritopsis befestigt ist. Das andere dickere Ende treibt zwei schlanke und biegsame Tentakeln, die sich bald rerdoppeln. Bisweilen treibt die Larve jetzt schon Knospen von ihresgleichen. Dann bekommt sie ein sehr dünnes und langes rüsselförmiges Magenrohr. Zwischen den vier Tentakeln sprossen vier andere hervor, und gleichzeitig mit diesen, und mit allen acht Tentakeln alternirend zeigen sich an einer Ringfalte, die sich von der Mitte des Körpers abhebt (der Anlage des Schirmrandes) acht Randbläschen. Die kleinen Larven halten sich in der Mantelhöhle der Turritopsis an den Wänden derselben und des Magenstiels fest mittelst der vier primären, nach dem Aboralpol hinauf gekrümmten Tentakeln, wïhrend das sehr lange rüsselförmige Magenrohr der Schmarotzer durch die Mundöffnung ihres Wohnthieres in dessen Magenhöhle hinein gestreckt wird und hier Nahrung aufnimmt. Gewiss ist diese schon an sich höchst auffalleude Form des Parasitismus um so merkwürdiger, als hier eine Meduse in einer Meduse schmarotzt, und der erste und natülichste Gedanke, den auch Mc. Cradrin seiner ersten ausführlichen Darstellung desselben hatte und festhielt, ist der, dass jene, gervissen Hỵdroidpolypen sehr ähnlichen Larven nicht die Schmarolzer, sondern die Nachkommen der Oceanide sind. Erst später, als Irc. Crady die völlige Umwandlung der mit langem Magenrohr versehenen schmarotzenden Larven in die freischwimmende, desselben entbehrende Cumina octonaria nachgewiesen latte, liess er jene erste Annahme fallen und entschied sich für den Parasitismus der Larven. In ler That scheint mir auch jetzt noch diese Deutung die wahrscheinlichste, wenngleich andrerseits, bei Erwiigung der sogleich darzulegenden Verhältnisse, loch der Gedanke nicht ganz ausgeschlossen werden darf, dass Mc. Graby's erste Deutung die richtigere war und dass die Cunina ostonaria wirklich die Brut der Turritopsis mutricola ist.

Höehst wahrscheinlich hat jedoch dieses merkwürdige Verhältniss mit demjenigen, welches uns hier vorliegt, nur eine oberflächliche und :iusserliche Aehnlichkeit, obgleich die Cunima octonaria durch ihre ganze Forn und Structur, durch die acht Randlappen und Tentakeln, wie

1) Proceedings of the Elliott Society of Charleston (South-Carolina). Vol. I, 1859, p. $55-90$, p. $209-212$. 
dureh die Bildung der Randbläschen und ihrer Spangen, der jüngsten achtstrahligen Form unserer Cumina rhododactyla sehr nahe steht. Dass aber hei derletzteren kein Parasitismus stattindet, scheint mir schon aus rler oben gegebenen Darstellung des Knospungsprocesses auf der Oberfläche des Zungenkegels zur Genüge erwiesen zu sein. Die Zunge del Carmarina hastata ist ein sellostständiges Organ, welches auch bei den nicht knospentreibenden Thieren völlig entwickelt ist (Fig. 4, 5). Die Entwickelung der Knospen aus ihrer Oherfläche lässt sich rom ersten Antinge an Schritt für Schritt verfolgen (Fig. 7\%, Fig. 94 A-F). Die Knospen sind mit einem grossen Theile ihrer Aboralthiche fest der Oberfläche des Zungenkegels verbunden und nur durch Continnitatstremnung daron ablösbar. Wie mit diesen und den ibbrigen oben geschilderten Verhiltnissen die Annahme eines Parasitismus des CuminaEmbryonen sich vereinbaren lassen sollte, vermag ich nicht einzusehen.

Es bleibt also in der That nichts Anderes übrig, als dic Gewissheit, dass die sechsstrahlige Carmarina und die achtstrahlige Cunina durch wirkliche Blutsverwandtschaft auf's nächste verbunden sind und einer und derselben »S pe ci es« angehören, d. h. einem Formenkreise, dessen Glieder nachweisbar durch die engste Blutsverwandtschaft zusammenhängen.

Nun sind aber die Geryoniden. zu denen die Carmarma und die Aeginiden, zu denen ihre Knospe, die Cunina gehört, hisher als völlig verschiedene Medusen-Familien allgemein behandelt worden. Nach den ubereinstimmenden Ansichten simmtlicher neuerer Naturforscher, welche die Medusen untersucht haben, sind die Aeginiden von allen ubrigen craspedoten Medusen in weit höherem Grade verschieden, als es je zwei andere Familien dieser Ordnung unter sich sind. Namentlich wird als Hauptkriterium stets angeführt, dass bei den Aeginiden bloss "blinde taschenförmige Fortsätze " von den Magen ausgehen und dass ein hinggefäss felılt, witurend bei allen übrigen Craspedoten » radiale Canäle « vom Nagen ausgehen, die am Rande durch ein Ring̣gefiss rerbunden sind. Gegrexaur, der von den neueren Autoren die Apginiden noch aın nächsten mit den anderen Craspedoten rerbindet und sie am Ende derselben als eine besondere Familie anf die Geryoniden folgen lässt, sagt von den Aeginiden : "Lnstreitig ist dies wohl die am wenigsten gekannte und von den bis jetzt von den Medusen gebriuchlichen Vorstellungen die grössten Abweichungen darhietende Gruppe, die sich aber eben dadurch und bei nur geringen verwandischaftlichen Beziehungen von allen ubrigen die grösste Einheit und Abrundung bieteł. Viel weiter gehen 
in der Trennung der Aeginiden von den übrigen niederen Medusen zwei andere neuere Bearbeiter derselben, Fritz Müllfr und Agassiz:

Fritz Müller, der treffliche Forscher, der bisher allein eine genaue anatomische und embryologische Darstellung einer Aeginide (der Cunince Köllilieri) gegeben hat ${ }^{1}$ ), glaubt gerade auf deren Ergebnisse hin die Aeginiden ganz von den Craspedoten oder Cryptocarpen abtrennen zu müssen ${ }^{2}$. Er theilt die ganze Classe der Hydromedusen in 4 Ordnungen: 1., Siphonophoren; 2., Hydroiden (Craspedoten nach Ausschluss der Aeginiden); 3., Acalephen (Acraspeden nach Ausschluss der Charybdeiden); 4., Aeginoiden (Aeginiden und Charybdeiden). Diese Aenderung wird auch von Levckant gebilligt.

Agassiz andrerseits nimmt in seinem grossen Medusenwerke die Aeginiden sogar ganz zu den höheren Medusen (Phanerocarpen oder Acraspeden) hinüber. Er trennt diese Ilauptabtheilung (Ordnung der Discophorae) ginzlich von den Iydroiden ab und theilt sie in drei Unterordnungen: 1., Rhizostomeen; 2., Semaeostomeen (Aureliden, Sthenoniden, Cyaneiden, Pelagiden); 3., Haplostomeen (Aeginiden, Brandtiden, Charybdeiden, Marsupialiden und Lucernariden). Wegen der weiten blinden radialen Magentaschen und des Mangels eines Cirkelcanals glaubt Agassız die Aeginiden unmittelbar mit den Ephyren, den Jugendformen der Aureliden, zusammenstellen zu können (1. c. p. 3).

Gegeniber dieser Auffassung glaube ich durch die obengegebene möglichst sorgfältige anatomische Analyse der Cunina rhododactyla und der Geryoniden dargethan zu haben, dass diese beiden Medusenformen im inneren Baue und zwar in den wesentlichsten Beziehungen desselben, ja sogar in der feineren histologisehen Structur auf das nächste verwandt sind, und wenn wir einen weiteren vergleichenden Blick auf die anatomisehen Verwandtschaftsverhältnisse der Geryoniden, einerseits zu den Aeginiden, andrerseits zu den übrigen Graspedoten werfen, dürfte sich leicht herausstellen, dass die ersteren zwischen den beiden letzteren in der Mitte stehen, ja sogar, dass die Geryoniden (namentlich im Larvenzustande) noch näher den Aẹ̦iniden, als den iibrigen Craspedoten verwandt sind. Da Fritz Mülúr die entgegengesetzte Ansicht am eingehendsten begründet und zugleich auf eine sehr sorgfältige anatomische Analyse einer Aeginide gestützt hat, so werde ich alle einzelnen ron ihm angebrachten Argumente mit meinen Untersuchungsresultaten vergleichen.

1) Archiv für Naturgeschichte. XXVII., 1. 1861. p. 42, Taf. IV.

2) Ibid. p. 303 (Ueber die systematische Stellung der Charybdeiden). 
Die Scheibe der H!droidmedusen oder Cryptoearpen (Craspedoten) - sag̣t Fritz. Müller (1. c. p. 306) "ist stets ganzrandig, und wie bei den Acaleplen glatt oder etwa mit schwach vorspringenden, von ter Mitte des Rückens ausgehenden Leisten versehen. - Dagegen ist die Scheibe der Cunina und ilsrer Yerwandten haiugg, wo nicht immer, am Rande gekerht, und wie bei den Charybdeiden, von mehr wenjg̣er tiofen, mels' weniger weit auf die Riickenfliche sich fortsetzenden Furchen durehzogen«. Das Letztere ist vollkommen richtig. Allein ganz dieselben Einschnitte des Scheibenrandes, welche sich auch als seichte rentripetale furchen eine Strecke weit auf der Aussenfliche des Schirmes hinaufziehen, finde ich auch bei den Gerģoniden; nur dass sie hier nicht so tief und weit gehend sind, wie bei den Aeginiden; desshall, springen auch die dadurch entstehenden Lappen des Randes weniger auflallend vor, als bei den letzteren. Die Zahl der Randeinsclınitte entspricht der Zahl der unmittelhar iiber denselben sitzenden Randbliischen und der marginaten Mantelspangen, die von ihnen ausgehen. Sellost an erwachsenen geschlechtsreifen Thieren von Carmarina (Fig. 1, 2) und noch melır von Gilossocodon (Fig. 13-10̈) tritt diese Kerbung des Randes dureh 12 oder 8 Einschnitte noch deutlich hervor. Weit auffallender erscheint dieselbe oft an den Lar en heider Arten (Fig. 5:5:9, 63; Fig. $36-38,40,41)$. Es ist also in der That bei den Geryoniden der Schirmsand ebenso (nur weniger tief) wie bei den Aeginiden (Fig. 78-80) eingeschnitten und den entsprechend auch das Velum bei beiden Familien an den Stellen, welehe den radialen Einsehnitten entsprechen, breiter als an den dazwischenlieg̣enden.

"Die Cryptocarpen॥ - sagl Futz Mülden weiter, whaben stets Strahlgefisse und Ringcanal, und zwar erstere, ausser bei sehr grosser Menge, in fester Zalıl. Bei den Aeginiden dagegen hat der Magen breite Seitentaschen in oft schwanhender Zahl, nie Strahlgefiisse oder Ringcanal《. Diese Dillerenz wird allqemein als die durehgreifendste und namentlich der Mangel des Ringeanals ron allen Autoren als der wesentlichste Charakter der Aeginiden angesehen. Dass diese Behauptung irrig ist, habe ich oben bei der Anatomie der Cuninu rhododactyla bestimmt nacligewiesen. Diese Aeginide, und cbenso die Cunina albescens, die ich ebenfalls hierauf untersuchte, haben einen vollkommnen Ringcanal an Schirmrande, so gut, wie alle anderen Craspedoten, nur dass er verhailtnissmaissig viel enger ist. Sowoht aul Qnersehnitten liisst sich sein Lumen (Fig. 81, 82c) als auf Flichenansichten sein charakteristisehes Epithel (Fig. $84 \mathrm{cs}$ ) ebenso leicht als bestimmt nachweisen. Ebenso sind auch die so sehr hervorgehobenen wblinden Seitentaschen des Magens ( der Aeginiden, die als etwas ganz 
Besonderes angesehen zu werken pflegen, ganz gewöhnliche, nur etwas breite und flache Padialcanäle, die innen in den Magen, aussen in das Ringgefiss einmünden. Ganz ebenso breit und flach findet man auch die taschenähnlichen Radialcanäle von jugendlichen Geryoniden-Larven (Fig. 36-38, 56- 38) wo, besonders bei sehr jungen Glossocodon, die Interstitien zwischen den breiten Radialcanälen $\mathrm{fl}$ schmäler sind als diese selbst. Iliermit ist also die Hauptscheidewand zwischen den Aeginiden und den anderen Graspedoten gefallen.

"Die Tentakeln der Cryptocarpen«, fährt Fiatz Mülden fort, "sind von sehr wechselndem Ban, nehmen aber doch stets die unmittelbare Nihe des Ringgefässes ein. - Bei den Aeginiden dagegen sind die Tentakeln, nie die Zahl der Magentaschen uberschreitend, stets ribkenstindig, oft sehr fern vom Rande entspringend; ausserdem sind sie bald durch eine eigenthimliche Starrheit, bald wieder durch eine, bei anderen Medusen gar nicht bemerkte Beweglichkeit ausgezeichnetu. Anch dieser Unterschied ist nicht durchgreifend. Vielmehr stimmen auch in dieser Bezichmg die Larven der Geryoniden ganz auffallend mit den Aeginiden überein. Sowohl bei den ïlteren Larven von Carmarina (Fig. 56-58) als von Glossocodon (Fig. 36-40) entspringen die interradialen sowohl als die radialen soliden Tentakeln anf der Rückenfläche der Scheibe, fern rom Rande, mit dem sie nur durch die marginalen Mantelspangen verbunden sind. Ferner haben sie ganz denselben sstarren Ilabitus und denselben eigenthiumlichen Bau wie die Tentakeln der Cumina: ein Knorpeleylinder, aus einer Reihe grosser Zellen gebildet: und iiberzogen von einem Schlauche von Lïngsmuskeln, iiber welchem das nesselnde Epithel liegt.

"In der Bildung der Geschlechtstheile endlich«, sagt zuletzt Frıtz Müller, "schliessen sich die Ilydroidquallen den Acalephen oder Phanerocarpen an; denn obschon von ungemeinem Formenreichthume, nehmen sie doch stets die ämssere Wand des Gastrovascularsystems ein und entleeren ihre Producte nach aussen. Die Geschlechtsstoffe der Cumima dagegen bilden sich in Innern der Seitentaschen, und zwar in den seillichen Winkeln derselben, von wo ihre Bildungsstaitte hufeisenförmig von einer Tasche zur andern sich hiniiberzieht«. Auch diese Differenz kann ich nur bis zu einem gewissen Grade gelten lassen und kann sie ausserdem nicht für wesentlich halten. Gerade durch die eigenthiimliche Bildung der Geschlechtsorgane scheinen mir die Gerjoniden nailier mit den A eginide $n$, als mit allen anderen Medusen verwandt zu sein. Bei Beiden sind die Radialcaniile zu blattförmigen Taschen erweitert und bei Beiden ist es das Epithel der un teren (subumbralen) Wand der blattförmigen Ganaltaschen, aus 
welchem sich unmittelbar die beiderlei Geschlechtsproducte entwickeln. Der einzige, und, wie mir scheint, nicht wesentliche Unterschied besteht darin, dass bei den Geryoniden sich diese taschenförmigen Erweiterungen nur während der Geschlechtsreife entwickeln, dann aber auf dem grössten Theile ihrer unteren Fläche (die radiale Mittellinie ausgenommen) Samenzellen und Eier produciren, während dieselben bei den Aeginiden zu allen Zeiten gefunden werden und nur auf einem kleinen Theile ihrer unteren Fläche (namentlich an der Umbiegungsstelle einer Tasche in die andere) Geschlechtsproducte entwickeln. Auch bei den Geryoniden sind es, wie bei den Aeginiden, nur die seitlichen Theile der unteren (subumbralen) Fläche der blattförmigen Radialcanäle, welche Eier und Samenzellen liefern, währeud das Epithel der radialen Mittellinie derselben unverändert bleibt. Ob die Geschłechtsproducte direct nach aussen, oder erst in die Höhlung des Gastrovascularsystems und dann durch den Mund nach aussen entleert werden, scheint mir gleichgültig zu sein und ich glaube, dass z. B. bei den Geryoniden beide Arten der Ausführung der Genitalproducte neben einander vorkommen.

Es bleibt also von allen Differenzen zwischen den Aeginiden und den übrigen Craspedoten, auf Grund deren Fritz MüLl.en beide trennen will, nur noch eine einzige übrig, die verschiedene Beschaffenheit der Randbläs chen, welche bei den Craspedoten, "wenn vorhanden, stets rundlich und sitzend«, bei den Aeginiden dagegen »meist gestielt« sind. Diese Verschiedenheit ist nun allerdings gerade zwischen den Geryoniden und Aeginiden vorhanden, und sie ist sogar, wie die von mir gegebene Darstellung ihres feineren Baues lehrt, bedeutender als man glaubte. Die Randbläschen der Geryoniden finde ich in der Gallertsubstanz des Mantelrandes eingeschlossen, diejenigen der Cunina frei auf einem Vorsprunge der Randlappen sitzend. Die Differenz ihres feineren Baues springt bei der Vergleichung der oben gegebenen genauen Darstellung der Randbläschen von Carmarina (Fig. 7, 8) und von Cumina (Fig. 84, 8.3) klar vor Augen. Doch glaube ich, dass auch diese Structurdifferenzen grösser scheinen, als sie sind. In beiden Fällen liegt der sogenannte Otolith ( $\mathbf{k}$ ) unbeweglich eingebettet in eine solide Zellenmasse welche von einer Membran kapselartig eingeschlossen ist und welche ich als Sinnesganglion ( $\mathrm{s}$ ) bezeichnet habe. In beiden Fillen tritt der Sinnesnerv (n) von einem hügelförmigen Ganglion (f) aus, welches das Randb)lischen trägt, in die Zellenmasse jenes Sinnesganglion hinein und läuft durch sie hindurch zum Otolithen. Der Hauptunterschied beschränkt sich also erstens darauf, dass bei Carmurinu zwei sich kreuzende, bei Cunina ein einfacher Sinnesnerv vorhanden ist, und zwei- 
tens darauf, dass bei den innerlich eingeschlossenen Randbläschen der Geryoniden das Sinnesganglion noch von einer in einer grossen Blase enthaltenen wässerigen Flüssigkeit umspült wird, während dasselbe bei den äusserlich gelegenen Randbläschen der Cunina ohne weitere Hülle, als die diinne Membran, frei in das Seewasser hineinragt und hier noch von den Borsten umstellt ist, die von dem Ganglion (f) ausstrahlen (Fig. 8:3).

Ausserdem aber ist siclıer gerade die Structur von so äusserlich gelegenen Sinnesorganen, die sich der Verschiedenheit der äusseren Verhälnisse in so hohen Maasse anpassen können und müssen, für die wahre Erkenntniss der inneren Verwandtschaft nur von sehr untergeordnetem Werthe. Wohl keine anderen körpertheile bieten bei nächstverwandten Thieren so bedeutende Differenzen dar, wie es bei den Sinnesorganen der Fall ist, und es ist auch in der That praktisch längst annerkannt, dass diese Organe für die Systematik nur von untergeordnetem Werthe sind. Da dieselben die Erkenntniss der Aussenwelt vermitteln, so werden sie von dieser selbst auf das vielfachste beeinflusst und durch die Anpassung an jene geht ihr erblicher Charakter früher und vollständiger verloren, als es bei anderen Körpertheilen der Fall ist. Wie verschieden ist z. B. das Auge bei beiden Generationen der Salpen gebildet! Die craspedoten Medusen selbst liefern das beste Bcispiel, wie ausserordentlich verschieden bei sonst sehr nahe verwandten Thieren die Sinnesorgane sich gestalten können. An derselben Stelle, wo bei den Einen ein einfacher Pigmentfleck, bei den Anderen ein solcher mit lichtbrechendem Medium liegt, finden wir bei einer anderen Reihe theils bläschenförmige, mit Flüssigkeit erfüllte, theils solide Körper, welche in eine Zellenmasse eingehüllt eine Concretion oder einen Krystall enthalten, zu welchen ein besonderer Nerv tritt. Mit Rücksicht hierauf glaube ich der Differenz, welche sich zwischen den Sinnesbläschen der Geryoniden und Aeginiden findet, nur eine untergeordnete Bedeutung zusehreihen zu müssen.

Abgesehen aber von dieser Verschiedenheit der Sinnesbläschen, ist wohl durch die oben gegebene vergleichende Anatomie der Carmarina und der Cunina die ausserordentlich nahe a n to $\mathrm{m}$ is che Verwandtschaft der bisher für sehr verschieden gehaltenen beiden MedusenFamilien in klares Licht gestellt worden. Ein vergleichender Blick auf die schematischen Körperdurchschnitte Fig. 95-99 lehrt das besser, als jede weitläufige Deduction. Zwei Puncte aber scheinen mir noch eine besondere Berücksichtigung zu verdienen. Es ist dies erstens die Bildung der marginalen Mantelspangen, welche bei der Carmarina, wie bei der Cunina wesentlich denselben Bau besitzen, und 
welehe moines Wissens bei andieren Medusen-Fanilien nicht rorkontmen. Ganz hesonders wichtig aber ist zweitens die besondere Beziehung, welche die Cumina zu der Larve der Carmarina hat. Vergleicht man den Durchsehnitt der Larve (Fig. 97) mit demjenigen der erwachsenen Carmarina (Fig. 99) einerseits, mit demjenigen der Cumina (Fig. 96) andrer'scits, so ist ohne weiteres klar, dass die Larve wcit mehr Uebereinstimmung mit der letzteren, als mit der crsteren hesitzl. Der für die erwachsene Geryonide so charakteristische $\mathbf{I}$ a g enstiel (p) mit seiner zungenfömigen Verlingerung in die tief glockenförmige Magenhöhle und mit den sechs in seiner Oberlliche getrennt aufsteigenden Radialeanislen fehlt der Larve noch völlig. Vielmehr führt hier, ganz wie bei Cumina, der einfache weite Mund sogleich in eine llache niedrige taschenförmige Haggenhöhle, von deren Unkreis unmittelbar die flachen taschenförnigen Radialcanäle ausstrahlen, um an der flachen Unterseite des Schirmes zum kande zu laufen und sich dort durch das Cirkelgefiss zu verbinden. Die Larve der Carmarina besitzt nur solide, starre Knorpelt en takeln (Fig. 6. st), ganz gleich gebaut denen der Cumina (Fig. 83), zusammengesetzt aus einem kinorpelcylinder, der von einem Längsmuskelschlanche und darüber von einem cinfachen einschichtigen Epithel überzogen ist. Die erwachsene Carmarina dagegen, die Imago, hat nur knorpellose, selır contractile, hohle Tentakeln, dic in gröberen wie im feineren Baue gänzlich von jenen ersten verselieden und aus einer inneren Ring- und äusseren complicirten Längslaserschicht zusanmengesetz, darüber von einem mehrschichtigen Epithel iiber\%ogen sind (Fig. 60-62). Diese hohlen Tenlakeln entspringen aus dem Cirkelcanal an Schirnmande (Fig. 98 t), waihrend die knorpeltentakehn der Larve, gleich denen der Cunina, aus der Riickenlliche des Schirmes entspringen.

In allen diesen wiehtigen Beziehungen steht ohne Zweifel die Larve der Carmarina weit niher der Cumina, als der erwachsenen Imago, in welche sie sich allmählich verwandelt. Fände man diese drei Formen neben einander im Meere, ohne von ihren Beziehungen etwas zu wissen, so wïrde man zweifelsohne im Słsteme die Cunina und die Larve der Carmarina, etwa als zwei Gattungen einer Familie, zusammenstellen, withrend man die erwachsene Carmarina als eine weit davon versehiedene Gattung sicher in eine andere Familie stellen würde ').

1) Ich schrieb diese willkürliche Vorausselzung nieder, ohne daran zu denken, dass dieser Fall in Wirklichkeit längst eingetreten ist. Eschscholtz hat in scinem trefflichen "System der Acalephen" die Eurybia, welche weiter nichts, als eine Geryoniden-Larve ist, unmittelbar neben Cunina in die Familie der Aequoriden 
152 X. Verwandischaft undgGienerationswechsel zwischen den Geryoniden und Aeginiden.

Diese Erwaigung der nahen verwandtschaftlichen Beziehungen zwischen den embryonalen Formen der Geryoniden und den erwachsenen Aeginiden führt uns zu den wichtigsten Betrachtungen über die allgemeine Stellung der letzteren Familie, die auch für unseren speciellen Fall hier von besonderem Interesse sind. Zuvor jedoch ist es nöthig, ausser den bereits erörterten Grundzügen des anatomischen Baues der Aeginiden auch die sämmtlichen bekannten EntwickelungsVerhältnisse dieser merkwürdigen Familie in Betracht zu ziehen. Was man davon bisher wusste, ist ausserordentlich wenig. Dieses Wenige aber ist dennoch von der höchsten Wichtigkeit. Ich werde desshalb alles bisher Bekannte hier kurz zusammenfassen.

Die erste und lange Zeit einzige, auf die Entwickelung der Aeginiden beziigliche Beobachtung wurde 18.51 von Johavxes MülLer veröffentlicht $\left.{ }^{1}\right)$. Er beobachtete den bewimperten Jugendzustand der zweiarmignen Aeginopsis mediterranea (Campanella mediterranea Agassiz), welcher sich von dem hall,kugeligen erwachsenen Thiere, ausser durch das Wimperkleid, auch noch durch linger gestreckte, fast cylindrische Körperform und durch viel geringere Länge der beiden Tentakeln unterscheidet. Johurves Mülu.er macht am Schlusse seiner Mittheilung folgende Bemerkung: "Da die jüngsten Exemplare Wimperbewegung auf der Oberfläche des Körpers besitzen, so scheinen sie denı Embryonenzustande noch nahe zu stehen. Der Umstand aber, dass sie in diesen Zustande in der Form und namentlich in den Armen von der späteren Medusenform wenig abweichen, scheint darauf hinzudeuten, dass diese Gattung von Medusen dem Generationswechsel vielleicht nicht unterworfen sein könne

Diese vorsichtige Bemerkung Jollaxxes Müller's wurde von den folgenden Autoren nicht mit derselben Vorsicht aufgenommen und verwerthet. Viclmehr grundete man auf diese eine, und noch dazu unvollständige Beobachtung den Schluss, dass alle Aeginiden sich nur auf homogenem Wege fortpflanzten und entweder durch geschlechtliche oder ungeschlechtliche Zeugung stets nur Ihresgleichen producirten. Ausserdem zog man daraus weiter den ebenfalls irrigen Schluss, dass das Wimperkleid jugendlicher Medusen für ihre Abkunft aus Eiern beweisend sei, obwohl doch zu dieser Annahme gar kein Grund rorlag, und nicht einmal von den bewimperten Embryonen der Aeginopsis

(die dritte der Cryptocarpen) gestellt, während er die Geryoniden als eine eigene Familie (die erste der Cryptocarpen) ansah.

1) Müllek's Archiv, 1851, p. 272, Tal'. XI. 
mediterranea selbst ihre Abkunft aus Eiern ermittelt, sondern bloss vermuthet war.

Eine zweite wichtige Beobachtung in diesen Gebicte wurde von KöLlıker 1833 mitgetheilt ${ }^{1}$ ). Dieser Forscher beschreibt unter dem Namen Stenogaster complanatus eine kleine Aeginide von I"' Durchmesser, mit 46 Tentakeln und 16 Sinnesbläschen (wahrscheinlich eine Cunina). Diese kleine Meduse wurde von ihm in Messina nur einmal, und zwar in der Leibeshöhle von Eurystoma rubiginosum gefunden. Unter letzterem Namen beschreibt Köl.lık eine andere Aeginide von $5-6^{\prime \prime \prime}$ Durchmesser, welche vermuthlich unserer Cumina rhododactyla nahe steht, und welche eine halbkugelige Scheibe mit 10 Randlappen, 10 Tentakeln und je $6-8$ Randbläschen zwisehen je 2 Tentakeln besitzt. In der Leibeshöhle (wahrscheinlich Magenhöhle) von Eurystoma fand nun Köllıker ausser jenem Stenogaster moch viele Formen, die höchst wahrscheinlich junge Zustinde des Stenogaster sind. Es zeigten sich da : 1., ovale kleine Körper mit einer iusseren Rindenlage und einer inneren geschlossenen Cavitai, ron denen nach einer Seite ein kurzer Arm abging; 2., ;ihnliche etwas grössere Embryonen mit 2 von entgegengesetzten Seiten abgehenden Fangfäden; 3., ebensolehe mit 4 kreuzweise gestellten $\mathrm{Ar}$ men ; 4., endlich noch grössere mit 5 und 6 Armen«. KöLlıker deutet diese Beobachtung dahin, "dass das fragliche Individuum von Eurystoma von einem ganzen Schwarm junger Stenogaster (mit dem Eurystoma unmöglich im Zusammenhang stehen kann) einige in sich aufgenoumen hatter.

Die wahrscheinlich richtige Erklärung dieser Beobachtung wurde erst 1861 von Futz Müller in Desterro gegeben, welcher die Behauptung aufstellte, dass Stenogaster nichts Anderes als die Brut ron Eurystoma sei, und diese Behauptung durch die ausführliche Schilderung eines ganz ähnlichen Fortpflanzungsvorganges an einer brasilischen Cunina begründete $\left.{ }^{2}\right)$. Diese Aeginide, welche er Cumina Köllikeri nennt, besitzt einen meist achtstrahligen Schirm von $6 \frac{1}{\mathrm{~m}}{ }^{\mathrm{mm}}$ Durchmesser, zwischen den 8 Tentakeln 8 Randlappen, und an jedem der letzteren 1-3 Randbläschen. Ausser den achtzähligen Individuen kommen jedoch bisweilen auch Andere mit 6 - 7, seltener mit 9 gleichen Körperabschnitten vor. In Magen und seinen Nebentaschen findet sich sowohl bei den geschlechtsreifen Individuen (die stets männlichen Geschlechts waren), als bei äteren, bei denen bereits die Samenbildung erloschen ist, in reicher Menge junge Brut, deren Segmentzahl von 1, 2, 4 bis auf 12 steigt. Die jüngsten Knospen, die sich eben erst als rundliche

1) Zeitschrift für wiss. Zool. IV, 1853, p. 322, 327.

2) Archiv für Naturgeschichte XXVII, 1, 1861, p. 42. Taf. IV. 
Knöpfehen von der Mağenwand abg̨elöst haben, tragen nur einen einzigen, die niblistilteren zwei gegenstindige Tentakełn. In der Mitte zwischen diesen entstehen zwei nere; slann ein Tentakel zu jeder Seite des ersten, wie des zweiten Tentahels, endlich ein laar vor und ein anderes hinter den mittleren Tentakeh. Nicht selten bleibt die Zahl der Tentakeln auf 11 oder 10 , seltencr auf 9 beschr:inkt". IZin einziges Val kam auch eine Form mit 13 Tentakeh vor. Die zwölfstrahligen Cuminen sind ihrem achtstrahligen Vater, in den sie natuirtich nicht durch Verwandlung übergehen können, in Uebrigen sehr :ihnlich, die jüngeren mit einem Flimmerepithel versehen, gheich dem der Magenhöhle, aus der sie hervorgesprosst sind. Das weitere Schicksal der heiderlei Formen von Cmma Köllikeri ist unbekannt.

Ein weiterer Fall von Knospenbildung in Magen einer Aeginide ist schon früher (18:54) von Gegexbacr mitgetheilt worden '). In dem peripherisehen Theile des Magens von Cumina prolifera (späterhin Aerjinetu proliferctgenannt), welche einen Schirm von $\mid \mathrm{f}$ in murchmesser und 16 Tentakehn nebst 20 Randbliischen besitzt, finden sich dicht gedrainğ zahtreiche kleine Knospen, die noch, wailnend sie als runde Knöplehen an der Magenwand festsitzen, die Anlage von vier im Kreuz stehenden Tentakeln erkennen lassen. Nach ter Ablösung bleiben die Knospen noch in der Magenhöhle der Mutter und erhatten hier die ubrigen Tentakeln und die Randblischen. Dieselbe Art ist auch von Kefersteiv und Ehlers ${ }^{2}$ ) später (1860) in Messina wiedergefunden und ats Aegineta gemmifere beschrieben worden. Der Unterschied beider Arten soll darin bestehen, dass die Magensidche der Aegineta prolifer' whalbbogenförmig abgerundet ", bei A. gemmifera nsanft abgerundet sind, und dass das Velum bei ersterer "breit und schlaff herunter hingend ", bei letzterer » schmal und straff « ist. Offenbar reduciren sich diese Differenzen auf verschiedene Contractionszustinde. Auch besclireiben Keferstein und Eulens die Knospung ebenso wie Gegexpavis. Die iltesten beobachteten Knospen waren flache Scheiben von I in m Durchmesser, mit 16 Tentakchn. Bei dieser Art scheint also die Segmentzahł des Körpers beim Stammthier und der Knospe gleich zu zu sein. Auch unterscheidet sich die knospung dadurch von den beiden Fällen Köllıker's und Fratz Müılen's, dass die'Tentakeln nicht paarweis nach einander auftreten, zuerst einer, dann noch einer, dann zwei, vier u. s. w., sondern dass gleich zucrst vier Tentakeln angelegt werden, mit denen atternirend die ibrigen hervorsprossen.

1) Zur Lehre vom Generationsweehcel. Wiirzburg 1854, p. 56, Fig. $24-31$.

2) Zoologisehe Beitrige. Leipzig 1861, pag. 93, Taf. XIV, Fig. 10, 11. 
Endlich ist hier nochmals der merkwürdigen, oben erwähnten Embryonen der Cunina octonuria zu gedenken, welche Mc. Crady in der Mantellıöhle von einer Oceanide, Turritopsis mutricola, schmarotzend fand, und anlangs selbst für die Embryonen dieser letzteren Meduse biclt, eine Ansicht, die wohl auch jetzt noch nicht ganz von der Hand gewiesen werden darf, wenngleich der Parasitismus derselben das Wahrscheinlichere ist. Auch bei diesen Embryonen sprossen die Tentakeln paarweise hervor, so dass also zuerst 2, clann 4, zuletzt 8 vorlanden sind. Die llerkunft dieser Embryonen, wie die Wege, auf welchen die jüngsten Embrỵonen in die Schirmhöhle ihres Wohnthieres grelangen, sind aber noch ganz unbekannt.

Vergleicht man alle diese vier, ïber die Entw ickelung der Aeginiden vorliegenden Angaben, so erscheinen sie durchaus ungenügend, um sich ein allgemeines Bild von den Entwickelungsvorgangen in dieser seltsamen Medusen-Familie zu entwerfen. Dennoch aber sind sie, namentlich die beiden von Kölıker und Fritz Mëlzer beobachteten Fäle, von hohem Werthe für die Beurtheilung des hier vorliegenden Falles von Cunina rhododactyla. In letzteren, wie in den beiden resteren Fillen ist jedenfalls ein Dimorphismus zweier verschiedener Generationen constatirt, on denen dic cine aus der anderen durch Knospung entstanden ist und nicht direct wieder in die Stammform durch Metamorphose sich umwandeln kann. KöLlıker's Eurysloma rubiginosum besitzt 10, seine Knospenbrut 16 Segmente des Körpers; Fritz Müller's Cunina Kullileri zeigt 8 , ihre Knospenbrut 12 Segmente. In beiden Fällen sind aber die Knospen im Uebrigen vom Stammthier wenig verschieden und gehören derselben Familie an. Anders dagegen in unserem Falle, wo die Knospe, Cumina rhododactyla mit 8 Segumenten, von ihrens Stanmthiere, Carmarina hastata mit 6 Segmenten, so sehr verschieden ist, dass ich selhst sie früher als Angehörige zweier ganz verschiedener Quallen-Familien beschrieben lıbe.

Die Auflösung dieser wunderbaren Riithsel und die Beantwortung der zahlreichen sich hier aufdringenden Fragen ist erst von ausggedehn ten und zusammenhängenden Beobachtungsreihen der Zukunft zu erwarten. Ich zweifle nicht, dass Dasjenige, was hier als ein höchst fremdartiger Ausnahmefall erscheint, sich später als eine weit verbreitete Erscheinung, wenigstens unter den niederen Medusen, und namentlich unter den Acginiden, wird nachweisen lassen. Wie vereinzolt erschien bei ihrem Bekanntwerden die Thatsache des Generationswechsels, und wie allgemein verbreitet hat sie sich jetzt in ganzen Thierdassen herausgestellt! Vielleicht geht es ähnlich mit dieser neuen Form der Fortplanzungsweise, die sich vom Generationswechsel we- 
sentlich unterscheidet; denn es findet hier kein Wechsel statt zwischen einer niederen, unvollkommenen und einer höheren, ausgebildeteren Generation, kein Wechsel zwischen einer geschlechtlich entwickelten und einer ungeschlechtlich bleibenden Generation, kein Wechsel zwischen einer polypoiden festsitzenden und einer medusoiden frei schwimmenden Generation. Vielmehr sehen wir hier durch unmittelbare Blutsverwandtschaft, durch das innige Verbajltniss der Sprossung, zwei ganz verschiedene Thierformen mit einander continuirlich verknupft, welche beide als vollkommen entwickelte Medusen mit wohldifferenzirten Organen und Geweben frei umlierschwimmen, beide ziemlich gleich hoch organisirt sind, und beide geschlechtsreif werden. Ton allen verschiedenen Formen des Generationswechsels ist diese Allotriogonie oder Alloe ogenesis, wie man sie nennen könnte, also ganz wesentlich verschieden.

Schon jetzt möchte ich hinweisen auf einige andere, allerdings noch nicht hinreichend sicher constatirte Verhälnisse, in denen wahrscheinlich ganz dieselbe Alloeogenesis, wie in unserem Falle sich findet. Zunichst möchte ich hierher zichen die schon oben erwähnte Knospenahre, welche Fritz Müller einmal in der Magenhöhle von Liriope catharimensis fand, und ron der er glaubt, dass sie von diesen Thiere verschluckt worden sei $^{1}$ ). Er sellost sagt von den betreffenden Knospen aus, dass »alle ihre Eigenthümlichkeiten mit der achtstrahligen Form von Cunina Köllikeri stimmen, während nicht die entfernteste Aehnlichkeit mit irgend einer anderen der im Laufe ron \& Jahren dort beobachteten Quallen besteht «. Höchstwahrscheinlich entsteht also die achtstrahlige Form von Cunina Köllikeri in gleicher Weise durch Knospung an dem Zungenkegel von Glossocodon catharinensis. wie Cumina rhododactyla an der Zunge von Carmarina hastata. Ebenso stammt vielleicht die Cunina (?) rubiginosa (KöLLıker's Eurystoma rubiginosum. vielleicht auch identisch mit Gegenbaur's Aegineta rosea?) aus Messina ab von der Geryonia proboscidalis (Carmarma umbrella??), welche in Messina von Gegenbavr und Krohn, von Letzterem mit Knospenahre an der Zunge, beobachtet worden ist. Den Glossocodon enrybiu aus Nizza habe ich niemals unit Knospen an der Zunge und in der Magenhölıle gefunden. Doch stammt vielleicht von ihm eine kleine Cunima al, welche der Cunina rhododactyla sehr änlich, aber $4-6$ mal kleiner ist, und welche ich vorlảufig als Cunina eurybia bezeichnen möchte. Ich hielt sie anfangs nur für eine Zwergform der mindestens 4 mal so grossen Cumina rhododactyla und habe sie desshalb nicht näher untersucht. Doch

1) Archiv für Naturgeschichte, XXVII, 1, 1861, p. 51, Taf. IV. Fig. 30. 
unterschied sie sich von ihr durch viel stiilker entwickelte halbmondförmige Wülste an der Basis der Tentakeln, durch lïngere, schlankere und nicht gefärhte Tentakeln und durch geringere Anzahl der Randblïschen. Ich habe von dieser Form Individuen mit 8, 10, 11 und 12 Tentakeln beobachtet. Die meisten hatlen deren 10.

Sollte sich durch fernere Beobachtungen dieser unmittelbare genealogische Zusammenhang $z$ wischen den Geryoniden und den Aeginiden bestatigen, wie ich ihn bei Carmarina und Cunina sicher nachgewiesen zu haben glaube, so kann man natürlich beide Familien nicht mehr getrennt halten. Man wird sie viehmehr ebenso vereinigen müssen, wie dies mit den Iydroidpolypen und den von ihnen abstammenden Graspedoten bereits geschehen ist. Der anatomische Charakter dieser vereinigten Medusen-Familien, gegeniuber den anderen Craspedoten, würde vor Allem durch die flachen Genitalblätter in sehr bestimmter Weise ausgesprochen sein, wonach man sie Phyllor chiden nennen könnte. Die nähere Charakteristik dieser Familie wiirde folgendermaassen lauten:

Phyll or chida: Radialcanäle entweder bleibend (Aeginida) oder vorübergehend (Geryonida) in tangentialer Richtung zu sehr flachen und breiten blattförmigen Taschen erweitert, in deren unterer (subumbraler) Wand sich die Geschlechtsproducte entwickeln, jedoch nur in den beiden Seitentheilen jedes Genitalblattes, so dass die radiale Mittellinie desselben freibleibt. Solide Knorpeltentakeln entweder uur in der Jugend (Geryonida) oder bleibend (Aeginida) vorhanden. Hohle knorpellose Tentakeln entweder gar nicht (Aeginida) oder nur beim erwachsenen Thiere (Geryonida) vorhanden. Das gegenseitige Verhältniss der drei verschiedenen Hauptformen, welche in der Phyllorchiden-Familie genetisch verbunden sind, wird durch die Vergleichnng der Diagramme Fig. 95-99, sowie durch nachstehende Tabelle deutlich hervortreten:

\begin{tabular}{|c|c|c|}
\hline $\begin{array}{l}\text { Aeginiden- } \\
\text { Generation. }\end{array}$ & $\begin{array}{l}\text { Larve der } \\
\text { Geryoniden- } \\
\text { Generalion. }\end{array}$ & $\begin{array}{l}\text { Imago der } \\
\text { Geryoniden- } \\
\text { Generation. }\end{array}$ \\
\hline Magenstiel fehlt. & Magenstief fehlt. & Magenstiel vorhanden. \\
\hline $\begin{array}{l}\text { 2. Solide Knorpelten takeln } \\
\text { vorhanden. }\end{array}$ & $\begin{array}{c}\text { Solide Knorpeltentakeln } \\
\text { vorhanden. }\end{array}$ & $\begin{array}{l}\text { Solide Knorpeltentakeln } \\
\text { fehlen. }\end{array}$ \\
\hline 3. Hohle Tentakeln fehlen. & Hohle Tentakeln fehlen. & HohleTentakeln vorhanden. \\
\hline $\begin{array}{l}\text { 4. Radialcanäle viel breiter } \\
\text { als der Ringcanal. }\end{array}$ & $\begin{array}{l}\text { Radialcanäle ungefähr eben } \\
\text { so breit als der Ringcanal. }\end{array}$ & $\begin{array}{l}\text { Radialcanäle ungefähr eben } \\
\text { so breit als der Ringcanal. }\end{array}$ \\
\hline $\begin{array}{l}\text { 5. Randbläschen äusserlich } \\
\text { aufdem Schirmrand. }\end{array}$ & $\begin{array}{c}\text { Randbläschen im Gallert- } \\
\text { mantel des Schirmrandes } \\
\text { eingeschlossen. }\end{array}$ & $\begin{array}{l}\text { Randbläschen im Gallert- } \\
\text { mantel des Schirmrandes } \\
\text { eingeschlossen. }\end{array}$ \\
\hline
\end{tabular}


Es ist nicht unwahrscheinlich, dass sich in den Bezichungen der einzelnen Aeginiden-Formen zu den rerschiedenen Geryoniden-Arten, und vielleicht auch zu anderen Medusen (z. B. den Trachynemiden, die sonst den Geryoniden von Allen am nächsten stehen), eine grosse Mannichfaltigkeit von rerschiedenen Modificationen ergeben wird, wie sie auch zwischen den Ilydroidpolypen und den genealogisch mit ihnen verwandten Graspedoten sich herausgestellt hat. Die Systematik dieser Thicre ist schon jetzt ausserst schwicrig, ja fast unuöglich geworden, indem es sich immer mehr auf das deutlichste gezeigt hat, dass weder die iussere Aehnlichkeit, noch die Uebereinstimmung im inneren Bau, noch die Aehnlichkeit in der Entwickelungsweise es ist, welche die systematische "Verwand $\mathrm{ts}$ chaft $\mathrm{r}$ der Thiere hedingt, sondern lediglich der continuirliche genetische Zusammenhang zwejer wemn auch noch so sehrverschicdenen Formen, das Princip der $A$ hstammung. so dass die sy stematisehe und die genealogische Verwandtschaft zusammenfallen. Der genetische Zusammenhang der Geryoniden unitden Aeginiden liefert hierfür einen neuen schlagenden Beweis.

Die Fanilic oder die Gruppe der Aeginiden im Allgemeinen scheint sehr alten Ursprungs zu sein, und als cine gemeinsame Ausgangsgruppe oder Stammform für verschiedene andere Quallenformen betrachtet werden zu miissen. Namentlich düfte dic Gattung Cumina als eine solche, mach verschichlemen Richtungen divergirende $\Lambda$ este treibende Stammform aufzufassen sein, wihrend vielleicht andere Acginicien. wie die Campanclla, die Aegineten, in homogener Weise sich fortptlanzen und den urspriinglichen Stanmtypus am reinsten zeigen. Für diese Auffassung scheinen mir mehrere anatomische Griunde zu sprechen. wir die iberwiegende Entwickelung der Radialcanile, wibrend das Ringgefiss noch auf einer sehr nicheren Stule steht; ferner die Bildung der starren soliden Knorpeltentakeln, welche nur bei den Embryonen der Geryoniden sich wiederfinden; und der Mangel der hohlen Tentakeln, welehe letztere im erwachsenen Zustande besitzen. Dieser embryonale Charakter im Bane der Aeginiden, der sich constant bei den ilteren Typen der thierischen Entwickelungsreilien findet, lässt auf ihr hohes Alter zuriickschliessen und annehmen, dass die noch jetzt existirenden Formen uns jenen alten Stamm-Typus noch ziemlich rein erhalten zeigen, von dem aus andere Medusen-Formen, wie namentlich die Geryoniden und Trachynemiden, nach verschiedenen Seiten hin sich entwickelt haben. Auch die habituelle und anatomische Verwandtschaft der Aeginiden und Charybdeiden, die namentlich von Fritz Müller und Agassız, wenn auch viel zu einseitig, betont worden ist, diirfte hier zu berücksichtigen sein. Vielleicht sind die Charybdei- 
den Mittelformen in der Uebergangsreihe von den Aeginiden zu den Acraspeden. Sind diese Anschauungen richtig, so könnte man sich vielleicht schon jetzt einen selır einfachen uralten Stammtypus der Aeginiden als gemeinsame Grundform oder Wurzel für versehiedene Stimme darstellen. Der eine Stamm würde sich in zicmlich gerader Richtung nur wenig verändert for'gepflanzt und diejenigen Aeginiden geliefert haben, welche auch heutzutage nur Aeg̣iniden erzeug̣en. Ein zweiter Stanm (Cumina) würde dnrch die Geryoniden zu anderen Craspedoten (Trachynemiden?) und ein dritter durch die Charybdeiden z.u Acrasperlen hinüberführen.

Ein Verhïltniss, welches mir ganz besonders diese Auffassung zu stützen scheint, finde ich, abgesehen von der embryonalen Structur der Tentakeln und des Gastrovascularsystems, in der sehwankenden $\mathrm{Zahl}$ der Körpersegmente, welche die Aeg̣iniden vor allen anderen Medusen auszeichnet. Bei allen bisher quenauer beschriehenen Aeginiden hat sich dieser Mangel einer festen homotypischen Grundzaht herausgestellt. Allerdings seheint auch hier die ursprüngliche gemeinsame homotypische Grundzahl Vier orler ein Muldiplum von Vier (namentlich Acht) zu sein. Allein wihrend einerseits, wie bei Aegmopsis (Campanella), auch nur Zwei als Grundzahl rorkommt und dadurch ein Stehenbleiben auf der früheren Entwickelungsstufe der oben beschriebenen zweiarmigen Cunina-Knospen angedeutet wird, sehwanktandrerseits die Grundzahl sehr oft in allen Stadien жwischen 8 und 16. wie es unsere Cumina rhododactyla in der eviflentesten Weise zeigt. Bei vielen Aeginiden steigt die Segmentzahl durch weitere Einschaltung neuer radialer Körperabschnitle bis über :0 und 30 hinauf. Am auffallendsten zeigt sich diese permanente Schwankung der Grundzahl an den Randblïschen, die selbst an rersehiedenen Lappen eines und desselben Thieres in sehr rerschiedener Zahl auftreten können.

Die allgemeine homotypische Grundzahl der Segmente des Medusenkörpers ist bekanntlich Vier: die einzigen Craspedoten, die auch in dieser Beziehung zu den Aeginiden sich hinüberneigen, sind wieder die Geryoniden, bei denen nur die eine Abtheilung, die Liriopiden, die Vierzahl zeigen, während bei der anderen Abtheilung, den Carmariniden, die Sechszahl sich consolidirt hat. Um so interessanter ist es, diss die Knospen, die von diesen getrieben werden, wieder in die Vierzahl $(8-16)$ der alten Stammältern zurückschlagen. 


\section{Gewebe der Geryoniden.}

Wenn ich schliesslich einen besonderen Abschnitt dieser Untersuchungen einer ausführlicheren Darstellung der Gewebe, aus denen sich der Geryonidenkörper zusammensetzt, widme, so geschieht dies theils, weil ich meine Untersuchungen nach dieser Richtung hin besonders ausgedehnt habe, theils weil unsere histologischen Anschauungen vom elementaren Bau des Medusenkörpers und von den Geweben des Coelenteratenorganismus überhaupt bisher nur höchst unvollhommene und fragmentarische waren. Zwar sind in der neueren Zeit zahlreichere Untersuchungen über den feineren Bau des Körpers der Coelenteraten und insbesondere der Hydromedusen angestellt worden; allein über die eigentliche elementare Zusammensetzung desselben aus den verschiedenen Geweben liegen nur sehr unbefriedigende Mittheilungen vor. So sind $\mathrm{z}$. B. in dem prachtvollen Medusen - Werke von Agassiz zwar zahlreiche Beschreibungen und Abbildungen der zelligen Elemente und der aus ihnen gebildeten Schichten gegeben worden; allein eine histologische Deutung und physiologische Verwerthung derselben, auf welche schliesslich doch unsere histologischen Arbeiten hinzielen, wird nur selten versucht. Es mögen mir diese Bemerkungen und der Hinweis auf die Unabhängigkeil meiner Untersuchungen von denen anderer Forscher zur Entschuldigung dienen, wenn die folgenden Mittheilungen nicht die erwünschte Vollstïndigkeit haben sollten und wenn sie mehrfach herrschenden Anschauungen entgegen treten. Es wird sich zeigen, dass die histologische Differenzirung des Körpers unserer Quallen eine weit grössere ist, als man gewöhnlich anzunehmen geneigt ist. Dass so viele feinere Verhältnisse in dieser Beziehung den bisherigen Beobachtern entgangen sind, hat allerdings seinen guten Grund auch in der ungewöhnlichen Schwierigkeit, welche der histologischen Untersuchung theils durch die allzugrosse Durchsichtigkeit, theils dureh die ungemeine Zartheit der Gewebselemente bereitet wird. Die gewöhnlichen Wirbelthiergewebe erscheinen grob und roh im Vergleich mit diesen höchst zerstörbaren Elementen.

Alles, was ich im Folgenden über den histologischen Bau des Geryoniden-Körpers mittheile, bezicht sich, wenn nichts Besonderes bemerkt ist, auf Carmarina hastata, die sich wegen ihrer betriehtlichen Grösse ganz besonders für die Isolirung und feinere Untersuchung der Elementartheile eignet. Die elementare Zusammensetzung des Körpers 
von Glossocodon eurybia stimmt wesentlich mit derjenigen der ersteren iberein; nur sind die Elemente im Ganzen kleiner, zarter und schwieriger zu belıandeln und zu erkemnen. Wo diese Art eigenthimliche Verhältnisse zeigt, werde ich dies hesonders erwahnen. Vieles, vielleicht das Meiste, was ich über die Structur der Gewebe bei diesen beiden Geryoniden gefunden habe, duirfte auch von der Mehrzahl der anderen craspedoten Medusen gelten, welche sich auch in histologischer Beziehung vielfach von den höheren Acraspeden zu unterscheiden scheinen. Wenigstens hat mir die vergleichende histologische Untersuchung der craspedoten Medusen, die ich im Frïljahr 1864 gleichzeitig mit Carmarina und Glossocodon in Nizza beobaclitete, und insbesondere der 14 neuen Arten, welche ich auf pag. 326-342 tes ersten Bandes der Jenaischen Zeitschrift fiir Medicin und Naturwissensch. kurz beschrieben habe, viele bei den Geryoniden aufgefundene Verhältnisse bestiitigt.

Die Elementarorganismen, welche den Körper der Geryoniden zusammensetzen, sind theils einfache, einen einzigen Kem enthaltende Zellen, heils Zellencomplexe, entstanden aus der Verbindung mehrerer Zellen und demgenäss mehrere Keme enthaltend. Die einfachen Zellen sind theils membranlose Zellen (Crzellen), theils von einer Membran umgebene Zellen (Hautzellen). Als membranlose Zellen, Urzellen oder Primordialzellen, d. h. als festweiche oder zähflüssige Klumpen von Zellsubstanz oder Protoplasma, welche einen Kern umschliessen, sind nachzuweisen: 1., die Nervenzellen der Ganglien, 2., die Knorpelzellen, 3., die dunkeln kernbaltigen Spindelzellen der radialen Ilaupttentakeln, 4., die blassen (scheinbarkernlosen) Spindelfasern der radialen Ilaupttentakeln (?), š., cinzelne Epithelien, namentlich das Epithel des Ectolerm, wenigstens zu einer gewissen Zeit des Lebens, 6., die jungeren Eier.

II a u tzell en oder Bläschenzellen, d. h. festweiche oder zahflüssi๕e Klumpen von Zellsubstanz oder Protoplasma, welche einen Kern enthalten und ausserdem von einer Membran, d. h. von einer festeren, chemisch differenten; oft ablösbaren Rindenschicht umgeben, in einem Sïckchen eingeschlossen sind, scheinen zu sein 1., die meisten Epithelien, 2., die iilteren Eier, 3., die Samenzellen.

Dic complexen Zellenelemente des Geryoniden-Körpers, welche durch den Besitz mehrerer Kerne ihre Entstchung aus mehreren verschmolzenen Zellen anzeigen, sind die quergestreiften Muskelfasern und die Nervenfasern. 


\section{Epithelialgewebe.}

Die Epithelien, welche die sämmtlichen iusseren Oberflächen des Geryoniden-Körpers, sowie die inneren Höhlungen des Gastrovascularsystems auskleiden, sind beim erwachsenen Thiere in sehr verschiedene Formen differenzirt. Bei den jüngsten beobachteten Larven (Fig. 26-28) sind dagegen nur zwei verschiedene Epithelialbildungen sichtbar, nämlich erstens die grösseren und helleren Zellen des Ectoderms, welche bloss die Oberflache des gallertigen kugeligen Schirms bekleiden, und zweitens die kleineren und dunkleren Zellen des E n to derms, welche die kleine embryonale Schirmhöhle und das Velum bekleiden, und aus denen sich später wohl die anderen Gewebe differenziren. Es scheint hierin eine sehr bemerkenswerthe Differenz von dem gewöhnlich bei den Coelenteraten vorkommenden Verhälniss zu liegen, wo das Entoderm bloss das Epithel des Gastrovascularsystems, das Ectoderm alle ubrigen Gewebe bildet, wie ich es auch oben von den Knospen der Carmarina dargestellt habe (Fig. 94 im VIII. Abschnitt).

Die meisten Epithelien sind einschichtig und bestehen nur aus einer einzigen Zellenlage. Sogenanntes geschichtetes oder $\mathrm{mehr}-$ schichtiges Epithel, aus mehreren über einander liegenden Zellenlagen zusammengesetzt, finclet sich nur an zwei Orten, nämlich als innere Auskleidung der Magenhöhle (Fig. 73) und als äusserer Ueberzug der radialen Ilaupttentakeln (Fig. 61, 91) und ist bei deren Darstellung oben genau beschrieben worden.

Flimmer-Epithelium finclet sich bloss in den Höhlungen des Gastrovascularsystems, doch kann ich über die allgemeine Aushreitung dasellsst nichts Bestimmtes angeben.

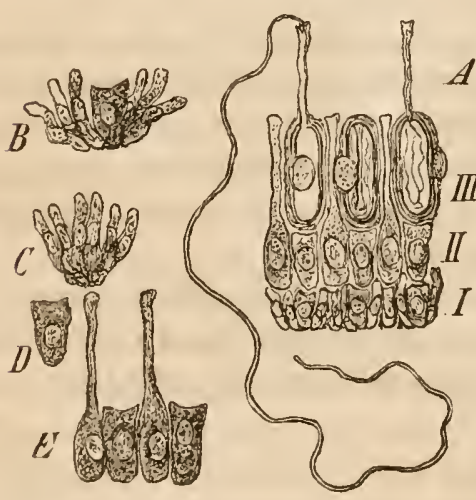

Fig. 91. Epithelzellen aus einem Nesselwulst der radialen Haupttentakeln ron Carmarina hastata. A. Ein Stück des Epithels in seiner ganzen Dicke, aus 3 Schichten bestehend: I. Schicht der Büschelzellen. II. Schicht der Flaschenzellen. III. Schicht der Nesselzellen. Aus 2 Nesselzellen der obersten Schicht ist der Nesselschlauch, aus einer zugleich der Nesselfaden hervorgetreten. B. Eine Kegelzelle der ersten, tiefsten Schicht, von Büschelzellen umgeben. C. Eine Gruppe von Büschelzellen der ersten Schicht. D. Eine Kegelzelle der ersten Schicht. E. Zwei Kegelzellen und zwei Flaschenzellen der zweiten, mittleren Schicht. 
Die Epithelien sind zum Theil flache Pflasterepithelien, deren Zellen breiter als hoch, meistens sehr dünne und flache Platten sind. Solche bilden 1., die äussere Bekleidung des Gallertmantels (Ectoderm, e 1) ; 2., das Epithel der Subumbrella (e s) ; 3., dessen Fortsetzung auf die ¿ussere Fläche des Magenstiels (p e); 4., das Epithel der unteren Velumfläche ( $\mathrm{v}$ e); 5., das Epithel der radialen Nebententakeln ( $\mathrm{s} \mathrm{e}), 6$, das Epithel der interradialen Tentakeln (y e); 7., das umbrale (innere, der Gallertsubstanz zugekehrte) Epithel der Radialcanäle (rl) und des Cirkelcanals (cl); 8., das Epithel der Randbläschen (b e ); 9., das Epithel des Zungenkegels (Fig. 6). Zu dem sogenannten Cylinderepithe l, dessen cylindrische, conische oder prismatische Zellen höher als breit sind, gehören: 1., Das Epithel des Schirmrandes (u e); 2., das Epithel der marginalen Mantelspangen (h e) ; 3., das Epithel der oberen Velumfläche (v e); 4., das Epithel der zuusseren Magenflache (k e); 丂̆., das subumbrale (der Schirmhöhle zugekehrte) Epithel der Radialcanäle (r s) und des Cirkeleanals (c s); 6., das innere (den Axencanal auskleidende) Epithel der radialen Haupttentakeln ( $\mathrm{t}$ e). Alle diese Cylinderepithelien sind einschichtig; daran schliesst sich als niehrschichtiges Cylinderepithelium 7., das äussere Epithel der radialen Haupttentakeln ( $\mathrm{t} \mathrm{u}$ ); 8., das Epithel der Magenhöhle ( $\mathrm{k} \mathrm{i}$ ).

Ein Theil der genannten Gylinderepithelien, nämlich die unter 1, 2, 7, 8 genannten Zellenlager, sind zugleich Nes selepithelien, d. h. einzelne, oft zahlreiche Zellen derselben werden zu Nesselorganen und entwickeln im Inneren je eine Nesselkapsel. Diese Organe zeigen an allen Stellen, wo sie vorkommen, den gleichen Bau. Sie sitzen in dem Cyylinderepithel theils zerstreut, theils auf einzelne Stellen concentrirt, gruppenweis versammelt. Unregelmässig zerstreut finden die Nesselzellen sich am Schirmrande und an den marginalen Mantelspangen. Reihenweis neben einander geordnet finden sie sich in den ringförmigen Nesselwülsten der radialen Itaupttentakeln, gegen deren Lïngsaxe ihre eigene Axe radial gerichtet ist. In convexe kreisrunde Polster geordnet setzen die Nesselzellen die Nesselpolster der interradialen Tentakeln zusammen. Ebenso bilden sie die halbkugeligen Nesselwarzen des Mundsaumes. Einen kugeligen Knopf, gegen dessen Centrum ihre Axe radial gerichtet ist, setzen sie an den radialen Nebententakeln zusammen.

Der Bau der Nesselorgane lässt sich bei Carmarina hastata wegen ihrer verhältnissmissigen Grösse deutlich erkennen (Fig. 67-69, Fig. 91). Jede einzelne Nesselzelle (Fig.67) ist cin an beiden Enden abgerundeter Cylinder von $0,03 \mathrm{~mm}$ Liinge, $0,008 \mathrm{~mm}$ Breite. Sie ist fast ganz ausgefüllt von der Nesselkapsel, so dass der grosse runde 
scheibenförmige Kern, welcher in der Mitte der Zelle zwischen ihrer Wand und der Aussenfliche der Nesselkapsel liegt, erstere bauchig vortreiben muss. Hier tritt die Membran der Zelle sehr deutlich hervor, die wegen ihres blassen zarten Contours oft übersehen wird. Die nur wenigk leinere Nes selkapsel (Fig. 68 A-D) ist ein sehr dickwandiyer Cỵlinder, dessen Axe gewöhnlich etwas verbogen, die beiden Enden abgerundet sind. Die derbe, starre Wand ist dunkel glänzend und doppelt contourirt. Durch ihre starke Lichtbrechung lässt sie die Nesselorgane überall sehr deutlich erkennen. Das untere Ende der Nesselkapsel ist geschlossen, das obere mit einer sehr kleinen, gewöhnlich etwas schiefstehenden Oelfnung versehen, an welcher sich das eine Ende des Nesselschlauchs inserirt. Der Nesselschlauch ist eine cylindrische, an beiden Enden offene Röhre, welche fast so lang als die Nesselkapsel, aber nur etwa $1 / 3$ oder $1 / 4$ so dick ist. Sie ist weich und zart und legt sich leicht in Falten. Ihre Wand ist zwar auch bei 600 maliger Vergrösserung doppelt contourirt, aber weit blasser und dünner, als die der Nesselkapsel. Am freien Ende ist der Nesselschlauch in ein rundliches Knöpfehen oder einen spindelförmigen Kolben angeschwollen, an dessen feiner Endöffnung sich der lange Nesselfaden inserirt. Der Nesselfade $n$ ist ein sehr langer und diinner, anscheinend solider cylindrischer Strang, nur etwa $0,001^{\mathrm{mm}}$ dick, mehrmals (ä- 20mal) länger als die Nesselkapsel. Bei sehr starker Vergrösserung erscheint er spiralig gewunden (Fig. 69); doch lässt sich nicht deutlich erkennen, ob er einfach, wie ein Tau, um seine eigene Axe gewunden ist, oder ob er aus zwei Strüingen, einem spiralig gewundenen Faden und cinem geraden Axenfaden zusammengesetzt ist, von denen der erstere um den letzteren herumliuft.

Man trifft die Nesselkapseln in drei rerschiedenen Zustinden an. Im Ruhezustande, wenn die Yesselkapsel noch in der unverselurten Nesselzelle eingeschlossen ist (Fig. 68 A ron der Seite, B ron oben), ist der Nesselschlauch im Innern der Nesselkapsel verborgen und erscheint in der Axe derselben als cin hellerer Streif. Die Höhlung des Nesselschlauchs ist leer und der Nesselfaden, der in mehreren Windungen rings um ihn herum zusammengelegt ist, erfüllt die llöhlung der Kapsel. Im zweiten Stadium (Fig. 68 C) ist der Nesselschlauch umgestülpt und durch die obere Oeffnung der Kapsel, an der er inserirt ist, vorgetreten. Das freie kolbenförmige Ende, welches vorher den Boden der Kapsel berủhrte, bildet jetzt die freie hnopfförmige Spitze. Die Hölılung des Schlauchs ist von dem Anfange des Nesselfadens erfüllt, dessen übrigel Theil in der llöhlung der Kapsel noch zusammengelegt ist. Im dritten Stadium endlich, wenn der Nesselfaden hervorgesehnellt ist (Fig. $68 \mathrm{D}$ ), 
ist sowohl die Höhlung der Nesselkapsel, als die damit zusammenhängende des Schlauches vollstandig leer.

Die Nesselzellen von Glossocodon eurybia sind nur 1/3 so lang, und fast um die Hailfte schmailer, als die von Carmarina hastata. Sie sind ellipsoid, an beiden Enden abgerundet, haben aber sonst den gleichen Bau (Fig. :52). Die ebenfalls eirunden Nesselkapseln sind $0,01 \mathrm{~mm}$ lang, $0,003^{\mathrm{m} \mathrm{m}}$ breit (Fig. 53). Nesselschlauch und Nesselfaden sind sehr zart und dünn.

\section{Mantelgewebe.}

Die eigenthümliche Structur des Gallertmantels, wie ich sie nicht allein bei den Geryoniden, sondern auch bei anderen craspedoten Medusen finde, zwingt mich, von dem üblichen Schema abzuweichen, nach welchem man die Gewebe in die vier Classen des Epithelial-, Bincle-, Muskel- und Nervengewebes eintheilt. Es ist allerdings diese Classification der Gewebe, clie sich auf ihre physiologische Function stützt, die cinzig durehführbare; indessen ist sie, wie namentlich Lernıg wiederholt hervorgehoben hat, immerhin eine künstliche und schliesst verbindende Uebergangsbiłdungen zwischen jenen vier Gruppen keineswegs aus. Eine solche evidente Mittelbildung scheint mir das Mantelgewebe der craspedoten Medusen zu scin, welches nach seiner Function mit gleichem Rechte zum Epithelial- wie zum Binclegewebe gestellt werden könnte.

Bei den Acraspeden oder phanerocarpen Medusen gehört bekanntlich die mächtige Gallertsubstanz des Mantels, wie namentlich Max Scncttze nachgewiesen hat, in dic Kategorie des gallertigen Bindegewebes, indem in der hyalinen homogenen Gallertmasse überall sternförmige Zellen zerstreut liegen, die durch ihre verästelten Ausläufer ein anastomosirendes Fadennetz herstellen. Dagegen hei den Geryoniden, wie bei allen ubbrigen Craspedoten, die ich untersucht habe, ist weder von einem solchen Zellennetze, noch überhaupt von Zellen in der ganz homogenen wasserklaren Gallertsubstanz irgend eine Spur zu finden. Die einzigen Formclemente, welche man darin vorfindet, sincl sehr feine, spitzwinklig verästelte und anastomosirende, sparsan zerstreute Fasern, die sich scharf von der Gallertsubstanz absetzen. Sie entsprechen vielleicht den ibulichen verastelten und anastomosirenden Fasern, welche auch im Mantel der Acraspeden zwischen dem Netzwerk der anastomosirenden Bindegewebszellen vorkommen, sich mit letzteren nicht verbinden und ganz unabhängig von ihnen sind. Die Mantelfasern finde ich bei Carnarince Fig. 63, 64 l f) und bei Glossocodon (Fig. 23, 
87 If) in ziemlich gleicher Form und Vertheilung vor. Doch sind sie bei ersterer stärker und zahlreicher. Sie finden sich nicht allein in dem Gallertmantel des Schirmes, sondern auch in dessen unterer centraler Fortsetzung, die den Magensticl bildet (Fig. 88). Sie sind meistens sehr fein und dünn, höchstens $0,001^{\mathrm{m} m}$ dick, gewöhnlich noch dünner. Sie sind von zwei sehr feinen und blassen parallelen Contouren eingefasst, die sich seharf von der umgebenden Gallertsubstanz absetzen, dennoch aber schwer zu erkennen sind, weil sie das Licht fast ebenso wie letztere selbst brechen. Im Schirme ist die Richtung der meisten Fasern senkrecht zur Oberfliche des Schirmes, mit dessen Ectodermepithel die Fasern zusammenzulängen scheinen. Viele Fasern sind in ihrer ganzen Länge einfach, die meisten aber sind dichotom veristelt und anastomosiren mittelst ihrer feinen Gabeliste mit anderen Faserzweigen, die ihnen entgegen kommen. Bei dem im frischen Zustande untersuchten Mantelgewebe fand ich die Fasern fast immer geradlinig gestreckt verlaufen, und scheinbar die ganze Dicke des Schirms durchsetzen; dagegen bei den in Salzlösung aufbewahrten Thieren zeigten sie stets einen stark geschlängelten, oft selbst spiralig gewundenen Verlauf. Zugleich erschicnen sie jetzt stärker lichtbrechend, als im frischen Zustand und erinnerten in vieler Bezichung sehr an feinere elastische Fasern des Wirbelthierleibes.

Da der Gallertmantel der Graspedoten allgemein, bei den jüngsten beobachteten Larven ebenso wie bei den erwachsenen Thieren, keine Zellen enthält, so muss die homogene Gallertmasse sammt den sie durchsetzenden dichotomen Fasern das Product der einfachen Epithelzellenschicht sein, welehe die Manteloberfliche allenthalben iberzielıt. Die hyaline Gallertsubstanz sehe ich als Ausscheidungsproduct dieser Epithelzellen, die gabelspaltigen Fasern in derselben dagegen als Protoplasmastränge an, welche ursprünglich die Zellen der beiden nahe an einander liegenden Epithelschichten der oberen und unteren Schirmfläche mit einander verbanden, und diese continuirliche Verbindung auch dann noch weiter unterhielten, als wiihrend der fortdauernden Ausscheidung der Gallertsubstanz beide Zellenlager sich, entsprechend dem fortschreitenden Wachsthum des Mantels, immer weiter von einander entfernten. $\mathrm{Ob}$ die anastomosirenden Protoplasmastränge, die später einen bedeutenden Grad von Festigkeit annehmen, ursprünglich bloss dem iuusseren Schirmepithel (e l) oder dem Epithel der Subumbrella (e s), oder beiden zugleich angehören, dürfte schwer zu entseheiden sein; doch ist das Wahrscheinlichste, dass sie bloss von der äusseren Epithelialschicht abgeleitet werden miussen.

Im Bau sowohl als in der wahrscheinlichen Bildung des gallertigen 
Mantelgewebes finde ich auffallende Aehnlichkeit mit dem Baue und der Entwickelung des Knochengewebes, wie sie kürzlich von Gegenbaur ${ }^{1}$ ) geschildert worden sind. So paradox dieser Yergleich zuerst klingen mag, so wird er dennoch ganz annehmbar, wenn man nur den verschiedenen Consistenzgrad der beiden Gewebe, jedenfalls ein secundäres Moment, ausser Betracht lässt. Es entspricht dann die Epithelschicht, welche den Mantel absondert, der ebenfalls aus einer einzigen Zellenlage bestehenden, epithelihnlichen Schicht der Osteoblasten; die verästelten und anastomosirenden Ausliufer des Protoplasma, welche von letzterem ausgchen, und das feine Netzwerk der sogenannten Knochencanälchen erfuillen, entsprechen den dichotomen Fasern; die homogene oder in concentrischen Lamellen abgelagerte Grundsubstanz des Knochens endlich entspricht der Gallerte selbst.

Dieser Vergleich wird weiterhin auch noch dadurch gestuitzt, dass die Epithelzellen der äusseren Manteloberfläche, ebenso wie die Osteoblasten des Knochengewehes, membranlose Urzellen, und zwar pflasterförmige Protoplasmaplatten zu sein scheinen. Wenigstens ist es mir auf keine Weise gelungen, mich von einer Differenz von Inhalt und Membran und von cler Blischennatur derselben bei verschiedenen Craspedolen zu überzeugen. Sehr häufig sind Zellengrenzen überhaupt nicht wahrzunehmen und man sieht auf der Schirmfläche nichts, als deutlich vortretende rundliche Zellenkerne, welche in bestimmten Abständen von einander zerstreut liegen (Fig. 26-30). Bisweilen ist jeder einzelne Kern rings von einem Hlofe sehrkleiner Körnchen umgeben, welche nicht selten reihenweis nach rerschiedenen Richtungen hin von dem Kerne ansstrahlen und sich mit anderen, ron benachbarten Kernen kommenden Körnchenreiben netzförmig verbinden, sodass ähnliche Bilder entstehen, wie sie die Pseudopodiennetze der Rhizopoden bieten. In der hyalinen vollkommen structurlosen Grundsubstanz der Schirmoberfläche zwischen den Kernen, in welcher später oft feine, scharfe Zellgrenzen nachzuweisen sind, ist in diesen Fïllen, namentlich bei jüngeren Craspedoten, auf keine Weise von den letzteren irgend eine Spur zu entdecken. Weder schicfe Beleuchtung, noch chemische Behandlung vermag solche zur Anschauung zu bringen und beim Zerzupfen erhïlt man unregelmässige, mit mehreren Kernen besetzte Fetzen, welche nirgends scharfe gerade oder polygonale Contourlinien zeigen. Die Kerne aber, welche in dieser homogenen Masse so regelmässig zerstreut sind und über ihre Oberfliche als flache rundiliche Hügel ein wenig

1) G. Gegenbatr, Ueber die Bildung des Knochengewebes. Jenaische Zeitschrift für Medicin und Naturwissenschaft. I. p. 343. 
hervorragen, sind ganz dieselben, wie in späteren Stadien, wo das zu jedem Kerne gehörige Theilchen der Grundmasse als eine polygonale Platte gegen die benachbarten Platten abgeschlossen ist (Fig. 32, 33). Diese Erscheinung liisst sich wohl kaun anders auslegen, als dass anfänglich die Zellen des einschichtigen Epithels weichere und mehr homogene, kernhaltige, hüllenlose Protoplasmaklumpen darstellen, welche vollkommen zu einer continuirlichen Lage versehmolzen bleiben, wihrend erst später sich die einzelnen Zellen differenziren und entweder durch blosse Verdichtung der Peripherie oder durch nachträgliche Bildung von Scheidewiinden ihre Bezirke gegen einander abgrenzen. Solche aus hüllenlosen Urzellen zusammengeset\%te Epithelien kann man Coenepithelien nennen. Sie scleinen bei niederen Thieren weit verbreitet zu sein, in manchen Gruppen vielleicht weiter, als die bei den höheren Thieren rorkommenden gewöhnlichen Epithelien, welche aus deutlich neben einander gesonderten Hautzellen bestehen und welche man im Gegensatz zu jenen als A utepithelien bezeichnen kann. Derartige Coenepithelien habe ich namentlich unter den niederen Gliederthieren (besonders Crustaceen) viclfach vorgefunden, wie ich schon an einem anderen Orte angeführt habe $\left.{ }^{1}\right)$. Hier will ich nur noch bemerken, dass das Epithel der Schirmoberfläche bei manchen Medusen zeitlebens den Charakter des Coenepithels beibehält und aus einer einfachen Schicht innig verbundener hautloser Zellen bestehen bleibt; so fand ich es z. B. bei Rhopalonema umbilicatum sehır deutlich, wo bloss die grossen, in regelmässigen Abstïnden zerstreuten Kerne die Zahl der zu cinem continuirlichen Protoplasmalager verschmolzenen Zellen andeuten.

Was das Coenepithel betrillt, welches als eine einfache Lage von hautlosen Urzellen die Sclirmoberlläche der Larven yon Carmarina bekleidet, so sei lier nur noch bemerkt, dass man fast immer viele Kerne desselben in Theilung findet, was wohl mit dem raschen Wachsthum der Schirmoberfliiche zusammenhängt. Bei den Larven von Glossncodon sind die ziemlich grossen Kerme keine flachen Platten, sondern ellipsoidische oder sphäroidale Körper; sie ragen daher etwas über die Schirmıfläche vor und bedingen so das eigenthümlich höckerige Ausschen, welches schon die kleinsten Larren auszeichnet (Fig. 26-30). An dem Schirmepithel der älteren Carmarina sind die Kerne oft nur sehr schwierig zu erkennen, blass und fein contourirt. Schon bei Larren inittleren Alters sind hier die Zellen bisweilen ron colossaler Grösse, von $0,8-0,19 \mathrm{~m} \mathrm{~m}$ Durchmesser, dabei aber so iusserst diinne Platten,

1) Jenaische Zeitschrift. I. 1864, p. 73 . 
dass sie auf dem Quersehnitt kaum doppelt contourirt erscheinen. Gewöhnlich sind die Zellen hier sehr regelmässig polygonal, meist sechseckig, andere Male rhombisch (Fig. $90)$. Ihre grossen rundlichen Kerne sind fein granulirt und halten durchschnittlich $0,02 \mathrm{~mm}$ Durchmesser. Die Consistenz der Platten ist übrigens nachweisbar bedeutend und scheint denjenigen der dichotomen Fasern, die als ihre Ausliufer zu betrachten sind,

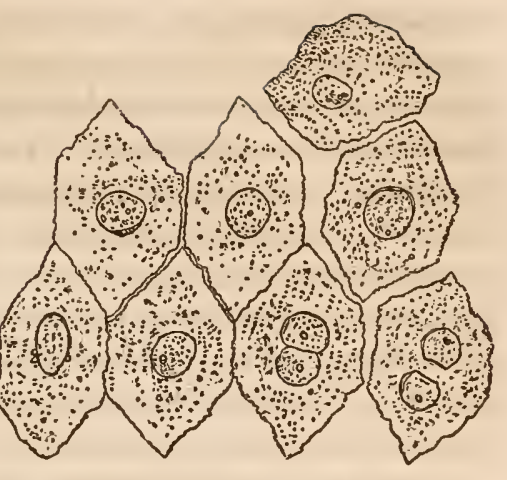

Fig. 90. Eine Gruppe von EpithelNichts nachzugeben. Die Ränder der zellen der äusseren schirmoberfläche Platten sind sehr fein gezähnelt, so von Carmarina hastata. Eimį̧e Zellen dass die Verbindung der ineinander sind aus dem Zusammenhang gelöst, greifendlen Ränder benachbarter Plateinige mit getheilten Kerı versehen. ten eine sehr innige ist (Fig. 90).

Da das Epithel der Schirmoberfläche als die Matrix des Gallertmantels wesentlich zu diesem Gewebe gehört, so ist es klar, dass man das Mantelgewebe sowohl in physiologischer, als in morphologischer Beziehung weder zu dem Epithelialgewebe noch zu dem Bindegewebe ausschliesslich rechnen kann. Ol)wohl seine homogene Gallertsubstanz die massebildende und formgebende Grundlage des ganzen Medusenkörpers liefert und obwohl seine Bildung sich an die des Knochengewebes anschliessen lässt, so unterscheidet sich seine Matrix doch wesentlich dadurch von der Osteoblastenschicht, dass sie zugleich als Aequivalent der Epidermis die Aussenfläche des Körpers iüberkleidet und epitheliale Functionen übernimmt.

\section{Knorpelgewebe.}

Das charakteristische Gewebe, welches ich in Folgendem als Medusenknorpel beschreibe, scheint im Körper der Geryoniden, wie vieler anderer Craspedoten, die einzige Gewebsform zu sein, welche ihrem Baue, wie ihrer Function nach die Gruppe der Bindesulsstanzen im Körper dieser Thiere reprisentirt. Eigentliches Bindegewebe oder sogenanntes "gewöhnliches Bindegewebe ", von der Art, wie dasselbe im Körper der höheren Thiergruppen so verbreitet ist, d. h. ein Gewebe nit mehr oder minder faserig differenzirter weicher Intercellularsubstanz zwischen den kleinen, oft durch Ausläufer verbundenen Zellen, kommt hier nirgends vor. Die verschiedenen anderen Gewebe, Nerven, Mus- 
kelfasern, Epithelien, findet man im Körper der Geryoniden uberall unmittelbar an einander gelagert und nur durch eine minimale, meist optisch gar nicht nachweisbare Menge einer verklebenden Zwischensubstanz zusammengekittet. Von zwischenliegenden bindegewebigen Schichten, Unterlagen der Epithelien, oder Ilüllen der Organe, wie Sarcolemm, Neurilemm und dergl. ist keine Spur wahrzunehmen. Sehr deutlich z. B. lässt sich am Velum nachweisen, dass dassclbe lediglich aus den beiden Muskelschichten und den beiden Epithelüberzügen besteht (Fig. 63,64v). Selbst die Wandungen der Gastrovascularcanaile bestehen bloss aus einer einfachen Epithelzellenlage, ohne eine besondere bindegeweloige Grundlage.

Dass das Gallertgewebe des Mantels nieht als eigentliche Bindesubstanz aulzufassen sei, vielmehr seiner Structur, wie seiner Function nach ebenso gut, als zu dieser, auch zum Epithelialgewebe gerechnet werden könne, wurde soeben bewiesen. Ob ein Theil des Fasergewebes der radialen Haupttentakeln (Fig 61,62), entweder die dunkeln kernhaltigen $(\mathrm{t} m)$ oder die bellen kernlosen Fasern $(t, t \mathrm{e})$, oder ob keins von beiden zur Bindesubstanz zu rechnen sei, haben wir nicht entscheiden kömnen (vergl. oben). Doch sind beide wahrscheinlich musculöser Natur.

Es bleibt also, als zur Bindesubstanzgruppe gehörig, nichts weiter übrig, als das Gewebe, welches das feste Skelet des Schirmes, sowie der interradialen und radialen Nebententakeln bildet. Sowohl seiner physikalischen Eigenschaften und seiner physiologischen Leistungen, wie seines histologischen Baues halher scheint mir dieses Gewebe den Namen des Knorpels mit vollem Rechte zu verdienen, so befremdlich es auch zunächt klingen mag, bei den zarten Medusen, deren ganze Körpermasse nur aus zerfliesslich weichen Geweben zu bestehen scheint, von einem sheletbildenden Knorpel zu reden. Das Gewebe besteht aus grossen kernhaltigen rundlichen Zellen mit mehr oder weniger ansehnlichen Mengen von Intercellularsubstanz. Da die Zellen desselben oft weit ansehnlicher und grösser sind, als alle anderen im Medusenkörper vorkommenden Zellen, so ist dies Gewebe, welehes bei den Medusen sowohl als bei den zugehörigen llydroidpolypen weit verbreitet zu sein scheint, auch schon mehrfach von anderen Autoren erwähnt, und bald als »zelliges«, bald als »fächeriges « Gewebe, bisweilen auch als »)luskelgewebe« gedeutet worden. Seine Bedeutung als Bindesubstanz, und zwar als eine Modification des Bindegewebes, welche den Knorpel der Wirbelthiere sehr nahe steht, finde ich aber von keinem Beobachter erkannt.

In der Familie der Geryoniden, und zwar sowohl bei den vierzah- 
ligen (Glossocodon); als bei den sechszähligen (Carmarina) bildet der Medusenknorpel den oben als »Knorpelring " beschricbenen kreisförmigen Skeletreifen, der zwischen dem Aussenrand des Velum und unteren freien Rand des Schirmes eingeschaltet ist und beiden zur festen Stütze dient. Ausserdem bildet er im Larvenzustande der Geryoniden die Hauptmasse der interradialen und der radialen Nebententakeln, welche mit dem Abschlusse der Metamorphose verloren gehen. Endlich stutzt er bei der sechszähligen Carmarina (nicht aber bei dem vierzihligen Glossocodon) die 12 vom Ringknorpel ausgehenden und in der äusseren Mantelfläche aufsteigenden spangenartigen Knorpelstreifen, welche wir oben als centripetale Mantelspangen beschrieben haben und welche sowohl dem Schirmrande selbst, als namentlich den interradialen und radialen Nebententakeln zur Stuitze dienen.

Das Knorpelgewebe verbialt sich an diesen verschiedenen Stellen etwas verschieden, so dass seine Identitat nicht sofort in die Augen springt. Namentlich sind am Ringknorpel die Zellen bedeutend kleiner, dafür auch die Intercellularsubstanz massenhafter entwickelt, als an den Knorpelstreifen der Tentakeln. Der Ringknorpel (uk) des Schirmrandes ist in Fig. 41, 63, 66 von der Fläche gesehen, in Fig. 63, 64. auf dem Querschnitt abgebildet. Fig. 70 stellt ein sehr feines Splitterchen eines ganz dünnen Querschnittchens dar, welches bei 600maliger Vergrösserung das Verhälniss der Knorpelzellen zur Intercellularsubstanz besonders deutlich zeigt. Die Zellen des Ringknorpels (Fig. 4. $70 \mathrm{uk}^{\prime}$ ) sind membranlose Urzellen oder Protoplasmaklumpen, welche einen rundlichen Kern umschliessen. Der Nucleus ist feinkörnig, scharf contourirt, oft mit einem grösseren Körnchen (Nucleolus) und hált 0,005-0,015 m 'Durchmesser. Er liegt gewöhnlich in der Mitte der Zelle, deren Protoplasmasubstanz hald ganz klar, wasserhell, bald von feinen Körnchen durehsetzt ist. Nicht selten finden sich in einer Zelle zwei Kerne, offenbar eben erst durch Theilung entstanden (Fig. ;0 oben rechts). Die Zellen kann man bisweilen aus den Höhien der Intercellularsubstanz isoliren und sich dann von der Abwesenheit einer Membran uberzeugen (Fig. 70 unten links). Die Form der Urzellen und der von ihnen ausgefülten Ilohlräume der Grundsubstanz (Knorpelhöhlen) ist meist unregelmässig rundlich, oft etwas polygonal abgeplattet, bisweilen stark in dic Lainge gezogen (Fig. 41 unten links). Ihr Durchmesser beträgt $0,02-0,04-0,06 \mathrm{~mm}$. Die Intercellularsubstanz oder Grundsubstanz des Ringknorpels (Fig. 41, 70 $u \mathrm{k}^{\prime \prime}$ ) ist durchaus homogen und lässt keine concentrische Streifung rings um die Knorpelhöhlen wahrnehmen, welche ihrem schichtenweisen Absatz aus dem Protoplasma entspräche. Sie ist stärker lichtbrechend 
als das letztere. In der Mitte zwischen je zwei Zellen ist sie meist bedeutend schmïler, dagegen in der Mitte zwischen je drei Zellen oft breiter als der Querdurchmesser der Zellen selbst. Wenn man ein sehr duinnes Knorpelsclınittehen in Wasser macerirt, so dass die Primordialzellen aus ihren IIöhlen herausfallen, so bleibt die Intercellularsubstanz ais ein fäeheriges Lückenwerk zuriick (Fig. 70). Durch chemische Behandlung und durch Zerzupfen gelingt es nicht, einzelne blasenförmige Fächer zu isoliren, welche sogenannten Knorpelkapseln entspriichen. Es scheint vielnehr, dass die von den benachbarten Primordialzellen ausgesehiedene intereellulare Substan\% sich sogleich \%u ciner homogenen Grundmasse verbindet.

An den Knorpel des Ringknorpels sehliesst sich zunächst seiner histologischen Beschaffenheit nach der Spangenknorpel an, der schmale dünne Knorpelstreif, weleher bei Carmarina das Knorpelskelet der 12 marginalen Mantelspangen (h) bildet (Fig. 63, 6i, 6马 h k). Bei (Flossucodon fehlt dieser Spangenknorpel. Er bestcht aus einer einzigen Reihe hinter einander liegender Zellen, welche anfïnglich sehr flache Scheiben darstellen (Fig. 64). Spiiterhin, wenn die Mantelspange wichst, dehnen sich die Knorpelzellen mehr in die Länge, und es erscheinen beim erwachsenen Thier namentlich die obersten, welche der Spitze der hornförmig gekrümmten Spange an meisten genähert sind, als sehr schmale und lange Gylinder (Fig. 63). Die Lïnge der Knorpelzellen wächst hier allmählich von der Basis bis zur Spitze, während ihre Dicke entsprechend abnimmt. Die Intereellularsubstanz der Spangenknorpel ist meist nur ron geringer Dicke. Der Kern der Zellen liẹ̦t meist wandstaindig an jener Wand der Zelle, welche der Spangenspitze zugekehrt, von dem Mautelrand abgewendet ist.

Der Tentakelknorpel, welcher das Skelet der interradialen und der radialen Nebententakeln bildet, und namentlich der der ersteren, zeichnet sich durch sehr bedeutende Grösse der Zellen, sowie dureh geringere Mengen von Intercellularsubstanz aus, besonders aber dadurch, dass häufig das Protoplasına, welches die Knorjelhöhlen aușfültt, grosse Vaeuolen enthält, wetche mit einer wässrigen Flüssigkeit erfüllt sind. Man könnte dieses Gewebe, statt zun Knorpel, auch zu dem sogenannten Blasengewebe oder dem hlasig-zelligen Bindegewebe rechnen, jener Modification der Bindlesubstan\%, welche bei niederen Thieren (Arthropoden, Mollusken ete.) so weit verbreitet ist und das faserige Bindegewebe der höheren Thiere ersetzt.

Das Knorpelskelet der radialen Nebententakeln bildet sowohl bei Carmarina als bei Glossocodon eine cylindrische Säule, welche aus einer einzigen Reihe hintereinander gelagerter scheibenför- 
miger Knorpelzellen zusammengesetzt ist (Fig. 38, 39, 65 s k). Wenn die longitudinalen Fasern des Muskelcylinders, der den Knorpelstab überzieht, stark contrahirt sind, so erscheinen die Knorpelzellen breiter und flacher, fastmünzenförnnig; sind dagegen die Muskelfasern erschlaflt, so dehnen sich die Knorpelzellen vermöge der Elasticitit der Intercellularsubstanz zu längeren und schmäleren cylindrischen Scheiben aus. Die Knorpelkapseln, welche die Intercellularsubstanz bilden, sind an den radialen Nebententakeln dicker, dagegen die Höhlungen der Kapseln und die membranlosen Zellen, welche diese Höhlen ausfüllen, kleiner, namentlich bedeutend kiirzer, als an den interradialen Tentakeln. Bei Carmarina (Fig. 63) sind die Knorpelzellen ( $\mathrm{sk}$ ) der radialen Nebententakeln oft deutlich sphäroid, und da die Grundsubstanz ( $\mathrm{s} \mathrm{k}$ ), welche zwei benachbarte Zellen scheidet, keine Spur einer transversalen Grenzlinie zeigt, welche die Kapsel der einen Zelle von der der benachbarten schiede, so erscheint die ganz honogene Intercellularmasse am dünnsten in der Axe des Tentakels, wo die einander zugekehrten Wölbungen der beiden sphäroiden Zellen sich am nächsten stehen. Am dicksten ist die Kapselsubstanz dagegen an der peripherischen Wand des Tentakels in der Mitte zwischen je zwei Zellen. Das Protoplasma der Zellen füllt bei den radialen Nebententakeln bald die ganze Knorpelhöhle aus; hald enthïlt es mit wässriger Flüssigkeit erfülte Vacuolen (Fig. $39 \mathrm{~s} \mathrm{k}$ ). Der ellipsoide oder planconvexe scheibenförmige Kern liegt meist an derjenigen Wand der Knorpelkapsel an, wolche der Spitze des Tentakels zugekehrt ist, seltner in der Mitte der Höhle.

Der Knorpeleylinder, welcher die Iauptmasse der in terradialen Tentakeln ( $y$ ) bildet, zeichnet sich durch die ausserordentliche Grösse seiner Knorpelzellen aus, welche bei weitem die grössten von allen zelligen Elementen sind, die im Körper der Geryoniden rorkommen (Fig. $40 \mathrm{y} \mathrm{k}$, Fig. 64 y k). Bei jüngeren Larven liegen dieselben nur in einer einzigen Reihe hinter einander. Das Tentakelskelet erscheint dann als ein einfacher cylindrischer Knorpelstab, welcher durch transversale Septa (die intercellularen Scheidewände je zweier hinter cinander gelegener Zellen) gleichsam geglicdert ist. Die einzelnen Zellen sind dann noch kurze Gylinder, in Mittel ungefähr so lang als breit. Beim weiteren Wachsthum des Tentakels verlängern sie sich und es beginnt die Bildung von longitudinalen Scheidewänden. so dass nun mehrere Zellen, die durch gegenseitigen Druck polygonal abgeplattet erscheinen, ncben einander zu liegen kommen. Diese Längstheilung der Ḱnorpelzellen tritt namentlich an der spindelförmig verdickten Basis des Tentakels reichlich auf (Fig. 40,64), so dass hier auf einem Querschnitt 4-8 Zellen neben einander gleichzeitig sich zeigen, wïhrend 
gegen die Spitze hin die Zellenreihe einfach bleibt, oder nur ein einziges Longitudinal-Septum dieselbe in zwei halbcylindrische Reihen theilt. Je grösser die Zahl der benachbarten Knorpelzellen, mit denen jede einzelne in Berührung steht, desto mehr geht ihre urspruingliche Cylinderform in eine unregelmaissig polyedrische uber. Ihr Durchmesser betrigt bei Glossocodon im Mittel $0,05-0,08^{\mathrm{mm}}$, bei Carmarina $0,06-0,1 \mathrm{~mm}$.

Während die Knorpelzellen der interradialen Tentakeln durch ihre ansehnliche Grösse die Knorpelzellen der radialen Nebententakeln, der Mantelspangen uud namentlich diejenigen des Ringknorpels betrichtlich übertreffen, so stehen sie dagegen bedeutend hinter diesen zurück hinsichtlich der Entwickelung der Grundsubstanz. Diese ist meist nur an den peripherischen Kapselwänden, welche an den umschliessenden Muskelcylinder des Tentakels stossen, von ansehnlicher Dicke, mchrmals dicker als der letztere, wahrend dagegen die transtersalen und namentlich die longitudinalen und diagonalen Scheidewände, welche die benachbarten Knorpelzellen von einander trennen, nur sehr dünn sind. Es sind daher diejenigen knorpelzellen, welche ganz in der Axe der verdickten Tentakelbasis liegen, nur von einer sehr zarten Knorpelkapsel umschlossen, während die Kapseln der peripherischen Zellen da, wo sie nach aussen an den Muskel grenzen, ansehnlich verdickt sind. Gegen die Spitze des Tentakels, wo bei jüngeren Larven die Zellen in einer Reilfe liegen, ist der Cylindermantel jeder Zelle meist stark verdickt, die beiden Grundflächen der Kapsel dagegen nur diunnwandig. Bisweilen ist in der Mitte derScheidewand je zweier benachbarter Zellen eine feine Linie sichtbar, welche die Grenze der den beiden Zellen zugehörigen Kapselwände andeutet, die noch nicht zu homogener Grundsubstanz verschmolzen sind. Bisweilen bleiben auch da, wo drei oder vier Knorpelkapseln in einerEcke zusammen treffen, kleine polyedrische Intercellularräume zwischen ihnen übrig (Fig. 64).

Die Kerne in den Knorpelzellen der interradialen Tentakeln sind bald Ellipsoide, bald planconvexe Scheiben, welche theils wandstindig der Innenfliiche der Knorpelkapseln anliegen (besonders derjenigen Wand, welche der Tentakelspitze zugekehrt ist), theils in der Mitte (ler Zelle oder an anderen Stellen der Höhle in das Protoplasma eingebettet liegen. Oft sind in einer Knorpelzelle mehrere Kerne sichtbar, bisweilen drei bis vier in einer Reihe hinter einander liegend, so dass es aussieht, als ob sie eben erst durch wiederholte Quertheilung des ursprünglich einfachen Kernes entstanden seien.

Das Protoplasma (Fig. 40, 64 y k') füllt die Knorpelhöhlen der interradialen Tentakeln bald vollstündig, bald nur theilweise aus, indem 
häufig eine Anzahl von kleineren und grösseren Vacuolen in dasselbe eingelagert sind, die mit einer wässerigen Flüssigkeit gefüllt zu sein scheinen. Oft nehmen diese Vacuolen an Ausdehnung so zu, dass der grösste Theil der Knorpelhöhle von der wässrigen Flüssigkeit erfüllt wird, waihrend das Protoplasma (meist deutlich zu unterscheiden durch sehr feine blasse Körnchen, die in seine zähflüssige Grundsubstanz eingelagert sind), sich beschrinkt auf eine diunne wandstindige Schicht, die die Innenwand der Knorpelhöhle auskleidet (Primordialschlauch) und auf mehrere einfache oder verïstelte Schleimfäden, welche die wassererfüllte Zellenhöhlung durchziehen und nicht selten durch Anastomosen ein Netzwerk herstellen (Fig. 93). Liegt der Kern nicht an der Innenwand der Knorpelhöhle an, sondern frei in derselben, so bildet er oft das Centrum dieses Fadennetzes, indem nach allen Richtungen Fäden von ihın ausstrahlen, welche zur Höhlenwand laufen und sich dort zur Bildung der' Wandschicht vereinen. Kurz es bieten dann die Knorpelzellen dasselbe Bild, wie es in grösseren Pflanzenzellen so häufig gefunden wird. Wahrscheinlich befinden sich auch im lebenden Knorpel die einzelnen Theilchen des Protoplasma in einer langsamen Bewegung; doch ist wegen der geringen Grösse und Zahl der in demselben suspendirten Körnchen diese Strömung schwer zu constatiren. Unmittelbar habe ich von derselben, auch bei anderen Craspedotenmedusen, mich niemals ubberzengen können; wohl aber bemerkte ich, dass an einer und derselben Zelle die Configuration des Schleimfadennetzes, das den Hohlraum der Knorpelhöhle durchzieht, sich nach einiger Zeit verändert hatte. Es sind diese Knorpelzellen ganz ähnlich den sogenannten strahligen oder radiirten, in runde Knorpelhöhlen eingeschlossenen »Knorpclkörperchen«, welche auch im Knorpel der Wirbelthiere hier und da vorkommen, auch bei Menschen öfter pathologisch beobachtet und z. B. von J. Laснимам ${ }^{1}$ ) aus einem menschlichen Enchondrome beschrieben worden sind.

Derselbe Knorpel, den ich hier von Carmarina und Glossocodon beschreibe, scheint bei den craspedoten Medusen weit verbreitet vorzukommen. Wenigstens habe ich bei der grossen Mehrzahl aller craspedoten Medusen, die ich zu beobachten Gelegenheit hatte, einzelne Skelettheile aus demselben gebildet gefunden. Insbesondere sind es diejenigen Formen von soliden Tentakeln, welche sich nicht bedeutend verkürzen können und welche man wegen ihrer eigenthümlichen Bewegungen als »starre Tentakeln " bezeichnet, bei denen der Medusenknorpel den grössten Theil des Volums bildet und die eigenthün-

1) Müllen's Archiv, 1\$57, p. 16, Taf. 11. 
lichen physikalischen Eigenschaften dieser Gebilde, ihre Starrheit, verbunden mit grosser Elasticitit bedingt. Die grösste Entwickelung erreichen diese sogenannten "starren Tentakeln " in der durch ihren starren Habitus ausgezeichneten und, wie wir im X. Abschnit gezeigt haben, den Gerỵoniden genetisch sehr nahe verwandten Fannilie der Aeginiden (Thalassantheen), deren bedeutendere Consistenz auch schon von anderen Beobachtern als wknorpelartig bezeichnet wird. In dieser eigenthimlichen Familie scheinen sämmtliche Tentakeln solid und aus einem dicken knorpelstabe gebildet zu sein, der von einem dünnen Huskelsehlauche und zu ausserst von einem Epithel überzogen ist (Fig. 81, 83). Die Knorpelzellen sind hier meist münzenförmig, flache kreisrunde Scheiben, welche in einer einzigen Reihe linter einander liegen und eine Knorpelsiinle, gleich einer Geldrolle bilden. Ihr Durehmesser ist oft colossal bis zu $1 / 2{ }^{\mathrm{mm}}$ und darüber. Die Knorpelkapseln der einzelnen Zellen können hier bisweilen von einander isolirt werden, sodass die Intercellularsubstanz, welche gewöhnlich als homogene Grundsubstanz zwischen je zwei Zellen eingeschaltet ist (Fig. 83), hier bisweilen in Form einer sehr dicken Zellenmembran auftritt. Diese verhindet in hohem Grade, gleich genuinem Knorpel, Festigkeit und Elasticitit. Der grösste Theil der Knorpelhöhle ist bei den Aeginidententakeln und ihren Wrurzeln, die sich ganz besonders zum Studium des MedusenKnorpels eignen (Fig. 93), meist von einer hellen wissrigen Flussigkeit (D) erfüllt, während das zähe, flüssige oder feinkörnige Protoplasma (B) sich auf eine Wandschicht beschräinkt, welehe die Innenfliiche der Knorpelhöhle (C) auskleilet. Von dieser Schicht gehen meist verzweigte Schleimfäden aus, welche, wie oben beschrieben, anastomosirend den hohlen Zellenraum durchziehen und, wenn der Kern (A) in der Mitte der Zelle liegt, von diesem auszustrahlen scheinen. Andere Male zieht nur ein einziger Protoplasmastrang, der Limgsaxe des Tentakels entsprechend, mitten durch die çlindrische Knorpelzelle hindurch, die Mitten ihres beiden Grundflichen verbindend, und in der Mitte den Kern umschliessend (Fig. 83). Diese Gebilde sind schon ron mehreren Autoren beschrieben, aber irrig gedeutet worden. Im letzteren

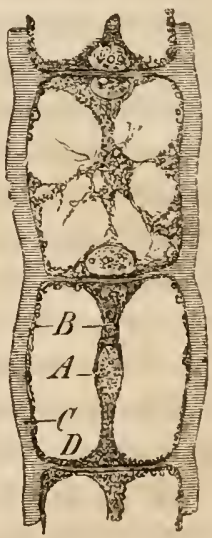

Fig. 93. Falle hat man z. B. die Summe der in der Tentakelaxe verlaufenden Protoplasmastriinge als einen centralen Canal aufgefasst. Die Proto-

Fig. 93. Ein Stiick einer Tentakelwurzel von Cunina rhododactyla. A Kern. B Protoplasma der Knorpelzellen. C Intercellularsubstanz (Knorpelkapseln).

D Wässrige Flüssigkeit innerhall, des Protoplasinaschlauchs. 
plasmastränge sind auch öfter als Muskeln beschrieben worden, während der Muskelschlauch, der den Knorpelstab überzieht, ganz übersehen wurde. Eine gute Abbildung einzelner Knorpelzellen aus den Tentakeln von Aegineta corona geben KeFersteir und EnLers ${ }^{1}$ ) und bemerken dazu: "Die Tentakeln sind von regelmässigem, fächerigem Bau: in jedem Fach befindet sich eine Muskelzelle, die an der Basis des Tentakels einfach spindelförmig ist (9a), in der Mitte desselben schon eine Anzahl Ausliunfer besitzt ( 9 b) nnd in der Tentakelspitze endlich sehr vielfach verzweigt ist $(9 \mathrm{c})$, so dass die Beweglichkeit der Tentakeln nach der Spitze hin zunimmt $\left.{ }^{2}\right)$. Diese verschiedenen Formen der "Muskelzellen « sind nur die versehiedenen Formen, welche der die Zellhöhle durehziehende Theil des Protoplasma annimmt, während der wandständige Theil desselhen, der in diesen Knorpelzellen einen geschlossenen Sach bildet, von ihnen, wie von den andern Beobachtern, ubersehen wurde. Was gewöhnlich als "Fach « bezeichnet wird, ist die Knorpelhapsel. Aus denselben Knorpelzellen und zwar allein aus ihnen sind allgenein die eigenthumlichen "Tentak elwurzeln zusammengesetzt, mittelst deren die Tentakehn der Aeg̣iniden in den Schirmrand eingesehlossen sind (Fig. $81 \mathrm{tw}$ ).

Ganz ebenso gebaut wie die Knorpeltentakeln der Geryoniden und Aeginiden sind auch diejenigen der nahverwantten Trachynemiden. Bei Rhopalonema velatum ist der cylindrisehe, von Muskeln und Epithel üherzogene diche Axenknorpel aus einer einzigen Reihe münzenförmiger Zellen zusammengesetzt, wïhrend bei $R$. umbilicatum deren mehrere neben einander liegen. Denselben Bau finde ich ferner an den Tentakeln der Aglaura, an den kleinen, meist spiral aufgerollten Nebententakeln und soliden Kolbententakeln von Mitrocoma und Cosmetira, an den Mundarmen vieler Oceaniden, sowie an den Randtentakeln und Mundarmen vieler anderer Craspedoten. Ausserdem finde ich den Medusenknorpel bei vielen Craspedoten am äussersten Schirmrande vor, wo er als festes ringförmiges Skelet sowohl dem Velum einen sicheren Insertionspunct bietet und die feste Basis des Schirmrandes bildet, als auch dureh seine Elasticitit den durch das Velum contrahirten Schirmrand wieder ausdehnt. Auch bildet der Knorpel bei einigen Craspedoten feste spangenförnige Leisten in der Subumbrella, welche die Radialeanäle begleiten und deren Lumen, auch bei starker Contrac-

1) Kefersteix und Ehlers, Zoologische Beiträge 1864, p. 95, Taf. XIV, Fig. 9.

2) Auch angenommen, es läge wirklich eine einfache oder verästelte Musketzelle in jedem solchen Fache, glaube ich doch nicht, dass man daraus diesen Schluss ziehen diurfe. Wie soll aus der Veristelung einer in ein starres fach eingeschlossenen Muskelzelle eine grössere Beweglichkeit dieses Thenles resultireu? 
tion der Muskelschicht der Subumbrella, offen erhalten helfen. So finde ich in sehr ausgezeichneter Weise bei Rhopalonema velatum jeden Radialcanal auf beiden Seiten von einer breiten Knorpelleiste eingefasst, welche ein rechtwinkliges Dreieck bildet und den Canal vom Ringgefäss bis zur Basis der Genitalien begleitet, wo sie zugespitzt endet. Offenbar haben diese Knorpelstreifen an der knorpelartigen Consistenz, welche den starren Schirm der Trachynemiden auszeichnet, wesentlichen Antheil; auch ist wohl die Elasticität des Knorpels hier die Ursache, dass der Schirm, unmittelbar nach der durch die ausserordentlich entwickelte Subumbrella bewirkten Contraction, mit solcher Kraft sogleich wieder in die flache Form zurücksclmellt.

Von besonderem Interesse endlich ist die Existenz des Medusenknorpels, und namentlich der letzterwihnten knorpeligen Schirmtheile, für die Frage von der Bedeutung jener in geschichteten Gesteinen enthaltenen Abdrücke, welche man als fossile Medusen gedeutet hat. Wenn man wegen der weichen zerfliesslichen Beschaffenheit der meisten Medusen Bedenken getragen hat, jene namentlich in den Sohlenhofener Schiefern enthaltenen Abdrüke, welche nur auf Medusensehirme, und auf keine anderen Organismen bezogen werden können, für solche zu erklären, so erscheinen diese Bedenken jetzt nicht mehr gereeltfertigt, da die Annahme, dass jene Arten einen theilweise knorpeligen Schirm hatten, gestattet ist (Vergl. Haeckel, über fossile Medusen, Zeitschrift für wissenschaftl. Zoologie. Bd. XV., Taf. XXXIX).

\section{Muskelgewebo.}

Das contractile Gewebe des Geryonidenkörpers tritt in zwei ganz verschiedenen Formen auf, als quergestreifte und als glatte Muskelfasern. Die letzteren bilden ausschliesslich das contractile Gewebe der radialen Ilaupttentakeln ( $t$ ) und zum Theil auch der Magenwand, während die ersteren die Muskeln aller übrigen Körpertheile zusammensetzen. Die verschiedene Structur der beiderlei Elemente bedingt auch eine differente Function derselben, die sich in den abweichenden $\mathrm{Be}-$ wegungsformen der aus ihnen zusammengesetzten Organe deutlich ausspricht.

Die glatten homogenen Muskelfasern (Fig. 61, 62) sind bereits oben, bei der detaillirten Darstellung des complicirten Baues der radialen Haupttentakeln von Carmarina, ausführlich besprochen worden. Wir mussten es unentschieden lassen, ob bloss die blassen kernlosen Fasern (theils longitudinal ( $t$ ), theils circular ( $t c$ ) verlaufend), oder ob bloss die dunkeln kernhaltigen longitudinalen Spindelzellen $(\mathrm{t} \mathrm{m})$, oder ob endlich beide Elemente zugleich musculöser Natur seien. 
Das letztere ist wohl das Wahrscheinlichste. Die glatten Muskeln, welche einen Theil der Magenwand bilden (Fig. 73), und dort in einer äusseren dünneren Längsfaserschicht $(k \mathrm{k})$ und einer inneren dickeren Ringfasersehicht ( $\mathrm{k}$ e) entwickelt sind, scheinen sich den hellen kernlosen Fasern der radialen llaupttentakeln anzuschliessen, unterscheiden sich aber von ihnen wesentlich dadurch, dass sie sich beim Zerfasern nicht in spindelförmige Stränge (Fig. 62 tl), sondern in Bündel von sehr feinen und langen structurlosen Fibrillen auflösen.

Die quergestreiften helerogenen Muskelfasern sind am stiirksten entwickelt im Velum, wo sie eine obere stärkere Lage von circularen und eine untere schwiichere Schicht von radialen Muskelfasern bilden. Sehr stark sind auch die longitudinalen Nuskelbinder, welche am Magenstiele die Zwischenräume zwischen den Radialcanälen ausfüllen. Viel schwächer sind die circularen Faserzüge der Subumbrella und die radialen Bänder, welche, von letzteren bedeckt, die Radialcanäle paarweise begleiten. Auch an der äusseren Magenfläche, oberhalb der oben erwähnten dicken Lagen von glatten Muskelfasern, findet sich eine dünne Schicht von longitudinal verlaufenden quergestreiften Fasern, welehe die untere Ausbreitung der breiten Längsmuskelbänder des Magenstiels darstellen. Sie bilden auf der Magenoberfläche 4-6 schmälere Längsbänder, welche den Mundsaum in 4 oder 6 Lappen einziehen können (Fig. 18-21, Fig. 58, Fig. 74). Auch über dem Knorpelskelet der interradialen und der radialen Nebententakeln bilden die quergestreiften Muskeln nur eine dünne Lage von longitudinalen Fasern.

Die Querstreifung der Muskelsubstanz tritt bei Carmarina und bei Glossocodon an allen genannten Theilen bei Anwendung genügend starker Vergrösserungen (600) so scharf und deutlich hervor, als bei den Muskeln der Vertebraten und Arthropoden (Fig. 10, 40, 64, 72). Nur ist die Grösse der Sarcous-Elements viel geringer, als bei den meisten der letzteren. Einfach und doppelt brechende Substanz sind aher eben so seharf von einander abgesetzt. Die Form unci Grösse der Elemente zu bestimmen, welehe die Muskelfasern zusammensetzen, hält sehr schwer. Sowohl beim Zerzupfen der frischen Muskeln als nach Behandlung derselben mit verschiedenen Säuren etc. erhält nan zwar bisweilen lange, oft sehr lange, spindelförmig an beiden Enden zugespitzte Fasern, welche in versehiedenen Abstiinden mit selır kleinen feingranulirten lïnglichen Kernen besetzt sind (Fig. $10 \mathrm{~m}$ ). In der Regel aber erhält man beim Zerzupfen nur ganz unregelmässige Bündel von sehr feinen und langen quergestreiften Fibrillen, die noch nicht $0,001^{\mathrm{m} \mathrm{m}}$ breit sind (Fig. $72 \mathrm{~m} \mathrm{~s}$ ). Mit den stärksten Vergrösserungen 
betrachtet, erscheinen die Fibrillen varieös, indem die dunkleren Sarcous-Elements breiter aussehen, als die blasseren Zwischenscheiben des Lingshindemittels. Nicht selten erscheinen die breiteren Muskelbänder, namentlich die sehr regelmässigen Längsmuskeln, welche die Radialcanäle am Magenstiele von einander trennen, und an der Subumbrella paarweise begleiten, wenn man sie unversehrt bei starker Vergrösserung betrachtet, zusammengesetzt aus zahlreichen, sehr regelmässig parallel nebeneinander verlaufenden und gleich breiten linearen Străngen von $0,003 \mathrm{~mm}$ Dicke. Beim Zerzupfen zerfialt jeder derselben sehr leicht in ein Bündel von Fibrillen. Von grösseren oder kleineren Scheiden um die Muskeln ist nirgends etwas wahrzunelımen. Die einzelnen feinen Fasern seheinen einfach neben einander gelagert und durch ein Minimum eines Querbindemittels verkittet zu sein. Verflechtung oder Anastomose der Fasern scheint nirgends vorzukommen.

\section{Nervengewebe.}

Die Elementartheile des Nerrensystems der Geryoniden sind, wie bereits oben erwähnt wurde, von zweierlei Art, sehr zarte und diinne homogene $\mathrm{F}$ asern und mit diesen zusammenhängende kleine kernhaltige membranlose Zellen. Beide sind sowohl bei Carmarina als bei Glossocodon schwer nachzuweisen. An den lebenden Thieren sind sie so vollkommen hell und durehsichtig, dass sie sich kaum von den ebenfalls glasartigen Nachbartheilen absetzen. Dabei sind sie so zart und z.erstörbar, dass man bei mechanisehen Priparationsversuchen mit Messer und Nadel meist nur unkenntliche Trimmer erhält und dass auch die Ilülfe chemiseh einwirkender Aggentien nur mit grosser Vorsicht in Anspruch genommen werden darf. Vicle Zeit und Itühe habe ieh vergeblich aufgewendet, ehe és mir gelungen ist, die nervösen Elementartheile völlig zu isoliren und als solche zu bestimmen (Fig. 92).

Soweit ieh diese sehr schwierigen Verhiltnisse mit einiger Sieherheit erforschen konnte, habe ich die Nervenzellen nicht allein auf die unmittelbar unter der Basis der Sinnesbläschen gelegenen Ganglienknoten beschrinht gefunden, sondern aueh im Verlaufe der Fasern mehrfach eingeschaltet zu erkennen geglaubt. Die rundlichen oder flach hügelförmigen Ganglienknoten (C), 12 bei Carmarina. 8 bei frlossocodon, sind bereits oben beschrieben worden. Sie sind in eine Vertiefung des Knorpelrings eingebettet (Fig. 63, 64 f), aus welcher sie sehr schwierig herauszulösen sind. Beim Zerzupfen der Knoten erhält man neben und in einer feinkörnigen detritusartigen Masse kleine und zarte unregelmässige Zelten von sehr versehiedener Grösse, welche zum 
'Theil mit sehr feinen Nervenfasern zusammenhängen. Die Kerne sind verhältnissmässig gross, die der grösseren Nervenzellen so gross, als die ähnlichen Kerne der Knorpelzellen des Ringknorpels, mit welchen auch die Zellen selbst leicht verwechselt werden können. Wie die aus ihren Knorpelhöhlen herausgelösten Knorpelzellen erscheinen auch die kleinen Nervenzellen als membranlose Crzellen, gebildet aus einer homogenen Substanz, welche feine Körnchen enthält, die namentlich um den Kern herum angehäuft sind. Lnter den isolirten Zellen kann man solche mit einem und zwei Fortsaitzen öfter finden, auch die verlängerten Fortsätze als identisch mit den Fasern erkennen. Seltener lassen sich sternförmnige Zellen isoliren, welche die Ansátze von meh-

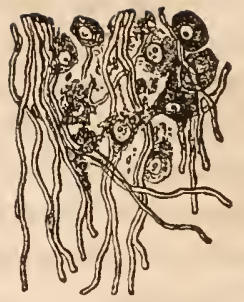

FIg. 92. Nervenfasern und Ganglienzellen von Carmarina hastata, aus dem Nervenring an der Austrittsstelle aus einem radialen Ganglion entnommen. reren abgerissenen Ausläufern zeigen.

In situ kann man kleine spindelförmige Nervenzellen im Zusammenhang mit den Nervenfasern an den zarten Nervensträngen verfolgen, welche zwischen dem Knorpelskelet und dem Muskelschlanche der interradialen Tentakeln verlaufen (Fig. 64 y $\mathrm{n}$ ). Die kleinen blassen Zellen können auch hier mit den ungefähr eben so grossen, oft von einem sternförmigen Protoplasmahofe umgebenen Kernen der grossen Knorpelzellen verwechselt werden. Leichter und sicherer, und zugleich in Menge beisammen liegend, kann man Nervenzellen in dem Basalganglion (w) der Sinnesblischen beobachten Fig. 7, 8, 22, 23). Sie scheinen hier meist spindelförmig zu sein. Auch die Zellen, welebe die das Concrement enthaltende Blase innerhalb der Sinnesblasschen erfüllen, sehe ich als Ganglienzellen an und deute jene Blase demgemäss als Sinnesganglion (s); um so melır, als die gekreuzten Sinnesnerven innerhalb derselben zwischen den Zellen ausstrahlen und sich wahrscheinlich mit ilmen verbinden. Die Zellen erscheinen hier in frischem Zustand als sehr helle homogene polyedrische Körper (Fig. 7), lassen aber nach Zusatz von Säuren den Korn sehr deutlich vortreten (Fig. 8).

Die Nervenfasern (Fig. i2 a r, 92) sind rollkommen homogene, sehr zarte und blasse Fibrillen von 0,0001 bis höehstens $0,001 \mathrm{~mm}$ Breite, welche nirgends eine Differenz von Hülle und Inhalt erkennen lassen. In situ untersueht man sie am besten an den unversehrten Randbläschen, an deren Innenwand sie die beiden gegenständigen halbkreisförmig gebogenen Nervenbügel $\left(n^{\prime}\right)$ zusammensetzen (Fig. 7, 8, 22, 23, 63, 65). Die sehr zarte Längsstreifung, welehe man an den letzteren wahrnimmt, ist jedenfalls auf die Zusammensetzung aus 
Fibrillen zu beziehen. In frischem Zustande vollkommen homogen, lassen sie nach Zusatz von Säuren, Sublimat etc. zerstreute sehr kleine längliche Kerne erkennen (Fig. 8). Ebenfalls in situ, aber schwieriger kann man die Nervenfasern in den schmalen blassen Nervensträngen nachweisen ( $\mathrm{yn}$ ), welche zwischen dem Knorpelskelet und dem Muskelrohr der interradialen Tentakeln verlaufen (Fig. 64). Hier ist auch ihr Zusammenhang mit eingestreuten Ganglienzellen bisweilen zu erkennen.

Zur Isolirung und Untersuchung der einzelnen faserigen Nervenelemente eignen sich am meisten die starken Radialnerven, welche man mit leichter Mühe aus den umgebenden Geweben herausschälen kann, besonders während ihres Verlaufes durch die Mitte der Genitalblätter. Beim Zerzupfen der Radialnerven mit Nadeln erhält man ziemlich leicht einzelne sowohl, als in kleine und grössere Bündel vereinigte Nervenprimitivfasern, welche als einfache unverzweigte Fäden parallel gelagert sind (Fig. 72 a r). Die meisten sind gleichbreit, noch nicht $0,0005 \mathrm{~m} \mathrm{~m}$ dick, hie und da mit sehr kleinen stäbchenförmigen Kernen besetzt. Sehr instructive Präparate erhält man von diesen Stellen dann, wenn an dem isolirten Nervenstuickchen noch ein Fetzen von der unmittelbar darüber liegenden circularen Muskelschicht der Subumbrella (m s) hängen geblieben ist. Fig. 72 giebt ein solches Präparat getreu wieder. Bei hinreichend starker Vergrösserung $(900)$ treten dann die Differenzen in der Lichtbrechung zwischen den blasseren, vollkommen bomogenen Nervenfibrillen und den dunkleren, quergestreiften Muskelfasern sehr deutlich hervor. Mit anderen Elementartheilen, als den letztgenannten, können aber auch bei schwächerer Vergrösserung dic Nervenfasern nicht verwechselt werden, da ähnliche fibrilläre Theilchen, namentlich bindegewebiger Natur (mit Ausnahme der im Gallertmantel verlaufenden dichotomen Fasern) in Geryonidenkörper nicht vorkommen. Weit schwieriger als die Radialnerven, ist der hingnerv zu isoliren und in seine Fasern zu zerlegen; doch gelingt es auch hier bei sorgfijltiger Präparation, die nervösen Elementartheile zu isoliren und die Nervenfasern noch im Zusammenhange mit den kleinen Ganglienzellen nachzuweisen. 


\section{Erklärung der Abbildungen.}

Die Bedeutung der Buchstaben ist in allen Figuren dieselbe.

a Nervenring am Schirmrand, zwischen huorpelring und Gefässring.

a p Radialnerven während ihres Verlaufs am Magenstiel (in der Mitte der äusseren Wand der Radialcanäle).

a $\mathbf{r}$ Radialnerven während ihres Verlaufs an der Subumbrella (in der Mitte der Genitalblätter).

b Sinnesbläschen oder Randbläschen.

b e Epithel der Innenwand der Randbläschen.

b i Interradiale Randbläschen.

b r Radiale Randbläschen.

c Gefässring am Sehirmrand (Cirkelcanal).

c c Lumen des Gefässringes.

c 1 Umbrales (der Gallertsubstanz zugekehrtes Epithel des Gefässringes.

c s Subumbrales (der Subumbrella zugekehrtes) Epithel des Gefässringes.

d Drüsenblätter in der Magenwand.

d' Mittelrinne der Driisenblätter.

$d^{\prime \prime} \quad$ Einzelne Drüsen aus einem Driisenblatt.

e Centripetalcanäle (Blindgefässe).

e c Ectoderm.

e 1 Epithel der äusseren Schirmoberfläche (des Gallertmantels).

e n Entoderm.

e s Epithel der Schirmhöhle oder der Subumbrella.

f Ganglienknoten des Ringnerven, unmittelbar unter dem Randbläschen.

g Genitalblätter.

g' Hoden.

$\mathrm{g}^{\prime \prime} \quad$ Eierstöcke.

h Marginale Mantelspange (centripetale Spange des Schirmrandes).

h e Epithel der Mantelspangen (zum Theil mit Nesselzellen).

h $\mathbf{k}$ Knorpelskelet der Mantelspangen.

h m Muskeln (longitudinale Muskelfasern) der Mantelspangen.

h n Nerv der Mantelspange.

i Ursprung der Radialcanäle aus dem Grunde der Magenhöhle.

k Magen.

$\mathrm{k}^{\prime} \quad$ Innenfläche des Magens, umgestülpt. 
1 Gallertsubstanz des llantels und des Schirmstiels.

If Dichotom verzweigte Fasern in der Gallertsulstanz.

Muskelbänder in der Aussentlache des Magenstiels zwischen den Radialcanälen.

s Circulare Nuskelfasern der Subumbrella.

Nerven im Randhläschen.

Sinnesnerven ( gegenstänligre Biigel) an der Innenwand des Randbläschens. Kreuzung (Chiasma) und Durchflechtung der beiden Sinnesnerven am freien P'ole des Randblaschens, beim Eintritt in das Sinnesganglion.

$\mathrm{n}^{\prime \prime \prime}$

Ausstrahlung der gekreuzten sinnesnerven innerhalb des sinnesganglion, rings um das Concrement.

Mund.

$0^{\prime}$

Nesselhnopfe am verdickten Sam des Mundes.

Magenstiel 'Schirmstiel.

p e Epithel des Nagenstiels.

q

Querschnitt der Radialcaniile.

Radialcanäle, in der Olıerfliche des Magens aufsteigend.

Umbrales der Gallertsubstanz zugekehrtes) Epithel der Radialcanäle.

subumhrales (der Subumbrella zugekehrtes) Epithel der Radialcanäle.

Sinnesganglion (mit Zellen erfullte Kapsel in Innern des Randbläschens).

s e Epithel der radialen Neluententakeln (s 1 ).

s f Geisselanhang der radialen Nebententaheln.

s k knorpelskelet der radialen Nebententakeln.

$s k^{\prime}$ (Membranlose) knorpelzelfen derselben.

$s \mathrm{k}^{\prime \prime}$ Intercellularsubstanz des Knorpels derselhen.

s m Muskeln (aus Longitudinallasem zusammengesetzter Muskelcylinder) der radialen Nelrententakeln.

Radıale Nebententakeln (primäre Larvententakeln).

Nesselknopt der radialen Nebententakeln.

Radiale Ilaupttentakeln.

Helle circulare Fasern der radialen Haupttentakeln. Inneres, das Centralrohr auskleidendes Epithel der radialen Haupttentakeln.

t $\mathrm{m}$ Dunkle longitudinale Fasern der radialen Haupttentakeln (spindelförmige, kernhaltige, stark lichtbrechende Zellen).

t $t$ Radiale Tentakeln der Cunina.

i u Aeusseres mehrschichtiçes Epithel der radialen Haupttentakeln.

t w Tentakelwurzeln der Cunina.

ix Dunkle Wülste an der Tentakelbasis der Cunina.

u

Aensserster Schirmrand (Mantelsaum , hestehend aus dem knorpelring und dem den letzteren überzielıenden, theilweis mit Nesselzellen durchselzten Epithel (Nesselsaum).

u e Epithel dos Schirmrandes, den Runghnorpel iiberziehend und theilweis mit Nesselzellen durclısetzt (Nesselsaumi).

u k hnorpelskelet (Ringknorpel) des Schirmandes.

$u k^{\prime}$ (Membranlose) Zellen des Ringknorpels.

" $k^{\prime \prime}$ Intercellularsulsstanz des Ringknorpels.

u t Rıngförmige Nesselwiilste der radialen Haupttentakeln.

v Velum oder Randinembran.

$\mathrm{v}^{\prime} \quad$ Freier Innenrand des Velum. 
v c Circulare Muskeln des Velum.

ve Unteres (flaches) Epithel des Velun.

$\mathrm{v} \mathrm{r} \quad$ Radiale Muskeln des Velum.

v s Oberes (hohes) Epithel des Velum.

Basalganglion des Randbläschens (Zellenpolster an der Innenflache seiner Basis, unmittelbar über dem Ganglion (f) des Nervenringes).

Concentrisch geschichtete, kalkhaltige Concretionen (Otolithen\%), eingeschlossen im Sinnesganglion der Randblasehen.

Interradiale Tentakeln (secundäre Larvententakeln).

y e Epithel der interradialen 'Tentakeln.

$y \mathrm{k}$ knorpelskelet der interradialen Tentakeh.

y $k^{\prime}$ Knorpelzellen.

y $k^{\prime \prime}$ Intercellularsubstanz des kinorpels.

y in Muskeln (aus Longitudinalfasern zusammengesetzter Muskeleylinder) der interradialen Tentakeln.

y $n$ Nerv (?) der interradialen Tentakeln.

y u Nesselpolster der interradialen Tentakeln.

z Zungenkegel Zunge`.

Tafel I.

\section{Carmarina hastata (Geryonia hastata).}

Fig. 1. Ein geschlechtsreifes Thier (Weibchen bewegungslos im Wasser schwebend. Von den schlaff lerahhängenden Tentakeln sind 3 in einen Knoten verwickelt. (Natiirliche Grösse.)

Fig. 2. Ein geschlerhtsreites Thier (Männchen) im Zustande der stärksten Contraction des Schirmes in der lehhaftesten Bewegung. Das Velum ( $v$ ) ist durch das krätig ausgestossene Wasser vorgetrieben, der Magenstiel (p) stark gekrummt, die Zunge (z) tastend vórgestreckt. Die leblıaft wurmförmig sich kirtimmenden Tentakeln sind knotigg verschlungen. Die Centripetalcanäle und der Cirhelcanal sind nicht abgebildet. (Natïrliche Grösse.)

Fig. 3. Ein geschlechtsreifes Thuer (Weilıelıen;, halb von oben gesehen, um die Centripetalcanäle (e) und die Genitalblätter $(g)$ deutlich zu zeigen. (Natuirliche Grösse.)

Fig. 4. Das untere Ende des Magenstiels (p), mit fast kugelig zusammengezogenem Magen $(k\rangle$. Der Zungenkegel $\langle z\rangle$ ist knieförnig gebogen und grösstentheils in den Magen zurüickgezogen.

Fig. 5. Das untere Ende des Magenstiels (p), mit sehr stark zusammengezogenem Magen (k). Der Zungenkegel $(z)$ ist sehr weit vorgestreckt und am Ende in eine spindelförmige Spitze angesch wollen. Die Gallertsubstanz (l) des Schirmstiels ist fast halbkugelig ïber der Schnitttlïche vorgequollen.

Fig. 6. Ein Stuck des Zungenkegrels. Das Epithel, welches die Obertliche des soliden Gallertcylinders iiberzicht, besteht aus 6 breiteren spiralig gewundenen Bändern von ziemlich regelmässig polygonalen Zellen, welche nnit 6 schmäleren Bändern abweehseln, die aus schmal lanzettförmigen Zellen bestohen.

Fig. 7. Ein Randbläschen, halb von aussen, halb von der Serte gesehen.

Fig. 8. Ein Randbläseben, halb von aussen, halb von oben gesehen, mit verdünntem Sublimat behandett, wodureh die Kerne in den Zellen des Sinnesganglion und in den Nerven deutlich hervorgetreten sind. 
Fig. 9. Ein Stiick eines radialen Tentakels. u' die ringförmigen Nesselwülste, $t$ die nesselzellenfreien Internodien.

Fig. 10. 2 Muskel-Primitivbündel vom Magenstiel. m’ die quergestreifte Muskelmasse.

Tafel 11.

Glossocodon eurybia (Liriope eurybia).

Fig. 11. Ein erwachsenes Thier, bewegungslos im Wasser schwebend. Die Tentakeln (t) sind ziemlich stark zusammengezogen. Der Zungenkegel (z) ist ganz zuriickgezogen.

Fig. 12. Ein erwachsenes Thier, in lebhafter Schwimmbewegung. Die Tentakeln (t) sind verlängert. Der Zungenkegel $(\mathbf{z})$ ist vorgestreekt.

Fig. 13. Ein geschlechtsreifes Thır (Mänuchen), von unten betrachtet. Das Velum (v) ist sehr stark zusammengezogen, der Magen $\left(k^{\prime}\right)$ umgestiilpt, der Zungenkegel $(\mathbf{z})$ weit daraus vorgestreckt, die Tentakeln ( $\mathbf{t})$ ziemlich zusammengezogen. g' Hoden.

Fig. 14. Ein geschlechtsreifes Thier (Weibchen), von oben betrachtet. Der Zungenkegel $(z)$ ist in die Magenhöhle $(k)$ zurüickgezogen, die Tentakeln ( $t$ ) stark zusammengezogen. g" Eierstöcke.

Fig. 15. Ein erwachsenes Thier, das sich mit vollkommen ausgebreitetem Magen an die Glasfläche angesaugt hat, von oben gesehen. In dem zu einer quadratischen Scheibe ausgedehnten Magen (k) treten die 4 Drüsenblätter (d) mit ihren Mittelrinnen (d') deutlich vor.

Fig. 16. Das untere Ende des Magenstiels mit zurückgezogenem Zungenkegel (z) und vollkommen zu einer quadratisehen Scheibe ausgedehntem Magen, der sich an die Glasfläehe angesaugt hat. d die 4 Drüsenblätter, d' deren Mittelrinne. o' Nesselknöpfe des Mundsaumes.

Fig. 17. Die Magenhöhle, durch den geöffeeten Mund von unten gesehen. Man sieht in der Mitte den (verkürzten) Zungenkegel (z) umgeben von den Lisprungsöffnungen der 4 Radialeanäle (i). Am Mundsaum erscheinen regelmässig vertheilt 16 Paar Nesselknöpfe $\left(0^{\prime}\right)$.

Fig. 18. Das untere Ende des Magenstiels, mit sehr stark zusammengezogenem Magen und vierzipflig eingezogenem Mundsaum.

Fig. 19. Das untere Ende des Magenstiels, mit verlängertem Magen und kragenartig umgestiilptem Mundsaum.

Fig. 20. Das untere Ende des Mageustiels, nit sehr stark verlängertem und halb nach aussen umgestülptem Magen, und vierzipflig ausgezogenem Mundsaum. Die Gallertmasse (I) des soliden Magenstiels ist ïber dessen Schnitt1läche fast kugelig vorgequollen. An den Radialeanälen $(r)$ ist das grosszellige Epithel angedeutet.

Fig. 21. Das untere Ende des Magenstiels, mit vollkommen nach aussen ungestiilptem Magen $\left(k^{\prime}\right)$, dessen unterster Theil $(k)$ sammt Mundsaum $\left(0^{\prime}\right)$ abermals nach unten umgeklappt ist.

Fig. 22. Ein Randbläsehen, halb von aussen, halb von der Seite gesehen.

Fig. 23. Ein Randbläsehen, halb von aussen, halb von oben gesehen.

Fig. 24. Ein Stiick eines radialen Tentakels. u' die ringförmigen Nesselwuilste, $t$ die nesselzellenfreien Internodien.

Fig. 25. Dichotom verästelte Fasern aus der Gallertsubstanz des Mantels. 
Tafel III.

\section{Glossocodon eurybia (Liriope eurybia).}

Fig. 26-28. Jïngste beobachtete Larve, in der ersten Periode, obne alle Anhänge. An dem kugeligen Gallertschirm von $0,3 \mathrm{~mm}$ Durchmesser ist bloss die kleine peripherische Schirmhöhle zu bemerken, deren Oeffnung durch das Velum (v) verschlossen ist. Die kleinen Körnchen auf der Obertläche des Gallertschirnes sind die vorstpringenden Kerne des Epithels. Vergrösserung 60 .

Fig. 26. Die Larve von unten, mit vollkommen contrahirtem Velum.

Fig. 27. Dieselbe Larve, von unten, mit erschlafftem Velum, in dessen Mitte der Eingang in die Schirmhöhle sichtbar ist.

Fig. 28. Dieselbe Larve, mit erschlafftem Velum, von der Seite.

Fig. 29-30. Larve in der zweiten Periode, mit erschlafftem Velum, in dessen Unkreise der Knorpelring sichtbar wird, und die 4 radialen Nebententakeln (s t) paarweis hervorgesprosst sind. Das ältere Paar unterscheldet sich durch bedeutendere Grösse von dem jiingeren. Vergrösserung 60 .

Fig. 29. Die Larve, von unten.

Fig. 30. Dieselbe Lạrve, von der Seite.

Fig. 31-34. Larve in der dritten Periode. Der zweite Kreis der Tentakeln, die 4 interradialen Tentakelı (y) sind hervorgesprosst.

Fig. 31. Larve im Anfang der dritten Periode, von unten gesehen. Es sind erst 2 gegenständige interradiale Tentakeln erschienen. Vergrösscrung 60 .

Fig. 32. Larve in der dritten Periode, hall von unten, halb von der Seite gesehen. Von den 4 interradialen Tentakeln besitzen die beiden gegenständigen jüngeren (kürzeren) erst $\mathbf{2}$, die beiden älteren 3 Nesselpolster. Im Umkreise des geöffneten Velum (v) ist der Knorpelring angelegt. Die Aussentläche des Gallertsehirms zeigt ihr Epithel. Vergrösserung 100.

Fig. 33. Larve in der dritten Periode, etwas weiter entwickelt, halls von unten, halb von der Seite gesehen. Die interradialen Tentakeln sind schon mehrmals länger als die radialen Nebententakeln, die beiden gegenständigen jüngeren mit 3 , die beiden älteren (längeren) mit 5 Nesselpolstern. Im Umkreise des geöflneten Velum (v) ist der Knorpelıing ( $u$ ) jetzt sehr deutlich. Vergrösserung 100.

Fig. 34. Larve in der dritten Periode, ans demselben Stadium wie Fig. 33, von der Seite (im Profil) gesehen. Die radialen Nebententakeln sind schon weiter vom Schirmrand entfernt und an der Aussenfläclıe des Schirmes hinaufgerückt. Vergrösserung 60 .

Fig. 35. Larve in der vierten Periode, von der Seite und etwas von unten gesehen. An der Basis der interradialen Tentakeln, welche länger als der Schirmdurchmesser sind, haben sich die interradialen Randbläschen entwickelt. Die beiden älteren interradialen Tentakeln zeigen 8 , die beiden jüngeren nur 5 - 6 Nesselpolster. In Grunde der bedeutend erveiterten Schirmhölıle ist die erste flach trichterförmige Anlage der Magenhöhle sichtbar, deren Mundöffnung aufgesperrt ist. In der Oberfläche des Schirms sind die Zellenkerne ihres Epithels als feine Puncte sichthar. Vergrösserung 60.

Fig. 36. Larve in der vierten Periode, von oben gesehen, etwas weiter entwickelt, die interradialen sind gleich den radialen Nebententakcln vom Schirmrande entfernt und an der Aussenfläche des Schirmes emporgestiegen. 
Das Gastrovasculars! stem tritt mit seinen sehr breiten Canalen und ihrem grosszelligen Sulsumbralepithel sehr deutlich hervor. Die vollkommen contrahirte Mundöffunng ist durch sternförmige Falten bezeichnet. Das Velum ist erschlafft. Vergrösserung 50 .

Fig. 37. Larve in der funften Periode, von unten gesehen. Die radialen Haupttentakeln sind erschienen, die beiden gegenständigen älteren durch bedeutendere Länge vor den mit ihnen alternirenden jüngeren ausgezeichnet. Die radialen Nebententakeln, weit an der Aussenfläche des Schirmes heraufgeriickt und in Rückbildung begrilfen, haben ihren Nesselknopf verloren. Das Velum ist sehr stark contrahirt. Zwisehen linorpelring und dem breiten Cirkelcanal ist als schmaler heller Streif der Nervenring sichthar. Die Canäle des Gastrovascularșstems simd strotzend gefüllt. Der viereckige Ylund ist geölfnet. Verğrösserung 50 .

Fig. 38. Ein Ausschnitt aus dem Schirmrande einer Larve in der füften Periode, von aussen betrachlet. Der radiale Haupttentakel ( $t$ ) ist eben erst als Ausstiilpung aus dem Cirkelcanal (es) rechts neben der centripetalen Mantelspange ( $\mathrm{h}$ ) hervorgesprosst. Der radiale Nebententakel ( $\mathrm{s}$ ) hat noch seinen Nesselknopf. Ueber dem Ringknorpel ( $u k$ ) ist der Nervenring (a) sichtbar. Vergrösserung 300 .

Fig. 39. Ein radialer Nebententakel von einer Larve aus der dritten Periode. Der Geisselanhang ( $\mathbf{f}$ ), welcher an seiner verdickten Spitze eine Reihe glänzender, heller Körperchen einschliesst, ist noch fast so lang als der knorpelige Theil des Tentakels, dessen Skelet aus einer Reile von 6 knorpelzellen zusammengesetzt ist. Von den centralen Kernen der Knorpelzellen gehen verzweigte Protoplasmaströme zur Innenwand der Knorpelkapseln. Vergrösserung 500 .

Fig. 40. Ein interradialer Tentakel aus der vierten Periode. In dickeren basalen Theile des Tentakels sind die quergestreilten longitudinalen Muskelfasern angedeutet, welche das cylindrisebe Knorpelskelet als zusammenhängenden Schlauch iberzichen. Von den Kernen der knorpelzellen gehen verzweigte Protoplasmaströme zur Innenwand der Knorpelkapseln. Von der Basis des Teutakels geht cine kurze Mantelspange, hinter welcher das interradiale Randbläschen versteckt ist, zu dem einspringenden Winkel des Ringknorpels herab. Im oberen Rand des Jetzteren ist der Nerventing (a) angedeutel. Vergrösserung 250 .

Fig. 41. Ein Stuick vom Ringknorpel einer Larve aus der vierten Periode. An den Ausschnitt des Ringknorpels befindet sich oben noch der untere Theil der Nantelspange, welche von demselben zur Basis eines radialen Nebententakels hinaufsteigt. Ber Knorpel, dessen Zellen durch ziemlich reichliche Intercellularsuhstanz getrennt sind, setzt sich nicht in die Spangenbasis hinein fort. Der letzteren gegenirher ist am unteren Rande des Knorpelıinges der einspringende Winkel sichthar. Vergrösserung 700.

Fig. 42. Der Magen einer Larve aus dem Ende der fünften Periode, dureh den sehr kurzen Magenstiel mit dem ausgeschnittenen Centraltheil der Subumbrella zusammenhängend. An letzterer sind die noch dicht aneinander liegenden Anfänge der 4 Radialcanale sichtbar. Der eben erst in Bildung begriffene Magenstiel setzt sich in die Magenhöhle hinein als ein kurzgestielter, eiförmiger, zugespitzter Körper fort, der die Anlage des Zungenkegels bildet. Der Mundrand ist unten kragenartig umgestulpt. Vergrösserung 50. 
Fig. 43. Der Magen einer etwas älteren Larve aus der sechsteı Periode. Der etwas längere Magenstiel setzt sich in einen bedeutend längeren und dickeren Zungenkegel fort, der weit aus der Mundöffnung hervorragt. Vergrösserung 30 .

Fig. 44-48. Entwickelung der Sinnesbläschen oder Randbläschen. Vergrösserung 400 .

Fig. 44. Erste Anlage eines Randbläschens. An der gangliösen Anschwellung des Ringnerven tritt ein solider, aus hellen Zellen zusammengesetzter sphäroider hnopf auf, umhüllt von einer doppelt contourirten Membran.

Fig. 45. Die Membran des Randbläschens hebt sich ringsum von den soliden Zellenknopf $\mathrm{ab}$, in welchen eine kleine dunkle Concretion lemerkbar wird.

Fig. 46. Es treten mchrere Concretionen in dem Zellenknopf (Sinnesganglion) des Randbläschens auf.

Fig. 47. Es werden die beiden gegenständigen Bügel der Sinnesnerven an der Innenwand des Randl) läschens sichtbar. Dieselben ragen am oberen Pol als kurzer Stiel, welcher das Sinnesganglion trägt, in das Bläschen hinein.

Fig. 48. Die zahlreichen kleinen Concretionen sind zu einem einzigen grossen Concrement versehmolzen, welehes einen grossen Theil des Sinnesbläschens ausfüllt.

Fig. 49-51. Verschiedene Formen des Sinnesganglion in den Randbläschen und der in ihm eingeschlossenen Concretionen. Vergrösserung 600.

Fig. 49. Ilöckeriges Sinnesganglion mit 2 grossen und melıreren kleinen Concretionen.

Fig. 50. Dreiseilig pyranidales Sinnesganglion, welches in unteren freien Theil wandständig eine einzige grosse Concretion umschliesst, die eine excentrische Höhle (?) enthält.

Fig. 51. Sehr ungleiches zweilappiges sinnesganglion mit einem zusammengebackenen Haufen von mehreren grossen und hleinen Concretionen.

Fig. 52. Eine geschlossene Nesselzelle aus den Nesselknople eines radialen Nebententakels. In der doppelt contourirten Nesselkapsel, welche wandständig den grössten Theil der ellipsoiden bläschenförnigen Nesselzelle ausfullt, ist der eingesenkte Nesselschlauch sichthar. Rechts nelien der Nesselkapsel der Zellenkern. Vergrösserung 600.

Fig. 53. Eine Nesselkapsel, frei, mit vorgestulptem Nesselschlauch; A) mit eingeschlossenem Nesselladen, B) mit ausgetretenem Nesselfaden. Verğösserung 600 .

Tafel IV.

Carmarina hastata (Geryonia hastata).

Fig. 54. Jüngste beobachtete Larve, eine solide Gallerthugel von ungefähr $1 \mathrm{~mm}$ Durchmesser, in der zweiten Periode. In Unkreise der flachen Schirmhöhle, die unten ron dem Velum begrenzt wird, sind die 6 radialen Nebententakeln sichthar. Vergrösserung 40.

Fig. 55. Larve in der dritten Periode, von $2 \mathrm{~mm}$ Durchmesser, halb von oben, halb von der Seite gesehen. Die erste Anlage des Gastrovascularsystems tritt deutlich hervor. Die 6 schmalen, durch den Cirkelcanal verbundenen Radialcanäle muinden in einer flachen sechseckigen Vagentasche im Grunde 
der Schirmhöhle zusammen. In der Mitte zwischen den 6 radialen Nebententaineln sind die 6 halb so dicken interradialen hervorgesprosst, welche bereits 3 Nesselknöpfe zeigen. Vergrösserung 40.

Fig. 56. Larve in der vierten Periode, von $3 \mathrm{~mm}$ Durchmesser, von unten gesehen. Am Grunde der 6 interradialen Tentakeln sind die 6 ersten Randbläschen erschienen, aufsitzend auf einem Ganglienknoten, der durch eine spindelförmige Verdickung des Knorpelrings geschiilzt und gestützt wird. Der Knorpelring ist in ein gleichseitiges Sechseck ausgezogen, dessen 6 Ecken durch centripetale Mantelspangen mit den an der Aussenseite des Mantels heraufgerïckten 6 radialen Nebententakeln verbunden sind. Zwischen Ringknorpel und Cirkelcanal ist der Nervenring sichthar. In der Mitte der Radialcanäle treten die Radialnerven deutlich vor. Der Magen ist in einen dicken Wulst contrahirt, der die sechseckige aufgesperte Mundöffnung umgiebt. Vergrösserung 30.

Fig. 57. Larve in der füften Periode, mit 18 Tentakeln, von $4 \mathrm{~mm}$ Durchmesser, halb von unten, halb von der Seite gesehen. Rechts neben der Basis der radialen Mantelspangen sind die 6 radialen Haupttentakeln hervorgesprosst. Entsprechend den 6 interradialen Tentakeln bildet der Cirkelcanal die 6 ersten Centripetaleanäle. Der Magenstiel beginnt deutlich vorzutreten. Vergrösserung 20.

Fig. 58. Larve in der sechsten Periode, von $8 \mathrm{~mm}$ Durchmesser, halb volı unten, halb von der Seite gesehen. Alle 12 Randbläschen sind entwickelt. Die radialen Nebententakeln haben bereits ihren Nesselknopf verloren. Die radialen Haupttentakeln sind schon mehrmals länger als die emporgekrummten interradialen Tentakeln, welche je 10-12 Nesselpolster tragen. Der Magenstiel ist noch kürzer als der Glockendurchmesser. Der Saum des weit geoffneten Mundes ist in 6 Lappen gefaltet. Der Zungenkegel ist in den Magen zurückgezogen. Zwischen je 2 Radialcanälen gehen vorn Ringcanal 3 centripetale blinde Canäle ab, welche noch sehr kurz und breit sind. Vergrösserung 9 .

Fig. 59. Larve in der siebenten Periode der Metamorphose, von $12 \mathrm{~mm}$ Durchmesser, ganz von unten gesehen. Alle Formen sind schlanker als bei der vorigen. Die radialen Nebententakeln sind abgefallen; die interradialen Tentakeln erscheinen stark reducirt und gehen ihrem Ende entgegen. Die radialen Haupttentakeln sind bedeutend langer, zum Theil in Knoten verschlungen. Die centripelalen Blindeanäle sind schmaler und länger. Doch sind immer noch nur je 3 zwischen je 2 Radialeanälen vorhanden. Der Magensack ist zurückgestulpt und der Zungenkegel weit daraus hervorgestreckt. Vergrösserung 6 .

Fig. 60. Querschnitt durch einen radialen Haupttentakel (t). Die Höhlung des Tentakels ist unschlossen von einem dicken Cylinderepilhel ( $t e)$, dieses von einer ebenso dicken, hellen Schicht von Ringfasern (t c). Die nun folgende breite, radial gestreifte Mittelsehicht besteht lediglich aus longtudinalen Fasern von zweierlei Art, helleren und dunkeln, welche in der Weise alterniren, dass ungefähr 60 radial gestellte Züge von hellen Längsfasern ( $t$ l) mit eben so vielen Radialblättern von dunkeln Längsfasern ( $\mathrm{t} \mathrm{m}$ ) wechseln. Aussen ist das Ganze von dem dicken, aus 3 Schichten zusainmengesetzten Cylinderepithel überzogen, desseı äusserste Schicht Nesselzellen führt. Vergrosserung 70 . 
Tafel V.

\section{Carmarina hastata (Geryonia hastata).}

Fig. 61. Ein Segment aus dem in Fig. 60 dargestellten Querschnitt eines radialen Haupttentakels, stärker vergrossert $(300)$. t e das innere Cylinderepithel, welches die Tentakelhöhle begrenzt. $t$ c helle Ringfasern; $t 1$ helle Längsfasern, im Querschnitt; $t \mathrm{~m}$ dunkle Längsfasern, im Querschnitt. $t \mathrm{u}$ äusseres Epithel des Tentakels, in 3 Schichten: I. Schicht der Büschelzellen, 1I. Schicht der Flaschenzellen, III. Schicht der Nesselzellen. Vergrösserung 300 .

Fig. 62. Ein Fragnıent ron einen tangentialen Längsschnitt durch die Mitte der dritten (radial gestreiften) Schicht eines radialen Haupttentakels. Die abwechselnden hellen und dunkeln Bander (welche auf dem Querschnitt Fig. 60 als ungefähr 60 Paare von alternirenden hellen und dunkelu Radialstreifen erscheinen) zeigen sich aus lauter longitudinalen Fasern zusammengesetzt, die dunkeln Streifen aus spindelförmigen, kernhaltigen Faserzellen $(\mathrm{t} \mathrm{m})$, die hellen aus spindelförmigen, kernlosen Strängen ( $\mathrm{t}$ ). Erstere $(\mathrm{t} \mathrm{m})$ sind auf der linken Seite des Präparates durch Zerzuplen isolirt. Letztere ( $\mathrm{I}$ ) erscheinen aul der rechten Seite des Präparates ebenfalls zum Theil isolirt und hier durch Einwirkung verdiunter Salpetersäure in eigenthümlicher Weise geschrumpft, wodurch die hellen Bänder fein quergestreift erscheinen. Vergrösserung 300.

Fig. 63. Ein verticaler Radialschnitt durch den Schirmrand eines erwachsenen Thieres, unmittelbar links neben einem radialen Randbläschen. Ver grosste Theil der Gallertsubstanz (1) des Schirmes ist der Raumersparniss halber weggelassen und nur derjenige Theil derselben mit seinen Gallertfasern (l f) gezeichnet, welcher unmittelbar das radiale Randbläschen (b r) umschliesst und der von letzterem ahgehenden radialen Mantelspange (h) anliegt. Von dem radialen Haupttentakel ist im Schnitt nichts zu sehen, da derselbe weiter rechts hinter der Schnttfläche liegt. Auch von der subunbralen Wand des Cirkelcanals (c s) und von dem Velum ( $v$ ) ist nur der zunächst an Ringknorpel $(\mathrm{u} \mathrm{k})$ gelegene Theil dargesteltt. Der querdurchschnittene Nervenknoten (f) des Ringnerven grenzt nach oben an das Randbläschen, nach aussen an die Basis der Mantelspange, nach unten an den Ringknorpel, nach immen an die Basis des Velum und des Cirkelcanals. Vergrösserung 150.

Fig. 64. Ein verticaler Radialschnitt durch den Schirmrand einer Larve aus der siebenten Periode, unmittelbar rechts neben einem interradialen Randbläschen (b i). Die Gallertsubstanz (1) des Schirmrands ist belrächtlich duinner als beim erwachsenen Thier (Fig. 63). Doch ist auch hier das Randbläschen (b i) völlig darin eingeschlossen. Von der subumbralen Wand (c s) des Cirkelcanals (c) und vom Velum (v) ist nur der zunächst an Ringknorpel ( $\mathbf{u}$ k) gelegene Theil dargestellt. Der Knorpel der Mantelspange ( $h$ k) verbindet continuirlich den Ringknorpel $(\mathrm{u} k$ ) mit dem voluminösen Knorpelskelet des interradialen Tentakels (y), von welchem nur die Basis dargestellt ist. Von der letzteren ist ein Theil (y k) in die anliegende Gallertsubstanz des Mantelrandes eingesenkt, und nicht mit Muskeln versehen. y $\mathrm{m}^{\prime}$ bezeichnet die Grenze zwischen diesem und dem freien Theile, welcher von einem cylindrischen Schlauche quergestreifter 
Mushelfaseru umschlossen i-t. Von den 12 Nezselpolstern y u des Tentakels sind nur die beiden untersten dargestellt. Vergrösserung 150.

Fig. 65. Ein radialer Nebententakel ( $\mathrm{s} t$ ) von einer Larve aus der vierten Periode (Fig. 56), nebst den zugehörigen radialen Abschnitte des Mantelrandes und der benachbarten Theile, vou ohen und aussen gesehen. Die grossen platt scheibenförunigen knorpelzellen $\left(s k^{\prime}\right)$ des Tentakelskelets sind durch dicke Wände von Intercellularsułstanz ( $\mathbf{s} \mathrm{k}^{\prime \prime}$ ) getrennt. Der Tentakel ist von seiuer Insertion nach unten, iitier dem Schirnrand, zuriickgeschlagen, und ragt mit dem Geisselanhang ( $\mathbf{f}$ ) des Nesselknopfs is $\mathbf{u}$; noch iiber den inneren Rand des schmalen Velum (v) hinuiber. Links von der Mantel-pange (I) ist der Radialnerv (a r), von Muskelfasern begleitet. sichtbar, indem er in der Mittellinie des Radialcanals durch dessen Epithel (e s) hindurchschinmert. Vergriosserung 150.

Fig. 66. Ein interradiales Randbläsetien $1, i$ ) von einer Larve aus der vierten Periode (Fi .56 ) nebst dem zugehörigen Abschnitt des Mantelrandes, von innen gesehen. Das Randhläsehen sitzt auf einem Gang̣lion (f) des Ringnerven al welches gestiitzt wird durch ene spindelförmige Verdickung des linorpelrings u $k$. Vergrösserung 150.

Fig. 67. Eine Nesselzelle von 3 verschiedenen Seiten hetrachtet (A B C). Die Zelle schliesst ausser der Nesselkapsel einen grossen kreisrunden kern ein, welcher als concar-conveve Scheibe die cylindrische Nesselkapsel $\mathbf{1 m -}$ fasst und die Zelle in der Mitte vorwölbt. Der kern ist in A von der Fiache, in B auf dem scheinharen Längsschnitt, in C von olıen gesehelı. Vergrösserung 700 .

Fig. 68. Fine Nes-elkapsel, in 3 verschiedenen Zuständen. A und B mit zurichgezogenem Nesselschlauche, A von der Sejte, B von ohen, C mit vorgestiilptem Schlauche und eingeschlosienem Nesselfaden, D mit vorgestulptem Nesselschlauche und ausgeworfenem Nesselfaden. Vergrösserung 700.

Fig. 69. Ein Stuickchen eines Nesselfadens, sehr stark (etwa 2000mal) vergrössert.

Fig. 70. Ein Stuckchen von einem sehr diunen Querschnitt durch den Ringknorpel, in Wasser macerirt, so dass die hautlosen Knorpelzellen zum Theil aus den Höhlungeu der lutercellularsubstanz lierausgefallen sind. Vergrösserung 700 .

Taf. VI.

\section{Carmarina hasiata und Cunina rhododactyla.}

Fig. $71-77$. Curmarina hastata.

Fig. 71. Ein verticaler Radialschinitt durch den Schirmrand eines erwachsenen geschlechtsteifen Weibchens von Carmarina. Der Schnitt ist so gefiihrt, dass er einen grossen Theil eines Ovariums (der flugelartigen Seitentasclie eines Radialcanales, $r$ ) eröffnet hat; in der subumbralen Wand desselhen ist das Epithel in Eier umgewandelt. Den Dotter ( $g d$ ) der Eier umgrebt ein sehır grosses Keinbläschen $(g \mathrm{~g})$, in dessen Keimfleck $(\mathrm{g} m)$ noch ein centraler Körper, der heimpunct (Nucleolinus) sichthar ist. Dje Gallertsubstanz (1) des Schirmes ist von vielen Fasern (If) durchsetzt. Zwischen dem Radialcanal (c c) nach oben, dem Knorpelring (u k) nach uuten, und dem ausseren Theil des Velum ( $\mathrm{v}$ ) nach innen, ist der Querschnitt des Ringnerveu (a) sichtlıar. Vergrösserung 50. 
Fig. 72. Ein kleines Stiick eines Radialnerven (a r ) ron Carmarina, senkrecht gekreuzt von den darunter liegenden circularen Muskelfasern der Subumbrella ( $\mathrm{m} s$ ). Die quergestreiften Muskelfasern sind kaum breiter, als die blassen, mit sehr kleinen Kernen besetzten Nervenlasern. Vergrösserung 900 .

Fig. 73. Querschnitt durch die Nagenwand von Carmarina. Zwischen dem dicken geschichteten Cylinderepithel der inneren ( $\mathrm{k} i$ ) und dem einfachen Epithel ( $k$ e ) der äusseren Magenfläche ist eine äussere dünnere Schicht von Längsmuskeln ( $k$ l) und eine innere dickere Schicht von Ringmuskeln ( $k$ c) sichtbar. Innen miindet rechts eine büschelförmige Gruppe von einzelligen Mlagendrüseu ( $\left.d^{\prime \prime}\right)$. Vergrösserung 300

Fig. 74. Der Magen einer knospentragenden Carmarina, nebst dem unteren Ende des Magenstiels, dessen Fortsetzung, die Zunge, dicht mit Knospen bedeckt ist. Vergrösserung 3 .

Fig. 75. Eine grosse Knospenähre aus dem Magen einer knospentragenden Carmarina. Jïngere und ältere Knospen bedecken die Zunge so dicht gedrängt, dass von deren Oberfläche Nichts zu sehen ist. Vergrösserung $\mathbf{3 0}$.

Fig. 76. Eine der reifsten Knospen, von $1 \mathrm{~mm}$ Durchmesser, aus der Knospenähre ahgelöst, von der Seite gesehen. An den nach abwärts gewendeten Tentakeln $(t)$ ist sehon die Zusammensetzung der Axe aus einer Reihe flacher Knorpelzellen durch feine Querstreifung angedeutet. Die Randbläschen (b) ragen frei iber die Spitze der 8 Randlappen vor. Vergrösserung $\mathbf{5 0}$.

Fig. 77. Eine der reifsten Knospen, von $1 \mathrm{~mm}$ Durchmesser, aus der Knospenähre abgelöst, von unten gesehen. Drei von den 8 Tentakeln $(t)$ sind nach abwairts (einwärts) geschlagen. An der Basis der iibrigen ist die helle Tentakelwurzel ( $t \mathrm{w}$ ) sichtbar. Der Mund $(0)$ ist geöffnet. Vergrösserung 50 .

Fig. 78-85. Cunina rhododactyla.

Fig. 78. Eins der jiingsten frei gefischten Individuen von Cunina, mit 8 Körpersegmenten, von $3 \mathrm{~mm}$ Durchmesser, von unten gesehen. Der Mund (o) ist mässig geöffnet, das Velum ( $v$ ) schlaff, breit. Die Lappen des Schirmrandes sind stark nach innen eingezogen und auf der rechten Hälfte völlig eingerollt. Zwei Tentakelı sind ganz nach innen geschlagen. Vergrösserung 20.

Fig. 79. Eine ältere Cumina, mit 10 Körpersegmenten, von $6 \mathrm{~mm}$ Durchmesser, von der Seite gesehen. Die hier dargestellte Haltung haben die Thiere gewolntlich, wenn sie ruhig im Wasser sehwelsen. Der Rand der Mantellappen ist nach innen und oben eingeschlagen. Vergrösserung 10.

Fig. 80A. Die Hallte einer älteren Cumina, mit 10 Körpersegmenten, von $7 \mathrm{~mm}$ Durchmesser, von unten gesehen. Yier Tentakelu sind ganz nach innen geschlagen, zwei nach aussen gestreckt. Die beiden rechten Lappen des Schirmırandes sind etwas eingezogen, die drei linken vollkommen eingerollt. Der Hund ( 0 ) ist weit geöffnet, das Velum mässig breit. Vergrösserung 12.

Fig. 80 B. Die Hälte einer völlig erwachsenen Cunina, mit 16 Körpersẹ̣menten, von $11 \mathrm{~mm}$ Durchmesser, von unten gesehen. Drei Tentakeln sind ganz nach innen geschlagen, die vier anderen iu verschiedenen Krümmungszuständen dargestellt. Der Mund $(0)$ ist viel weıter geöffnet, als in der 
vorigen Figur und das Velum (v) sehr stark zusammengezogen und schmal. Die 4 rechten Lappen des Schirmrandes sind eingezogen, die 4 linkeı vollkommen eingerollt. Vergrösserung $\mathbf{8}$.

Fig, 81. Radialer Verticalschnitt durch den unteren peripherischen Theil des $\mathrm{Cu}$ nina-körpers. Der Schnıtt ist unmittelbar neben einem Tentakel $(t \mathrm{t})$ gefiihrt, so dass die Insertion der Wurzel ( $t w$ ) desselben auf der oberen Wand ( $\mathbf{r}$ l) der radialen Nagentasche ( $\mathbf{r}$ ) in ihrer ganzen Länge sichtbar ist. Ausserdem sieht man den an den Tentakel angrenzenden und hinter demselhen liegenden Randlappen, dessen Rand nach innen und oben eingerollt ist und den Durchschnitt des Ringgefässes (c c) zeigt. Vergrösserung 30 .

Fig. 82. Radialer Verticalschnitt durch den eingezogenen Schirnmand der Cunina. Der Nerveuring (a) grenzt nach innen an die Insertion des Velum (v), nach oben an das Ringgefäss ( $\mathrm{c}$ ), nach aussen an den Ringknorpel ( $\mathrm{u}$ ) , nach unten an das Ganglion, welches das Randbläschen (b) triigt. Vergrösserung 60.

Fig. 83. Ein Stück von dem ausseren Theile eines Tentakels der Cunina. In der Axe des Knorpeleylinders verlaufen die centralen Protoplasmastränge der Knorpelzellen, welche den Kern dersellsen umschliessen. Die dünne Längsmushelschicht ( $\mathrm{s} \mathrm{m}$ ) ist von einem Epithel ( $\mathrm{se}$ ) überzogen, dessen Zellen kugelige glänzende Nesselkapseln entwickeln. Vergrösserung $\mathbf{1 5 0} 0$.

Fig. 84. Ein Stiick von dem eingerollten Schirmrande der Cunina, von innen und unten her betrachtet. Das Randblisehen (b) ist ganz nach inmen gezogen, so dass es der unteren Fläche des Velum (v) fest aufliegt. Die dickwandigen polyedrischen Zellen, welche das äussere (subumbrale) Epithel des Gefássringes (c s) bilden, treten so sehr hervor, dass man die darüber liegenden Schichten (Gallertmantel und umbrales, inneres Epithel des Ringcanals) gar nicht bemerkt. Zwischen kinorpelring ( $\mathrm{u}$ k) und Gefässring tritt der Nervenring (a) deutlich hervor. Vergrösserung 200.

Fig. 85. Ein Sinnesbläschen (Randbläschen) der Cunina rhododactyla, in welchem der Sinnesnerv (u) sehr deutlich hervortritt. Von dem auf dem Nervenring (a) aufsitzenden Ganglion (f) strahlt ein Biischel von sehr langen und leinen, starren Borsten aus, welche das Sinnesbläschen umgeben. Vergrösserung 600. 


